
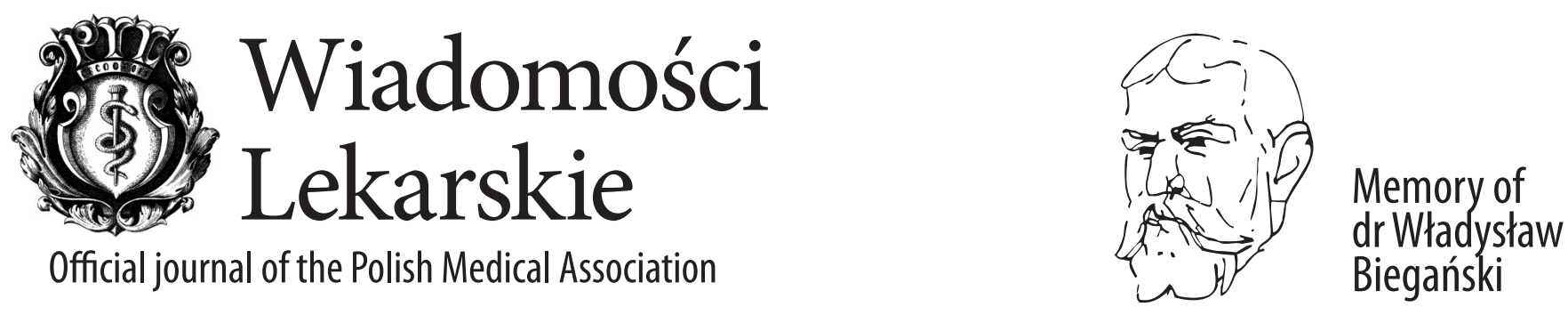
Wiadomości Lekarskie is abstracted and indexed in: PUBMED/MEDLINE, SCOPUS, EMBASE, INDEX COPERNICUS, POLISH MINISTRY OF EDUCATION AND SCIENCE, POLISH MEDICAL BIBLIOGRAPHY

\section{Copyright: @ ALUNA Publishing House.}

Articles published on-line and available in open access are published under Creative Common Attribution-Non Commercial-No Derivatives 4.0 International (CC BY-NC-ND 4.0) allowing to download articles and share them with others as long as they credit the authors and the pu-

blisher, but without permission to change them in any way or use them commercially.

\section{Wiadomości Lekarskie monthly journal}

You can order the subscription for the journal from Wydawnictwo Aluna by: prenumerata@wydawnictwo-aluna.pl

Wydawnictwo Aluna

Z.M. Przesmyckiego 29

05-510 Konstancin-Jeziorna

Poland

Place a written order first.

If you need, ask for an invoice.

Payment should be done to the following account of the Publisher:

account number for Polish customers (PLN):

82194010763010740700000000

Credit Agricole Bank Polska S. A., SWIFT: AGRIPLPR

account number for foreign customers (EURO):

57249000050000460076043035

Alior Bank S. A.: SWIFT: ALBPPLPW

Subscription of twelve consecutive issues (1-12):

Customers in Poland: 360 PLN/year

Customers from other countries: $320 \mathrm{EURO} /$ year 


\section{Tiadomości Lekarskie}

Editor in-Chief:

Prof. Władysław Pierzchała

\section{Editor of the issue:}

Viktor Vus, Director-at-Large,

World Federation for Mental Health;

Coordinator, Mental Health Division of NPA, Ukraine

\section{Deputy Editor in-Chief:}

Prof. Aleksander Sieroń
Managing Editor:

Agnieszka Rosa - amarosa@wp.pl

International Editorial Office:

Lesia Rudenko (editor) - I.rudenko@wydawnictwo-aluna.pl Nina Radchenko (editor's assistant)

-n.radchenko@wydawnictwo-aluna.pl

Polish Medical Association (Polskie Towarzystwo Lekarskie): Prof. Waldemar Kostewicz - President PTL

Prof. Jerzy Woy-Wojciechowski - Honorary President PTL

\section{Statistical Editor:}

Dr Lesia Rudenko

\section{International Editorial Board - in-Chief:}

Marek Rudnicki

Chicago, USA

\section{International Editorial Board - Members:}

Kris Bankiewicz

Christopher Bara

Krzysztof Bielecki

Zana Bumbuliene

Ryszarda Chazan

Stanislav Czudek

Jacek Dubiel

Zbigniew Gasior

Andrzej Gładysz

Nataliya Gutorova

Marek Hartleb

Roman Jaeschke

Andrzej Jakubowiak

Oleksandr Katrushov

Peter Konturek

Jerzy Korewicki

Jan Kotarski
San Francisco, USA

Hannover, Germany

Warsaw, Poland

Vilnius, Lithuania

Warsaw, Poland

Ostrava, Czech Republic

Cracow, Poland

Katowice, Poland

Wroclaw, Poland

Kharkiv, Ukraine

Katowice, Poland

Hamilton, Canada

Chicago, USA

Poltava, Ukraine

Saalfeld, Germany

Warsaw, Poland

Lublin, Poland
George Krol

Krzysztof Łabuzek

Henryk Majchrzak

Ewa Małecka-Tendera

Stella Nowicki

Alfred Patyk

Palmira Petrova

Krystyna Pierzchała

Tadeusz Płusa

Waldemar Priebe

Maria Siemionow

Vladyslav Smiianov

Tomasz Szczepański

Andrzej Witek

Zbigniew Wszolek

Vyacheslav Zhdan

Jan Zejda
New York, USA

Katowice, Poland

Katowice, Poland

Katowice, Poland

Memphis, USA

Gottingen, Germany

Yakutsk, Russia

Katowice, Poland

Warsaw, Poland

Houston, USA

Chicago, USA

Sumy, Ukraine

Katowice, Poland

Katowice, Poland

Jacksonville, USA

Poltava, Ukraine

Katowice, Poland
Distribution and Subscriptions:

Bartosz Guterman prenumerata@wydawnictwo-aluna.pl Graphic design / production:

Grzegorz Sztank

\section{Publisher:}

ALUNA Publishing House

ul. Przesmyckiego 29,

05-510 Konstancin - Jeziorna www.wydawnictwo-aluna.pl www.wiadomoscilekarskie.pl www.wiadlek.pl 


\section{FOR AUTHORS}

1. The monthly "Wiadomości Lekarskie" Journal is the official journal of the Polish Medical Association. Original studies, review papers as well as case reports are published.

2. In 2022, the cost of publishing the manuscript is PLN 1,500 plus 23\% VAT. From 2022, the publication costs for foreign authors amount to EUR 450, of which EUR 50 is payable with the submission of the article (includes the costs of review, anti-plagiarism system, English language level assessment, checking the compliance of the manuscript with the regulations of the publishing house, etc.), and the remaining EUR 400 - after accepting the article for publication. Thanks to obtaining funding for authors from Ukraine, the cost of publication for Ukrainian authors is EUR 350 . EUR 50 is payable together with the submission of the article, and EUR 300 - after accepting the article for publication. The publisher issues invoices. If the first author of the manuscript is a member of the Editorial Board, we do not charge a fee for printing the manuscript. Membership of the Polish Medical Association with documented paid membership fees for the last 3 years is also the exempt from publication fee.

3. Only papers in English are accepted for publication. The editors can help in finding the right person for translation or proofreading.

4. Papers should be sent to the editor via the editorial panel (Editorial System), available on the journal's website at https://www.wiadlek.pl. In order to submit an article, free registration in the system is necessary. After registration, the author should follow the instructions on the computer screen.

5. All editorial work is under control and using the editorial panel. This applies in particular to sending manuscripts, correspondence between the editor and author and the review process. In special cases, the editor may agree to contact outside the panel, especially in case of technical problems.

6. Acceptable formats for individual elements of the article are as follows:

A) Content of the article - doc, docx, rtf, odt.

B) Tables - doc, docx, rtf, odt

C) Figures $-J P G$, GIF, TIF, PNG with a resolution of at least $300 \mathrm{dpi}$

D) Captions for figures and tables.

These elements are sent to the editor separately using the editorial panel. References and article metadata such as titles, keywords, abstracts etc. are supplemented by the author manually in the editorial panel in appropriate places.

7. The volume of original papers - including figures and references - must not exceed 21,600 characters (12 pages of typescript), and review papers - up to 28,800 characters (16 pages).

8. The original manuscript should have the following structure: Introduction, Aims, Material and methods, Results, Discussion and Conclusions which cannot be a summary of the manuscript.

9. When using abbreviations, it is necessary to provide the full wording at the first time they are used.

10. In experimental manuscripts in which studies on humans or animals have been carried out, as well as in clinical studies, information about obtaining the consent of the Ethics Committee should be included.

11. The Editorial Board follow the principles contained in the Helsinki Declaration as well as in the Interdisciplinary Principles and Guidelines for the Use of Animals in Research, Testing and Education, published by the New York Academy of Sciences Ad Hoc Committee on Animal Research. All papers relating to animals or humans must comply with ethical principles set out by the Ethics Committee.

12. The abstract should contain 150-250 words. Abstracts of original, both clinical and experimental, papers should have the following structure: Aims, Material and methods, Results, Conclusions. Do not use abbreviations in the title or the abstract. The abstract is pasted or rewritten by the authors into the appropriate field in the application form in the editorial panel.

13. Keywords (3-5) should be given according to MeSH (Medical Subject Headings Index Medicus catalogs - http://www.nim.nih.gov.mesh/MBrower.html). Keywords cannot be a repetition of the title of the manuscript.

14. Illustrative material may be black and white or color photographs, clearly contrasting or drawings carefully made on a white background. With the exception of selected issues, the Journal is printed in shades of gray (black and white illustrations).

15. The content of the figures, if present (e.g. on the charts), should also be in English

16. Links to all tables and figures (round brackets) as well as references (square brackets) the author must place in the text of the article.

17. Only references to which the author refers in the text should be included in the list of references ordered by citation. There should be no more than 30 items in original papers and no more than 40 items in review papers. Each item should contain: last names of all authors, first letters of first names, the title of the manuscript, the abbreviation of the journal title (according to Index Medicus), year, number, start and end page. For book items, please provide: author's (authors') last name, first letter of the first name, chapter title, book title, publisher, place and year of publication. It is allowed to cite websites with the URL and date of use of the article, and if possible the last names of the authors. Each literature item should have a reference in the text of the manuscript placed in square brackets, e.g. [1], [3-6]. Items should be organized as presented in Annex 1 to these Regulations.

18. When submitting the article to the editor, the authors encloses a statement that the work was not published or submitted for publication in another journal and that they take full responsibility for its content, and the information that may indicate a conflict of interest, such as:

1. financial dependencies (employment, paid expertise, consulting, ownership of shares, fees),

2. personal dependencies,

3. academic and other competition that may affect the substantive side of the work,

4. sponsorship of all or part of the research at the stage of design, collection, analysis and interpretation of data, or report writing.

19. The authors in the editorial panel define their contribution to the formation of scientific work according to the following key:

A - Work concept and design

B - Data collection and analysis

C - Responsibility for statistical analysis

D - Writing the article

E-Critical review

F- Final approval of the article.

20. In the editorial panel along with the affiliation, the author also gives her or his ORCID number.

21. The Journal is reviewed in double, blind review mode. The submitted papers are evaluated by two independent reviewers and then qualified for publishing by the Editor-in-Chief. Reviews are anonymous. The authors receive critical reviews with a request to correct the manuscript or with a decision not to qualify it for publishing. The procedure for reviewing articles is in line with the recommendations of the Ministry of Science and Higher Education contained in the paper "Good practices in review procedures in science" (Warsaw 2011). Detailed rules for dealing with improper publishing practices are in line with COPE guidelines. The publishing review rules are in the Review Rules section.

22. Each manuscript is subject to verification in the anti-plagiarism system.

23. Manuscripts are sent for the author's approval. The author's corrections should be sent within the time limit indicated in the system. No response within the given deadline is tantamount to the author's acceptance of the submitted material. In special cases, it is possible to set dates individually.

24. Acceptance of the manuscript for publishing means the transfer of copyright to the Aluna Publishing House (Aluna Anna Łuczyńska, NIP 5251624918).

25. Articles published on-line and available in open access are published under Creative Common Attribution-Non Commercial-No Derivatives 4.0 International (CC BY-NC-ND 4.0) allowing to download articles and share them with others as long as they credit the authors and the publisher, but without permission to change them in any way or use them commercially.

26. The authors receive a free PDF of the issue in which their mansucript is enclosed, and on request - a printed copy. The printed copy is sent to the address indicated by the authors as the correspondence address.

27. Manuscripts not concordant with the above instructions will be returned to be corrected.

28. The editors do not return papers which have not been commissioned.

29.The editors take no responsibility for the contents of the advertisements. 


\section{CONTENTS}

\section{ORIGINAL ARTICLES}

Lina A. Kolesnichenko, Lyudmila V. Muzychko, Olena V. Savchenko, Elizaveta M. Kolesnichenko, Anastasiya Lovegrove

NEUROTIC CONDITIONS: PROBLEM, DIAGNOSIS, CORRECTION BY COGNITIVE-BEHAVIORTHERAPY

Olena V. Savchenko, Lyudmila V. Muzychko, Lina A. Kolesnichenko

THE INFLUENCE OF UNHEALTHY NEUROTICISM ON THE PECULIARITIES OF PERSONAL DECISION MAKING

Liudmila M. Omelchenko, Lidiya G. Chorna, Nataliya Dyshlova, Anna Bezhnar, Olha T. Pletka, Tetiana M. Vakulich, Giuseppina Ancona THE READINESS OF A YOUNG COUPLE TO ADOPT A CONSTRUCTIVE BEHAVIOR DURING CONFLICT AS A FACTOR OF MENTAL HEALTH AND MARITAL SATISFACTION

Larysa L. Borysenko, Larysa V. Korvat, Olga V. Lovka, Antonina M. Lovochkina, Oksana P. Serhieienkova, Ketevan Beridze STUDY OF THE MENTAL STATE OF STUDENTS IN THE PROCESS OF ONLINE EDUCATION DURING THE CORONAVIRUS PANDEMIC

Viktor V. Vus, Liudmyla M. Omelchenko, Oksana Boiko, Ioanna V. Papathanasiou, Evangelos C. Fradelos, Vladislav Zharin, Kateryna Zharina PUBLIC CONFIDENCE IN FORMAL MEDICINE: CURRENT CONTEXT

Iryna A. Martyniuk, Ioanna V. Papathanasiou, Evangelos C. Fradelos

SELF-EDUCATIONAL ACTIVITY IN THE STUDENT AGE AS AN INDICATOR OF MENTAL WELL-BEING OF PERSONALITY

Iryna I. Boiko, Olha I. Herus, Larysa D. Klymanska, Victor Y. Savka, Liliia Y. Klos, Mariana V. Shkoliar, Valentina Vitale

COVID-19 PANDEMIC LIFESTYLE: STUDENTS MENTAL HEALTH CHALLENGES

Ivan R. Romash, Mykhailo I. Vynnyk

PECULIARITIES OF BRAIN-DERIVED NEUROTROPHIC FACTOR AND MATRIX METALLOPROTEINASE-9 EXPRESSION DYNAMICS IN PATIENTS

WITH PARANOID SCHIZOPHRENIA DEPENDING ON THE DURATION OF THE DISEASE

Larysa A. Rybyk, Olha Sandal, Kateryna S. Honcharenko, Oleksandra Manzii, Olha Podilchak, Stanislav Andreichuk, Monica Paduraru

PERCEPTION OF TIME PERSPECTIVE IN WIDOWS OF LAW ENFORCEMENT OFFICERS DURING THE FIRST YEAR AFTER THE LOSS

Tatiana I. Svatenkova, Alexander V. Svatenkov

EMOTIONAL POTENTIAL IN THE CHILDREN'STEAM

Antonina I. Kononchuk, Alexander V. Svatenkov, Tatiana I. Svatenkova, Danylo I. Kononchuk, Mitzi Waltz

YOUTH HEALTH MANAGEMENT SPHERE

Oksana V. Tymoshchuk, Roman Z. Han, Iryna Y. Makoida, Olha B. Molodovets, Iryna B. Romash, Nataliia Yermakova, Valentina Vitale THE QUALITY OF LIFE FOR STUDENTS IN EDUCATIONAL INSTITUTIONS: CURRENT SITUATIONS AND BASIC PRINCIPLES

OFPSYCHOHYGIENIC IMPROVEMENT

Tetiana M. Tytarenko, Maryna S. Dvornyk, Tetiana 0. Larina, Kateryna V. Myronchak, Volodymyr V. Savinov, Julia D. Hundertaylo, Giuseppe Vella CITIZENS OBTAINING PSYCHOSOCIAL SUPPORT DURING THE COVID-19 PANDEMIC IN UKRAINE: A CROSS-SECTIONAL STUDY

Svitlana L. Fedko, Alona Kurbatova, Natalya Remesnyk, Iryna Matviienko, Alina Parasiei-Hocher, Nataliia Kryvda, Fatma Elzahraa Hussin CULTURAL AWARENESS IN CONTEMPORARY MENTAL HEALTH PRACTICE

Oksana V. Boriak, Anna V. Chobanian, Oleksandr V. Kolyshkin, Yurij Y. Kosenko, Tetiana M. Dehtiarenko, Alla P. Kolyshkina, Galina Itskovich INTELLECTUAL DISABILITIES IN PRESCHOOLERS: MENTAL HEALTH DETERMINANTS DURING THE PERINATAL PERIOD OF DEVELOPMENT

Oksana M. Mykytyuk, Tamara G. Tiurina, Tereza M. Klymus, Marta Ya. Kozak, Ihor I. Yatsyshyn, Natalia A.Umanets, Nina M. Hayduk 
Tetiana M. Dziuba, Liudmyla M. Karamushka, Lyubov J. Halushko, Iryna M. Zvyagolskaya, Taras V. Karamushka, Ali Hamaidia, Tetiana M. Vakulich MENTAL HEALTH OF TEACHERS IN UKRAINIAN EDUCATIONAL ORGANIZATIONS

Maryna B. Klimanska, Larysa D. Klymanska, Halyna Z. Herasym, Janusz Sierosławski, Viktor Ye. Savka, Olha I. Herus MOTIVATION FOR ALCOHOL CONSUMPTIONS BY ADULTS: TRADITIONS OR AN ATTEMPT TO SOLVE MENTAL HEALTH PROBLEMS (EXEMPLIFIED BY THE (ITY OF LVIV AND LVIV REGION, UKRAINE)

Iryna B. Volevakha, Nataliia V. Kolomiiets, Tetiana V. Kukhar

ORGANIZATIONAL FACTORS OF PSYCHOLOGICAL SAFETY IN THEWORKPLACE

Oleksandr R. Malkhazov, Iryna V. Zhadan, Svitlana I. Poznyak, Giuseppe Vella

PERSONALITY FACTORS OF EMOTIONAL RESILIENCE IN THE CHALLENGING ENVIRONMENTS FOR MENTAL HEALTH

Oleg Kokun

TESTING IN MENTAL HEALTH RESEARCH: PROFESSIONAL HARDINESS QUESTIONNAIRE (ENGLISH-LANGUAGEVERSION)

Mariia S. Kanibolotska, Marharita A. Dergach, Neonila V. Partyko, Anastasiia Cherkasova, Oleg Blinov, Olga Litvinova, Daniela Dumitru THE ABILITY OF YOUNG PEOPLE TO SELF-REGULATE EMOTIONS AS MENTAL HEALTH SIGN

Mykola M. Slyusarevskyy, Svitlana Chunikhina, Maureen Flaherty

SOCIAL TENSION AS A MACRO INDICATOR OF THE PSYCHOLOGICAL WELL-BEING OF SOCIETY

Sergii Maksymenko, Oleg Kokun, legor Topolov, Olena Nemesh, Maureen Flaherty

THE INFLUENCE OF OCCUPATIONAL STRESS ON EMPLOYEES'MENTAL HEALTH

\section{REVIEW ARTICLES}

Liliia Y. Klos, Mariana V. Shkoliar, Sofiya G. Stavkova, Olena P. Kokhanova

SOCIAL WORKERS'ACTIVITIES IN THE FIELD OF POPULATION'MENTAL HEALTH PRESERVATION IN THE XXI CENTURY

Christos Tsagkaris, Andreas S. Papazoglou, Iryna B. Romash, Dimitrios V. Moysidis, Ivan R. Romash, Luiza Gabunia, Taras Gorbatiuk

THE BONE-BRAIN AXIS? BIOPSYCHOSOCIAL ASPECTS OF ORTHOPEDICS AND A MENTAL WELLBEING ACTION PLAN IN MUSCULOSKELETAL CARE

Viktor Vus, Anastasiia Puzyrina

COVID-19IMPACT: NEW TENDENCIES AND TRENDS IN MENTAL HEALTH RESEARCH

Galina Itskovich, Elena Shopsha, Liudmyla Fedosova

USE OF THE HEROIC JOURNEY NARRATIVE IN THE DIAGNOSTIC INTERVIEW AND TREATMENT WITH FAMILIES OF CHILDREN WITH SPECIAL NEEDS

Christos Tsagkaris, Dimitrios V. Moysidis, Svetlana Storozhuk, Natalija G. Mozgova, Andreas S. Papazoglou, Anna Loudovikou, Galyna Poperechna LESSONS FROM THE HEART: REVISITING THE PSYCHOCARDIOLOGICAL THEORIES OF ARISTOTLE IN THE 21ST CENTURY

Tetiana V. Danylova, Vitalii M. Shmarhun, Anton V. Vertel, Bogdan K. Matyushko, Aleksandr F. Bondarenko, Tetiana Kychkyruk, Jørli Petersen EFFECTS OF THE EASTERN MIND-BODY PRACTICES ON MENTAL HEALTH DURING THE COVID-19 PANDEMIC:WHEN EAST MEETSWEST 


\title{
NEUROTIC CONDITIONS: PROBLEM, DIAGNOSIS, CORRECTION BY COGNITIVE-BEHAVIOR THERAPY
}

DOI: 10.36740/WLek202111101

\author{
Lina A. Kolesnichenko ${ }^{1}$, Lyudmila V. Muzychko ${ }^{1}$, Olena V. Savchenko ${ }^{1}$, Elizaveta M. Kolesnichenko ${ }^{2}$ \\ Anastasiya Lovegrove ${ }^{3}$ \\ 'KYIV NATIONAL ECONOMIC UNIVERSITY NAMED AFTER VADIM HETMAN, KYIV, UKRAINE \\ 2UKRAINIAN CATHOLIC UNIVERSITY, LVIV, UKRAINE \\ ${ }^{3}$ GREENWICH PSYCHOLOGY CLINIC, LONDON, GREAT BRITAIN
}

\begin{abstract}
The aim: To identify the relationship between neurotic states and hardiness as an indicator of mental health, to explore the possibility of using the cognitive-behavior therapy techniques to correct neurotic states in young people.

Materials and methods: The methods "Clinical questionnaire for the detection and evaluation of neurotic conditions" (K. Yakhin, D. Mendelevich) and "Hardiness Survey" (S. Muddi, adapted by D. Leontev, 0 . Rasskazova) were used for diagnosis. Wilcoxon test was used to determine changes in the manifestations of neurotic states in the conditions "before" and "after" the application of cognitive-behavior therapy techniques. Correlation analysis was used also to distinguish the relationship between neurotic states, hardiness and its components.

Results: It has been identified that various neurotic states are differently related to hardiness as an indicator of mental and social health. The level of anxiety and obsessivephobic disorders has inverse negative relationship with general level of hardiness $(r=-0.31$ and $r=-0.34)$, but the level of asthenia has a positive connection with this indicator $(r=0.49)$. The level of neurotic anxiety is inversely related with the level of personal involvement in life $(r=-0.27)$. The effectiveness of CBT techniques (psycho-education, distancing, cognitive reassessment) for the correction of neurotic states, namely: anxiety $(p<0.01)$ and hysterical reaction type $(p<0.01)$ was proved.

Conclusions: Neurotic states are correlated with level of hardiness (an indicator of mental and social health) and personal involvement in life. The correction of neurotic states can be effectively carried out by means of CBT.
\end{abstract}

KEY WORDS: mental health, neurotic state, hardiness, correction, cognitive-behavior therapy, psychodiagnostics of neurotic states, cognitive and emotional shift

Wiad Lek. 2021;74(11 p.l):2689-2694

\section{INTRODUCTION}

According to figures from WHO, for the last 65 years the number of people with neurotic disorders has increased in 24 times, particularly, the depression and anxiety have been the most common mental disorders. In 2015, their prevalence was 5.1\% (44.3 million) and 4.3\% (37.3 million). It was found that women have a $50 \%$ higher incidence of depression and anxiety disorder than men. These disorders are psychogenic and have the reversible nature. They manifest themselves as emotional instability, increased exhaustion, disorders of general well-being and various somato-vegetative functions. Even with high levels of neuroticism, people have saved the adequate self-vision and self-esteem. However, such conditions form neuroses that negatively affect a person's mental health [1-3].

Although these disorders are reversible, their impact on life can be quite significant, so their detection and correction is extremely important for reinforcement of mental health. According to the numerous researchers, one of the most effective means of correcting such conditions is cognitive-behavior therapy (CBT) [4-7].

\section{THE AIM}

The purpose of the study is to identify the connection between neurotic states and hardiness as an indicator of mental health, to explore the possibility of using cognitive-behavior therapy techniques to correct neurotic states in young people. We have hypothesized that CBT would be effective method in correcting neurotic conditions, especially those related with anxiety.

\section{MATERIALS AND METHODS}

Neurotic states were identified using the method "Clinical questionnaire for the detection and evaluation of neurotic states" (K. Yakhin, D. Mendelevich), which contains 6 scales: anxiety (occurs in a situation of uncertain danger and manifests itself in anticipation of negative developments); neurotic depression (mild form of depression, which is shown as sad mood, decreased activity, inhibition, fatigue); asthenia (neuropsychiatric weakness, manifested itself in increased fatigue and exhaustion, high sensitivity, extreme mood swings and difficulty sleeping); hysterical reaction type (the tendency to transform of emotional experience into 


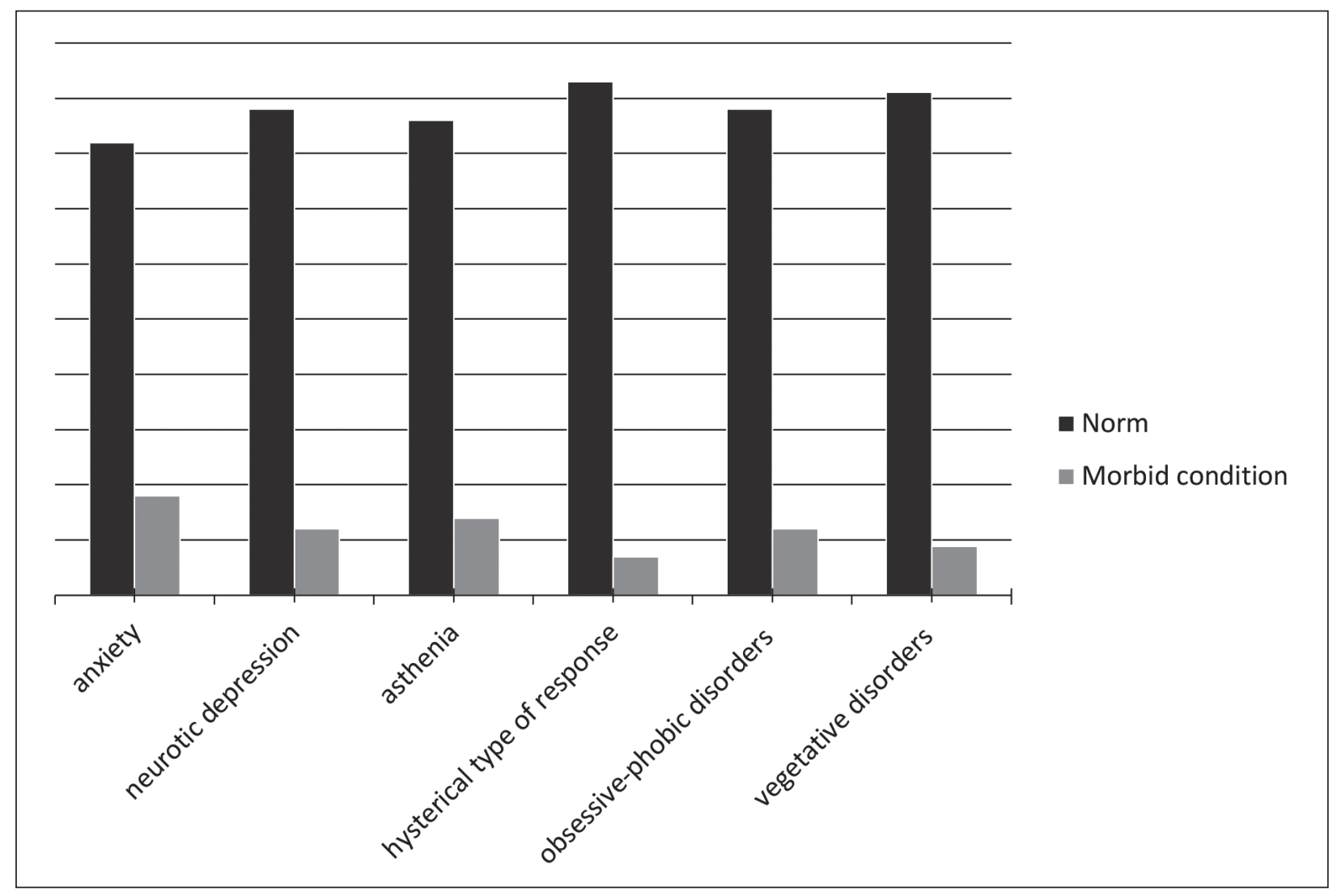

Fig.1. Indicators of neurotic states according to the method "Clinical questionnaire for detection and evaluation of neurotic states" (K. Yakhin and D. Mendelevich)

somatic symptoms); obsessive-phobic disorder (manifested itself in pedantry, hypersusceptibility to habits and rituals, careful consideration of their steps); autonomic vegetative disorders (physiologic failure of internal organs).

To diagnosis the hardiness as one of the indicators of mental health was used test "Hardiness Survey» (S. Muddi, adapted by D. Leontev, O. Rasskazova). Researchers S. Muddi and D. Khoshaba interpreted hardiness as a personal trait that determines the level of mental health and consists in three life settings:

1) scale "Personal involvement in life" ("Commitment") reflects the level of life activity, which resonates with the acceptance of own life style, life enjoyment and the lack of feeling "out" of life;

2) scale "Control over the life events" ("Control") reflects in the fact that a person believes that it is he who influences the events of his life, even if this influence is relative, sometimes it is successful, and sometimes - not successful; in contrast to the fact that she feels helpless and unable to influence her life;

3) scale "Willingness to take risks" ("Challenge") determines the personal relations to events, which has been happening with him. High readiness indicates that a person is open to the development of any events, and it does not matter what experience he (she) receives (positive or negative), the main thing is that the result will be taken into account next time. This position allows person to act with lack of reliable guarantees of success and achievement, at their own risk [9].
Wilcoxon test was used to determine changes in the manifestations of neurotic states in the conditions "before" and "after" the application of cognitive-behavior therapy techniques. This criterion does not require a normal distribution of the compared populations. It is used to assess the differences between two series of measurements made for the same set of subjects, but under different conditions or at different times. Pearson's correlation analysis was used to find the connection between neurotic states and hardiness (as an indicator of person's mental and social health).

The study was conducted online in a sample of adolescents $(\mathrm{N}=100$, age from 18 to 30 years). Among the study participants we have had $84 \%$ of women ( 84 persons) and $16 \%$ of men (16 persons). The main population is students $82 \%$ ( 82 persons) and $18 \%$ of subjects (18 persons) are employed people. $14 \%$ (14 persons) of subjects live in the village and $86 \%$ ( 86 persons) - in the city; $3 \%$ (3 persons) are married, $49 \%$ (49 persons) are not married and $48 \%$ (48 persons) are in a love relationship.

In this study we have investigated the possibilities of correction of neurotic states by CBT techniques, in particular: psycho-education, distancing, cognitive reassessment, etc.

\section{RESULTS}

We present the obtained results on six scales of the questionnaire K. Yakhin and D. Mendelevich in Fig. 1. We found that the majority of young people $(82 \%)$ have had 


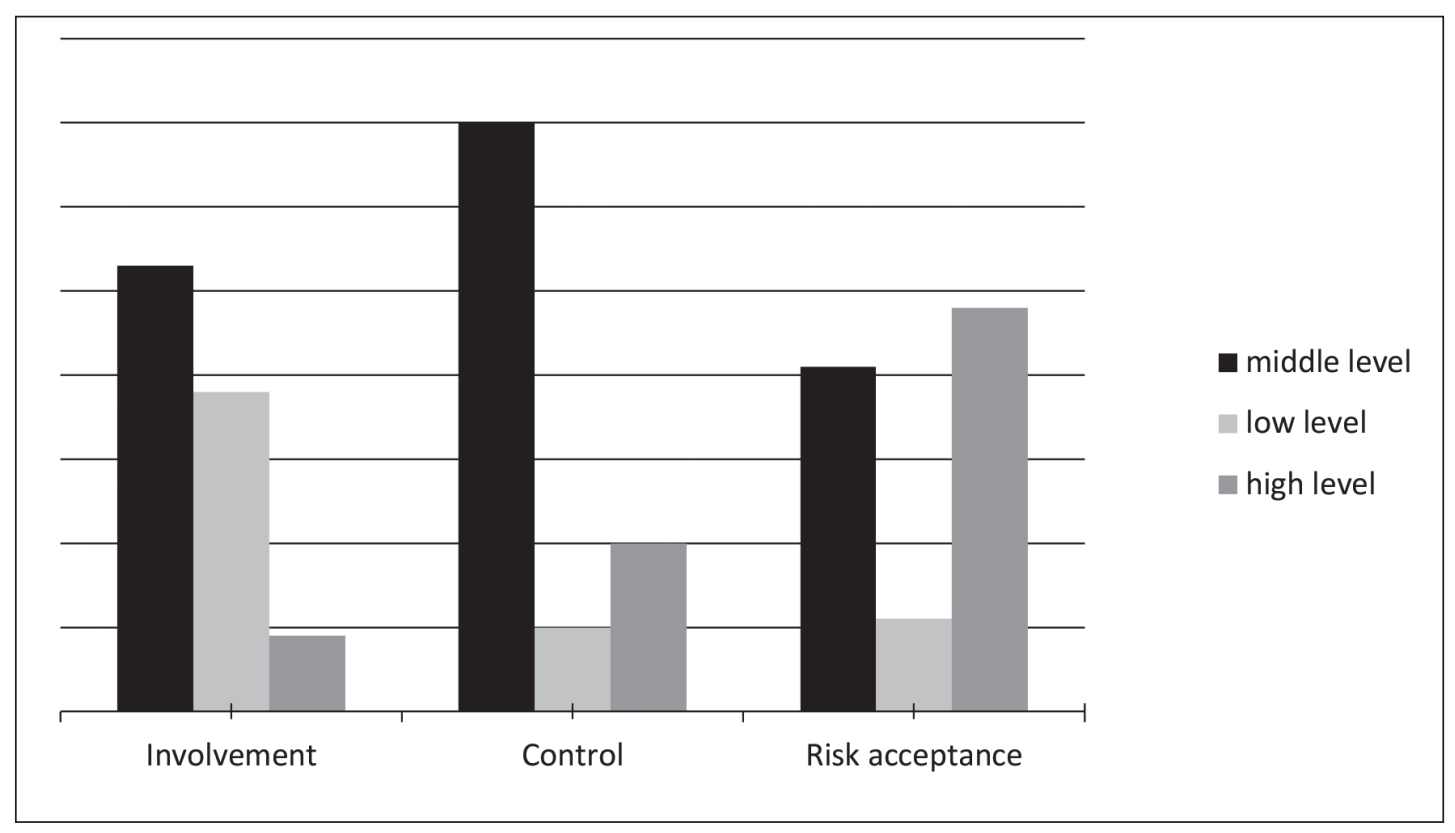

Fig. 2. The expression level of hardiness indicators, according to the test "Hardiness Survey" (S. Muddi, adapted by D. Leontev, 0. Rasskazova)

anxiety at the level of health and only $18 \%$ of subjects have had anxiety at the level of illness. The most people who participated in the study have had the level of neurotic depression within normal limits $(88 \%)$, but $12 \%$ of respondents have had a predisposition to this disease. $14 \%$ of subjects have had asthenia at the level of morbidity, and $86 \%$ of respondents have been in good health. The majority of young people have had a hysterical reaction type within health $(93 \%)$ and only $7 \%$ of subjects have had it on the level of illness. Obsessive-phobic disorder has been characteristic of $12 \%$ of respondents, this disorders nave not been detected in $88 \%$ of respondents. The high level of vegetative disorder has been diagnosed in $8.9 \%$ of young people, but the majority of respondents (91.1\%) have been within normal limits.

Thus, we can conclude that the intensity of neurotic states of young people is low and their mental state is closer to the norms of mental health. It was found that the most widespread diseases in young age are anxiety $(18 \%)$ and asthenia (14\%).

In modern research, indicators of personal hardiness are considered by scientists as important indicators of mental and social health of personality $[4,8-10]$, which provide the ability to survive stressful situations, maintaining internal balance and withstanding a temporary relative decline in productivity. People with high level of hardiness can quickly restore personal resources, find additional resources and turn changes into opportunities for their further development.

The results of diagnosis the components of personal hardiness using the test "Hardiness Survey" (S. Muddi, adapted by D. Leontev, O. Rasskazova) are presented in Fig. 2. It was found that more than half of the subjects have had the middle expression level of involvement in life (53\%); more than one third of them (38\%) have had a low level of this property and only $9 \%$ of subjects have had a high level of its expression.

Also it was identified that the most of study participants have had a middle expression level (70\%) on the scale "Control". Accordingly $20 \%$ of subjects have had a high level of this property and $10 \%$ of respondents have demonstrated a low expression level of ability to control their emotions and drives.

It is noteworthy that the number of people with a high expression level of tendency to risk (48\%) has predominated among young people, $41 \%$ of respondents have had a middle level and only $11 \%$ of study participants have demonstrated a low expression level of this property.

It is disturbing facts that one third of young people (38\%) have had a low level of involvement in life, and therefore they caught feel themselves as "out" of life, not finding something interesting and valuable for them, not enjoying their own way of life. Perhaps these data are generated by two factors:

- young men and women, looking for ways to realize their potential and achieve meaningful goals, have faced certain real difficulties (unreasonable expectations, nonnormality of their activity, corrupt structures, etc.), and these factors have caused their experiences of excluding of life, losing confidence in their ability to influence events; - this study has been conducted in situation, when young people have faced with activity limitations due to a pandemic caused by the CoVid-19 virus.

At the same time, it was found that almost half of respondents (48\%) have had a high level of risk acceptance. Therethrough, the most part of respondents have had a fairly good attitude towards functioning in complex or new situations. They have perceived them as challenges, which have opened different opportunities to gain a new experience). Then most of the respondents might use inap- 
Table I. Connection between indicators of neurotic states and hardiness

\begin{tabular}{cccc}
\hline Neurotic states & Indicators of hardiness & Pearson's correlation coefficient & The level of significance \\
\hline Neurotic depression & Involvement in life & -0.27 & $\mathrm{p}<0.01$ \\
\hline Anxiety & Hardiness & -0.31 & $\mathrm{p}<0.01$ \\
\hline Asthenia & Hardiness & 0.49 & $\mathrm{p}<0.001$ \\
\hline Obsessive-phobic disorder & Hardiness & -0.34 & $\mathrm{p}<0.001$ \\
\hline
\end{tabular}

propriate actions, overestimating the probability of success and underestimating the threatening factors. It is referred to an "unjustified risk", which associated with neglect of security and certainty, unwillingness to case analysis and situation forecast (see Fig. 2).

According to the general indicator of hardiness, which takes into account the results of all three scales, we found that $25 \%$ of people have had a low level of this property, $49 \%$ of respondents have showed a middle of hardiness level and $26 \%$ of young people - a high level. Thus, the middle hardiness has been prevailing, but a quarter of subjects have been characterized by low and high levels of ability to withstand life's hardships and stressors.

The next task of our study is investigating the relationships between neurotic states and components of hardiness. The obtained results are presented in table I.

The rate of neurotic depression has an inverse significant connection with the factor of involvement in life $(r=-0.27$; $\mathrm{p}<0.01$ ). Thus, neurotic depression "removes" a person from life, reduces the personal ability to jump with two feet into life and take pleasure in doing that.

Anxiety and obsessive-phobic disorders have an inverse significant connection with the general indicator of hardiness: the more pronounced these conditions, the lower the overall personal ability to withstand life's problems and difficulties $(\mathrm{r}=-0.31 ; \mathrm{p}<0.01$ and $\mathrm{r}=-0.34 ; \mathrm{p}<0.001)$. These facts mean that personal mental and social health would deteriorate and the individual's ability to successfully cope with stressful situations would decline too, if the anxiety and obsessive-phobic disorder became more intense. The opportunities of young people to maintain internal balance in situations of uncertainty, limitations, dangers, constant changes, as well as their ability to withstand temporary productivity slump rapidly either.

Our attention was drawn to the positive significant correlation between the level of asthenia and the general level of hardiness: the more pronounced asthenia, the more willingness to cope with difficulties $(r=0.49 ; \mathrm{p}<0.001)$. Thus, asthenia acts as a protective mechanism, which saves from excessive stress. It manifests itself as an unconscious response to the inability to realize desires and drive. At the same time, a person remains socially included, but does not have a vital resource for social activity. Due to the intensification of more resource-saving strategies of self-control and self-regulation, the personality continues to make some resistance to stressors, while maintaining their integrity.

Individuals with the highest level of neuroticism were invited to participate in the therapeutic community. Thus, an experimental group was created, which included 10 students: 8 girls and 2 boys (average age 19 years). A program of short-term personal psychotherapy was developed. The program included CBT techniques aimed at reduce anxiety, increase understanding of subjective nature of the events assessment and develop the skill to identificate the sources of unpleasant emotions, etc. The duration of one meeting was 30-40 minutes; the number of meetings was 10. At each meeting, homework was provided.

Techniques psycho-education, distancing, cognitive reassessment were used. Psycho-education is a mandatory first step in CBT when psychologists deal with any disorder. The purpose of the technique is to explain to a client the sense of mental health, their problems and their consequences for life; provide specific information about certain neurotic state, such as anxiety, the action of negative automatic thoughts (NATs) and the means of overcoming these states. Psycho-education also involves the use of metaphors to help a person better understand their difficulties and their causes. Examples of metaphors: "Darkness in the future", "Frightened eyes" and others.

The technique of distancing was represented by the exercises "Tram" and "Radio", which have had the aim to switch attention from anxiety to something pleasant or useful for a person. The meaning of this technique is that a person imagines that he (she) is on the tram track and when he sees the approach of the tram, he takes a step forward. When the door opens, instead of passengers there are a lot of anxious thoughts. In this moment the idea about opportunity to make a personal choice switches on. The person asks themselves the question: "Do I want to get on the tram?", "How will I feel if I get on?". Realizing that the desire to be in this place is zero, the person takes a step back and in a minute sees another tram. In this case, when the door opens, there are the ideas and words about support and love, which are highly useful in difficult times of their life. The technique oriented to realize that person will not necessarily plunge into a state of anxiety; he (she) can switch their attention to something pleasant.

The technique of cognitive reassessment was presented by the exercise "Useful and Useless Experiences", aimed at recognizing thoughts that trigger experiences and analyzing them. Such procedures help people stay in active position, use algorithms and plan to organize their practice, check out their experience through the comparing with reality and blocking the getting stuck in a state of anxiety. The purpose of the exercise is to teach person to separate real anxiety, relating with the real events, from fictional or exaggerated ones. The exercise is supplemented by an analysis of how useful these experiences are for human life. 
Table II. Changes in the expression level of neurotic states after the use of CBT techniques

\begin{tabular}{cccc}
\hline No & Questionnaire scale & Empirical value of Wilcoxon T-test & The level of significance (p) \\
\hline 1 & Anxiety & 0 & $\mathbf{p}<0.01$ \\
\hline 2 & Neurotic depression & 11.0 & - \\
\hline 3 & Asthenia & 13.5 & - \\
\hline 4 & Hysterical reaction type & 2 & $\mathbf{p}<0.01$ \\
\hline 5 & Obsessive-phobic disorders & 12.0 & - \\
\hline 6 & Vegetative disorders & 12.5 & - \\
\hline
\end{tabular}

At the end of the program, participants were re-diagnosed with a questionnaire by K. Yakhin and D. Mendelevich to determine the changes in the expression level of neurotic states. Wilcoxon T-test was used to distinguish the discrepancies in situation "before" and "after" participation in the therapy group. The obtained results are shown in table II.

The results show that significant changes occurred in two neurotic states: decreased level of anxiety $(T=0$; $\mathrm{p}<0.01)$ and hysterical reaction type $(\mathrm{T}=2 ; \mathrm{p}<0.01)$. Since these CBT techniques were primarily aimed at correcting anxiety, it could be concluded that the hysterical reaction type has been also characterized by anxiety.

\section{DISCUSSION}

We have chosen a model of short-term personal psychotherapy in order to obtain constructive changes in participants' personal sphere, which have been achieved through the disclosure, analysis, awareness of problems and correction of inadequate attitudes, emotional and behavioral stereotypes. The basis for this program has been the principles and algorithms for psychotherapeutic treatment of anxiety disorders on the neurotic level, carried out by a group of scientists T. Karavaeva, A. Vasileva and S. Poltorak. According to their approach, the main changes are planned in three spheres (cognitive, emotional and behavioral). This is about changing the perception of one's own role in the onset, repetition and development of conflict situations as the basis of new constructive behavior; a more favorable self-attitudes formation, which becomes a functional condition for reacting emotions and deactivating anxious experiences; the new forms of behavior construction for optimal adaptation, better functioning in society and prevention of recurrence of unconstructive behavior [2].

The result of our intervention program was significant changes in the expression of anxiety and hysterical reaction type. These results are consistent with the opinion of A. Alexandrov that in different psychopathological conditions the processing of information is influenced by systematic bias, which he called "cognitive shift". The author uses the analogy with a computer program for explanation of principles of symptoms operation.

Each disorder has its own specific program that determines the type of information processing: it entering, analyzing and the choosing of resulting behavior. In case of anxiety disorders, the "survival" program is activated: the person from the information flow snatches "danger signals" and blocks "safety signals". The resulting behavior is characterized by an overreaction to relatively insignificant stimuli as a powerful threat, and the person begins to respond with avoidance. Thus, the activated program causes a cognitive and emotional shift in information processing, as a result of which the normal program of adequately selected and interpreted data is replaced by an "anxiety program", which leads to the manifestation of neurotic symptoms [1].

These are the strong arguments for the use of CBT techniques to correct neurotic states and, as a consequence, increase the hardiness of the personality, which will lay the ground for improving the personal mental and social health. Among the various approaches to the restoring of mental health after trauma, T. Tytarenko as well puts the establishment of balance by means of self-regulation in the first place and then the restoring of lost self-efficacy, which is linked to the overall increase in hardiness [11].

\section{CONCLUSIONS}

The results of the study suggest that the majority of young people have the level of mental health for selected indicators of neurotic states. The anxiety and asthenia most often occur among neurotic disorders. The neurotic states are related to a person's level of hardiness, which is an indicator of their mental and social health. CBT techniques can be successfully used to correct neurotic states, namely anxiety and hysterical reaction type.

Based on these results, we can assume that certain CBT techniques affect specific neurotic states, and our further work may be to select techniques that would correct other states.

\section{REFERENCES}

1. Aleksandrov A.A. Sovremennaya psihoterapiya. Sankt-Peterburg: Akademicheskiy proekt. 1997, 335p. (in Russian).

2. Karavaeva T.A., Vasileva A.V., Poltorak S.V. Printsipyi i algoritmyi psihoterapii trevozhnyih rasstroystv nevroticheskogo urovnya (trevozhno-fobicheskih, panicheskogo igeneralizovannogo trevozhnogo rasstroystv). Obozrenie psihiatrii i meditsinskoy psihologii im. V.M. Behtereva. 2016; 4: 42-51. (in Russian).

3. Mendelevich V.D. Klinicheskaya i meditsinskaya psihologiya. Moskva: MBD press. 2009, 430p. (in Russian).

4. Rasskazova E.I. Psihologicheskie kontseptsii stressa i ego posledstviy. Psihologiya psihicheskih sostoyaniy. 2006; 6: 371-384. (in Russian). 
5. Romanchuk 0.I. Kohnityvno-povedinkova terapiia tryvozhnykh rozladiv: model rozuminnia, terapii ta empirychni dokazy efektyvnosti. Neironews. 2012; 4 (39):67. (in Ukrainian).

6. Yang D.I. Odinochestvo, depressiya i kognitivnaya terapiya: teoriya i eYo primenenie. Labirintyi odinochestva (red. N.E. Pokrovskiy). Moskva: Progress. 1989, 593p. (in Russian).

7. Butler J., Fennell M., Hackmann A. Cognitive therapy for anxiety disorders: mastering clinical challenges. New York: Guilford Press. 2008, $241 p$.

8. Maddi S., Khoshaba D. Hardiness and Mental Health. Journal of Personality Assessment. 1994; 63 (2): 265-274.

9. Maddi S.R. The story of hardiness: Twenty years of theorizing, research, and practice. Consulting Psychology Journal: Practice and Research. 2002; 54 (3): 173-185. doi: 10.1037/1061-4087.54.3.173.

10. Maddi $S$. The role of hardiness and religiosity in depression and anger. International Journal of Existential Psychology \& Psychotherapy. 2004; 1: 38-49.

11. Tytarenko T. Psychological Health Restoration as a Way of SocioPsychological Rehabilitation of a Person. Mental Health: Global Challenges Journal. 2019; 1(1): 81-82. doi: 10.32437/mhgcj.v1i1.33.

\section{ORCID and contributionship:}

Lina A. Kolesnichenko: 0000-0003-0196-4744 ${ }^{A-F}$

Liudmyla V. Muzychko: 0000-0002-3209-0376 A, D-F

Olena V. Savchenko: 0000-0002-7069-7419 A, D- F

Yelyzaveta M. Kolesnichenko: 0000-0001-5076-7208 A-C

Anastasiya Lovegrove: 0000-0002-9455-0016 ${ }^{E}$

\section{Conflict of interest:}

The Authors declare no conflict of interest.

\section{CORRESPONDING AUTHOR}

\section{Lina A. Kolesnichenko}

Kyiv National Economic University

named after Vadym Hetman

54/1 Prospect Peremohy, 03057 Kyiv, Ukraine

tel: +380677662992

e-mail: linaalikovna@gmail.com

Received: 19.05 .2021

Accepted: 11.10 .2021

A - Work concept and design, B - Data collection and analysis, C - Responsibility for statistical analysis,

$\mathbf{D}$-Writing the article, $\mathbf{E}$-Critical review, $\mathbf{F}$ - Final approval of the article 


\title{
THE INFLUENCE OF UNHEALTHY NEUROTICISM ON THE PECULIARITIES OF PERSONAL DECISION MAKING
}

DOI: 10.36740/WLek202111102

\author{
Olena V. Savchenko, Lyudmila V. Muzychko, Lina A. Kolesnichenko \\ KYIV NATIONAL ECONOMIC UNIVERSITY NAMED AFTER VADIM HETMAN, KYIV, UKRAINE
}

\begin{abstract}
The aim: To determine the influence of unhealthy neuroticism (the high level of personal neuroticism) on the properties of the decision-making process, to identify the differences in the decision-making process features of persons with high and low levels of neuroticism.

Materials and methods: A comparative design was used with two contrasting groups, which differed in the level of neuroticism. Causal relationships were defined using one-way analysis of variance (ANOVA). The methods «Diagnosis of the neurotic personality tendency" (L. Vasserman), "Diagnosis of decision-making features" (D. Myroshnyk, 0 . Savchenko), "Locus of control” (0. Ksenofontova) were used for diagnosis.

Results: It was identified that individuals with a high level of neurotic personality tendency have exhibited less self-control in the decision-making process $(p<0.01)$, have formed a pessimistic expectations of the ways in which decisions should be fulfilled $(p<0.01)$. A high level of neurotic personality tendency has occurred mostly in students with a high level of external locus of control $(p<0.01)$, a low assessment of self-competence $(p<0.01)$, low internality in the field of interpersonal relations $(p<0.05)$, unformed willingness to overcome difficulties $(p<0.05)$. The level of neuroticism is an important factor of the peculiarities of decision-making process (self-control ( $p<0.001)$ and optimistic expectations $(p<0.02))$. The general level of internality has determined the level of neurotic personality tendency $(p<0.02)$

Conclusions: Unhealthy neuroticism, which manifests itself in a high level of neurotic personality tendency, is a risk factor of mental health, and it prevents timely make appropriate decisions. The high level of external locus of control mediately (through increasing the level of neurotic personality tendency) affects the procedural and effective properties of the decision-making process.
\end{abstract}

KEY WORDS: mental health, neuroticism, unhealthy neuroticism, neurotic personality tendency, decision-making process, diagnosis of the neuroticism level, selfreflection, self-control, locus of control, personal expectation

Wiad Lek. 2021;74(11 p.l):2695-2699

\section{INTRODUCTION}

In modern psychological studies, mental health is considered as the optimal state of personality life, which is characterized by activity, harmonious development, balance of various aspects and areas, the full expression of vital forces, etc. [1-3]. Mental health support, according to researchers D.V. Kolesov and D.D. Kolesov, has fulfilled itself through "health processes" (self-support and self-preservation), aimed at ensuring the "dynamic stability" of the personality functioning (stability of appearance, behavior, social relations, etc.) [2-16]. Among the personal risk factors for mental health, most foreign researchers have distinguished the level of neuroticism $[7,13,14]$. However, the correlation between neuroticism and indicators of mental health is not linear, as people with high neuroticism often show a high sensitivity to stressors and threatening situations, anxiety about their own health, which have a positive effect on their physical condition, because they control their behavior and seek medical attention in a timely manner $[8,9,17,18]$. Modern studies have proved that there are two forms of neuroticism: healthy and unhealthy. Healthy neuroticism is provided by a combination of high emotional excitability and high awareness, which are the positive factors in maintaining and promoting mental health. Unhealthy neuroticism has an adverse effect on the well-being and physical health of the individual due to inattention to their inner conditions, self- treatment, attempts to reduce the mental stress level treatment of alcohol and tobacco. The cause of unhealthy neuroticism is a low level of self-reflection, unformed personal ability to be aware of their own emotions, experiences and thoughts [10]. According to O. Savchenko, self-reflection expresses itself in ability "to develop understanding and interpretation of different life events" [15], which helps people to reduce an external and internal uncertainty in situation. The high self-reflection is the necessary condition for mobilization of necessary resources, maintenance of well-being and high performance, enhancing their activity at limited resource settings [15].

The form of unhealthy neuroticism expression is a high level of neuroticism as a pronounced predisposition to neuroses, functional disorders of mental activity caused by traumatic events. According to V. Mendelevich, the reasons of formed neurotic personality tendency are im- 
mature personal protective mechanisms and inadequate anticipation of future results of their own actions [5]. Despite the numerous research works in this sphere of study the factors and conditions, which increase the level of neuroticism, inadequate attention of researchers was paid to study of key issues of changes in the characteristics of decision-making under the influence of an increase in the level of neuroticism. Does negative (unhealthy) neuroticism affect the procedural and effective aspects of decision making? We consider this issue is highly topical because obtained results can help to find a way out of the vicious cycle: "increasing neuroticism - experiencing health problems - trying to solve problems - getting stuck in decision-making - increasing neuroticism".

The high level of neuroticism affects all areas of personality. In the emotional sphere, we can observe high excitability, which is manifested itself in anxiety, irritability, experiencing high inner tension. Egocentric orientation, which expresses in hypochondriac fixation on somatic sensations, excessive attention to shortcomings and problems, prevails in the motivational sphere of personality. The thoughts that relate to the negative course of events, overestimation of past failures and underestimation of the probability of future success dominate in the cognitive sphere. In the behavioral personal sphere, the individual shows lack of initiative, passivity, social cowardice, dependence on others. Obviously, such patterns affect the decision-making process. The impact may affect the procedural properties, such as: consistency, timeliness, efficiency, and effective aspects of the decision-making process (adequacy to the real conditions, complexity, probability of successful enactment, etc.).

\section{THE AIM}

The aim of the study is to determine the impact of unhealthy neuroticism (high neurotic personality tendency) on the properties of the decision-making process, to differentiate the features of the decision-making process of people with high and low levels of neuroticism.

We assumed that a person with a high level of neurotic personality tendency will make decisions based on other people's opinions, so will demonstrate more dependent behavior, will inadequately assess the likelihood of its successful implementation in the future (excessively overestimate the probability of success or completely devalue it), will not adhere to a certain algorithm, and therefore demonstrate chaos and impulsiveness in decision-making, or, conversely, get stuck at the stage of the alternatives analysis.

\section{MATERIALS AND METHODS}

The scheme of comparative study with contrast groups, which differed in the level of neuroticism, was chosen to test these hypotheses. The personal level of neuroticism was diagnosed using the method of "Diagnosis of the neurotic personality tendency" (L. Vasserman). The method
"Diagnosis of decision-making features" (D. Myroshnyk, O. Savchenko) was used to determine the procedural and effective aspects of decision-making process. It includes three scales suitable for diagnosing the specific features of the decision-making process: the level of self-control (ability to control negative experiences, regulate the level of affective arousal), optimistic expectations (belief in the feasibility of the decision, which reduces emotional stress, transforming it into operational tension, which helps a person work at a rapid pace, timely activate the necessary resources, adequately distribute attention, etc.), independence (confidence in the correctness of the decision, willingness to stand their ground under the influence and pressure of others).

The research involved 74 students of Kyiv National Economic University named after Vadym Hetman. They studied the different specialties (Economic, Management, Psychology) of different courses (first, second and third year of studying). The study was conducted online in AprilMay 2021, during a lockdown, hence in a condition of the social constraints caused by the COVID- 19 epidemic. We assumed that social isolation would increase the neurotic personality tendency (the high level of neuroticism) due to the increase of adverse factors (experiencing one's own insecurity, social isolation, increased psycho-emotional and mental work load, etc.). However, the obtained results fully correspond to the nature of the normal distribution according to the single-sample Kolmogorov-Smirnov criterion $(\lambda=0.944)$. Thus, we cannot report that the number of students with a high level of neurotic personality tendency increases in in the sample. According to the level of neurotic tendency, two contrast groups of students were formed: with a high level of neurotic tendency (11 people, $14.9 \%$ of the total sample) and with a low level (18 people, 24.3\%). The Mann-Whitney U-test was used to identify significant differences between the levels of expression of certain properties.

One-way analysis of variance (ANOVA), from the STATISTICA 13.0 package, was used to establish causal relationships. Additionally, the "Locus of Control" technique (O. Ksenofontova) was used to diagnose factors that could potentially determine the level of neurotic tendency. This method identifies 17 aspects of the locus of personal control, among which the most important for our study are the general level of internality, willingness to overcome difficulties, internality in the field of achievement and failure, competence and responsibility in the field of interpersonal relationships and others.

\section{RESULTS}

The results of psychological diagnostics by the method " $\mathrm{Di}$ agnosis of decision-making features" are presented in table I.

According to the obtained results, students with a low level of neurotic personality tendency demonstrate a higher level of ability to regulate their emotions and behavior $(\mathrm{Md}=5)$ than individuals with a high level $(\mathrm{Md}=2)$. Making a final decision leads to calming, reducing the level of 
Table I. Features of decision-making properties of students with different levels of neurotic personality tendency

\begin{tabular}{|c|c|c|c|c|c|}
\hline № & Peculiarity & $\begin{array}{l}\text { Median in the group } \\
\text { with low level of } \\
\text { neurotic tendency } \\
(\mathrm{N}=18)\end{array}$ & $\begin{array}{l}\text { Median in the group } \\
\text { with high level of } \\
\text { neurotic tendency } \\
(\mathrm{N}=11)\end{array}$ & $\begin{array}{c}\text { Empirical value } \\
\text { Mann-Whitney } \\
\text { U-test }\end{array}$ & $\begin{array}{l}\text { Significance value } \\
\text { (alpha level) }\end{array}$ \\
\hline 1 & $\begin{array}{l}\text { Self-control in the decision- } \\
\text { making process }\end{array}$ & 5 & 2 & 33.5 & 0.01 \\
\hline 2 & $\begin{array}{l}\text { Optimism in the result } \\
\text { expectation }\end{array}$ & 4 & 2 & 42.5 & 0.01 \\
\hline 3 & $\begin{array}{l}\text { Independence in the } \\
\text { decision-making process }\end{array}$ & 3 & 4 & 71.0 & - \\
\hline
\end{tabular}

Table II. Differences in the level of internality in groups with different level of neurotic personality tendency

\begin{tabular}{cccccc}
\hline No & Property & $\begin{array}{c}\text { Median in the group } \\
\text { with low level of } \\
\text { neurotic tendency } \\
(\mathbf{N = 1 8}\end{array}$ & $\begin{array}{c}\text { Median in the group } \\
\text { with high level of } \\
\text { neurotic tendency } \\
(\mathbf{N}=\mathbf{1 1})\end{array}$ & $\begin{array}{c}\text { Empirical value } \\
\text { Mann-Whitney } \\
\text { U-test }\end{array}$ & $\begin{array}{c}\text { Significance value } \\
\text { (alpha level) }\end{array}$ \\
\hline 1 & General level of internality & 27 & 23 & 47 & 0.01 \\
\hline 2 & $\begin{array}{c}\text { The level of interpersonal } \\
\text { competence }\end{array}$ & 5 & 3 & 37.5 & 0.01 \\
\hline 3 & $\begin{array}{c}\text { The level of internality in the } \\
\text { field of interpersonal relations }\end{array}$ & 10 & 8 & 50.5 & 0.05 \\
\hline 4 & $\begin{array}{c}\text { The level of willingness to } \\
\text { overcome difficulties }\end{array}$ & 6 & 4 & 56.5 & 0.05 \\
\hline
\end{tabular}

inner tension. As Yu. Glazunov notes, "every decision is aimed at relaxing the tension of a certain significant situation and the risk associated with it" [1]. However, the high level of neurotic personality tendency blocks an individual's ability to quickly regulate level of inner over tension and feeling calm. The ability to self-regulate decreases as the person loses the ability to use "mental means of reflection and modeling of reality" [12]. Students with low level of ability to regulate their emotions structure their decision-making process in such a way that it lead to an increase the tension, as their thoughts about possible mistakes are activated, their negative expectations of failure are formed. Thus, a high level of inner tension prevents young people from controlling their negative experiences, normalizing their emotional state in a decision-making situation, they are stuck in the decision-making process for a long time because they cannot gather the necessary information, compare options and choose the best alternative.

As a result, people with a low level of neurotic personality tendency form more optimistic expectations about their ability to implement outcomes and achieve a positive result $(\mathrm{Md}=4)$. Young people with a high level of neurotic tendency, on the contrary, underestimate their ability to succeed $(M d=2)$, they much more often focus their attention on adverse factors, on their own failures and mistakes of team members, they expect and therefore try to avoid criticism from others, afraid to get stuck in situation of choice, waste time, and therefore they can make reckless impulsive decisions.

It is interesting that the level of neurotic personality tendency did not affect such an aspect of the decision-making process as dependence-independence of outcomes from the opinions of others. It can be assumed that independence-dependence is a factor, which determinates by personality's properties; it is not affected by the level of emotional tension. We also suggested that the level of neurotic tendency depends on the dominance of external fundamental attitudes, such as: "I am not able to control the events of my life", "My result depends on the coincidence of circumstances, the actions of others", etc. Such mindsets prevent individuals from quickly mobilizing efforts, structuring their activities. Activating of external attitudes leads to slowdown in the decision-making process, extreme increasing the tendency to procrastination. In order to test this hypothesis, we have diagnosed the property "internality - externality" by the method of "Locus of Control" (O. Ksenofontova) in groups of people with different level of neurotic personality tendency. The obtained significant differences are presented in table II.

The results show that our hypothesis has been confirmed. Indeed, students with a high level of neurotic tendency have a higher general level of externality $(U=47$; $<<0.01)$ and a more pronounced externality in explaining events in the field of interpersonal relationships $(\mathrm{U}=50.5 ; \mathrm{p}<0.05)$. Individuals with a low level of neurotic tendency show a more pronounced internal locus of control, demonstrate a greater willingness to take responsibility for the consequences of their actions, to rely on their own strength. Also, they appreciate their competence in interpersonal relationships more highly, perceive themselves as quite effective in forming and maintaining social contacts $(\mathrm{Md}=5)$, than people with a high level of neurotic ten- 
Table III. The results of One-way analysis of variance (by factor of neurotic personality tendency)

\begin{tabular}{cccc}
\hline № & Peculiarity of the decision-making process & $\begin{array}{c}\mathbf{F} \\
\text { (empirical value) }\end{array}$ & $\begin{array}{c}\mathbf{p} \\
\text { (significance value) }\end{array}$ \\
\hline 1 & Self-control in the decision-making process & 8.78 & 0.0004 \\
\hline 2 & Optimism in the result expectation & 4.11 & 0.02 \\
\hline 3 & Independence in the decision-making process & 1.44 & 0.24 \\
\hline
\end{tabular}

Table IV. The results of One-way analysis of variance (by factor of the general level of internality)

\begin{tabular}{cccc}
\hline No & Peculiarity of the decision-making process & $\begin{array}{c}\mathbf{F} \\
\text { (empirical value) }\end{array}$ & $\begin{array}{c}\mathbf{p} \\
\text { (significance value) }\end{array}$ \\
\hline 1 & Self-control in the decision-making process & 2.99 & 0.06 \\
\hline 2 & Optimism in the result expectation & 2.99 & 0.06 \\
\hline 3 & Independence in the decision-making process & 0.22 & 0.79 \\
\hline
\end{tabular}

dency $(\mathrm{Md}=3)$. The consequence of higher competence $(\mathrm{U}=37.5 ; \mathrm{p}<0.01)$ is the fact that students with a low level of neurotic tendency have much more formed willingness to overcome difficulties $(U=56.5 ; \mathrm{p}<0.05)$.

The results of One-way analysis of variance (ANOVA) have proved that the level of neurotic personality tendency can be considered as a factor that determines the features of the decision-making process. The results are presented in table III.

As we can see, the level of neurotic personal tendency determines the ability of a person to regulate their emotional state, normalize the emotional background by suppressing negative emotions, relaxation, switching attention to other objects $(\mathrm{F}=8.78 ; \mathrm{p}<0.001)$. Also, the state of high neurotic tendency has a significant impact on the anticipative aspects of the decision-making process. Underestimation of the probability of success and overestimation of possible negative consequences have tendency to increase with growth in level of neurotic personality tendency $(\mathrm{F}=$ $4.11 ; \mathrm{p}<0.02)$. The results of One-way analysis of variance confirm that the level of neurotic tendency does not affect the orientation to others in decision-making. Thus, we can state that the decrease in mental health due to increased neurotic personality tendency affects the peculiarities of decision-making process: students find it more difficult to regulate their emotional state; they underestimate the likelihood of future success because their attention focuses only on expectations with negative consequences, opportunities for failure.

According to the results of One-way analysis of variance, which are presented in table IV, we can say that the general level of internality does not directly affect the peculiarities of the decision-making process, but the external locus of control may affect indirectly by increasing the level of neurotic personality tendency. In our research it was found that the level of internality has a significant effect on the level of neurotic personality tendency $(\mathrm{F}=4.09 ; \mathrm{p}<0.02)$.

\section{DISCUSSION}

Experiencing the state of stuck in the decision-making process increases the level of inner tension, which stim- ulates the growth in feeling uncertainty in their ability to overcome this situation. People get the feeling that the situation is out of their control, that they cannot effectively manage the events of their life. Note that such thoughts lead to a state of functional deficit, described by $\mathrm{H}$. Heckhausen. Functional deficit manifests itself in the experience of personal helplessness due to the recognition of own nonnormality (discrepancy between obtained results and certain standards), in feeling uncertainty in own ability to overcome a difficult task, in anticipation of failure [6].

The unwillingness of people with a high level of neurotic personality tendency to overcome failures and difficulties is explained by the anticipative concept of neurosis [5], according to which neurotic disorders are the result of inadequate mechanisms of anticipation, inability to effectively predict the results of their activity in uncertain situations, "unpredictable personality events "[4]. Inherently, it also affects the decision-making process, the situation of choice one among the set of alternatives, as the subjects have a reduced ability to form forecasts for the future and anticipate possible changes in operating conditions. V. Mendelevich notes that the function of anticipation is to reduce the level of situation uncertainty, which is realized through the activation of the intuitive prediction mechanisms. As the level of neurotic personality tendency increases, the ability to use intuitive mechanisms related to implicit learning, heuristic decision-making strategies and unarticulated knowledge is blocked. According to the theory of bounded rationality, in uncertain situations a person can make an irrational decision because he (she) does not know how to use their intellectual resources to the fullest. D. Kahneman and K. Stanovich have explained such incompetence with "cognitive laziness" [11] or "cognitive miser" [16]. Scientists have associated the personal reluctance to analyze the necessary information fully and to consider alternative scenarios events with a lack of critical thinking (non-acquaintance of the scientific thinking rules, logical reasoning principals). The reason of cognitive laziness can be in the inability to assess the correctness of reasoning and evidence, in the presence of certain defective patterns of behavior ("virus programs»). K. Stanovich has pointed out that such cognitive misers easily become objects 
of other people's manipulation, because the bright labels are paid people's attention and give opportunities others "to hold the anchors in their hands" [16].

\section{CONCLUSIONS}

Based on the obtained results of the study, we can argue that the increased level of neurotic personality tendency negatively affects the peculiarities of the decision-making process. As the level of unhealthy neuroticism increases, the individual's ability to regulate their own emotional state and behavior little by little decreases, and pessimistic predictions about the probable results of their actions stably increase. This creates a state of functional deficit, in which a person does not try to optimize their mental resources and makes decisions based on a simplified model of the situation. External locus of control is a factor that increases a neurotic personality tendency. The reason of formating of this propensity is the attitude, according to which person cannot control the events of their life, the outcomes of activity depend on a favorable coincidence, not on their efforts and competence. Such attitudes also limit a person's ability to find ways to overcome a difficult situation mobilize and update resources.

From the perspective of our research results, we can speculate that increased neurotic personality tendency contributes to a decrease in the ability to make rational decisions; the verification of this hypothesis will be the goal of our next scientific research.

\section{REFERENCES}

1. Glazunov Yu.T. Informatsionno-psihologicheskie aspektyi prinyatiya resheniya. Vestnik Udmurtskogo universiteta. Seriya Filosofiya. Psihologiya. Pedagogika. 2018; 29 (2): 235-243. doi: 10.35634/24129550-2019-29-2-235-243 (in Russian).

2. Kolesov D.V., Kolesov D.D. Sostoyaniya cheloveka (semantika, psihologiya, meditsina). Moskva: Izd-vo Moskovskogo psihologosotsialnogo instituta; Voronezh: Izd-vo NP0 «MODEK». 2008; 704p. (in Russian).

3. Kuznetsov M.A., Zotova L.N. Psihologicheskie mehanizmyi i determinantyi podderzhaniya zdorovya cheloveka. Visnyk Kharkivskoho natsionalnoho pedahohichnoho universytetu imeni H.S. Skovorody. 2016; 53: 102-125. (in Russian).

4. Mendelevich V.D., Granitsa A.S. Rol prognosticheskoy kompetentnosti i intuitivnostiv mehanizmah nevrozogeneza. Ekologiya cheloveka. 2019; 12: 40-45. (in Russian)

5. Mendelevich V.D., Soloveva S.L. Nevrozologiya i psihosomaticheskaya meditsina. Moskva: Gorodets. 2016; 596p. (in Russian)

6. Hekhauzen H. Motivatsiya i deyatelnost. Sankt-Peterburg: Piter; Moskva: Smyisl. 2003; 860p. (in Russian)

7. Friedman H.S. Neuroticism and health as individuals age. Personality Disorders: Theory, Research, and Treatment. 2019; 10(1): 25-32. doi: 10.1037/per0000274.

8. Graham E.K., Bastarache E.D., Milad E. et al. Physical activity mediates the association between personality and biomarkers of inflammation. SAGE Open Medicine. 2018; 6(9): 1-10. doi: 10.1177/2050312118774990.

9. Hampson S.E., Friedman H.S. Personality and health: A lifespan perspective. Handbook of personality: Theory and research. New York: The Guilford Press. 2008, 794p.
10. Donnellan B.M. et al. Is Healthy Neuroticism Associated with Health Behaviors? A Coordinated Integrative Data Analysis. Collabra: Psychology. 2020; 6(1). doi: 10.1525/collabra.266.

11. Kahneman D. Thinking, fast and slow. New York: Farrar, Straus \& Giroux. 2011; 499p.

12. Kostyuchenko 0 . Recreational potential of metaphorization in mental self-regulation of the students. Mental Health: Global Challenges Journal. 2020; 3(2): 28-37. doi: 10.32437/mhgcj.v4i2.78.

13. Mroczek D.K., Spiro III A., Turiano N.A. Do health behaviors explain the effect of neuroticism on mortality? Longitudian findings from the VA Normative Aging Study. Journal of research in personality. 2009; 43(4): 653-659. doi: 10.1016/j.jp. 2009.03.016.

14. Shanahan M.J., Hill P.L., Roberts B.W. et al. Conscientiousness, health, and aging: The Life Course of Personality Model. Developmental Psychology. 2014; 50(5): 1407-1425. doi: 10.1037/a0031130.

15. Savchenko 0. Psychosemantic tools of Self-assessing individual reflectivity. East European Journal of Psycholinguistics. 2019;6(2): 98-106. doi: 10.5281/zenodo.3637765.

16. Stanovich K.E. What Intelligence Tests Miss: The Psychology of Rational Thought. New Haven: Yale University Press. 2009, 288p.

17. Taga K.A., Friedman H.S., Martin L.R. Early personality traits as predictors of mortality risk following conjugal bereavement. Journal of Personality. 2009; 77(3): 669-690. doi: 10.1111/j.1467-6494.2009.00561.x

18. Weston S.J., Hill P.L., Edmonds G.W. et al. No Evidence of healthy neuroticism in the Hawaii Personality and Health Cohort. Annals of Behavioral Medicine. 2018;11(5): 426-441. doi: 10.1093/abm/kay055.

\section{ORCID and contributionship:}

Olena V. Savchenko: 0000-0002-7069-7419 A-D, F

Liudmyla V. Muzychko: 0000-0002-3209-0376 A, E, F

Lina A. Kolesnichenko: 0000-0003-0196-4744 A,E,F

\section{Conflict of interest:}

The Authors declare no conflict of interest.

\section{CORRESPONDING AUTHOR \\ Olena V. Savchenko \\ Kyiv National Economic University \\ named after Vadym Hetman \\ 54/1 Prospect Peremohy, 03057 Kyiv, Ukraine \\ tel: +380677970707 \\ e-mail: savchenko.elena.v@gmail.com}

Received: 15.04 .2021

Accepted: 28.09 .2021

A - Work concept and design, B - Data collection and analysis, C - Responsibility for statistical analysis, D-Writing the article, $\mathbf{E}$-Critical review, $\mathbf{F}$-Final approval of the article 


\title{
THE READINESS OF A YOUNG COUPLE TO ADOPT A CONSTRUCTIVE BEHAVIOR DURING CONFLICT AS A FACTOR OF MENTAL HEALTH AND MARITAL SATISFACTION
}

DOI: $10.36740 /$ WLek202111103

\author{
Liudmila M. Omelchenko ${ }^{1}$, Lidiya G. Chorna ${ }^{2}$, Nataliya Dyshlova² ${ }^{2}$ Anna Bezhnar ${ }^{3}$, Olha T. Pletka ${ }^{2}$, \\ Tetiana M. Vakulich ${ }^{4}$, Giuseppina Ancona ${ }^{5}$ \\ 'NATIONAL UNIVERSITY OF LIFE AND ENVIRONMENTAL SCIENCE OF UKRAINE, KYIV, UKRAINE \\ ${ }^{2}$ INSTITUTE OF SOCIAL AND POLITICAL PSYCHOLOGY NATIONAL ACADEMY OF EDUCATIONAL SCIENCES OF UKRAINE, KYIV, UKRAINE \\ ${ }^{3}$ TARAS SHEVCHENKO NATIONAL UNIVERSITY OF KYIV, KYIV, UKRAINE \\ ${ }^{4}$ INTERREGIONAL ACADEMY OF PERSONNEL MANAGEMENT, KYIV, UKRAINE \\ ${ }^{5}$ AZIENDA SANITARIA PROVINCIALE DI AGRIGENTO: AGRIGENTO, SICILIA, ITALY
}

\begin{abstract}
The aim: To study the readiness of young couples to adopt a constructive behavior during conflict as a factor of mental health and marital satisfaction. Materials and methods: The study used a descriptive cross-sectional plan. The sample comprised 216 young families $(n=432$ persons), and mixed methods design was used. The respondents were asked to evaluate the level of marital satisfaction, family value coherence, and anxiety to make a self-assessment of the level of conflict in their own family. Results: The participants showed a fairly high degree of marital dissatisfaction, as a consequence of the COVID-19 pandemic. The members of young dysfunctional families resorted to destructive behavior during conflicts, indicating the deteriorating mental health in these families. The stability of relationship between spouses is founded in their willingness to adopt a constructive behavior during conflict.

Conclusions: The study helps understand the importance of the ability to adopt a constructive behavior during conflict in the context of family mental health and marital satisfaction. The findings of this study can serve as the basis for framing counseling programs for young families.
\end{abstract}

KEY WORDS: young family, mental health, willingness to behave constructively during conflict, marital satisfaction, COVID-19

Wiad Lek. 2021;74(11 p.l):2700-2704

\section{INTRODUCTION}

Despite a significant amount of research concerning the family mental health, the COVID-19 pandemic has aggravated the relevance of this topic. The phenomenon of conflict negatively affects young families, particularly by deteriorating mental health and reducing marital satisfaction. An important factor of family mental well-being and a stable marriage is the willingness of spouses to behave constructively during conflict.

\section{MENTAL HEALTH AND MARITAL SATISFACTION OF SPOUSES}

In the modern scientific paradigm, the concept of "mental health" is interpreted as a state of well-being in which everyone can realize their potential, cope with life stresses, work productively and effectively, and contribute to the life of their community [1]. Accordingly, mentally healthy marital relations contribute to harmonious relations between husband and wife, which in turn leads to the satisfaction of the actual needs of the spouses and determination of their personal development and social activity. Such rela- tionships are quite resourceful, characterized by resistance to stressors [2], and an indicator of the marriage quality. Conversely, mentally unhealthy marriages become a source of personal trauma. During the COVID-19 pandemic, the use of forced restrictive measures, which made it impossible to exercise personal freedom to a large extent, caused the spread of emotional stress [3]. Moreover, the increased intensity of family communication and uneven distribution of family responsibilities between spouses increased their level of anxiety and provoked the destructive conflicts. All this confirmed the inability of young family members to cope with life stress, which is a sign of maladaptation of spouses at different levels of interaction [4]. This situation made it impossible for the spouses to realize their need for love, acceptance, support, communication, and openness. In addition, personal growth, important for modern marriage, was hindered [5], and the possibility of establishing mutual understanding was destroyed. This led to a deterioration in mental health and, therefore, a decrease in marital satisfaction. In such circumstance, timely psychological treatment can stabilize the relationship of spouses and provide constructive behavioral strategies to handle 
conflict $[6,7]$. Moreover, it can also prevent aggressiveness in the family [8], mental illness, alcohol abuse, suicide, and social outsiderness, which in turn reduce social payments and benefits.

\section{THE READINESS OF YOUNG COUPLES TO} ADOPT CONSTRUCTIVE CONFLICT RESOLUTION Marital relations are the basis of marital stability in the current situation of social development of the family as a small group [9]. Most scientists are inclined to believe that one of the factors of family maladaptation is the inability to resolve marital conflicts constructively [10], which is especially acute for the young families [11]. The ways of overcoming the conflicts are formed at the stage of marital adaptation [12]. In addition, the conflict cannot be prevented, as it exists as a dialectal opposite of consensus, and the main way to resolve it is a settlement $[13,14]$. Thus, an important contributor of a mentally healthy relationship is the willingness of young couples to behave constructively during conflict. From the standpoint of a personal approach, psychological readiness is the result of preparedness for a certain activity and leads to stable, multifaceted, and hierarchical formation of personality [15]. Psychological readiness for constructive behavior in conflict is a personal formation, which is manifested in the ability of young couples to resolve conflicts constructively and predict the possible emergence of contradictions of living together [16]. Its structure includes the following components: motivational and value-based (motives, expectations, claims, values of family life), cognitive (system of knowledge and ideas about conflict), emotional-regulatory (behavioral tactics, self-regulation, and mental state) [17].

All this gives solid ground to highlight the importance of scientific research on the readiness of young couples to adopt constructive behavior during conflict. Many scholars have focused on studying the impact of conflicts on the stability of marriages [9], personality traits that cause conflicts [14], and the reasons for conflicts in young families [18]. We focused on the impact of young couples' willingness to behave constructively during conflict on marital satisfaction and family mental health.

\section{THE AIM}

The purpose of this article is to study the readiness of young couples to adopt a constructive behavior during conflict as a factor of mental health and marital satisfaction.

\section{MATERIALS AND METHODS}

The descriptive cross-sectional study plan was used to explore the readiness of young couples to adopt a constructive interaction. The sample consisted of 216 young families (432 individuals), randomly selected from 6 regions of Ukraine. Such quantitative and regional selection provided an opportunity to represent young families in Ukraine.

The design of mixed methods was applied. The study was conducted in three stages (January-February 2020).
The following data were collected during the study: a) the socio-demographic characteristics of respondents and b) peculiarities of mental health and marital satisfaction of young families.

\section{DATA COLLECTION TOOLS}

The first part of the survey involved collecting the socio-demographic characteristics of the respondents by means of a questionnaire consisting of 15 questions concerning the residence, age, gender, marital experience, presence/ absence of children, level of education, life situation, employment, etc.

In the second part of the survey, using the standardized methods, participants were questioned regarding a) satisfaction with marriage (the questionnaire by Stolin, Romanova, and Butenko: a one-dimensional scale containing 24 statements about different areas of family life, with each statement offering three options for answer); b) family value coherence (Volkova's questionnaire: 2 subtests [options for women and men], consisting of 36 statements concerning family values, expectations, claims of spouses, and their ideas about family roles); and c) level of anxiety (the Spielberger-Hanin questionnaire: self-assessment scale, consisting of 40 statements divided into 2 blocks, to determine situational and personal anxiety).

In the third stage of survey, participants were asked for a self-assessment of the level of conflict in their family using the nominative scale. Following was the question: "How often do you have conflicts?" Answers were to be given on a 4-point scale, ranging from 1 to 4 ( $4=$ very often, $3=$ often, 2 = rarely, and 1 = sometimes).

\section{DATA ANALYSIS}

The data analysis was performed using SPSS statistical software (Armonk, NY: IBM). Since the questionnaires were a combination of categorical and nominal data, the descriptive statistics, the analysis of variance, and the correlation analysis were used in accordance with the specifics of data. The correlation analysis revealed the relationship between marital satisfaction and its determining factors.

\section{RESULTS}

Results obtained can be divided into following categories: the key socio-demographic characteristics of the sample; marital satisfaction and subjective perception of the conflict level; the indicators of the level of anxiety of spouses, as well as the correlation between these characteristics; spouses' behavioral strategies in conflicts; the potential areas of conflict during interaction of spouses; and the level of family values coherence.

\section{SOCIO-DEMOGRAPHIC CHARACTERISTICS}

The sample consisted of 216 young families ( 432 individuals) aged 18 to 30 years, with an average of 25 years (SD = 
2.53). In terms of gender, the sample had $50 \%$ women and $50 \%$ men. The participants are representatives of different regions of Ukraine (Kyiv, Cherkasy, Odesa, Vinnytsia, Kharkiv, Zhytomyr cities and Kyiv, Zhytomyr, Cherkasy, Kharkiv regions). Among the families, $42 \%$ reside in large cities, 39\% in towns and urban-type settlements, and $19 \%$ in villages.

\section{INDICATORS THAT REFLECT THE WILLINGNESS OF YOUNG COUPLES TO BEHAVE CONSTRUCTIVELY DURING CONFLICT}

The study of the level of marital satisfaction and the subjective perception of spouses concerning the level of conflict in their interaction made it possible to identify the results presented in Table I.

The indicators of variance on the scale "marriage satisfaction": men $=20.07(\mathrm{SD}=4.48)$; women $=20.88(\mathrm{SD}=4.57)$.

Statistical study of the relationship among the values gave ground for establishing the correlation coefficient: $\mathrm{r}=0.275(\mathrm{p} \leq 0.01)$.

The distribution of dominant behavioral strategies adopted by spouses during conflict is presented in Table II.

The role expectations study helped rank the potential areas of conflict during interaction of spouses. Following are the areas in the order of their ranks, starting with highest-ranked category: household: 56\% (121 families); educational: 51\% (110 families); social activity: 50.4\% (109 families); emotional and psychotherapeutic: 39\% (84 families), personal: $33 \%$ (71 families), external attractiveness: $9 \%$ (20 families); and intimate and sexual: 5\% (10 families). Here, it must be noted that the percentages do not add up to 100 , since each family had several conflicting areas (difference between the scales of family values of husband and wife $>3$ ).

The results of the study of personal and situational anxiety level are presented in Table III.

By applying the correlation analysis between the values of "marriage satisfaction" and "personal anxiety," the following indicators were obtained: men: $r=0.502$ ( $p \leq$ $0.01)$; women: $r=0.523(p \leq 0.01)$. Moreover, between the values of "marriage satisfaction" and "situational anxiety," following indicators were obtained: men: $\mathrm{r}=0.537$ ( $\mathrm{p} \leq$ $0.01)$; women: $\mathrm{r}=0.592(\mathrm{p} \leq 0.01)$.

\section{DISCUSSION}

This study helped identify the level of satisfaction between spouses in the sample. Since the values of the variance of men and women participants showed non-significant statistical difference, the level of family satisfaction was determined by the arithmetic mean. The obtained data gave ground to conclude that more than one third of families $(82 ; 37.9 \%)$ are satisfied with family life; they were classified as "functional families" (absolutely functional: $M=45$, $\mathrm{SD}=0.82$; functional: $\mathrm{M}=35, \mathrm{SD}=0.77$; probably functional: $\mathrm{M}=30$; $\mathrm{SD}=0.88$ ). In contrast, 106 families (49.1\%) had a low level of marital satisfaction; these were classified as dysfunctional (absolutely dysfunctional:
$\mathrm{M}=7, \mathrm{SD}=0.83$; dysfunctional: $\mathrm{M}=19, \mathrm{SD}=0.75$; probably dysfunctional: $\mathrm{M}=24, \mathrm{SD}=0.92)$. Further, 28 families were classified as transitional $(\mathrm{M}=27, \mathrm{SD}=0.71)$. A relatively high level of dissatisfaction with marriage confirmed our assumption that the phenomenon of the COVID-19 pandemic negatively affected the mental health of young families; further, the interaction of spouses suffered from the destruction of trusting and harmonious relationships, provoking a traumatic situation. Our results were in agreement with the findings of other researchers on the detrimental effects of emotional stress on the interaction of spouses at the beginning of family development $[2,11]$.

Measuring the subjective assessment of the level of conflict in young families showed a high intensity of conflict between spouses. A total of 75 (35\%) families identified conflict as a phenomenon that often manifests itself in their interaction and $52(24 \%)$ claimed that "the conflicts are frequent." Most of these families belonged to the dysfunctional category. Comparing the results, we suggested the possibility of an inverse relationship between the level of family conflict and spouses' satisfaction with marriage. However, this hypothesis was not confirmed, since the correlation index for men was $r=-0.201(p \leq 0.01)$ and for women was $r=-0.219(p \leq 0.01)$. This data confirmed that the family conflicts perform not only a destructive but also a constructive function [19]. Consequently, it can be concluded that only the destructive behavior of one or both spouses has a negative effect on marital satisfaction, while a constructive strategy for resolving conflicts contributes to the harmonization of relationship.

The analysis of the prevalence of anxiety level among spouses gave ground to state that the level of situational anxiety of the spouses was higher than the level of personal anxiety. The total number of spouses with a high level of personal anxiety was 83 ( $19 \%$ of the total sample; $M=52$, $\mathrm{SD}=2.01)$, whereas 129 spouses had a high level of situational anxiety ( $30 \%$ of the total sample; $\mathrm{M}=61, \mathrm{SD}=1,92$ ). The percentage of people with low situational anxiety was 0 . These results indicate an increase of anxiety as an emotional response to the negative impact of destabilization of marital relations resulting from the spread of the COVID-19. The correlation analysis confirmed the relationship between the level of situational anxiety and satisfaction with marriage-men: $\mathrm{r}=0.537(\mathrm{p} \leq 0.01)$; women: $\mathrm{r}=0.592(\mathrm{p} \leq$ 0.01 ); a higher empirical significance was seen in this case than in the case of personal anxiety.

Our conclusions were confirmed by the results of the analysis of the propensity of spouses to a certain strategy of conflict behavior. A lot of men $(69 ; 31.9 \%)$ and women $(54 ; 25 \%)$ are prone to rivalry. The application of such a behavior during marital conflict caused destabilization of relations and deepened the destructive impact of the conflict on each spouse and on the family as a whole. Rivalry made it impossible to reach a compromise solution; consequently, spouses could not get together, and the other's help was accepted only to strengthen their own position.

A quarter of men $(54 ; 25 \%)$ and $18 \%$ (39) of women recourse to avoidance. This style of behavior contributed to 
Table I. Distribution of grouped sampling frequencie.

\begin{tabular}{|c|c|c|c|c|c|c|c|c|}
\hline \multirow{2}{*}{ № } & \multirow{2}{*}{ Family type } & \multicolumn{3}{|c|}{ Marriage satisfaction } & \multicolumn{4}{|c|}{ Level of conflict } \\
\hline & & $\mathbf{n}$ & $\%$ & $\mathbf{M}$ & 1 & 2 & 3 & 4 \\
\hline 1 & Absolutely dysfunctional & 41 & 19 & 7 & - & - & 13 & 28 \\
\hline 2 & Dysfunctional & 32 & 14,8 & 19 & - & - & 17 & 15 \\
\hline 3 & Probably dysfunctional & 33 & 15,3 & 24 & - & 4 & 23 & 6 \\
\hline 4 & Transitional & 28 & 13 & 27 & - & 11 & 15 & 2 \\
\hline 5 & Probably functional & 37 & 17,1 & 30 & 4 & 30 & 2 & 1 \\
\hline 6 & Functional & 25 & 11,6 & 35 & 2 & 22 & 1 & - \\
\hline 7 & Absolutely functional & 20 & 9,2 & 45 & 2 & 17 & 1 & - \\
\hline
\end{tabular}

Table II. Distribution of respondents by behavioral strategies

\begin{tabular}{ccccc}
\hline \multirow{2}{*}{ Behavioral strategy } & \multicolumn{1}{c}{ Men } & \multicolumn{2}{c}{ Women } \\
\cline { 2 - 5 } & $\mathbf{n}$ & $\%$ & $\mathbf{n}$ & 25 \\
\hline Rivalry & 69 & 31.9 & 54 & 20 \\
\hline Adaptation & 26 & 12 & 43 & 18 \\
\hline Avoidance & 54 & 25 & 39 & 28 \\
\hline Compromise & 46 & 21.2 & 61 & 9 \\
\hline Cooperation & 21 & 9.9 & 19 & \\
\hline
\end{tabular}

Table III. Distribution of respondents by the level of anxiety percentage

\begin{tabular}{cccccccc}
\hline \multirow{2}{*}{ Type of anxiety } & \multicolumn{4}{c}{ Men } & \multicolumn{3}{c}{ Women } \\
\cline { 2 - 7 } & Low & Moderate & High & Low & Moderate & High \\
\hline Personal & 12 & 51 & 37 & 8 & - & 48 & 27 \\
\hline Situational & 2 & 42 & 56 & 73 \\
\hline
\end{tabular}

the prolongation of the conflict, since avoiding the conflict does not help solve the problem, rather increases its negative impacts such as the escalation of negative emotions and reduction of the intensity of relations at all levels of interaction.

A significant percentage of women $(20 \% ; 43)$ and $12 \%$ (26) of men are prone to adjustment while interacting during conflict. Such a strategy determines the spontaneity of conflict resolution and makes it impossible to discuss controversial issues, to obtain information about the true attitude of husband and wife to the conflict.

More than $20 \%$ of men (21.2\%) and women (61.28\%) showed a tendency to compromise in a conflict situation. Their relationship is characterized by a refusal to confront, a rational analysis of the causes of the conflict situation, and a willingness to make mutual concessions and take into account the needs of the partner.

Cooperation was inherent in a limited percentage of men (21.9.9\%) and women (19.9\%). These individuals tend to meet the needs of both members and implement the approved agreements in marital interaction. This leads to stable marital relations.

The majority of spouses belonging to dysfunctional families are prone to rivalry; among these, 66 out of 106 are men and 55 out of 106 are women. Moreover, a significant proportion of them are prone to avoidance ( 26 out of 106 men and 20 out of 106 women) and accommodation ( 9 out of 106 men and 28 out of 106 women). Further, only some members of this group tend to compromise (5 out of 106 men and 3 out of 106 women). Conversely, spouses from functional families often tend to compromise and cooperation in conflict. Thus, constructive behavioral strategies were inherent in spouses from functional families.

A comparative analysis of marital expectations of representatives of functional and dysfunctional families allowed us to conclude that the difference between the expectations and claims of husbands and wives in functional families was 0 in 19 of 83 families and not more than 2 in 51 of 83 families, and only 13 families reached 3 on the scale against potential conflict in the field of household, parental, and social activity categories. These results give ground for the conclusion that the spouses prone to constructive behavior during conflict are characterized by the ability to adequately assess their own demands and claims to another member of the married couple. They are characterized by high demands; responsibility concerning their own behavior, the partner's life, and the upbringing and care of children; and awareness about partial restriction of their own freedom.

In contrast, in dysfunctional families, the role expectations and demands on most scales of family values were radically opposite in 86 of 106 families, and in 20 (19\%) families, they were different. This indicator shows the disagreements in the value-role sphere of spouses. 


\section{LIMITATIONS}

Our study presents the results of a survey conducted mainly with representatives of young urban families in Ukraine, since a greater number of such families suffered from the negative effects of the pandemic in comparison to the rural families. Therefore, the sample is not representative of the entire population of Ukraine.

Nevertheless, our study presents valid results, which are provided by well-reasoned methods of survey and empirical data analysis.

\section{CONCLUSIONS}

Our study of the willingness of young couples to engage constructively during conflict helps understand the importance of this ability in the context of family mental health and marital satisfaction. We have shown that emotional stress negatively affects the interaction of spouses in the early stages of family development, leading to the destabilization of marital interaction; moreover, it becomes a source of trauma for family members. One of its factors is the destructive behavior of spouses in conflict. Further, conflicts between spouses are most often manifested in the household and educational spheres as well as in the field of social activity.

In addition, it was found that marital satisfaction is related to the husband's and wife's propensity for constructive behavioral strategies-compromise and cooperationduring conflict; the level of personal and situational anxiety of spouses; and their ability to adequately assess their own and the partner's demands, needs, and values. All these components contribute to the readiness of spouses to adopt a constructive behavior during conflict. The positive value of readiness is that the spouses gain experience in resolving the conflicts peacefully, without aggression or violence. Thus, it determines the possibility of harmonization of marital relations, which form the basis of a family's mental health. Therefore, our research will help to further enhance family psychological services.

\section{REFERENCES}

1. World Health Organization. Mental health: strengthening our response. https://www.who.int/news-room/fact-sheets/detail/mental-healthstrengthening-our-response. 2005. [date access 11.06.2021]

2. Pfefferbaum B., North C.S. Mental Health and the Covid-19 Pandemic. N Engl J Med. 2020; 6; 383:510-512.

3. Schneider L. Family psychology. Academic Project. 2006, 400p.

4. Eidemiller E., Yustickis V. Psychology and psychotherapy of the family Peter. 2001, 76p.

5. Schneider LB. Family problems in empirical research. Moscow Psychological and Social Institute. 2008, 402p.

6. Buss D.M. Conflict between the sexes: Strategic interference and the evocation of anger and upset. Journal of Personality and Social Psychology. 1989; 56(5)::735-747. doi: 10.1037/0022-3514.56.5.735

7. Stinnett N., Walters J., Stinnett N. Relationships in Marriage and Family, 4th Edition. Prentice Hall. 2003, 523p.
8. Straus M.A., Gelles R.J., Steinmetz S.K. Behind Closed Doors: Violence in the American Family. Doubleday Press. 1980, 79p.

9. Berardo F.M. Decade preview: Some trends and directions for family research and theory in the 1980s. Journal of Marriage and the Family. 1980; 42(4): 723-728. doi:10.2307/351820.

10. Peseshkian N. Psychotherapie des Alltagslebens. Konfliktlösung und Selbsthilfe. Fischer (Tb.). 1996, 65p.

11. Satir V., Baldwin M. Satir step by step: a guide to creating change in families. Palo Alto, CA: Science and Behavior Books. 1983, 115p.

12. Zharovtseva T. Dysfunctional families: identity, problems, educational support. East Publishing House. M. Cherkasova. 2004, 304p.

13. Chumikov A. Management of conflict and conflict management as new paradigms: thinking and action. Sociological research. 1995; 3:52-57.

14. Georgas J., Berry J.W., van de Vijver F.J. R. et al. Families across cultures: A30-nation psychological study. Cambridge University Press. 2006, 52p.

15. Bodalev A. Psychology about personality. Moscow University. 2005, 62p.

16. Omelchenko L. Social and pedagogical conditions of conflicts removal in a young family. National M. Dragomanov Pedagogical University. 2007, 112p.

17. Kiz 0 . Formation of psychological readiness of boarding school inmates to start a family. National M. Dragomanov Pedagogical University. $2003,45 p$.

18. Shuman S.G., Shuman V.P. Family conflicts: causes, ways of elimination. Laboratory "Practical Psychology and Pedagogy". 1992, 301p.

19. Grishina N. Psychology of conflict. 2nd ed. Peter. 2008, 56p.

\section{ORCID and contributionship:}

Liudmila M. Omelchenko: 0000-0002-9963-0306 A-D

Lidiya G. Chorna: 0000-0002-8107-7573 E,F

Nataliya Dyshlova: 0000-0002-8788-3111 ${ }^{E, F}$

Anna Bezhnar: 0000-0002-4516-352X ${ }^{E, F}$

Olha Pletka: 0000-0002-9248-246X E,F

Tetiana M. Vakulich: 0000-0002-5700-5035 E,F

Giuseppina Ancona: 0000-0003-3283-1565 E,F

\section{Conflict of interest:}

The Authors declare no conflict of interest.

\section{CORRESPONDING AUTHOR Liudmila M. Omelchenko \\ National University of Life and \\ Environmental Science of Ukraine \\ 15 Heroes of Defense St., 03041 Kyiv, Ukraine \\ tel: +380979418668 \\ e-mail: omelchenk02006@ukr.net}

Received: 04.05 .2021

Accepted: 07.10.2021

A - Work concept and design, B - Data collection and analysis, C - Responsibility for statistical analysis, 


\title{
STUDY OF THE MENTAL STATE OF STUDENTS IN THE PROCESS OF ONLINE EDUCATION DURING THE CORONAVIRUS PANDEMIC
}

DOI: 10.36740/WLek202111104

\author{
Larysa L. Borysenko ${ }^{1}$, Larysa V. Korvat ${ }^{1}$, Olga V. Lovka ${ }^{1}$, Antonina M. Lovochkina ${ }^{2}$, Oksana P. Serhieienkova ${ }^{3}$, \\ Ketevan Beridze ${ }^{4}$ \\ ${ }^{1}$ KYIV NATIONAL ECONOMIC UNIVERSITY NAMED AFTER VADYM GETMAN, KYIV, UKRAINE \\ 2TARAS SHEVCHENKO NATIONAL UNIVERSITY, KYIV, UKRAINE \\ ${ }^{3}$ BORYS GRINCHENKO KYIV UNIVERSITY, KYIV, UKRAINE \\ ${ }^{4 B}$ BATUMI STATE UNIVERSITY NAMED AFTER RUSTAVELI, BATUMI, GEORGIA
}

\begin{abstract}
The aim: Exploring the specifics of the underlying mental states of university students in the context of online learning during the COVID-19 pandemic and identifying their relationship to mental health.

Materials and methods: The study of mental states was carried out using three valid methods, namely: a clinical questionnaire for the detection and evaluation of neurotic states (K. Yakhin, D. Mendelevich), a questionnaire for diagnosing the level of social frustration (L. Wasserman, adaptation of V. Bojko), State-Trait Anxiety Inventory (STAI) (Ch. Spielberger, adaptation by Yu. Khanin). The author's questionnaire (L. Borysenko) was used to study the connection between the factors of online learning and emotional states of students. The obtained empirical data were subjected to qualitative and quantitative processing.

Results: The analysis of the obtained data allows to state the fact of predominance of high and increased level of situational and personal anxiety in the subjects in the conditions of online learning. In the process of psychodiagnosis of neurotic states, it was found that most students have a level of painful or borderline mental conditions such as anxiety, neurotic depression, asthenia and autonomic disorders. It was found that students have an elevated level and high level of social frustration. The main factors of online learning, which, according to students, cause them to deteriorate mental health are: forced to stay in a confined space, lack of direct social contacts, prolonged stay in a static position, increased study load and volume of tasks, anxiety for academic success and quality professional training, concern for their health and the health of their loved ones.

Conclusions: The forced transition to online learning due to the COVID-19 pandemic has negatively affected the mental state of many students. In most respondents, this manifested itself in increased anxiety, depression, autonomic reactions due to limited opportunities to communicate with teachers and classmates, new learning conditions and increased workload.
\end{abstract}

KEY WORDS: mental health, mental states, online learning, anxiety, social frustration, neurotic states

Wiad Lek. 2021;74(11 p.l):2705-2710

\section{INTRODUCTION}

Student life in society is perceived as a period of optimism and activity, diversified growth and expectations of great achievements. However, in reality, young people face many problems that are detrimental to their mental health from such routine situations as overload in preparation for seminars and exams, to internally complex, existential, such as going through various stages of social adaptation, personal self-definition in a professional space etc. Various emotional experiences, stresses, and their consequences pose a serious threat to a student's mental health, especially when personal resources seem inexhaustible and optimism about health outweighs concern for the student.

Various socio-economic shocks have a significant impact on mental health. The challenge for students was to study during the COVID-19 pandemic, when the offline format in March 2020 was translated into an online form, through which all classes, exams, defense of scientific papers, etc. were conducted. Student attendance was partially resumed in September and October through a combination of offline and online tuition, but online tuition was reintroduced in November.

A comprehensive study of student life during a pandemic showed that a significant number of students do not have sufficient online learning skills, but increased workload, the need to adapt to new requirements and online learning, which is accompanied by states of anxiety, anxiety, frustration, disappointment, and boredom, etc. [1] Research has shown that university students suffered the most during lockdown due to uncertainty about academic success, future careers and social life [2].

Online learning was unfavorable for a large number of students due to difficulties in understanding the materials, technical problems, lack of interest in online classes, limited access to educational materials. Students faced obstacles such as social and economic disruptions, uncertainty about 
their future careers, isolation, fear of losing loved ones, and so on $[3,4]$.

These circumstances significantly emphasize the need for a comprehensive study of the development and manifestations of various mental states in university students in online learning, the impact of lockdown on the mental health of students and the associated forced self-isolation.

\section{THE AIM}

The aim of the article is to present the results of studying the features of the basic mental states of university students in the context of online learning in connection with the pandemic COVID-19 and to determine their relationship with the mental health of students.

\section{MATERIALS AND METHODS}

The survey was conducted on the Internet through the Google form in March-April 2021 among students of the Kyiv National University of Economics (KNEU). The sample consisted of 95 students aged 18-20 years.

For the study, 3 valid methods were selected that allow a comprehensive study of the mental state of the individual and created an author's questionnaire to collect information about the characteristics of certain aspects of students' lives in online learning.

Clinical questionnaire for detection and evaluation of neurotic states (K. Yakhin, D. Mendelevich) allows to analyze neurotic manifestations and identify symptoms of neurotic states. The questionnaire contains 68 questions aimed at diagnosing the manifestation of 6 mental states: anxiety, neurotic depression, asthenia, hysterical response, obsessive-phobic disorders, autonomic disorders [5].

The second method is the questionnaire for diagnosing the level of social frustration (L. Wasserman, adaptation of V. Bojko) [6, 7], which is an original tool for assessing social well-being and quality of life. The questionnaire consists of 20 questions related to various frustrators, such as dissatisfaction with family relationships, work, education, socio-economic status, health, ability to work, leisure, etc.

The third method is the State-Trait Anxiety Inventory (STAI), which makes it possible to diagnose two types of anxiety: reactive as a condition and personal as a stable characteristic of a person. The questionnaire was developed by C. Spielberger [8] and adapted by Y. Khanin [9]. It contains 40 statements, which are evaluated by the subject from 1 to 4 points, depending on his condition.

The theoretical basis for the study of mental states was the theory of functional systems by P. Anokhin [10], which provided specific opportunities for systematic analysis of different classes of natural and social phenomena - in the relationship between the human body (students) and the environment (online learning), in the interaction of selectively involved components (anxiety, depression, neurotic states, social disorders of students) and organizational and technical conditions of learning during a pandemic - to obtain a certain result in terms of mental health.

\section{RESULTS}

First of all, to study the peculiarities of students' attitudes to online learning, a survey was conducted on satisfaction with organizational and methodological, logistical support and psychological support of the educational process. It was found that $65.3 \%$ of respondents rated low satisfaction with various aspects of online learning. Students noted the deterioration of efficiency, learning outcomes, functional status in general. Students most often noted the following frustrators that led to the deterioration of mental state: violation of the regime of educational activities and recreation, inefficient time management, violation of biorhythms, social isolation, sanitation and hygiene conditions, inconvenience of working posture, hypokinesia, computer and Internet failures etc.

According to the results of an empirical study of anxiety according to the method of Ch. Spielberger-Y. Khanin, the levels of manifestation of reactive (situational) (Fig. 1) and personal (Fig. 2) anxiety of students during online learning were revealed.

Of the 95 students, $61.8 \%$ of respondents found high levels of situational anxiety and 57.5\% - high levels of personal anxiety.

Such indicators are due to stress and anxiety about the events associated with the COVID-19 pandemic and their perception as threatening, on the one hand, and the increase in mental stress, physical and mental fatigue during online training - on the other. Low levels of personal anxiety were found in $12.6 \%$ of people and low levels of situational anxiety $-4.76 \%$ of students, which indicates that a critical and rational view of events and their constructive assessment is inherent in a small proportion of respondents.

Assessment of neurotic states of students in the general sample was carried out using the method of K. Yakhin-D. Mendelevich. Neurotic states are defined by the authors of the method as a complex of peculiar manifestations of human states (from painful to health) in the emotional and autonomic spheres, but with the preservation of adaptive capabilities of the individual and behavior control [11].

According to the results of the study, the indicators of neurotic states of respondents on the scales of anxiety, neurotic depression, asthenia, hysterical type of response, obsessive-phobic and autonomic disorders were obtained. Each of mental states has the following levels of manifestation: painful nature of the course, intermediate state and a sign of health (Fig. 3).

Analysis of the obtained data indicates that anxiety is painful in the majority of respondents $-54.7 \%$; intermediate state (uncertainty) was found in $16.9 \%$ of people, and anxiety, which has a sign of health was found only in $16.9 \%$ of respondents. It should be noted that high levels of anxiety in students on this scale indicate emotional instability, negatively colored experience of internal worry and concern about current events, the need to find addi- 

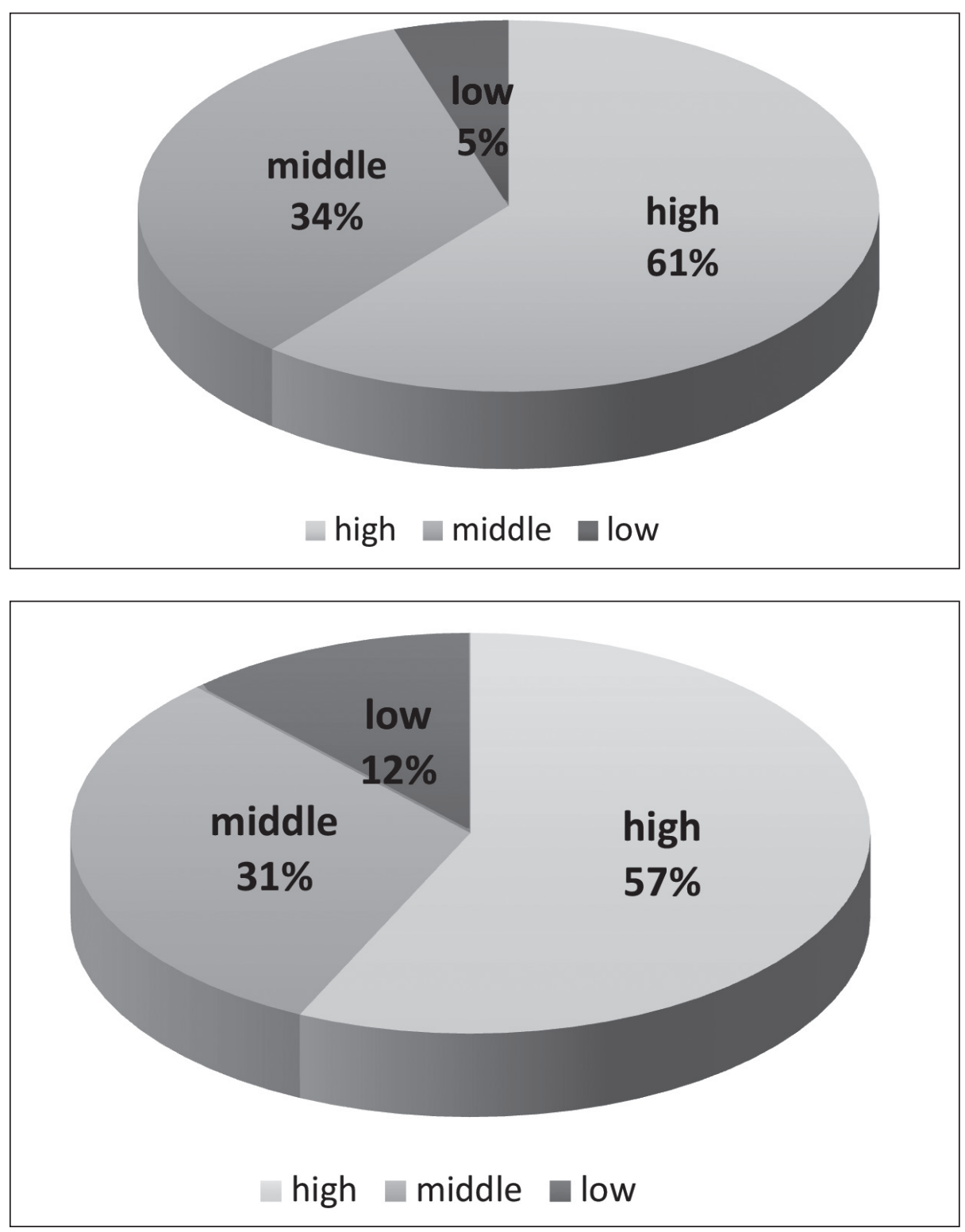

Fig. 1. Features of the manifestation of reactive anxiety in students

Fig. 2. Features of the manifestation of personal anxiety in students tional information on the implementation of educational tasks; tendency to perceive a wide range of situations as threatening one's own self-esteem, prestige or vital activity; increased sensitivity to anticipated adverse events or failures that may occur.

The scale "neurotic depression" showed a tendency to the painful nature of its course in $57.7 \%$ of people compared with the intermediate state in $36.8 \%$ of people and health status in $16.8 \%$ of people. Thus, more than half of the respondents have obvious signs of depression, which is manifested in a decrease in emotional reactions, lethargy, slowness, decreased interest in the environment, monotony of behavior; indifferent attitude to the environment, depressed mood with a feeling of helplessness, reduced motivation, narrowing the range of interests, negative attitude towards loved ones, manifestations of resentment, lack of desire to work. there are ideas of self-blame and inferiority, manifestations of apathy. These data are consistent with the results of the assessment on the scale of "asthenia". An even larger proportion of respondents $(70.6 \%)$ found an unhealthy course of asthenia compared to the intermediate state $(18.9 \%)$ and health status $(10.5 \%$ of people). A characteristic manifestation of asthenia are signs of anxiety, insecurity, passivity; feeling tired, expecting trouble, feeling worse, decreased activity, mood; predisposition to stress, decreased motor activity. The conditions of online learning and interpersonal relationships are perceived as psycho-traumatic, dominated by chronic dissatisfaction with their own learning activities and themselves as its subject.

According to the "hysterical type of response" scale, $48.4 \%$ of people showed a predominance of health and $23.2 \%$ of intermediate state. On the scale of "obsessive-phobic disorders" signs of a painful course of the neurotic state were detected only in $17.9 \%$ of people, with a predominance of a healthy course in $58.9 \%$ of people and an intermediate state in $23.2 \%$ of people.

The situation with the results on the scale "autonomic 

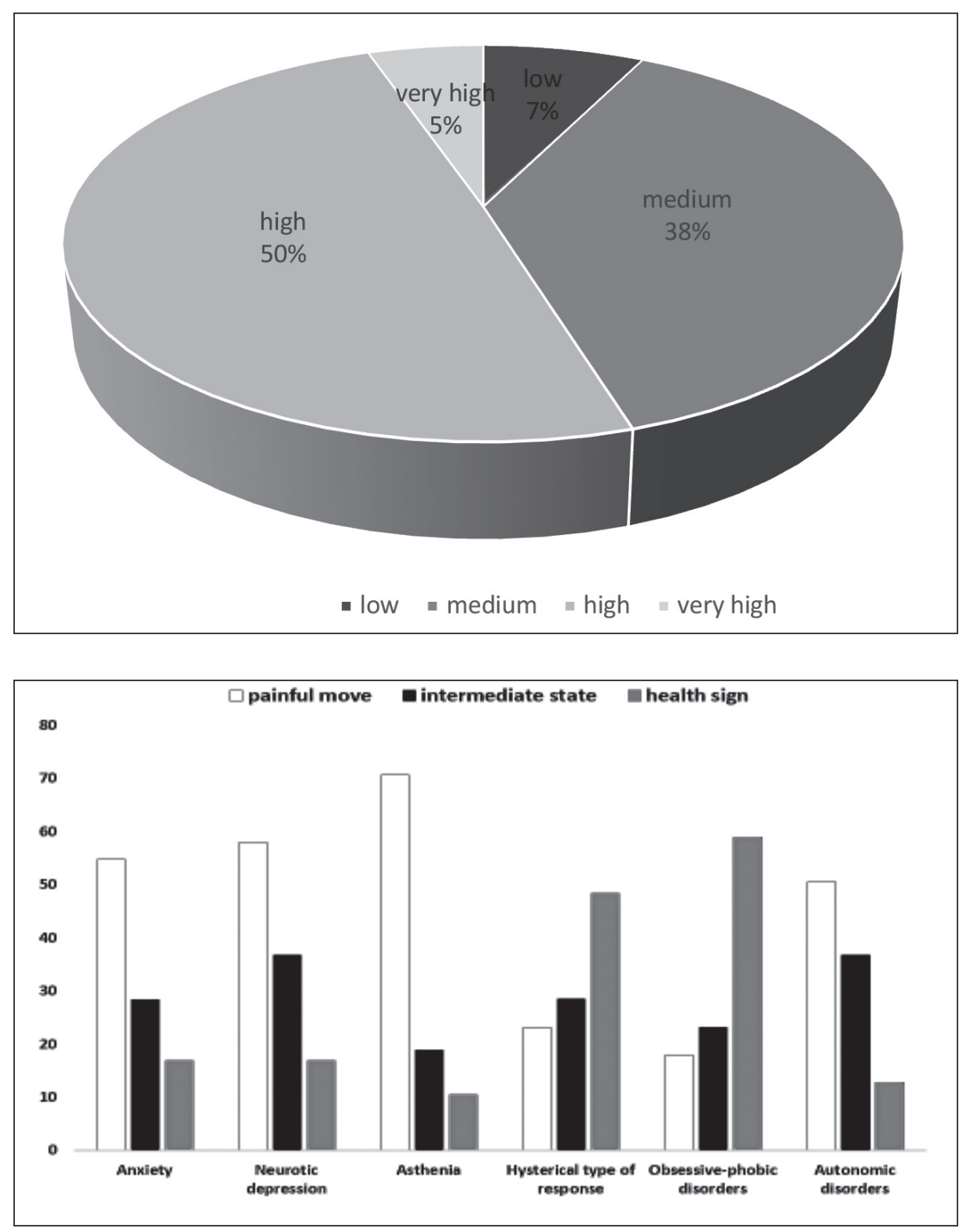

Fig. 3. The results of measuring the neurotic states of students according to the method of Yakhin - Mendelevich
Fig. 4. Levels of manifestation of social frustration of students in the conditions of online learning disorders" is very disappointing. According to this scale, the state of health was found in only $1.7 \%$ of people. Unhealthy state of the course was found in $50.5 \%$ of respondents, intermediate state - in $36.8 \%$ of people. These phenomena are manifested in a constant feeling of fatigue; frequent headaches; feeling emotionally and physically exhausted; general weakness and decreased activity; complete or partial insomnia; shortness of breath and respiratory disorders during exercise; noticeable decrease in sensory sensitivity: impaired vision, hearing, touch.

Measurement of students' social frustration was performed using the Wasserman-Boyko method [6]. According to the authors of the method, social frustration is a type of mental stress caused by the inability for any reason to realize their current social needs: their achievements in society, relationships with others, social status and more. Prolonged destabilizing effects of frustrating factors lead to reduced adaptive capacity of the individual and partial maladaptation, and in the absence of benign mechanisms of psychological protection and lack of social support - to the emergence of anxiety, depression and neurotic states.

The results of the diagnosis of social frustration of students are presented in Figure 4.

Analysis of the results indicates that most students have an increased level (49.5\% of people) and a high level (5.3\% of people) of social frustration, which is manifested in increased mental stress due to dissatisfaction with themselves and academic achievement, the need for long stays before monitor, information overload, forced social isolation, unsatisfactory leisure, fear for the health of themselves and their families. All this leads to a loss of interest in learning, indifference, deepening anxiety and the emergence of neurotic states.

To determine the relationship between indicators of social frustration, anxiety and neurotic states, we performed 
Table I. Correlation coefficients (according to Pearson) between indicators of social frustration, personal and situational anxiety and neurotic states $(n=95)$, degree of freedom $(n-2), p \leq 0.05$

\begin{tabular}{cccc}
\hline Neurotic states & Personal anxiety & Situational anxiety & Social frustration \\
\hline "Anxiety" scale & 0,457 & & 0,586 \\
\hline "Neurotic Depression" Scale & 0,679 & & 0,487 \\
\hline Asthenia scale & & 0,532 & 0,674 \\
\hline Scale «Hysterical type of response» & & 0,387 & \\
\hline Scale "Obsessive-phobic disorders" & 0,564 & & 0,764 \\
\hline Scale "Vegetative disorders" & 0,664 & 0,489 & \\
\hline
\end{tabular}

a correlation analysis according to Pearson, the results of which are presented in table. I.

The results of correlation analysis revealed positive statistically significant relationships between indicators of "social frustration" and indicators of neurotic states on the scales: "anxiety" $(\mathrm{r}=0.586)$, "neurotic depression" $(\mathrm{r}=0.487)$, "asthenia" $(\mathrm{r}=0.674)$, "autonomic disorders" $(\mathrm{r}=0.764)$; between indicators "personal anxiety" and indicators on the scales "anxiety" $(r=0.457)$, "neurotic depression" ( $r=0.679)$, "obsessive-phobic disorders" $(\mathrm{r}=0.564)$, autonomic disorders " $(\mathrm{r}=0.664)$; between indicators "situational anxiety" and indicators on the scales "asthenia" $(\mathrm{r}=0.532)$, "hysterical type of response" $(\mathrm{r}=0.387)$, "autonomic disorders" $(\mathrm{r}=0.489)$.

The obtained correlation coefficients indicate a significant direct relationship between frustrators, mental states of the individual during online training and the current quarantine restrictions.

\section{DISCUSSION}

This study was aimed at identifying the characteristics of the mental states of university students during a pandemic. A comparison of different studies indicates that the pandemic has a significant negative impact on the emotional well-being and mental health of students [13-18]. Despite circumstances such as differences in research goals and measurement tools, the researchers conclude that the COVID-19 pandemic has significantly affected human mental health. The study of the impact of the pandemic on the psychological health of staff in educational institutions revealed such signs of negative emotional states as anxiety, irritability, aggression, fear, depression, confusion, anger, panic, etc. - in 58.3\% of respondents; deterioration of various spheres of health (psychological, physical, professional, spiritual) - 18.0\%; uncertainty about the future of $12.8 \%$ [13].

When analyzing the dynamics of depression and anxiety of respondents from the beginning of lockdown during 3 weeks 2020, researchers noted an increase in depression and anxiety, which the authors associate with physical limitations, lack of sufficient external stimuli: impressions, events, intensity of interaction with others [13].

Steven Taylor, who studied the effects of the pandemic on the human psyche and introduced the concept of "Covid stress" into psychology, pointing out that it most often occurs in people who have obsessive-compulsive disorder and are prone to anxiety and fear for their health. But students generally have a high level of adaptation and stress in a pandemic [19].

The results of our study are fully consistent with the above works. It should be noted some limitations of this study, as we were not able to perform a comparative analysis of empirical data - the mental state of students throughout the period of online learning. This is due, firstly, to the difficulties in organizing the educational process at the university at the beginning of the lockdown and the uncertainty of the transition from offline to blended and online forms of learning; secondly, - technical limitations when conducting a survey of students using Google-form while maintaining a constant composition of the total sample of respondents.

\section{CONCLUSIONS}

The study of the peculiarities of mental states in the conditions of forced online learning in connection with lockdown revealed changes in mental states and emotional sphere of the individual, which were manifested in the dominance of increased and high levels of reactive and personal anxiety; asthenic and depressive states, autonomic disorders, social frustration.

Although it is believed that young students easily recover from negative situations and adapt to new conditions, we believe that students need help to find the resources to maintain mental health at the required level.

We consider that in order to confirm the link between mental states and students 'mental health, it is necessary to continue research on students' mental states, regardless of whether the online form of education will be maintained or whether learning will return to offline. Identifying the dynamics of mental health indicators will allow us to draw appropriate conclusions about the role of online and offline forms of learning for students' mental health.

\section{REFERENCES}

1. Browning M., Larson L., Sharaievska I. et al. Psychological impacts from COVID19 among university students: Risk factors across seven states in the United States. PLOS ONE. 2021; 16(1): e0245327. doi:10.1371/ journal.pone.0245327.

2. Aristovnik A., Keržič D., Ravšelj D. et al. Impacts of the COVID-19 pandemic on life of higher education students: A global perspective. preprints.org: 2020. doi:10.20944/preprints202008.0246.v2. 
3. Mamun F., Hosen I., Misti J.M. et al. Mental Disorders of Bangladeshi Students during the COVID-19 Pandemic: A Systematic Review. Psychology Research and Behavior Management. 2021: 14; 645-654.

4. Nenko Yu, Kybalna N., Snisarenko Ya. The COVID-19 Distance Learning: Insight from Ukrainian students. Revista Brasileira de Educação do Campo, 2020; 5: 1-19.

5. Yahin K.K., Mendelevich D.M. Klinicheskij oprosnik dlya vyyavleniya i ocenki nevroticheskih sostoyanij / Klinicheskaya i medicinskaya psihologiya. Red. V.D. Mendelevich. M. 2005, 469p. (in Russian).

6. Vasserman L.I., Shchelkova 0.U. Psihologicheskaya diagnostika rasstrojstv emocional'noj sfery i lichnosti [Psychological diagnosis of emotional and personality disorders]. Kollekt. monogr. SPb.: Scythia print: 2014, 405p. (in Russian).

7. Kokun 0. Optymizatsiya adaptatsiinykh mozhlyvostei liudyny: psykhofiziologichnyi aspekt zabezpechennia diialnosti: Monografiia. [0ptimization of adaptation possibilities of the person: psychophysiological aspect of maintenance of activity]. K. Milenium: 2004, 265p. (in Ukrainian).

8. Spielberger C.D., Gorssuch R.L., Lushene P.R. et al. Manual for the StateTrait Anxiety Inventory. Consulting Psychologists Press. 1983, 504p.

9. Khanin Yu. Stress i trevoga v sporte. Moskva. Fizkultura i sport. 2003, 288p. (in Russian).

10. Anokhin P.K. Uzlovyye voprosy teorii funktsionalnoy sistemy. M.: Psikhologiya. 1980, 197p. (in Russian).

11. Mendelevich V. D. Klinicheskaya i medicinskaya psihologiya. 6th ed. M.: MEDpress inform. 2008, 432p. (in Russian).

12. Karamushka L.M. Sotsialna frustrovanist osvitnoho personalu: zviazok zi skladovymy organizatsiinoi kultury zagalnoosvitnikh navchalnykh zakladiv. Aktualni problemy psykholohii: zb. nauk. prats In-t psykholohii imeni H.S. Kostiuka NAPN Ukrainy. Organizatsiina psykhologiia. Ekonomichna Psykhologiia. Sotsialna Psykhologiia. 2016; 1(45): 40-48. (in Ukrainian).

13. Maksimenko S.D. , Karamushka L.M. Psihologichne zdorov'ya personalu organizatsiy v umovah pandemiyi COVID-19: problemy ta tehnologiyi zabezpechennya. Materialy XIV Mizhnarodnoyi naukovo-praktichnoyi onlayn-konferentsiyi z organizatsiynoyi ta ekonomichnoyi psihologiyi. Kyiv: 2020, 603p. (in Ukrainian).

14. Visser M., Law-van Wyk E. University students' mental health and emotional wellbeing during the COVID-19 pandemic and ensuing lockdown. South African Journal of Psychology. 2021; 51(2): 229-243. doi:10.1177/00812463211012219.

15. Gasteiger N., Vedhara K., Massey A. et al. Depression, anxiety and stress during the COVID-19 pandemic: results from a New Zealand cohort study on mental well-being. BMJ Open. 2021; 11(5):67.
16. Hena Y., Salman K. et al. Covid 19: Stress Management among Students and its Impact on Their Effective Learning. International Technology and Education Journal. 2020; 4 (2): 65-74.

17. Lischer S., Saf N., Dickson Ch. Remote learning and students' mental health during the Covid-19 pandemic: A mixed-method enquiry. PROSPECTS: Comparative Journal of Curriculum, Learning, and Assessment: 2021. doi:10.1007/s11125-020-09530-w.

18. Snider C. J., Flaherty M. P. Stigma and mental health: The curious case of COVID-19. Mental Health: Global Challenges Journal. 2020; 3(1): 27-32. doi: $10.32437 /$ mhgcj.v3i1.89.

19. Taylor S. The Psychology of Pandemics: Preparing for the Next Global Outbreak of Infectious Disease. UK. Cambridge Scholars Publishing: 2019, 114p.

\section{ORCID and contributionship:}

Larysa L. Borysenko: 0000-0002-4318-997X A-D, F

Larysa V. Korvat: 0000-0001-5531-9535 D-F

Olga V. Lovka: 0000-0002-6198-5144 C-E

Antonina M. Lovochkina: 0000-0002-8454-2354 D, E

Oksana P. Serhieienkova: 0000-0002-1380-7773 D, E

Ketevan Beridze: 0000-0001-6268-7037 D, E

\section{Conflict of interest:}

The Authors declare no conflict of interest.

\section{CORRESPONDING AUTHOR}

Larysa L. Borysenko

Kyiv National Economic University

named after Vadym Hetman

54/1 Peremogy Ave., 03057 Kyiv, Ukraine

tel: +38-067-911-52-02

e-mail: borisenko-l@ukr.net

Received: 29.04.2021

Accepted: 05.10.2021

A - Work concept and design, B - Data collection and analysis, C - Responsibility for statistical analysis, $\mathbf{D}$-Writing the article, $\mathbf{E}$-Critical review, $\mathbf{F}$ - Final approval of the article 


\title{
PUBLIC CONFIDENCE IN FORMAL MEDICINE: CURRENT CONTEXT
}

D0I: 10.36740/WLek2021111 05

\author{
Viktor V. Vus ${ }^{1}$, Liudmyla M. Omelchenko², Oksana Boiko ${ }^{3}$, Ioanna V. Papathanasiou ${ }^{4}$, Evangelos C. Fradelos ${ }^{4}$, \\ Vladislav Zharin ${ }^{5}$, Kateryna Zharina ${ }^{5}$ \\ 'INSTITUTE OF SOCIAL AND POLITICAL PSYCHOLOGY NATIONAL ACADEMY OF EDUCATIONAL SCIENCES OF UKRAINE, KYIV, UKRAINE \\ 2NATIONAL UNIVERSITY OF LIFE AND ENVIRONMENTAL SCIENCES OF UKRAINE, KYIV, UKRAINE \\ ${ }^{3}$ NATIONAL UNIVERSITY OF KYIV MOHYLA ACADEMY, KYIV, UKRAINE \\ ${ }^{4}$ UNIVERSITY OF THESSALY, LARISSA, GREECE \\ 5POLTAVA STATE MEDICAL UNIVERSITY, POLTAVA, UKRAINE
}

\begin{abstract}
The aim: To explore the current context and the main factors of public confidence in formal medicine.

Materials and methods: The article is based on the outcomes of a cross-sectional survey designed to reflect varied dimensions of individual/population' perception of healthcare services, namely: socio-demographic information, reflection on individuals' own health, confidence in healthcare services. A total of 2478 self-referred respondents took part in the survey.

Results: The study outcomes evidenced that the vast majority of respondents trusted in formal medicine. High level of public confidence in formal medicine is correlated with the lack of confidence in alternative methods. Amongst the factors influencing formation of public confidence in formal medicine are "satisfaction of basic needs and physical condition of the body", as well as "healthy behavior". It was identified that the most significant influence on the level of public confidence in medicine is made by the individual's satisfaction with the level and quality of physical exertions, satisfaction with the individual's physical condition, and satisfaction with the quality of food.

Conclusions: The survey outcomes provide the background for outlining specific ways to enhance public confidence in formal medicine, contribute to optimization of funding provided to public health care projects and programs.
\end{abstract}

KEY WORDS: healthcare systems, public policies, public confidence, community health, healthy behavior

Wiad Lek. 2021;74(11 p.l):2711-2716

\section{INTRODUCTION}

Quality of medical care is turning into one of the most urgent amongst the global problems facing humanity in the twenty-first century. From the world perspective its relevance is resulted from the need to enhance the potential of medical systems across the world in order to improve the population health, to guarantee for citizens their safety and life quality as core values. Moreover, such a need is resulted from COVID-19 impact at all the levels.

\section{QUALITY OF MEDICAL CARE}

The modern concept of medical care quality is oriented at exploring the patient's own opinion as a consumer [1]. Trust is formed as the basic human attitude [2]. Trust in formal medicine arises from the experience of obtaining medical services (within the context of the treatment effectiveness measurement) based on a clear knowledge of the subject (disease, its consequences, the process of treatment, prevention of disease) and warning of their irrelevance [3]. The basis of a patient's attitude is experience of vulnerability which ensures the base for trust (to a doctor, to the whole system of health care) or leads to mistrust arisen [4]. People who do not trust formal medicine tend to deny scientific findings, ignore doctors' prescriptions, and make it impossible to achieve therapeutic cooperation (compliance). This complicates the process of health care provision, often results into cases when population loses it working capacity, as well as it creates a significant financial burden on the budgets of communities and countries.

\section{PUBLIC CONFIDENCE IN FORMAL MEDICINE AND POPULATION QUALITY OF LIFE}

Public mistrust in formal medicine is resulted from a range of factors, namely: a significant number of medical errors due to the lack of modern medical equipment or its inaccessibility to patients, especially in transition countries [5], differences in education and experience of service providers, changing composition of patients, and an outdated strategy of focusing only on pathological symptomatic dynamics as the core criteria of health care quality $[6,7]$. The low level of public confidence in formal medicine leads to deterioration in general population wellbeing, reducing personal responsibility of all the stakeholders - both the health service provider and the user [8]. 
Trust is a sign that an individual or a collective subject (group, ethnic group) is confident of the security of environment surrounding world and social environment $[2,9$, $10,11]$. Individual health is based on a trustful communication with others. Cooperation relationships are formed as a result of trusting attitude, which is the key to success of all the actors engaged into interaction [12]. Trust is occurring resulted from self-disclosure - communicating an intimate information about oneself [10].

The willingness to receive health care belongs to a safety human need [13]. Satisfaction of both physiological and safety needs is of paramount importance for the development and vital functions of the individual [14]. Physiological needs which directly affect human health include the need for food and drink, physical activity; safety includes the need to maintain physical health which is manifested by healthy lifestyle of an individual, a certain system of nutrition, satisfaction with one's own physical condition. Actualization of these needs forms the basis for requests which determine expectations for medical care provision. If interaction with the medical system resulted into meeting these needs, and the patients' expectations were met - an individual has developed trust in formal medicine. If the terms of interaction were directly opposite, the service recipient will be seeking alternative ways of obtaining assistance (meeting safety need).

\section{THE AIM}

The aim of the article is to examine contemporary public attitudes towards health care; to explore the relationship between satisfaction of patient/population's basic needs and healthy behavior as key factors for building confidence in formal medicine

\section{MATERIALS AND METHODS}

\section{DESIGN}

The study was designed as a cross-sectional survey. The questionnaire contains a set of questions asking respondents to choose one or several options from the presented list, open-ended questions (options "other" in the questions), rating questions (on a Likert scale of 1-10).

The survey design collected data on: demographic, social and work characteristics of respondents; the respondents' reflection on health.

\section{TOOL}

The survey consists of 3 subsections reflecting varied dimensions of individual/population' perception of health care services

The 1st part collects socio-demographic information through five standard questions on age, gender, living situation (urban or rural area), employment/working status and level of education

In the 2 nd part participants were asked about "how individual/population looks after own health" and this part included a set of seven questions. The definition "Looking after own health" was conceptualized as a combination and interaction of a range of activities. The areas researched include physical activity, eating and drinking, individual physical health condition, healthy life style

The $3 r d$ part is designed to explore individual/population confidence in health care services

\section{ANALYSIS}

The data analysis was executed in SPSS. Due to the fact that the questionnaire data is a mixture of categorical and nominal data, in addition to the descriptive statistics, methods such as Pearson's Chi-Square analysis, factorial analyses, $\mathrm{t}$-criteria were used.

\section{ETHICAL CONSIDERATIONS}

This study was in accordance with the APA ethical principles regarding research with human participants. Participants were informed before participating that their responses will be treated confidentially and anonymously; all data will be analyzed in a generalized manner; they give their consent by proceeding past the welcome text of the online survey. Participation in this study was voluntary.

\section{RESULTS}

Below the socio-demographic characteristics of the study sample are provided as well as the study outcomes on population confidence in formal medicine, the evolution of the above-mentioned variable over the last year, the comparison with the level of confidence in alternative treatments. An analysis of the population subjective perception of the level of satisfaction of basic needs (nutrition, physical condition) is made.

\section{SOCIO-DEMOGRAPHIC CHARACTERISTICS}

The sample was formed from 2478 (15-90 years) respondents: $72 \%$ women, $28 \%$ men; $69 \%$ full-time, $3 \%$ students, $14 \%$ unemployed, $12 \%$ pensioners and $2 \%$ disabled.

\section{PUBLIC ATTITUDES TOWARDS MEDICAL CARE}

As a result of analysis of the indicators obtained, there were three levels of trust in formal medicine identified amongst the survey respondents: high, medium and low. The vast majority of respondents have an average level of trust in formal medicine $(46,9 \%, \mathrm{M}=5,9, \mathrm{SD}=0,84)$. However, most assessments of individual attitudes towards the respondent's health system at this level have low confidence values $\left(M_{0}=5\right)$. The quantitative indicator of high level was $28.7 \%(\mathrm{M}=8,67, \mathrm{SD}=0,79)$, and low $-24,4 \%(\mathrm{M}=$ $2,9, \mathrm{SD}=1,1)$. Quantitative indicator of an individual level of trust might be considered as a tendency in population attitude to formal medicine (Table I). 
Table I. Public attitudes towards health care

\begin{tabular}{|c|c|c|c|c|c|c|c|}
\hline Attitude & Level & $\mathbf{N}$ & $\%$ & $M_{0}$ & $M_{e}$ & M & SD \\
\hline \multirow{3}{*}{ Confidence in formal medicine } & High & 711 & 28,7 & 8 & 9 & 8,67 & 0,79 \\
\hline & Medium & 1164 & 46,9 & 5 & 6 & 5,9 & 0,84 \\
\hline & Low & 603 & 24,4 & 4 & 2,5 & 2,9 & 1,1 \\
\hline \multirow{3}{*}{$\begin{array}{l}\text { Confidence in alternative } \\
\text { treatments }\end{array}$} & High & 222 & 9 & 9 & 8,5 & 8,8 & 0,77 \\
\hline & Medium & 726 & 29,3 & 5 & 5,5 & 5,5 & 0,73 \\
\hline & Low & 1530 & 61,9 & 1 & 2 & 2,3 & 1,14 \\
\hline
\end{tabular}

Table II. How people look after own health

\begin{tabular}{|c|c|c|c|c|c|c|c|}
\hline Indication & Degree & $\mathbf{N}$ & $\%$ & $M_{0}$ & $M_{e}$ & $M$ & SD \\
\hline \multirow{3}{*}{$\begin{array}{l}\text { Satisfaction with individual } \\
\text { physical health }\end{array}$} & High & 861 & 34,7 & 8 & 9 & 8,7 & 0,81 \\
\hline & Medium & 1092 & 44,1 & 5 & 6 & 5,9 & 0,85 \\
\hline & Low & 525 & 21,2 & 3 & 3 & 3 & 0,75 \\
\hline \multirow{3}{*}{$\begin{array}{l}\text { Satisfaction with the level and } \\
\text { quality of physical activity }\end{array}$} & High & 888 & 35,8 & 8 & 9 & 8,7 & 0,8 \\
\hline & Medium & 1086 & 43,8 & 5 & 6 & 5,9 & 0,83 \\
\hline & Low & 504 & 20,3 & 3 & 3 & 2,9 & 1,03 \\
\hline \multirow{3}{*}{$\begin{array}{l}\text { Satisfaction with the quality of } \\
\text { individual nutrition }\end{array}$} & High & 972 & 39,2 & 8 & 9 & 8,8 & 0,86 \\
\hline & Medium & 1047 & 42,3 & 7 & 6 & 6 & 0,89 \\
\hline & Low & 459 & 18,5 & 3 & 3 & 3 & 1,1 \\
\hline \multirow{3}{*}{$\begin{array}{l}\text { Maintaining the system of } \\
\text { healthy lifestyle }\end{array}$} & High & 1062 & 42,9 & 9 & 9 & 8,9 & 0,84 \\
\hline & Medium & 1002 & 40,4 & 7 & 6 & 6 & 0,84 \\
\hline & Low & 414 & 16,7 & 3 & 3 & 2,9 & 1,2 \\
\hline
\end{tabular}

\section{POPULATION CONCERN OF ITS OWN HEALTH}

The population concern of its own health was identified by the following criteria: satisfaction with individual physical health, satisfaction with the level of physical activity, satisfaction with the quality of individual nutrition, compliance with the system of healthy lifestyle, compliance with the nutrition system.

Based on the results of factor analysis (Table II), there are two factors identified which determine the population's confidence in the formal medical system. These factors have been identified by applying the Kaiser criteria [14]. The factors we detected were: $\mathrm{F}_{1}=2.6$ ( $41.8 \%$ of the total sample); $F_{2}=1,7(29,2 \%)$.

The highest load in the first factor has a variable «satisfaction with the level and quality of physical activity» $(r=$ $0,900)$. The variable "satisfaction with individual physical condition" ( $r=0.857)$ is close to it in terms of the factor load. The variables "satisfaction with the quality of individual nutrition" ( $\mathrm{r}=0.829)$ and "adherence to the system in a healthy style" $(\mathrm{r}=0.520)$ also had a significant load. The highest load in the second factor had the variables "compliance with the nutrition system" $(\mathrm{r}=0.867)$ and "maintaining the system during physical activity" $(r=0.845)$.

The correlation between the studied variables has been identified. Based on our study purpose, an interesting finding is the identified relationship between the variable that has the largest factor load for $\mathrm{F}_{1}$ - " satisfaction with the level and quality of physical activity" with indicators of "satisfaction with individual physical health" $(\mathrm{r}=0.785)$ and "satisfaction with the quality of individual nutrition " $(r=0.661)$ at $p \leq 0.01$. A correlation of average empirical significance has also been found between the indicators «system storage in physical load» and «nutrition system compliance» $(\mathrm{r}=0.512, \mathrm{p} 0.01)$.

\section{DISCUSSION}

\section{CONFIDENCE IN FORMAL MEDICINE AND MEETING PHYSICAL NEEDS}

The vast majority of respondents have confidence in formal medicine. This is evidenced by the quantitative indicators of high and average levels of confidence in the formal health care system, totaling 75.6 per cent of the sample. The level of confidence in alternative treatments is low: $61.9 \%$. Only 9 $\%$ of respondents showed a high level of trust for alternative treatment. The t-criterion (Student's t-distribution) applied to compare the size, provided the base to conclude that the difference between the indicators is empirically significant $(t=5.65848, p=0.01)$. Consequently, the high level of public confidence in formal medicine has traditionally been accompanied by lack of confidence in alternative methods, which improves the overall picture of relationships formed between health care providers and consumers. The above findings support the outcomes of the studies by the other scientists [15]. High level of confidence in formal medicine 
is the evidence that while addressing their health problems Ukrainians rely on the outcomes of health care studies.

While considering the determinants which result into the citizens' trust in medicine, in this study there was the impact of demographic factors tested on this phenomenon. However, there was not found any significance of the impact of age, status factors on confidence in formal medicine.

At the same time, there were factors identified in the study which make impact on formation of citizens confidence in formal medicine, i.e. two factors which can be conditionally designated as «satisfaction of basic needs and physical condition of an organism» (F1), as well as «healthy behavior» (F2)). The most significant impact on the level of public confidence in medicine is the individual's satisfaction with the level and quality of physical activities, satisfaction with the individual physical condition, and satisfaction with the quality of individual nutrition. Such results enable explaining conditionality of the population's confidence in formal medicine, as well as confirm the conclusions by A. Maslow on hierarchy and interrelationship of human needs [16]. It was identified that over the past year 39\% of those surveyed had changed their level of confidence ( $1 \%$ had it improved and $38 \%$ had it deteriorated). A significant percentage of deterioration, we believe, is due to the adaptive quarantine conditions imposed by the COVID-19 pandemic. Such a situation often led to restrictions on people's physical activity, changes in their traditional eating and drinking patterns, and, therefore, was turned into the stress factor. In addition, the level of confidence might be affected by the general tendency to burnout of medical staff in the situation of overload, as well as slowing down of health care system reforms, low level of its management.

A detailed analysis of the sample group which showed a high level of confidence in formal medicine, leads to conclusion that participants are satisfied with the level and quality of individual physical activities. Less than $1 \%$ of respondents $(0.51 \%)$ expressed dissatisfaction with this indicator. The dissatisfaction with this indicator in the group of average confidence in formal medicine was even smaller, amounting to only $0.11 \%$. This is an indication that they make reasonable use of their life potential, are aware of the importance of the physical component of health, care for their life quality, are guided by the scientists' recommendations, and have positive experience in implementing these prescriptions. Such results confirm high level of trust in health care system as a public institution [17]. The relatively high level of satisfaction with this variable was demonstrated also by persons who expressed an average level of confidence in formal medicine; the combined indicator of high and average rates was $83 \%$, while $17 \%$ reported a low level. In contrast to the above results, the participants of the group with a low level of confidence in medical system, showed a high level of dissatisfaction with individual physical activities (46\%). While the average level of satisfaction with this variable was $39 \%$, a significant number of self-assessments is approaching a low level of satisfaction. Factor weight of the variable «satisfaction level and quality of individual physical exertions» is 0,900 , which is proof that it has a significant influence on formation of trust of the population in formal medicine.

This feature is correlated with the other variables: for example, it is the most strongly tied with the indicator «satisfaction of individual physical health condition» $(\mathrm{r}=$ 0.785 at $p=0.01$ ). This correlation reinforces the concept of human health integrity as a state of physical and psychological well-being. The level of satisfaction with the individual physical condition of the interviewees who were part of the high level of confidence in formal medicine, was quite high: $90.1 \%$ (51.3 \% - high, $38.8 \%$ - average). Representatives of the average level of confidence also showed close results - $93.2 \%$ (44.8 - high level, 48.4 - average level). The factor load of this component is also high -0.857 , which evidences the importance of this variable as a determinant of public confidence in formal medicine. British scientists have drawn similar conclusions [18].

Another variable which has a high factor load (0.829) also correlates with satisfaction with individual physical activities, - satisfaction with the quality of individual consumption of nutrition and drink. Traditionally, the highest level of satisfaction was shown by representatives of high level of confidence in formal medicine -95.8 per cent. The group with the average level of confidence also evidenced high outcomes $-82.6 \%$. Such empirical data evidences that the respondents' expectations regarding the quality and the scope of nutrition and drink are met, they are not surviving basic needs frustrations, they are not depleted by hunger or excessive nutrition. The latter ensures opportunities for actualization of the need for confidence in formal medicine.

The component that formed the first factor of confidence in formal medicine was the variable "compliance of the system in a healthy style». Its factor load was lower (0.520), which, in our opinion, is due to the fact that it is based on a system of behavior, as well as human habits that are more difficult to correct. It is quite a common case when refusal from traditional food products or drinks used results into the lack of satisfaction which was usual for an individual.

Another explanation might be that the level of human competence in disease prevention and maintaining health has significantly increased in recent decades. And the latter is evidenced by the results of our study: $83.3 \%$ of participants from the full sample follow healthy lifestyle (42.9\% - high level, $40.4 \%$ - average level). Such data evidences a high level of population self-care: citizens use health care services provide by the formal system, follow recommendations of treatment providers, avoid any behavior which might be harmful to health (observe the rules of balanced nutrition, are engaged in physical activities, maintain positive attitude to the world, have a good sleep and rest, prevent their emotional burnout). However, it's worth noting that the majority of sample was rural population, representing the cultural traditions of Ukrainian people, so, such results may differ from those representing the self-assessment of the city residents. 


\section{CONFIDENCE IN FORMAL MEDICINE AND HEALTHY BEHAVIOR}

A study of healthy behavior has evidenced contradictory outcomes: despite the identified fairly high level of satisfaction with quality and individual physical activities, as well as high level of compliance with the system in a healthy lifestyle, the participants noted the absence of nutrition system as well as maintaining the system in physical activity. Only $21.3 \%$ of the total sample of respondents maintain the system as physically active. Although those respondents who were part of the group with the high level of trust in formal medicine, confirmed compliance with the system at the level of $43.9 \%$. In terms of nutrition system, $20.3 \%$ of respondents adhere to it. The data obtained from the respondents of the group with high confidence in formal medicine was $42.6 \%$. We consider this situation to be caused by a superficial understanding of these questions as well as by the lack of certain competence of respondents. Perhaps that was the reason for the second factor being lower than the first one. Although the percentage data obtained was not high enough for the entire sample, they were relevantly significant for the high level. This was evidenced by the factor load of the above-mentioned components: 0.867 - «the system of maintaining nutrition and drinking», 0.845 - «storage of system in physical activity». This provides the background for the generalization that compliance with these systems is important for building public confidence in formal medicine.

\section{CONCLUSIONS}

The study resulted into the following findings: there are two main factors which have significant impact on formation of confidence in citizens in formal health care system, namely: 'satisfied individual's basic needs and physical condition of organism', and 'healthy behavior of population'. The general level of Ukrainians' confidence in formal medical care system has proved to be quite high. This is an evidence of relevance of safety need - human willingness to obtain high-quality health care service. It was found within this study that public trust in formal medicine is dynamic. Its rapid deterioration is caused by frustration of the population' basic needs, as well as by the inability to quickly meet expectations on safety need implementation.

The most important factor in building confidence in formal medicine is human satisfaction with the level and quality of physical activity. The self-assessment of a given variable by sample members is quite high. Consequently, the promotion of the satisfaction of population with this need makes it possible to enhance people's interest in medical research, as well as implementation of recommendations of medical staff regarding the full utilization of health-care system and compliance with medical prescriptions. The components that build the confidence in formal medicine are also: satisfaction with individual physical condition, satisfaction with the quality of individual nutrition; compliance with the nutrition system; maintaining the system in physical activity. The above components are interlinked and interrelated.

\section{REFERENCES}

1. Ahlfors U. et al. Assessment of patient satisfaction with psychiatric care, Nordic Journal of Psychiatry. 2001. 55: 71-90. doi: 10.1080/08039488.2001.12016711.

2. Erikson E. Childhood and society (2nd ed.). New York: Norton. 1963, $401 \mathrm{p}$.

3. Stroebe W. et al. The Social Psychology of Intergroup Conflict. Springer Series in Social Psychology. Springer, Berlin, Heidelberg. 1988. doi: 10.1007/978-3-642-52124-9_4.

4. Allan N., Harden J. Parental decision-making in uptake of the MMR vaccination: a systematic review of qualitative literature.J Public Health. 2015; 37(4):678-87. doi:10.1093/pubmed/fdu075.

5. Vus V., Syurina E., Brückner T. et al. Youth and Mental Health: life satisfaction, wellbeing, and societal participation in the context of a transitioning state. Wiadomosci Lekarskie, 2021;74(7):1687-1694. doi: 10.36740/WLek202107123.

6. Hughes R. Patient Safety and Quality: An Evidence-Based Handbook for Nurses. Rockville (MD) Agency for Healthcare Research and Quality (US). 2008, 206p.

7. WHO. Health 2020: the European policy for health and well-being. https://www.euro.who.int/en/about-us/regional-director/regionaldirectors-emeritus/dr-zsuzsanna-jakab,-2010-2019/health-2020the-european-policy-for-health-and-well-being [date access 04.06.2021].

8. Brander P. et al. Compass. A handbook on human rights education for young people. Council of Europe portal. 2020, 305p.

9. Jourard S. The Transparent Self; Self-disclosure and Well-being Mass Market. Van Nostrand. 1964, 78p.

10. McLeod S. Carl Rogers. Simply Psychology. 2014.

11. Zhao D., Zhao H., Cleary P.D. International variations in trust in health care systems. Int J Health Plann Manage. 2019; 34(1):130-139. doi: 10.1002/hpm.2597.

12. Deutsch M. The Handbook of Conflict Resolution: Theory and Practice. (2nd ed.). San Francisco, CA. 2006

13. Hjelle L., Ziegler D. Personality Theories: Basic Assumptions, Research, and Applications. 3th ed. McGrow-Hill. 199263p.

14. Yeomans K., Golder P. The Guttman-Kaiser Criterion as a Predictor of the Number of Common Factors. The statistician. 1982; 31(3):221-229. doi:10.2307/2987988.

15. Bezreh T. et al. Challenges to physician-patient communication about medication use: a window into the skeptical patient's world. Patient Prefer Adherence. 2012;6:11-8. doi: 10.2147/PPA.S25971.

16. Maslow A. Motivation and Personality. New York. Harper \& Row. 1987, 54p.

17. Giddens A. The Constitution of Society: Outline of the Theory of Structuration. University of California Press. 1986, 62p.

18. Plomp H.N., Ballast N. Trust and vulnerability in doctor-patient relations in occupational health. Occup Med. 2010; 60(4):261. doi: 10.1093/ occmed/kqq067.

\section{ORCID and contributionship:}

Viktor V. Vus: 0000-0002-1042-5323 ${ }^{A, B, F}$

Liudmyla M. Omelchenko: 0000-0002-9963-0306 ${ }^{A, C, D}$

Oksana Boyko: 0000-0001-8445-3813 D,E,F

Ioanna V. Papathanasiou: 0000-0002-8874-8085 E,F

Evangelos C. Fradelos: 0000-0003-0244-9760 E,F

Vladislav Zharin: 0000-0002-4491-220X ${ }^{E, F}$

Kateryna Zharina: 0000-0002-0077-1484 E,F 


\section{Conflict of interest:}

The Authors declare no conflict of interest

\section{CORRESPONDING AUTHOR}

Viktor V. Vus

Institute of Social and Political Psychology National Academy

of Educational Sciences of Ukraine

15 Andriyivska St., 02000 Kyiv, Ukraine

tel: +380677408429

e-mail:viktor.vus@mhgc21.org

Received: 22.04 .2021

Accepted: 08.10.2021

A - Work concept and design, B - Data collection and analysis, C - Responsibility for statistical analysis,

D-Writing the article, $\mathbf{E}$-Critical review, $\mathbf{F}$ - Final approval of the article 


\title{
SELF-EDUCATIONAL ACTIVITY IN THE STUDENT AGE AS AN INDICATOR OF MENTAL WELL-BEING OF PERSONALITY
}

DOI: 10.36740/WLek202111106

\author{
Iryna A. Martyniuk', Ioanna V. Papathanasiou' ${ }^{2}$, Evangelos C. Fradelos ${ }^{2}$ \\ 'NATIONAL UNIVERSITY OF LIFE AND ENVIRONMENTAL SCIENCES OF UKRAINE, KYIV, UKRAINE \\ 2UNIVERSITY OF THESSALY, LARISSA, GREECE
}

\begin{abstract}
The aim: The aim of the article is to highlight the results of an experimental study of the indicators of students'mental health depending on their involvement in self-educational activities. Materials and methods: We conducted a comparative experimental research. There was a block of questionnaires, which required to choose one of the answers offered in the list and evaluate it on a given scale. The research collected data on respondents' self-educational activities and indicators of their mental health: meaningfulness of life, reflexivity, internal motivation for learning, stress resistance, components of self-actualization.

Results: Respondents engaged in self-educational activities in the profession they acquire have significantly higher rates of internal motivation for learning, time orientation and autonomy than respondents who are not engaged in self-educational activities. Respondents engaged in self-educational activities which are not related to the profession they acquire have significantly higher rates of internal motivation for learning, time orientation, cognition and creativity needs than non-self-educated respondents.

Conclusions: The research helps us to understand the progress of students' mental well-being. The results of the research help to find the ways of providing the mental health to students. In particular, encouragement of students' self-educational activities will help to improve the mental well-being of their personality.
\end{abstract}

KEY WORDS: self-educational activities of students, mental health of the person, research of the indicators of students' mental well-being

Wiad Lek. 2021;74(11 p.l):2717-2722

\section{INTRODUCTION}

Today we know a lot of research how to improve the quality of specialists' preparation in higher educational establishments [1-3]. The vast majority of such studies relate to finding ways to ensure that students meet the requirements of the professional activity for which they are preparing $[4,5]$. However, any training or education will not have the necessary effect without ensuring the mental health of the individual. The mental well-being allows a person to realize their own potential, cope with life stresses, work productively, as well as contribute to the life of their community [6]. Mental health is a resource and a state and is realized in the mental well-being of an individual [7].

And although in the student age the psychological potential of the individual is quite high, they are vulnerable to various social factors [8]. Knowledge of the ways to strengthen the mental health of students and their introduction will enable to prevent many negative phenomena (decreased motivation to learn, emotional burnout, anxiety, depression, apathy, etc.). It can also have a positive impact on youth employment, the filling of competent jobs, the development of society as a whole.

\section{PSYCHOLOGICAL FEATURES OF PERSONALITY} AND ITS MENTAL WELL-BEING IN STUDENT AGE During the student years, the physical maturation of the body ends, the degree of mental and spiritual development is reached, which allows young people to solve problems related to the choice of field of activity after graduation. The following psychological features are typical for this age: the orientation to self-affirmation, the formation of the individual as a subject of personal development, the development of volitional potential, intelligence (a person masters the most complex ways of intellectual activity, while the development of intelligence is closely linked to creative development), reflection, maximum efficiency, the stability of personality traits is produced $[8,9]$. As a subject of educational and professional activity the student is characterized by: a combination of intellectual and social maturity, which allows the formation of high cognitive activity in the professional sphere, the ability to organize their own activities, the emergence of a sense of responsibility for their future, formation of self-awareness and professional self-determination $[10,11]$.

\section{FACTORS THAT AFFECT THE MENTAL HEALTH OF A STUDENT}

In a student age, a person experiences the effect of a number of factors that affect his mental health and can weaken the mental well-being. Among them are: the beginning of independent life, high mental load during studying, mastering many new social roles, not always favorable socio-domestic and economic circumstances, fatigue. This age has many 
critical social events in the life of the individual: coming of age, criminal liability, the right to vote, the possibility of marriage, choosing a profession, and others [12].

\section{THE IMPORTANCE OF STUDENTS' SELF- EDUCATIONAL ACTIVITIES FOR THEIR MENTAL WELL-BEING}

Our long-term observations of university students show that the more a person is aware of their goals, opportunities, abilities, strives for self-realization in life, the more actively he is engaged in self-education - trying to learn more about his profession or acquire other competencies. Self-educational activity, as a rule, is purposeful and creative, it is motivated by internal motives of self-improvement, bears the imprint of personality and involves the use of special means of finding and mastering social experience [13]. We assume that by its nature, self-education activates such important characteristics for the psychological health of the individual as internal motives for activity, reflection and understanding of their actions and life in general, stress in situations of uncertainty, the desire for self-actualization in its various aspects. An experimental study was conducted to verify the proposed assumption.

\section{THE AIM}

The aim of the article is to highlight the results of an experimental study of indicators of mental health of students depending on their involvement in self-educational activities.

\section{MATERIALS AND METHODS}

\section{DESIGN}

We have developed a comparative experimental research. A block of questionnaires was used to select one of the answers in the list (questionnaire, Reflexivity Questionnaire by A. Karpov, Methodology for Diagnosing the Orientation of Learning Motivation by T. Dubovytska, «Forecast» Methodology by VA Bodrov, SAMOAL Methodology) and to evaluate on a scale (Test SJO by D. Leontiev). The study collected data on (a) respondents' self-education and (b) indicators of their mental well-being: meaningfulness of life, reflexivity, intrinsic motivation to learn, stress resistance, components of self-actualization.

\section{ADMINISTRATION}

The survey was conducted in Ukrainian, as it is the most common language for respondents in this region.

\section{DATA COLLECTION TOOLS}

The research contains two parts, which is due to the specifics of the comparative experiment.

The first part collects information on the employment of respondents in self-educational activities. For this purpose, a survey was used, during which the respondents had to choose the answer to the incomplete sentence: «Studying in a higher education institution, I...».

The presented answer options were as follows:

a) I am interested only in the information that is necessary for passing exams or tests;

b) I am interested in studying certain disciplines, and it happens that I work up much more information than required for exams or tests;

c) I am actively interested in information that is not directly related to the disciplines taught at our faculty, and I spend more time processing it than the program task;

d) I do not feel the desire to learn something new, to acquire new skills and abilities in any field.

The answer "a» was regarded as indicating that the student's educational activities are limited only by the tasks set by teachers; answer «b» - indicated involvement in self-educational activities related to the profession; answer «in» - indicated involvement in self-educational activities not related to the profession; the answer «g» - indicated a passive attitude to learning in general.

In the second part of the research we studied psychological characteristics - the indicators of mental well-being of three groups of respondents: meaningfulness of life (was diagnosed by the SJO Test by D. Leontiev), reflexivity (diagnosed by Reflexivity Questionnaire by A. Karpov), internal motivation of studying (studied by educational motivation of T. Dubovytska), stress resistance (studied according to the Methodology «Forecast» by V.A. Bodrov), self-actualization and its components (studied using the method of SAMOAL).

\section{DATA ANALYSIS}

Program SPSS.24.0 was used to compare the indicators of mental well-being of students with different self-educational activities. Descriptive statistics methods were used to determine the mean values of the mental health of the individual. And the U-criterion of Mann-Whitney was used to calculate the reliability of differences between independent groups of people on the criteria of mental well-being of the individual.

\section{ETHICAL CONSIDERATIONS}

This research was conducted in accordance with the principles of the APA for human researches. The students were provided with a set of forms of these methods, approved by the ethics commission of the Department of Psychology of the National University of Life and Environmental Sciences of Ukraine. The research was anonymous, the participants were informed that their responses would be treated confidentially, anonymously, all data would be analyzed in a generalized form without any conclusions about respondents. Participation in the study was voluntary. Students of 1-5 courses of various specialties of higher education institutions of Ukraine (National University of Life and Environmental Sciences of Ukraine, V. Hnatiuk Ternopil 
Table I. The average values of mental well-being of the individual in different groups of respondents, M

\begin{tabular}{|c|c|c|c|c|c|c|c|}
\hline \multirow{3}{*}{ No } & \multirow{3}{*}{$\begin{array}{l}\text { Indicators } \\
\text { mental well-being of the } \\
\text { individual }\end{array}$} & \multicolumn{6}{|c|}{ Average values in the groups of respondents } \\
\hline & & \multicolumn{2}{|c|}{$\begin{array}{c}\text { Group } 1 \\
\text { Students who carry } \\
\text { out self-educational } \\
\text { activities in the specialty } \\
\text { they acquire }\end{array}$} & \multicolumn{2}{|c|}{$\begin{array}{l}\text { Group } 2 \\
\text { Students engaged in self- } \\
\text { educational activities not } \\
\text { related to the profession } \\
\text { they are acquiring }\end{array}$} & \multicolumn{2}{|c|}{$\begin{array}{c}\text { Group } 3 \\
\text { Students whose } \\
\text { educational activity is } \\
\text { limited to the performance } \\
\text { of tasks in disciplines }\end{array}$} \\
\hline & & M & $\Sigma$ & M & $\sigma$ & M & $\boldsymbol{\sigma}$ \\
\hline 1 & Meaningfulness of life & 94,67 & 13,71 & 98,73 & 18,31 & 93,7 & 16,74 \\
\hline 2 & Reflexivity & 121,33 & 11,6 & 117,23 & 13,05 & 117,77 & 9,68 \\
\hline 3 & Internal motivation for learning & 13,8 & 3,39 & 18,5 & 10,2 & 10,7 & 3,08 \\
\hline 4 & Neuropsychological stability & 23,7 & 6,84 & 22,83 & 8,2 & 24,87 & 8,53 \\
\hline 5 & Orientation in time & 5,9 & 1,11 & 6,1 & 1,39 & 5 & 1,27 \\
\hline 6 & $\begin{array}{c}\text { Values of self-actualized } \\
\text { personality }\end{array}$ & 9,03 & 1,76 & 9,3 & 2,1 & 8,7 & 1,94 \\
\hline 7 & Belief in human capabilities & 3,9 & 1,26 & 4,33 & 1,56 & 3,63 & 1,12 \\
\hline 8 & The need for knowledge & 5,97 & 1,18 & 6,3 & 0,97 & 5,43 & 1,37 \\
\hline 9 & Creativity & 9,4 & 2,04 & 9,83 & 2,21 & 8,03 & 2,64 \\
\hline 10 & Autonomy & 8,47 & 1,64 & 7,83 & 2,33 & 6,93 & 1,87 \\
\hline 11 & Spontaneity & 6,4 & 1,85 & 6,93 & 2,33 & 6,9 & 1,79 \\
\hline 12 & Self-understanding & 4,13 & 1,36 & 4,87 & 1,48 & 4,5 & 1,2 \\
\hline 13 & Autosympathy & 6,63 & 2,1 & 7,1 & 2,69 & 7,57 & 2,26 \\
\hline 14 & Contact & 4,83 & 1,52 & 5,5 & 1,47 & 4,97 & 1,37 \\
\hline 15 & Flexibility in communication & 5,6 & 1,4 & 5,57 & 1,16 & 5,2 & 1,43 \\
\hline
\end{tabular}

National Pedagogical University, National Pedagogical Drahomanov University and Yu. Fedkovych Chernivtsi National University) were involved, a total of 324 persons. The research was conducted in the 2018-2019 academic year.

\section{RESULTS}

\section{ENVOLVEMENT OF STUDENTS IN SELF- EDUCATIONAL ACTIVITIES}

In the first part of the study, according to the results of the survey, all students were divided into four groups:

1) students engaged in self-educational activities related to the specialty they acquire;

2 ) students who are engaged in self-educational activities that are not related to the specialty they acquire;

3) students who are not engaged in self-educational activities (their self-educational activities do not go beyond the performance of tasks in academic disciplines);

4) students who are not engaged in self-educational activities (and passive attitude to the implementation of educational tasks).

Since the fourth group was represented by only two students out of all respondents, we further analyzed the empirical data of the students only of the first three groups.

To increase the reliability of the results of the research, the groups were balanced by the following indicators: university, specialty, course and gender in a random way.
Therefore, each of the selected groups included 30 people who were full-time students of 1-4 courses of specialties «Construction and Civil Engineering» (NULES of Ukraine), «Economic Cybernetics» (NULES of Ukraine), «Forestry» (NULES of Ukraine), «Social work» (NULES of Ukraine), «Psychology» (NULES of Ukraine, Volodymyr Hnatiuk State Pedagogical University, MP Drahomanov National Pedagogical University), «Publishing» (Yu. Fedkovych National University). The total number of respondents is 90 people.

\section{INDICATORS OF MENTAL WELL-BEING OF STUDENTS WITH VARIOUS SELF-EDUCATIONAL ACTIVITIES}

In the second part of the study, in consequence of the application of methods for determining the indicators of mental well-being of the individual the following results were obtained (see Table I).

The results of the study showed (see Table 1) differences in the average values of mental well-being of the individual in different groups of respondents. In particular, in the first group of respondents the indicators of reflexivity, autonomy, flexibility in communication were higher in comparison with other groups. In the second group dominated the meaning of life, internal motivation for learning, time orientation, the value of self-actualized personality, belief in human capabilities, the need for knowledge, creativity, spontaneity, self-understanding, contact, and the best in- 
Table II. The results of comparing the values of mental health of the individual in different groups studied by the Mann-Whitney U-criterion

\begin{tabular}{|c|c|c|c|c|c|}
\hline \multirow{3}{*}{ No } & \multirow{3}{*}{ Indicators mental well-being of the individual } & \multicolumn{4}{|c|}{ Comparable groups of recipients } \\
\hline & & \multicolumn{2}{|c|}{ Group 1 i 3} & \multicolumn{2}{|c|}{ Group 2 i 3} \\
\hline & & $\mathbf{U}_{\text {emp }}$ & $\mathbf{p}$ & $\mathbf{U}_{\mathrm{emp}}$ & $\mathbf{p}$ \\
\hline 1 & Meaningfulness of life & 445 & $\geq 0,05$ & 402 & $\geq 0,05$ \\
\hline 2 & Reflexivity & 349 & $\geq 0,05$ & 413,5 & $\geq 0,05$ \\
\hline 3 & Internal motivation for learning & 253,5 & $\leq 0,05$ & 286 & $\leq 0,01$ \\
\hline 4 & Neuropsychological stability & 431,5 & $\geq 0,05$ & 381,5 & $\geq 0,05$ \\
\hline 5 & Orientation in time & 318,5 & $\leq 0,05$ & 299,5 & $\leq 0,05$ \\
\hline 6 & Values of self-actualized personality & 398 & $\geq 0,05$ & 371,5 & $\geq 0,05$ \\
\hline 7 & Belief in human capabilities & 402,5 & $\geq 0,05$ & 345 & $\geq 0,05$ \\
\hline 8 & The need for knowledge & 368,5 & $\geq 0,05$ & 319 & $\leq 0,05$ \\
\hline 9 & Creativity & 338,5 & $\geq 0,05$ & 303 & $\leq 0,05$ \\
\hline 10 & Autonomy & 280,5 & $\leq 0,01$ & 356 & $\geq 0,05$ \\
\hline 11 & Spontaneity & 351 & $\geq 0,05$ & 405,5 & $\geq 0,05$ \\
\hline 12 & Self-understanding & 394 & $\geq 0,05$ & 391 & $\geq 0,05$ \\
\hline 13 & Autosympathy & 357,5 & $\geq 0,05$ & 422,5 & $\geq 0,05$ \\
\hline 14 & Contact & 416,5 & $\geq 0,05$ & 390 & $\geq 0,05$ \\
\hline 15 & Flexibility in communication & 390,5 & $\geq 0,05$ & 389 & $\geq 0,05$ \\
\hline
\end{tabular}

dicator of neuropsychological stability (according to the method "Forecast" the lower is the rate, the higher is the level of neuropsychological stability). In the third group of respondents the average rates of self-understanding and autosympathy were higher than in other groups. In this case, each of the groups is relatively homogeneous on the values of each of the indicators, except for the indicator of internal motivation of learning in the second group.

In general, the average values obtained in Table I show that there are differences in the mental health of those students who are engaged in self-educational activities and those who are not engaged (limited to the performing of educational tasks set by teachers). The Mann-Whitney $\mathrm{U}$-criterion was used to verify the significance of such differences (see Table II).

Table II highlights the significant differences between the indicators of internal motivation for learning of the studied groups 1 and 3, and groups 2 and 3. Moreover, the statistical error in the differences of this indicator is less between 2 and 3 groups. In addition, groups 1 and 2 differ significantly from group 3 in terms of orientation over time. The subjects of the first group significantly differ from the subjects of the third group also in terms of personality autonomy. The subjects of the second group significantly differ from the subjects of the third group also in terms of the need for cognition and creativity.

According to other indicators, no significant differences between the groups were found.

\section{DISCUSSION}

This article presents a research of indicators of mental well-being and self-education of students of universities of Ukraine.

\section{THE INFLUENCE OF SELF-EDUCATIONAL ACTIVITIES ON INDICATORS OF} PSYCHOLOGICAL WEALTH OF THE INDIVIDUAL.

The study showed that students who are engaged in self-educational activities are significantly more likely to have higher rates of internal motivation for learning, orientation in time, than those students who are not engaged in self-education and only perform the tasks of teachers. Internal motivation of learning is characterized by the manifestation of the student's own activity during educational activities; he is directly involved in the process of cognition and this brings him emotional satisfaction [14]. Orientation in time allows students to understand the existential value of life "here and now", to enjoy the current moment, without comparing it with the past and without devaluing the expectation of future success [15].

\section{ORIENTATION OF STUDENTS' SELF- EDUCATIONAL ACTIVITY AND INDICATORS OF} THEIR MENTAL WELL-BEING

Students carry out various types of self-educational activities: in the specialty they acquire, and not related to their future profession, which they master at the university [16].

The type of self-educational activity also activates the indicators of mental well-being of the individual.

Students who are engaged in self-educational activities in the specialty they acquire have significantly higher rates of autonomy than those who are not engaged in self-educational activities. Autonomy of the individual, according to most humanistic psychologists, is the main criterion of psychological health, its integrity and completeness; in essence, it is close to the concepts of «inner-directed», «aliveness», «self-support», «ripeness» [15; 17]. 
Students who are engaged in non-educational non-university activities are significantly more likely to have higher levels of cognition and creativity than respondents who are not self-employed. The need for knowledge is characteristic of people who are open to new impressions; it provides instant cognition; people with a high level of such need tend to effectively learn something new and appreciate it [15]. Creativity and the need for it mean a person's creative attitude to life [15].

The conducted empirical research allowed to achieve the set goal - revealed more pronounced indicators of mental well-being of students engaged in self-educational activities.

The results of the work are presented for discussion for the first time.

\section{LIMITATIONS}

We have singled out an incomplete range of mental health indicators for diagnosis; no study of the impact of the duration of self-educational activities on the mental well-being of the individual.

Potential perspectives of the research are the observation of the dynamics of indicators of mental well-being of a person engaged in self-educational activities, compared with the dynamics of such indicators in a person who is not engaged in self-education.

\section{CONCLUSIONS}

The study led to the conclusion that the self-educational activities of students are evidence of several indicators of psychological health, such as: internal motivation to learn, good orientation in time (i.e. the ability to live in the present without postponing their lives "for later"). In addition, self-educational activities in the context of the specialty that students acquire, indicates a good autonomy of the individual (i.e. its integrity, completeness, vitality, maturity). And self-educational activities that are not related to the specialty that students acquire also show their higher need for knowledge and creativity (as a creative attitude to life).

The above suggests that the stimulation of self-educational activities of students will help to improve the mental health of their personality.

\section{REFERENCES}

1. Vyhrushch A., Shulga F., Fedchyshyn N. et al. Yakist vyshchoyi medychnoyi osvity. [Quality of higher medical education]. Ternopil: TDMU: Ukrmedknyga, 2017, 480p. (In Ukrainian).

2. Dembitska S., Kobylianska I. Zabezpechennia yakosti fahovoyi pidgotovky v zakladah vyshchoyi tehnichnoyi osvity. [Ensuring the quality of professional training in higher institutions technical education]. Pedagogika bezpeky. 2018; 2: 131-136. (In Ukrainian).

3. Vasyliuk A., Dei M., Bazeliuk V. et al. Yakist vyshchoyi osvity: teoriya i practyka. [Quality of higher education: theory and practice]. Kyiv; Nigyn: Lysenko. 2019, 176p. (In Ukrainian).
4. Sharov S. Kompetentnisnyi pidhid: perevagy, struktura, osoblyvosti. [Competence approach: advantages, structure, features]. Naukovyi Visnyk MNU imeni V. 0. Suhomlynskogo. 2018; 4(63): 194-199. (In Ukrainian).

5. Akimova 0. , Haluziak V. Rozvytok profesiyno vaglyvyh yakostey u maybutnih uchyteliv. [Development of professionally important qualities in future teachers]. Vinnytsia: Nilan-LTD. 2016, 248p. (In Ukrainian).

6. WHO. Psihicheskoye zdorovye. [Mental health].Vsemirnaya organizaciya zdravoohraneniya. 2018. https://www.who.int/ru/news-room/factsheets/detail/mental-health-strengthening-our-response [dare access 03.05.2021] (In Russian).

7. Galecka I. Psyhologichne zdorovya yak problema nacionalnoyi bezpeky. [Psychological health as a problem of national security]. Naukovyi visnyk Lvivskogo dergavnogo universytetu vnutrishnih sprav. 2012; 2(1):49-58. (In Ukrainian).

8. Varban Y. Strategiyi podolannia gyttievyh kryz v yunackomu vici. [Strategies for overcoming life crises in adolescence]. Kyiv: Universytet menedgmentu osvity. 2009, 20p. (In Ukrainian).

9. Gamezo M., Petrova E., Orlova L. Vozrastnaya i pedagogicheskaya psihologiya. [Developmental and pedagogical psychology]. Moskva: P.0.R. 2003, 232p. (In Russian).

10. Medvedev D. Obraz mira sovremennogo studenta: osnovy sistemnotekstologicheskoy paradigmy. [The image of world of the modern student: the foundations of the system-textological paradigm]. Astrahan: Izdatelstvo Astrahanskogo pedagogicheskogo universiteta. 2001, 110p. (In Russian).

11. Tarasova T. Psyhologichni osoblyvosti studenstva. [Psychological features of students]. Sumy: SumDPU im. A. Makarenka. 2004, 43p. (In Ukrainian).

12. Pavelkiv R. Vikova psyhologiya. [Developmental psychology]. Kyiv: Kondor. 2011, 233p. (In Ukrainian).

13. Martyniuk I. A. Sutnist poniattia "samoosvitnia diyalnist osobystosti" [The essence of the concept of "self-educational activity of the individual"]. Teoretychni ta prykladni problemy psyhologiyi. 2015; 2(38):204-217. (In Ukrainian).

14. Dubovitskaya T. Metodika diagnostiki napravlennosti uchebnoi motivacii. [Methodology of diagnostics of orientation learning motivation]. Psihologicheskaya nauka I obrazovaniye. 2002, 242p. (In Russian).

15. Fetiskin N., Kozlov V., Manuilov G. Socialno-psihologicheskaya diagnostika lichnosti i malyh grup. [Socio-psychological diagnosis of individuals and small groups]. Moskva. 2002, 433p. (In Russian).

16. Kalugin Y. Vidu samoobrazovaniya. [Types of self-education]. Dopolnitelnoye obrazovaniye. 2003; 2:16. (In Russian).

17. Vus V., Syurina E., Brücker T. et al. Youth and Mental Health: life satisfaction, wellbeing, and societal participation in the context of a transitioning state. Wiadomosci Lekarskie, 2021;74(7):1687-1694. doi: 10.367440/Wlek202107123.

\section{ORCID and contributionship:}

Ioanna V. Papathanasiou: 0000-0002-8874-8085 E,F

Evangelos C. Fradelos: 0000-0003-0244-9760 E,F

Iryna A. Martyniuk: 0000-0003-1644-5381 A-D

\section{Conflict of interest:}

The Authors declare no conflict of interest 


\section{CORRESPONDING AUTHOR}

Iryna A. Martyniuk

National university of life and

environmental sciences of Ukraine

19 Henerala Rodymtceva st., 03041 Kyiv, Ukraine

tel: +380500334036

e-mail:martirenet@ukr.net

Received: 05.05 .2021

Accepted: 07.10.2021

A - Work concept and design, B - Data collection and analysis, C - Responsibility for statistical analysis,

$\mathbf{D}$-Writing the article, $\mathbf{E}$-Critical review, $\mathbf{F}$ - Final approval of the article 


\title{
COVID-19 PANDEMIC LIFESTYLE: STUDENTS MENTAL HEALTH CHALLENGES
}

DOI: 10.36740/WLek202111107

\author{
Iryna I. Boiko', Olha I. Herus' ${ }^{1}$ Larysa D. Klymanska', Victor Y. Savka', Liliia Y. Klos', Mariana V. Shkoliar', \\ Valentina Vitale ${ }^{2}$ \\ 'LVIV POLYTECHNIC NATIONAL UNIVERSITY, LVIV, UKRAINE \\ 2ROMA TRE UNIVERSITY, ROME, ITALY
}

\begin{abstract}
The aim: To determine how quarantine restrictions affect the lifestyle of Ukrainian students, and their mental health.

Materials and methods: 37 student essays were submitted to the university contest held at Lviv Polytechnic University in May-June 2020. They were analyzed with the help of qualitative thematic analysis and standard qualitative analysis method. Essays are focused on a list of issues important for assessing the social well-being of students during quarantine. Each fragment of essay's answer was coded into the data matrix system according to either multiple or single themes, built in the statements. The thematic analysis identified several categories that determine students' attitude to the pandemic situation and its consequences for them.

Results: It is determined that students' lifestyle, including study and leisure, has changed significantly, which has affected their mental health. Learning online provoked a number of emotional disorders. At the same time, the desire for communication in person and self-improvement increased. «Quarantine lessons» were divided into categories: challenges, threats and opportunities. Threats and challenges were considered at the global level, while opportunities affected rather the personal level.

Conclusions: Mental health of students disorders: anxiety, restlessness, fear, self-doubt, feelings of loneliness, panic, sleep disturbances, and increased fatigue indicate the negative effects of the pandemic. At the same time, recording such facts as the feeling of satisfaction from communication with loved ones, the ability to help them, the desire for self-improvement, etc. allows to say about the positive effects.
\end{abstract}

KEY WORDS: Covid-19, pandemic, learning practices, lifestyle, mental health, students

Wiad Lek. 2021;74(11 p.l):2723-2727

\section{INTRODUCTION}

The COVID-19 pandemic has been a significant test for the modern world. However, it did not come as a surprise to everyone. Canadian psychologist S. Taylor began studying the danger of a pandemic two years before the COVID crisis. Studying the mental health problems of communities in the context of the COVID-19 pandemic, S. Taylor and a group of colleagues from Canada, the United States and the United Kingdom describe the mental problems caused by infectious epidemics and pandemics as a "parallel epidemic» [1-2].

S. Taylor, together with psychologist G. Asmundson, conducted a study of the expansion of fear and anxiety among 7,000 adults in Canada and the United States. $75 \%$ of respondents feel well, while the remaining $25 \%$ of respondents develop COVID-stress syndrome. People who previously had mental health problems are the most vulnerable [3].

Among the works dedicated to the study of psychological reactions of various social groups in Ukraine during the COVID-19 pandemic, it is necessary to mention the publication of a team of authors from the Institute of Sociology of the National Academy of Sciences of Ukraine [4].

Empirical analysis of the reactions of society as a whole and its groups to the problems caused by the pandemic is mainly based on the so-called quantitative methods, and therefore allows to record the main characteristics of phenomena at the macro social level [5]. For example, according to a study conducted in Lviv among young people aged 14-35, it was determined that the dominant triggers of deteriorating emotional and psychological mood and changes in the lifestyle are the lack of opportunities for travel - for $86 \%$ of respondents, the lack of offline communication with friends, relatives $-77 \%$, and the absence of the usual study / work schedule $-75 \%$. Children often enjoy quarantine $(60 \%$ dissatisfied), and young people are more concerned about such changes (78\%). Among the reasons that upset young people the most are a lack of diversity of leisure practices $-65 \%$, shut down of their own business - 22\% [6].

Studies, in which the starting point of the analysis is the individual reactions of representatives of certain social groups to these macro social phenomena, are quite rare. For example, Polish researchers studied the factors of youth activity during a pandemic [7]; a team of Canadian scientists studied the impact of the spread of COVID-19 on the symptoms of anxiety and depression among university students [8]; Greek and Ukrainian scientists studied the relationship between religiosity, psychological stability and psychological well-being of nurses [9] etc. 
To analyze the attitude of Ukrainian students to their adaptation to quarantine conditions and to determine how quarantine restrictions affect students' lifestyles, their mental health, we conducted a sociological study of essays submitted to the university contest «Pandemic and lifestyle: challenges, threats and new opportunities «.

Lifestyle should be understood as a holistic system of life practices that are implemented on a daily basis, inherent in both social groups as a whole and for individuals - their members. We need to outline the methodological principles that were implemented in the analysis:

- life practices are relatively constant and are transformed, first of all, under the influence of changes in the social environment in which they are implemented;

- changes in the system of practices - components of lifestyle are the result of internal, self-controlled factors, which is, for example, intrinsic motivation. Therefore, despite the action of macro social factors common to the whole social group, the individual reactions of the members of this group to them can vary in a wide range;

- systemic life practices - a component of lifestyle implies that they are interdependent, where the change of some components of lifestyle provokes changes in others, the ones they are in constant organic relationship;

- while analyzing these transformations, it is necessary to identify the most significant component of lifestyle, changes in which will determine the main vector of transformations of the whole system. Such a core component of students' lifestyles are learning practices, which are correlated with other components of students' lifestyles;

- the lifestyle of certain social groups in general, and their individual representatives has a significant impact on the mental well-being of these groups and individuals.

\section{THE AIM}

The aim of this article is to determine the impact of quarantine restrictions on the lifestyle and mental health of Ukrainian students.

\section{MATERIALS AND METHODS}

The empirical base was processed by the method of quantitative content analysis of student essays, within which the procedure of thesaurus selection and calculation of frequencies of words and combinations of language elements was implemented. In the course of data analysis, units were categorized, the text was divided into categories according to thesauri and the number of units corresponding to one or another category was counted, and their comparison was made.

Sample. The array of texts for analysis is formed from essays submitted to the competition, held at Lviv Polytechnic University in May-June 2020 and dedicated to the changes that have taken place in student life due to quarantine caused by the COVID-19 pandemic.

For the analysis of the content of student essays, thematic analysis was used, which is attributed to the methods of qualitative analysis [10]. Thematic analysis was conducted by a single researcher (Larysa Klymanska). After reviewing the data, initial thoughts and impressions about the similarities and differences in the answers were recorded. Based on the codes formulated in the thematic analysis, from this initial analysis a system of initial classification was created, improved over several iterations. A random ten percent of responses were independently coded by another researcher (Mariana Shkoliar). As there was 100\% agreement in these cases, the responses were not further analyzed.

\section{RESULTS AND DISCUSSION}

The results of the analysis of essay texts. As already mentioned, the contest of student essays «Pandemic and lifestyle: challenges, threats and new opportunities» was held at the National University «Lviv Polytechnic» on the initiative of the Department of Sociology and Social Work with the support of the University Administration in MayJune 2020. Under the terms of the contest it was offered to write an essays focused on a list of issues important for assessing the social well-being of students during quarantine, in particular - changes in attitudes to learning, leisure, interactions with the social environment, those that are crucial for shaping students' lifestyles, affect their mental health. The format of the essay competition was chosen in order to make the collection of information less formal and, consequently, to attract more respondents into this process. 52 essays were submitted to the contest, but only 37 texts were analyzed, the authors of which complied with the conditions of the contest. The thematic analysis identified several categories that determine students' attitudes to the pandemic situation and its consequences for them.

The main issues that were mentioned in the terms of the competition are grouped into six categories, three of which are directly related to the issues of this article:

1. Lifestyle - participants' reproduction of daily practices of learning and spending their free time, their transformation and assessment of these changes in lifestyle;

2. Life changes - participants' assessment of the changes taking place in the world, in the country, society, at the University, the higher education system;

3. The outcomes of quarantine - in a broad sense, along with perceptions of the pandemic and assessment of changes that have taken place at the individual level, in the university community, in Ukrainian society in general, as a result of reflection on the situation.

The largest (excluding the image of a pandemic) part of mentions in the texts are categories related to education (Table I).

The lifestyle of students, as noted in most essays, has changed significantly. This applies to both learning and leisure activities that affected their mental health.

First of all, more time is dedicated to training ( $«$ I think I spend more time on studying during quarantine» (2) [here and below in parentheses is the code number of the essay that was assigned to it for research purposes]; «Almost all of my time I dedicate to study «(9);»... I study every day 
Table I. Generalized categories highlighted in the texts

\begin{tabular}{|c|c|c|c|}
\hline $\begin{array}{l}\text { Generalized } \\
\text { categories }\end{array}$ & \multicolumn{2}{|c|}{ Content units of text content analysis } & $\begin{array}{l}\text { Number of } \\
\text { repetitions in } \\
\text { the text }\end{array}$ \\
\hline \multirow{5}{*}{ Teaching } & \multicolumn{2}{|c|}{ learning, study, learn, distance learning, education } & \multirow{5}{*}{407} \\
\hline & \multicolumn{2}{|c|}{ teachers, students, professors } & \\
\hline & \multicolumn{2}{|c|}{ lectures, trainings } & \\
\hline & \multicolumn{2}{|r|}{ zoom, MS } & \\
\hline & \multicolumn{2}{|c|}{ Virtual learning environment } & \\
\hline \multirow{5}{*}{ Lifestyle } & \multirow{2}{*}{ change of lifestyle } & life, live, survive & \multirow{2}{*}{324} \\
\hline & & lifestyle, way of life & \\
\hline & \multirow[t]{2}{*}{ new forms of communication } & $\begin{array}{c}\text { social networks (Instagram, Twitter, Facebook, } \\
\text { Snapchat, YouTube) }\end{array}$ & \multirow[t]{2}{*}{118} \\
\hline & & to communicate, communication & \\
\hline & Time management & time, on time, not in time & 362 \\
\hline
\end{tabular}

for an average of eight hours... Sometimes twelve hours in a row «(9);» At this stage, studying takes up most of... my day «(20)), it comes to the point where most of the responders note that «learning takes almost all of my free time» (32). In one of the essays, there was a phrase «it is kind of university-dependence» (12). It was the «increase in training» that triggered the development of time management skills - «Every weekend I make a schedule for the next week, alternating it when necessary ...» (2); «After sitting in quarantine for three months, I realized that the problem is not in the lack of time... The problem is that I do not know how to use this resource right.» (6).

Secondly, the training became more intensive- «I continue to study more actively than in regular classes.» Probably, there has been a reassessment of the very value of learning in a life-threatening situation. The attitude towards such intensification of the educational process is ambiguous: from the realization that learning is a contribution to the further development of a person - «I study a lot and invest the maximum in my development» (17) , and that "intensive learning leaves no room for anxiety and «overthinking»(10), to the claims that the complicated course of the educational process has repeatedly caused stressful situations -» with distance learning a lot of work was added, and the deadlines remained the same; I have some rest only when sleeping, but I haven't had a sound sleep for a long time "(12). There was even «my parents suggested that I quit my classes as they could see how it affected my health, and especially my mental stability» (12). Before exams there are traditional fears «I might fail» (9); «The first virtual exams will cause great fear» (35).

It is obvious that the intensification of learning, the complexity of the learning process, that were accompanied by stressful situations, increased fear, sleep disorders were evidence of negative emotional dynamics that threaten mental health.
At the same time, we can state that the attitude to distance learning, as well as to quarantine, has changed over time. At the beginning of the "quarantine life» there was a state of euphoria about the next unexpected vacation - «I remember from school how happy and cheerful the words sounded that we are going to quarantine ... No more deadlines, you learn when you wish to»(6); «We imagined a three-week vacation, how we would relax and hang out with friends...» (8). Time was a sobering factor «... but no one expected it to take so long» (23); «It seemed fun until the quarantine was extended» (6).

Students recorded their unpreparedness for new challenges, one of which was online learning. "Initially, distance learning "was so alien, unusual and scary» (11). Later came the period - «small steps» of «entering» the essence of new forms and platforms of learning: - «slowly learn how to work in VNS, Zoom and Teams «(11). There was a statement- "Learning in this format is a kind of going out of your comfort zone, the opportunity to try to learn differently» (34) and expressions of being interested in changing forms of learning - «I always thought that virtual learning is difficult and boring, but in reality it turned out to be even more difficult than studying in person, but nevertheless classes are as interesting as regular ones"(37). «It is quite interesting... my dreams came true and I am able to study at home, staying with my family» (13).

As the quarantine continued, students began to experience «all the beauties» of distance learning» (11): distance learning is as tiring as usual one (10); (8); distance learning forced students to sacrifice (10); (4).

Thus, online learning is a challenge for students. First and foremost, the challenge for mental health. It provoked fatigue from being overstrained, the appearance of a number of negative emotional states (frustration, fear, anxiety, panic attacks, sleep disturbances) («I have neither enthusiasm nor desire to do something») (26). At the same time, 
such realities have strengthened the need for in person communication and have become for many students an incentive for self-improvement.

The authors of the essays also focused on the changes caused by the pandemic. Hypothetically, they can be viewed from several perspectives. First, it is a personal change. The point is that this situation allowed us to look back at our pre-quarantine life - "It seems to me that I have had a «retirement effect». When you have a close look at your whole life and you can clearly see what was crucial for you»(1), the value of money is brushed aside -» I do not want to give up my sleep for money, which I will then spend on some material nonsense «(1). There are reflections on the topic of «before» and «after» quarantine: «My own views, which previously seemed to me completely correct, now mean almost nothing to me. They have changed, as have I. I also realized that we have only one life and it is, unfortunately, very fast paced and fragile (19).

Secondly, among the changes that accompany the life of an individual in quarantine, the most frequently mentioned are those that can be seen on the surface of human existence: the «mask» requirements, social distance (3); spending more time in social media and limited live communication(14), huge interest in sports and meditation practices, «quarantine self-expression» as another type of creativity (16).

The so-called "quarantine lessons" - the "quintessence» of individual reflection on the quarantine situation - are also analyzed. We categorized them into: challenges, threats and opportunities, plus taking into account the level at which they are considered by the authors of essays (global, personal). Regarding the category of "challenges", we came to only one conclusion, which can be considered global - "quarantine has become a challenge for us and made it clear that the simple things in life make us happy» (6). Threats are mainly addressed at the global level - quarantine «will be a lesson to all mankind that we must stop and start solving global problems such as: environmental, food, use of the oceans, peace and disarmament, prevention of a new world war» (7); «The coronavirus showed us the unattractive truth of what a cruel world we have created and how much we ourselves suffer in it» (22). At the personal level, the threat is seen through a change in views on social interactions - «I saw the attitude of people to each other in terms of restrictions in both social networks and reality.... People have started to prioritize themselves, they want to benefit and get rich on the misery of others."(5).

Most attention in the essays was paid to the opportunities (both in terms of the number of reviews and the quality of statements). At the same time, most of the opportunities that students wrote about were not related to the global, but rather the personal level:

- from the philosophical comprehension (rethinking) of one's life - «the world has given us a chance to change, to improve our lives, to see who is who» (32); «Reconsider views on the world and realization that humanity must change its lifestyle in order to have a future» (2); Rethinking what life is and what it means to «live» (26); «Find yourself» (11); «Reboot and understand what is really needed in life and what to strive for» (34); opportunities for significant personal change - «this is a very good time for the reincarnation of the individual» (20); the ability to realize the importance of simple things - «the situation (with quarantine)... proved the importance of simple things, which make up our lives and which can not be taken for granted» (10);

- from the awareness of one's own belonging to the group: the opportunity and need to «learn empathy and get out of their small social aquariums» (30); the realization that "personal responsibility for one's own health, the routine of washing hands no longer becomes a personal but a collective responsibility» (30); «The pandemic has made all Ukrainians feel again that we are one body. COVID-19 has caused a worldwide epidemic of kindness"(22);

- to pragmatic instrumental skills: opportunities for «development of multitasking» (15); «Learn something new, know yourself and improve» (17); to acquire new skills - «we now know that distance learning is possible and even very real» (23); "Improve the level of organization of their lives - through time management» (9).

Thus, the method of thematic qualitative analysis of essays allowed to obtain empirical material not only less formal than in mass surveys using standardized questionnaires, but also to record individual observations of students concerning social processes that go beyond their individual existence.

Rather critical moment was noticed in the students' feelings of the pandemic, especially what prevails in it: seeing it as danger, challenge, crisis and at the same time as an opportunity to change something in University life and society as a whole. Such mental health disorders as anxiety, uneasiness, fear, self-doubt, loss of interest in learning or any extracurricular activities, feelings of loneliness, panic, sleep disturbances, increased fatigue indicate the negative effects of the pandemic. At the same time, a sense of satisfaction with communication with loved ones, the ability to help them, the desire to care for other, a sense of shared danger of coronavirus infection and confidence in the community's ability to emerge from a pandemic with achievements - experience of self-development and responsibility for your own health and life and health and life of relatives and other people - allows us to tell about the positive effects. It is noteworthy that in the texts of essays the reference to the pandemic as a source of change and the use of opportunities is significant -268 , while the pandemic as a challenge has been mentioned half less- 123 .

\section{CONCLUSIONS}

An analysis of available sources of information in comparison with the results of our study of student essays allows us to conclude that the mental health of students in quarantine caused by the COVID-19 pandemic has been significantly affected by both external social factors and internal, individual.

These macro-social changes have affected the mental health of student youth. Despite the high level of com- 
puter efficiency of students, the constant online life has proved to be a real challenge for their mental health. On the other hand, the results of the study revealed the positive aspects of adaptation to pandemic conditions and quarantine measures - awareness of new opportunities for both self-development and the formation of responsibility for life and health at the level of mass consciousness. Of course, to determine the relationship between the positive and negative effects of the COVID-19 pandemic on the mental health of student youth, it is advisable to conduct additional research.

\section{REFERENCES}

1. Kochmar-Tymoshenko S. Shcho take syndrom COVID-stresu ta khto na noho strazhdaie. Interviuz kanadskym psykholohom Stivenom Teilorom [What is COVID-stress syndrome and who suffers from it. Interview with Canadian psychologist Stephen Taylor]. 2020. https://life.pravda.com. ua/health/2020/08/3/241840/ [reviewed 2021.05.10] (in Ukrainian)

2. Vigo D., Patten S., Pajer K. et al. Mental Health of Communities during the COVID-19 Pandemic. The Canadian Journal of Psychiatry. 2020; 65: 681-687. doi: 10.1177/0706743720926676.

3. Taylor S., Landry C., Paluszek M. et al. COVID stress syndrome: Concept, structure, and correlates. Depression and Anxiety. 2020; 37: 706-714. doi: 10.1002/da.23071.

4. Dembitskyi S., Zlobina 0., Sydorov M. et al. Stan psykholohichnoho dystresu sotsialnykh hrup v Ukraini pid chas pandemii COVID-19 [The state of psychological distress of social groups in Ukraine during the COVID-19 pandemic]. Ukrainskyi sotsium. 2020;2: 74-92. (in Ukrainian)

5. COVID-19 Public Opinion Research. 2020. https://wapor.org/resources/ covid-19-public-opinion-research/ [reviewed: 09.05.2021] (in Ukrainian)

6. Yak zhyve molod Lvova v umovakh karantynu [How the youth of Lviv lives in conditions of quarantine] 2020. https://dyvys.info/2020/04/09/yakzhyve-molod-lvova-v-umovah-karantynu-doslidzhennya/ [reviewed: 30.11.2020] (in Ukrainian)

7. Warecka J., Huriy B., Awasiak S. Aktywizacja młodzieży w czasie pandemii COVID-19. Analiza treści konkursu literackiego „Pandemiczna codzienność. Horyzonty Polityki. 2020; 11: 105-123. doi: 10.35765/ hp.1954.

8. Vigo D., Jones L., Munthali R. et al. Investigating the effect of COVID-19 dissemination on symptoms of anxiety and depression among university students. BJPsych Open, 2021; 7(2): E69. doi: 10.1192/bjo.2021.24.
9. Fradelos E., Alikari V., Vus V. et al. Assessment of the relation between religiosity, anxiety, depression and psychological resilience in nursing staff. Health Psychology Research. 2020; 8(1): 30-34. doi: 10.4081/ hpr.2020.8234.

10. Braun V., Clarke V. Using thematic analysis in psychology. Qualitative Research in Psychology, 2006; 3(2): 77-101. doi:10.1191/1478088706qp0630a.

The work is a fragment of the research project «Research Initiatives and Practical Implementation of Social and Political Projects to Resolve Social Problems of Modern Ukraine», state registration No. 0118 U000886.

\section{ORCID and contributionship:}

Iryna I. Boiko: 0000-0002-3347-5585 ${ }^{A, B}$

Olha I. Herus: 0000-0003-1780-3793, ${ }^{B, C}$

Larysa D. Klymanska: 0000-0002-3693-7503 A, B, D, F

Victor Y. Savka: 0000-0002-1751-7562 A, D-F

Liliia Y. Klos: 0000-0001-9972-7450 A, B,D

Mariana V. Shkoliar: 0000-0002-8407-4394 E, F

Valentina Vitale: 0000-0001-7888-7041 ${ }^{E, F}$

\section{Conflict of interest:}

The Authors declare no conflict of interest.

\section{CORRESPONDING AUTHOR}

\section{Larysa D. Klymanska}

Lviv Polytechnic National University

12 Bandera St., 79013 Lviv, Ukraine

tel: +38068-5004696

e-mail: larysa_kl@ukr.net

Received: 04.06.2021

Accepted: 13.10 .2021

A - Work concept and design, B - Data collection and analysis, C - Responsibility for statistical analysis,

D-Writing the article, $\mathbf{E}$ - Critical review, $\mathbf{F}$ - Final approval of the article 


\title{
PECULIARITIES OF BRAIN-DERIVED NEUROTROPHIC FACTOR AND MATRIX METALLOPROTEINASE-9 EXPRESSION DYNAMICS IN PATIENTS WITH PARANOID SCHIZOPHRENIA DEPENDING ON THE DURATION OF THE DISEASE
}

DOI: 10.36740/WLek202111108

\author{
Ivan R. Romash' ${ }^{1}$, Mykhailo I. Vynnyk' \\ 'IVANO-FRANKIVSK NATIONAL MEDICAL UNIVERSITY, IVANO-FRANKIVSK, UKRAINE
}

\begin{abstract}
The aim: To study the expression of brain-derived neurotrophic factor (BDNF) and matrix metalloproteinase-9 (MMP-9) in the blood serum of patients with paranoid schizophrenia and to trace the features of their dynamics depending on the duration of the disease and analyse the correlation between BDNF, MMP-9 serum levels and symptoms severity by using the Positive and Negative Syndrome Scale (PANSS).

Materials and methods: The study included 120 patients, namely 20 patients with paranoid schizophrenia diagnosed less than 3 years ago (Comparison Group) and 100 patients with a diagnosis of paranoid schizophrenia (Study Group): 20 of them have been suffering from this disease from 3 to 5 years (Subgroup I); 10 patients - from 5 to 10 years (Subgroup II); 10 patients - from 10 to 15 years (Subgroup III); 10 patients - from 15 to 20 years (Subgroup IV); 10 patients - from 25 years and more (Subgroup V). The groups did not differ with respect to age or gender. The content of BDNF and MMP- 9 in blood serum was determined by enzyme-linked immunosorbent assay.

Results: BDNF concentration averaged $28.327 \pm 5.32 \mathrm{pg} / \mathrm{ml}$ in the patients of Group I; $25.40 \pm 2.31 \mathrm{pg} / \mathrm{ml}$ in Group Il; $24.32 \pm 3.1 \mathrm{pg} / \mathrm{ml} \mathrm{in} \mathrm{Group} \mathrm{IIl;} 23.8 \pm 1.32 \mathrm{pg} / \mathrm{ml}$ in Group IV; $21.39 \pm 0.97 \mathrm{pg} / \mathrm{ml}$ in Group V; $9.36 \pm 4.38 \mathrm{pg} / \mathrm{ml}$ in Group VI. The expression of MMP-9 in the experimental groups constituted: $942.84 \pm 87.80 \mathrm{pg} / \mathrm{ml}, 1042.84 \pm$ $87.80 \mathrm{pg} / \mathrm{ml}, 1142.53 \pm 77.20 \mathrm{pg} / \mathrm{ml}, 1752.84 \pm 77.80 \mathrm{pg} / \mathrm{ml}, 1542.84 \pm 37.70 \mathrm{pg} / \mathrm{ml}, 2042.74 \pm 47.80 \mathrm{pg} / \mathrm{ml}$, respectively. Decreased BDNF negatively correlated with MMP-9 expression $(r=0.46 ; p<0.05)$.

Conclusions: The development of paranoid schizophrenia was manifested by an imbalance in BDNF level and MMP-9 expression which could affect neurogenesis, synaptic plasticity, ability to learn and remember, therefore, they could be considered as diagnostic markers of the pathology. With the increase in the duration of the studied pathology, BDNF parameters decreased and MMP-9 expression increased. A negative correlation between them was noted.
\end{abstract}

KEY WORDS: paranoid schizophrenia, brain derived neurotrophic factor, matrix metalloproteinase-9, neuroplasticity

Wiad Lek. 2021;74(11 p.l):2728-2732

\section{INTRODUCTION}

The prevalence of schizophrenia in the population is estimated at approximately $0.7-1.0 \%$. According to the Global Burden of Disease Study (GBD) 2017, schizophrenia is one of the most disabling and costly disorders [1-3].

In an attempt to find a neurobiological explanation for schizophrenia, a "disconnection hypothesis" has been offered. According to this hypothesis, the pathogenetic core of schizophrenia is a violation of functional connections between neural networks. According to the scientific data, the disconnection is caused by the dysfunction of N-methyl-d-aspartate receptors (NMDAR) and disorders of modulation of synaptic plasticity which provides the ability to change the sensitivity of the synapse in response to activation of postsynaptic receptors [4]. The involvement of these phenomena in the pathophysiology of schizophrenia has been studied in recent years. The NMDAR hypofunction hypothesis has been proposed to help understand the etiology and pathophysiology of schizophrenia. This hypothesis is based on early observations that NMDAR antagonists can cause the full range of schizophrenia symptoms in normal people. In particular, scientists and clinicians have noticed that if healthy volunteers are administered drugs that are blockers of NMDA receptors (a significant part of them are used for anesthesia), they can contribute to very similar symptoms as in case of schizophrenia, namely delusions, hallucinations, paranoia, disorganization of thinking and speech, etc. $[5,6]$.

In recent years, the concept of neuroplasticity has been formulated. It lies an extraordinary property of nervous tissue to structural and functional rearrangement and restoration of lost neural connections in case of damage [4]. Neurotrophic factors, a group of endogenous polypeptides play an important role in the regulation of neuroplasticity processes. The leading mediator in the mechanisms of neurogenesis and neuroplasticity is considered to be the brain derived neurotrophic factor (BDNF). It is one of the physiologically active polypeptides that regulate the growth and differentiation of neurons in the process of phylogenesis promoting the formation of new synaptic 
connections [7]. As the main mechanism for memory and learning, synaptic plasticity plays an important role in the pathogenesis of schizophrenia, and matrix metalloproteinase-9 (MMP-9) is able to disrupt this synaptic plasticity. According to the scientific data, MMP-9 plays an important role in BDNF maturation on the way to its transformation from proBDNF to biologically active mature BDNF. In addition, in stimulated neurons, the matrix MMP-9 is secreted from dendritic spines, in which short single or multiple protrusions of the postsynaptic membrane of the dendrites come into contact with synaptic expansion. Spiny devices significantly increase the number of synaptic contacts on the neuron, and hence the amount of processed information [8].

According to epy scientific data, BDNF plays an important role in the pathogenesis of the paranoid form of schizophrenia. It is able to stimulate the growth of neurons, axons and dendrites, participates in the formation of synapses and other processes of neuroplasticity. According to the recent scientific data, this property is present not only in early ontogenesis, but also in the brain of an adult, which was previously considered impossible. Decreased serum levels correlate with the severity and duration of the disease and affect the effectiveness of treatment. We also have more and more research on the effects of the BDNF gene on the development and manifestations of schizophrenia as a disease in general $[9,10]$.

BDNF is also closely related to the serotonergic (5-HT) system of the brain, which is actively involved in various behaviors, including aggression regulation, plays an important role in learning processes, namely memory consolidation, sleep regulation, sexual motivation. According to the latest scientific data, BDNF has a protective effect on damage to 5-HT neurons, increasing the number of their axons. Popova NK and co-authors, reviewing the literature and comparing the information with their own research confirmed the positive effect of BDNF on the 5-HT system of the brain, even a month and a half after a single central injection of its synthetic analogue. This unique feature of its action further confirms its exceptional role in the formation of synaptic connections and in neurogenesis [11].

Therefore, as can be seen from the literature analysis, at present, there are limited scientific data on the relationship between BDNF and MMP-9 in case of schizophrenia, and their dynamics depending on the duration of this pathology has not been studied, which determines the relevance of this study [12].

It is apparent that the indicators of BDNF and MMP-9 in the blood serum will be characterized by fluctuations depending on the duration of the disease. Tracing the patterns of the fluctuations will provide a possibility to predict and conduct therapy for this category of patients more rationally.

\section{THE AIM}

The aim was to study the expression of brain derived neurotrophic factor (BDNF) and matrix metalloproteinase-9 (MMP-9) in the blood serum of patients with paranoid schizophrenia and to trace the features of their dynamics depending on the duration of the disease and to analyse the correlation between BDNF, MMP-9 serum levels and the symptoms severity by using the Positive and Negative Syndrome Scale (PANSS).

\section{MATERIALS AND METHODS}

The research was conducted at the premises of the Municipal non-commercial enterprise «Precarpathian regional clinical center of mental health of Ivano-Frankivsk regional council» and «Pohonyansky psychoneurological residential care facility». The diagnosis was verified according to the criteria of ICD-10 (F20.0).

The study included 120 patients. The patients were divided into two groups. Group I (Comparison Group) consisted of 20 patients with Paranoid schizophrenia diagnosed less than 3 years ago and Group II (Study Group) included 100 patients with a diagnosis "Paranoid schizophrenia" diagnosed more than 3 years ago: 20 of them have been suffering from this disease from 3 to 5 years (Subgroup I); 10 patients - from 5 to 10 years (Subgroup II); 10 patients from 10 to 15 years (Subgroup III); 10 patients - from 15 to 20 years (Subgroup IV); 10 patients - from 25 years and more (Subgroup V). The groups did not differ with respect to age or gender.

The main criteria for inclusion in the study groups were as follows: the presence of "Paranoid schizophrenia" diagnosis, individual consent of the patient.

Symptoms of schizophrenia were assessed using the Positive and Negative Syndrome Scale (PANSS). Cases of schizophrenia with the comorbidities of substance-related disorders or mental retardation were excluded.

The concentration of MMP-9 was determined in all subjects by enzyme-linked immunosorbent assay on the device "Immuno Chem-2100, Microplate Reader", using the laboratory kit "The RayBiotech Human MMP-9 Ensyme Immunoassay Kit" (USA) and expressed in $\mathrm{pg} / \mathrm{ml}$.

BDNF indices were determined in all patients in the blood serum by enzyme immunoassay method with the use of RayBio ${ }^{\circledR}$ Human BDNF Ensyme Immunoassay Kit (RayBiotech, Inc. USA).

To minimize assay variance, plasma levels of mature BDNF and MMP-9 were measured in each patient on the same day.

The research was approved by the Bioethics Committee of the Ivano-Frankivsk National Medical University and conducted according to the principles of the Helsinki Declaration. All patients signed a voluntary informed consent before the study.

Statistical processing and visualization of the obtained results was performed using the statistical package of the Microsoft Excel 2016 program. The significance of the obtained results was confirmed on the basis of the calculation of Student's coefficient. Correlation analysis was conducted according to Pearson correlation coefficient. The quantitative characteristics were described using arithmetic mean $(\mathrm{M})$, standard error $( \pm \mathrm{m})$, mode $(\mathrm{Mo})$, median (Me). 
Table I. The results of the correlation analysis between the indicators of the PANSS scale and the indicators of BDNF and MMP-9 in the examined patients

\begin{tabular}{|c|c|c|c|c|}
\hline \multirow{2}{*}{ Indices } & & \multicolumn{3}{|c|}{ PANSS scale indicators } \\
\hline & & PANSS-N & PANSS-P & $\begin{array}{c}\text { PANSS } \\
\text { (general symptoms) }\end{array}$ \\
\hline \multirow{6}{*}{ BDNF (pg/ml) } & Comparison Group & $-0.172^{*}$ & $-0.151^{*}$ & $-0.144^{*}$ \\
\hline & Subgroup I & $-0.252^{*}$ & $-0.365^{* *}$ & $-0.196^{*}$ \\
\hline & Subgroup II & $-0.215^{*}$ & $-0.362^{* *}$ & $-0.298^{*}$ \\
\hline & Subgroup III & $-0.362^{* *}$ & $-0.396^{* *}$ & $-0.234^{*}$ \\
\hline & Subgroup IV & $-0.393^{* *}$ & $-0.316^{*}$ & $-0.365^{* *}$ \\
\hline & Subgroup V & $-0.521^{* * *}$ & $-0.363^{* *}$ & $-0.431^{* *}$ \\
\hline \multirow{6}{*}{$\begin{array}{l}\text { MMP-9 } \\
\text { (pg/ml) }\end{array}$} & Comparison Group & $0.263^{*}$ & $0.135^{*}$ & $0.195^{*}$ \\
\hline & Subgroup I & $0.382^{* *}$ & $0.130^{*}$ & $0.225^{*}$ \\
\hline & Subgroup II & $0.321^{* *}$ & $0.281^{*}$ & $0.237^{*}$ \\
\hline & Subgroup III & $0.352^{* *}$ & $0.315^{* *}$ & $0.361^{* *}$ \\
\hline & Subgroup IV & $0.534^{* * *}$ & $0.372^{* *}$ & $0.397^{* *}$ \\
\hline & Subgroup V & $0.531^{* * *}$ & $0.434^{* *}$ & $0.312^{* *}$ \\
\hline
\end{tabular}

Notes:

* - weak correlation $(p>0.05)$;

** - moderate correlation $(p<0.05)$;

*** - significant correlation $(p<0.05)$.

Table II. The results of the correlation analysis between the indicators of BDNF and MMP-9 in the examined patients

\begin{tabular}{|c|c|c|c|}
\hline \multirow{2}{*}{\multicolumn{2}{|c|}{ Indices }} & \multicolumn{2}{|c|}{ BDNF (pg/ml) } \\
\hline & & $\mathbf{r}$ & $\mathbf{p}$ \\
\hline \multirow{6}{*}{$\begin{array}{l}\text { MMP-9 } \\
\text { (pg/ml) }\end{array}$} & Comparison Group & $-0,234$ & $>0.05$ \\
\hline & Subgroup I & -0.454 & $<0.05$ \\
\hline & Subgroup II & -0.397 & $<0.05$ \\
\hline & Subgroup III & -0.413 & $<0.05$ \\
\hline & Subgroup IV & -0.361 & $<0.05$ \\
\hline & Subgroup V & -0.431 & $<0.05$ \\
\hline
\end{tabular}

\section{RESULTS AND DISCUSSION}

The relationship between BDNF levels and the severity of psychopathology was studied in the course of the research. The results of the correlation between the PANSS scale and the level of BDNF and MMP-9 are shown in Table I.

According to the obtained data, a weak negative relation between the data of the PANSS scale and the BDNF level was noted in the Comparison Group, as well as a direct, positive connection and between PANSS and MMP-9. Whereas mainly moderate correlation was observed in the experimental subgroups. The most significant negative correlation between BDNF and MMP-9 was observed with the manifestations of negative psychopathology. In particular, astrong correlation was recorded between: PANSS-N / BDNF -0.521 $(\mathrm{p}<0.05)$ in Subgroup V patients; PANSS-N / MMP-9 0.534 and 0.531; $(\mathrm{p}<0.05)$ in Subgroup IV and Subgroup V, respectively. The data on the relation of positive symptoms with these values were equally important. A weak negative correlation between the BDNF and PANSS-P was noted in the patients of the Comparison Group. That correla- tion was moderate and negative in all research subgroups. Statistically significant negative correlations were registered between the indicators of general symptoms according to the PANSS scale and BDNF only in subgroups IV and V, constituting -0.365 and $-0.431(\mathrm{p}<0.05)$, respectively. The results of the study of MMP-9 level in the serum of the examined patients are shown in Figure 1.

As can be seen from the data presented, the concentration of MMP-9 in the patients of the Comparison Group constituted $942.84 \pm 87.80 \mathrm{pg} / \mathrm{ml}$, which was $9.38 \%$ less compared to the first experimental subgroup, where this figure constituted $1042.84 \pm 87.80 \mathrm{pg} / \mathrm{ml}$.

MMP-9 constituted $1142.53 \pm 77.20 \mathrm{pg} / \mathrm{ml}$ on average in the patients of Subgroup II, which was by $21.21 \%$ more than in the Comparison group. It constituted $1752.84 \pm$ $77.80 \mathrm{pg} / \mathrm{ml}$ in the Subgroup III, which was by $85.9 \%$ higher compared to the Comparison group. MMP-9 constituted $1542.84 \pm 37.70 \mathrm{pg} / \mathrm{ml}$ in the Subgroup IV, which was by $63.6 \%$ higher than in the Comparison group. It amounted to $2042.74 \pm 47.80 \mathrm{pg} / \mathrm{ml}$ in the Subgroup IV, 

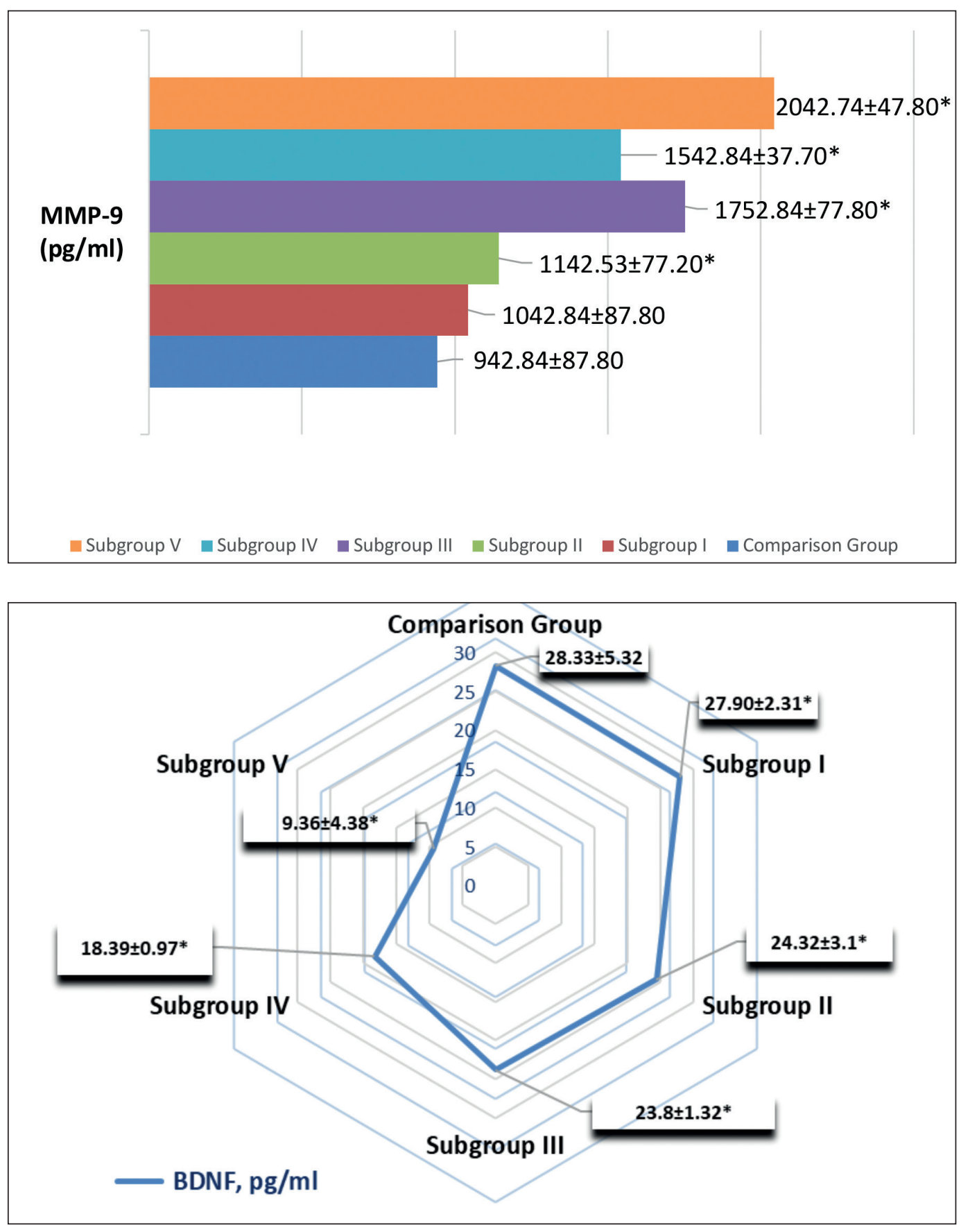

Fig. 1. MMP-9 level in the serum of the examined patients Note: ${ }^{*}-(p<0.05)$ the data are reliable between the comparison and study subgroups.
Fig. 2. BDNF level in the serum of the examined patients Note: ${ }^{*}-(p<0.05)$ the data are reliable between the comparison and study subgroups. which was more than twice as high as in the Comparison group $(\mathrm{p}<0.05)$.

As can be seen from the data presented in Figure 2, BDNF concentration in the patients of the Comparison group averaged $28.327 \pm 5.32 \mathrm{pg} / \mathrm{ml}$, while these values were slightly lower in the main Experimental groups. In particular, this indicator was lower by only $1.4 \%$ in Subgroup I as well as in the Comparison Group and amounted to $27.90 \pm 2.31 \mathrm{pg} / \mathrm{ml}$. It was lower by $14.12 \%$ and constituted $24.32 \pm 3.1 \mathrm{pg} / \mathrm{ml}$ in the Subgroup II. This indicator was lower by $15.96 \%$ and amounted to $23.8 \pm$ $1.32 \mathrm{pg} / \mathrm{ml}$ in the Subgroup III. It decreased by $35.06 \%$ and constituted $18.39 \pm 0.97 \mathrm{pg} / \mathrm{ml}$ in the Subgroup IV., the value of BDNF was lower than in the Comparison group by as much as $66.9 \%$ in the Subgroup V and amounted to $9.36 \pm 4.38 \mathrm{pg} / \mathrm{ml}(\mathrm{p}<0.05)$.

Thus, it should be noted that this figure is inversely proportional to the duration of the disease, and its sharp decline occurs after 5 years of illness. Our data partially coincide with the studies of Yamamori $\mathrm{H}$ et al. [8].

The results of the correlation analysis are shown in Table II. According to the presented data, a significant inverse moderate correlation between MMP-9 and BDNF was observed in the patients of all experimental subgroups. Whereas a weak inverse correlation was noted in the Comparison Group. A similar tendency was observed by Hen- 
driati D and co-authors [13]. Thus, the decrease in BDNF in the patients with paranoid schizophrenia was negatively correlated with MMP-9 expression, and the strength of this relationship increased with increasing duration of the disease. The obtained data confirmed that MMP-9 played a special role in the maturation of BDNF by converting it from proBDNF to biologically active mature BDNF.

\section{CONCLUSIONS}

Paranoid schizophrenia was established to be manifested by an imbalance in BDNF levels and MMP-9 expression being able to affect the processes of neurogenesis, synaptic plasticity. According to the PANNS scale, this affected emotions, thought processes, cognition, caused loss of interest in social and environmental phenomena, contributed to memory impairment, therefore, they could be considered as diagnostic markers of such pathology. With the increase in the duration of the studied pathology, BDNF parameters decreased and MMP-9 expression increased. A negative correlation between them was noted. Therefore, the approach to such patients' treatment should take into account these changes.

\section{REFERENCES}

1. Moreno-Küstner B., Martín C., Pastor L. Prevalence of psychotic disorders and its association with methodological issues. A systematic review and meta-analyses. PLOS ONE. 2018;13:e0195687. doi:10.1371/journal. pone.0195687.

2. Romash I. The role of metformin hydrochloride in complex therapy of disorders of carbohydrate metabolism in patients with paranoid schizophrenia treated with atypical antipsychotics. Mental Health: Global Challenges Journal. 2020;3:45-51. doi:10.32437/mhgcj.v3i1.93.

3. Romash I.B., Mishchuk V.G. The frequency of visceral and phenotypic markers in patients with the combination of undifferentiated connective tissue disease and gastroesophageal reflux disease. Wiadomości Lekarskie. 2020;73 (7): 1492-1498.

4. Mateos-Aparicio P., Rodríguez-Moreno A. The impact of studying brain plasticity. Frontiers in cellular neuroscience. 2019; 13:66. doi:10.3389/ fncel.2019.00066.

5. Lee G., Zhou Y. NMDAR Hypofunction Animal Models of Schizophrenia. Front. Mol. Neurosci. 2019; 12:185. doi:10.3389/fnmol.2019.00185.

6. Adel A. Brain NMDA Receptors in Schizophrenia and Depression. Biomolecules. 2020; 10: 947. doi:10.3390/biom10060947.

7. Leal G., Afonso P.M., Salazar I.L., Duarte C.B. Regulation of hippocampal synaptic plasticity by BDNF. Brain Research. 2015; 1621: 82-101. doi:10.1016/j.brainres.2014.10.019.

8. Yamamori H., Hashimoto R., Ishima T. et al. Plasma levels of mature brain-derived neurotrophic factor (BDNF) and matrix metalloproteinase-9 (MMP-9) in treatment-resistant schizophrenia treated with clozapine. Neuroscience Letters. 2013; 556: 37-41. doi:10.1016/j.neulet.2013.09.059.
9. Janicijevic S.M., Dejanovic S.D., Borovcanin M. Interplay of Brain-Derived Neurotrophic Factor and Cytokines in Schizophrenia. Serbian Journal of Experimental and Clinical Research. 2018. doi:10.1515/sjecr-2017-0031.

10. Manchia M., Primavera D., Deriu L. et al. The longitudinal trajectory of serum brain-derived neurotrophic factor (BDNF) levels in psychotic patients: a prospective observational study. European Neuropsychopharmacology. 2017; 27: 913.

11. Popova N.K., Ilchibaeva T.V., Naumenko V.S. Neurotrophic factors (BDNF and GDNF) and the serotonergic system of the brain. Biochemistry. 2017; 82: 308. doi:10.1134/s0006297917030099.

12. Bitanihirwe B.K.Y., Woo T.-U.W. A conceptualized model linking matrix metalloproteinase-9 to schizophrenia pathogenesis. Schizophrenia Research. 2020; 218: 28-35. doi:10.1016/j.schres.2019.12.015.

13. Hendriati D., Effendy E., Amin M.M. et al. brain-derived neurotropic factor serum level and severity symptom of bataknese male patients with Schizophrenia in North Sumatera, Indonesia. J Med Sci. 2019; 7(12):1957-1961. doi:10.3889/0amjms.2019.550.

The work is a fragment of the research project "Complications of therapy with psychotropic agents in scase of schizophrenia and depressive disorders" (№ state registration 0115U004881) on the Department of Psychiatry, Addiction and Medical Psychology, Ivano-Frankivsk National Medical University.

\section{ORCID and contributionship:}

Ivan R. Romash: 0000-0002-6591-6613 A-F

Mykhailo I. Vynnyk: 0000-0002-8822-3174 ${ }^{E, F}$

\section{Conflict of interest:}

The Authors declare no conflict of interest.

\author{
CORRESPONDING AUTHOR \\ Ivan R. Romash \\ Ivano-Frankivsk national medical university \\ 5/7 Pylyp Orlyk st., 76010 Ivano-Frankivsk, Ukraine \\ tel: +380976430271 \\ e-mail: iromashr@gmail.com
}

Received: 05.05 .2021

Accepted: 20.09.2021

A - Work concept and design, B - Data collection and analysis, C - Responsibility for statistical analysis, D-Writing the article, E-Critical review, F - Final approval of the article 


\title{
PERCEPTION OF TIME PERSPECTIVE IN WIDOWS OF LAW ENFORCEMENT OFFICERS DURING THE FIRST YEAR AFTER THE LOSS
}

DOl: 10.36740/WLek202111109

\author{
Larysa A. Rybyk ${ }^{1}$, Olha Sandal' ${ }^{2}$ Kateryna S. Honcharenko ${ }^{3}$, Oleksandra Manzii ${ }^{4}$, Olha Podilchak ${ }^{5}$, \\ Stanislav Andreichuk ${ }^{4}$, Monica Paduraru ${ }^{6}$ \\ 'NATIONAL ACADEMY OF INTERNAL AFFAIRS, KYIV, UKRAINE \\ 2NATIONAL ACADEMY OF EDUCATIONAL SCIENCES OF UKRAINE, KYIV, UKRAINE \\ ${ }^{3}$ DRAGOMANOV NATIONAL PEDAGOGICAL UNIVERSITY, KYIV, UKRAINE \\ 4LVIV POLYTECHNIC NATIONAL UNIVERSITY, LVIV, UKRAINE \\ ${ }^{5}$ KYIV NATIONAL UNIVERSITY OF TRADE AND ECONOMICS, KYIV, UKRAINE \\ ${ }^{6 B}$ BUCHAREST UNIVERSITY OF ECONOMIC STUDIES, BUCHAREST, ROMANIA
}

\begin{abstract}
The aim: The aim of this study is to examine the impact of the loss of a loved one on the perception of subjective time as well as analyse the changes occurring during the psychological care programme, in which special attention was given to finding a new meaning in life.

Materials and methods: The study was undertaken with 240 wives of deceased law enforcement officers. The age of the respondents ranged from 28 to 56 years. According to the results of the analysis of personal data and interviews obtained during the empirical study, experimental and control groups were formed - 32 women who had been widows for up to one year and expressed a desire to receive psychological assistance formed an experimental group (EG), while 34 others formed a control group (CG). They subsequently participated in the formative part of the experiment which provided 10 months of psychological support with preliminary and repeated psycho-diagnostic testing. Results: The article theoretically analyses studies by foreign and domestic experts on a person's perception of his psychological time under the influence of emotional trauma. It presents the results of a comparative experimental psychological examination of the widows of law enforcement officers to determine the tendency for changes in the perception of the time perspective while experiencing grief.

Conclusions: A break caused by a loss, especially that of a loved one, disrupts a holistic view of life. Such breaks result in mental health problems, which in turn impact social relations and social realisation. Timely psychological assistance helps solve problems of legitimising behavioural change and accumulating resources for adapting to changing life scenarios.
\end{abstract}

KEY WORDS: bereavement, time perspective, widows, grief, loss

Wiad Lek. 2021;74(11 p.l):2733-2737

\section{INTRODUCTION}

Everyone, sooner or later, must deal with losing their loved ones. Loss causes grief and suffering, which can lead to significant psychological and physiological problems with longterm consequences [1-6] on multiple levels, which manifest in the emotional, cognitive and behavioural spheres. The individual begins to experience a new psychological reality which requires adaptation to new conditions of existence.

Grief is a normal process and one adapts to it over time, experiencing certain stages and reorganising their life. Loss impairs the mental health of the individual to varying degrees.

However the reorganisation of life and the degree of well-being depend on many factors. In this article, we will consider one such factor, which in our opinion, is the main one - the impact of loss on the perception of subjective time.
Previous research has shown that subjective perception of time has qualitative differences from objective astronomical time. People in general are characterized by individual features of the sense of time: the quantity of events or their absence, slow or dynamic time, smooth or jerky time. The revealed relationship between the past, present and future, when a person experiences the present, is associated with thoughts about the future and memories of the past' [3]. Thus, thoughts of the present, filled with pain and suffering, affect the development of the future, particularly the form it will take and one's future self-perception. This process may be harmful for one's current mental health.

Even Michael Bury proved that suffering and illness are special kinds of destructive experiences. At the same time, such suffering during the search for new patterns of existence enables one to find a deeper meaning of experience [1]. 
It is difficult to find such meaning while experiencing emotional tumult, mental disorientation and a flood of memories. The death of a loved one can engender an existential crisis and lead to a spiritual search [7]. There is then a gradual transformation of meaning structures, which is reflected in one's self-perception [5] and future.

Recently, an increasing number of studies confirm the positive effect of psychological intervention regarding bereavement and for the prevention of pathological manifestations of grief $[4,6]$. However, at the same time, while there is frequent emphasis on the need to reorganise life without the deceased and to learn to set goals for a future without them, research to study the perception of past, present and future after the loss of a loved one is lacking.

\section{THE AIM}

The aim of this study is to examine the impact of the loss of a loved one on the perception of subjective time, as well as to analyse the changes inspired by a program of psychological care in which special attention is paid to finding a new meaning in life.

\section{MATERIALS AND METHODS}

A study was undertaken in 2015-2019, in which a set of diagnostic, corrective and therapeutic methods was used to verify the theory and prepare a practical guideline. The study was conducted on 240 widows of deceased law enforcement officers. The age of the respondents ranged from 28 to 56 years: $<30$ years -12 people, $31-49$ years -213 people, $>50$ years -5 people.

According to the results of the analysis of personal data and interviews obtained from the respondents, experimental and control groups were formed - 32 women who had been widows for up to one year and expressed a desire to receive psychological assistance formed an experimental group (EG), while 34 others formed a control group (CG). They subsequently participated in the formative part of the experiment, which provided 10 months of psychological support with preliminary and repeated psycho-diagnostic testing.

To analyse the impact of loss on the perception of time, the Zimbardo Time Perspective Questionnaire (ZTPI) was chosen. This technique is aimed at diagnosing the system of personality relations to the time continuum.

Time perspective is a subjective perception of the psychological concepts of the past, future and present, whereby time and its manifestations are imbued with psychological meaning. There is an individual tendency to remain preoccupied with a particular time period, resulting in an orientation towards either the past, present or future.

The questionnaire consists of 56 items, and the answers are classified according to a 5-point Likert scale. The study investigated five indicators: the factors of perception of (a) the negative past, (b) positive past, (c) hedonistic present, (d) fatalistic present and (e) degree of future orientation.

The obtained data was analysed using the program Statistical Package for the Social Sciences (SPSS) Statistics 23.
The calculation and comparison to determine the factor incremental value from the first test to the second were performed according to Student's t-test.

The test and retest were separated by an interval of 12 months, and the result was determined by comparing the indicators of the experimental and control groups.

\section{RESULTS}

Respondents of both groups showed an identical orientation during the initial study.

Negativism is usually associated with guilt as well as an 'unrealised life' or individual subjective reconstruction of events (did not pay enough attention, did not like, did not go fishing, etc). Orientation towards the 'negative past' was observed in $28.1 \%$ of the respondents in the EG and $32.3 \%$ in the CG (Figure 1, Figure 3).

The ones who orient themselves towards the 'hedonistic present' have the ability to have fun 'here and now', or in the current moment. No respondent from either group demonstrated this, however.

'Emphasis on the future' is the ability to plan and succeed but also a source of anxiety. The future affects decision-making and the choice of action. This tendency was seen in $6.25 \%$ of the respondents in the EG and $1.2 \%$ in the CG (Figure 1, Figure 3).

The 'positive past' has an emotional colouration since it relates to subjective reality rather than an objective reconstruction of past events - it provides an escape from reality. A harmonious combination of future orientation and a positive perception of the past is interpreted as the search of own resources for achieving goals. This was witnessed in $15.6 \%$ of those in the EG and $25 \%$ in the CG (Figure. 1, Figure. 3).

Those oriented towards the 'fatalistic present' have a high risk of personal pathology, such as depression or anxiety. It was exhibited by $50 \%$ of the respondents in the EG and $38.2 \%$ in the CG (Figure 1, Figure 3).

After the initial study, psychological assistance - a dynamic construct to guide a person through the clinical stages of grief and loss - was offered to the women in the programme. Psychological assistance is also systematised and easy to plan; it remains focused on the mental state, does not limit the psychologist to choosing between psycho-corrective and psycho-therapeutic measures and has a clear methodology.

The fact that law enforcement psychologists had the opportunity to communicate with the family of the deceased while notifying them of the death, made psychological assistance possible at an early stage of grief.

\section{UNIT - 'CRISIS SUPPORT'}

This stage denotes the end of the stage of shock, numbness, terror or protest, and the transition to the stage of psychogenic response to acute grief.

The main tasks include gathering information, determining the dynamics of mental states and helping the client 

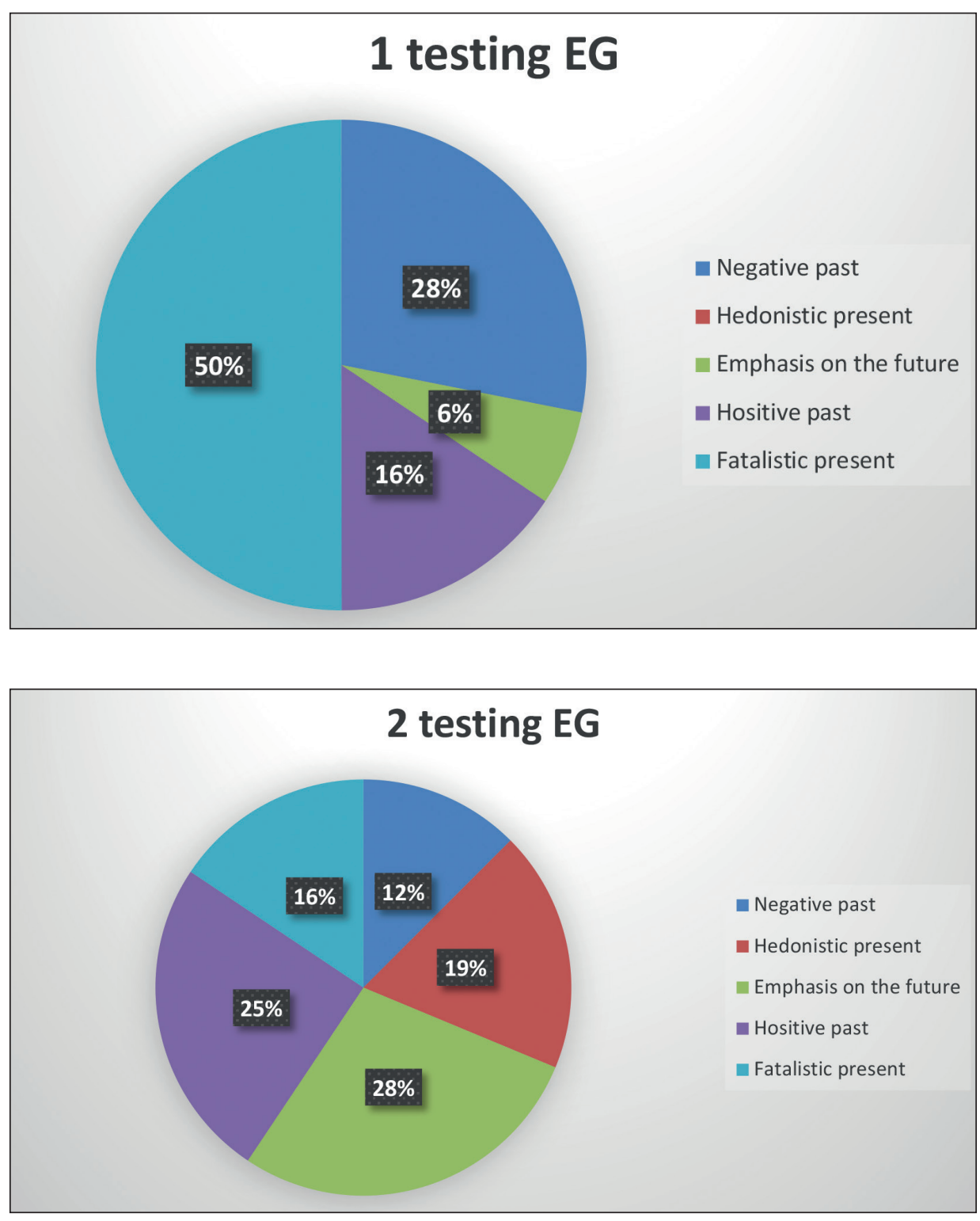

Fig. 1. First test in the experimental group

Fig. 2. Second test in the experimental group verbalise thoughts accumulated during the period of trauma. Thus, the ability to express emotions, the level of adaptability, openness and even suicidal ideation are diagnosed.

The methodology of working with a pathological reaction constitutes a psychodynamic approach within the framework of general psychoanalytic theory. Thus, the work on pathological reactions is based on the general principles of psychoanalytic theory, relying specifically on the theory of personality, which applies to both the norm and the pathology.

Form of work - individual and group.

\section{UNIT - 'SEARCH FOR A NEW MEANING'}

At this stage, there is a search for the meaning of the situation. Although the trauma of death destroys a part of oneself, it makes the gifts of destiny appear more prominent - there is development of such qualities that would not have appeared under more favourable circumstances, but the acceptance of these 'gifts' is possible only by accepting the loss.
The methodology of work draws from the domain of existential psychology through the basic knowledge of human existence.

Form of work - individual.

\section{UNIT - 'REORGANISATION OF LIFE AND THE ORGANISATION OF A NEW SOCIAL ENVIRONMENT'}

At this stage, we offer psychotherapy for reconstructing the future and preventing the recurrence of negative experiences from the past and present in the future.

The methodological basis of this block is a combination of concepts from behaviourism and cognitivism.

Form of work - individual and group.

The time perspective of the participants changes, as shown by the dynamics of indicators in Figure 3. During the period of participation in the psychological support programme, the orientation towards the future increases 

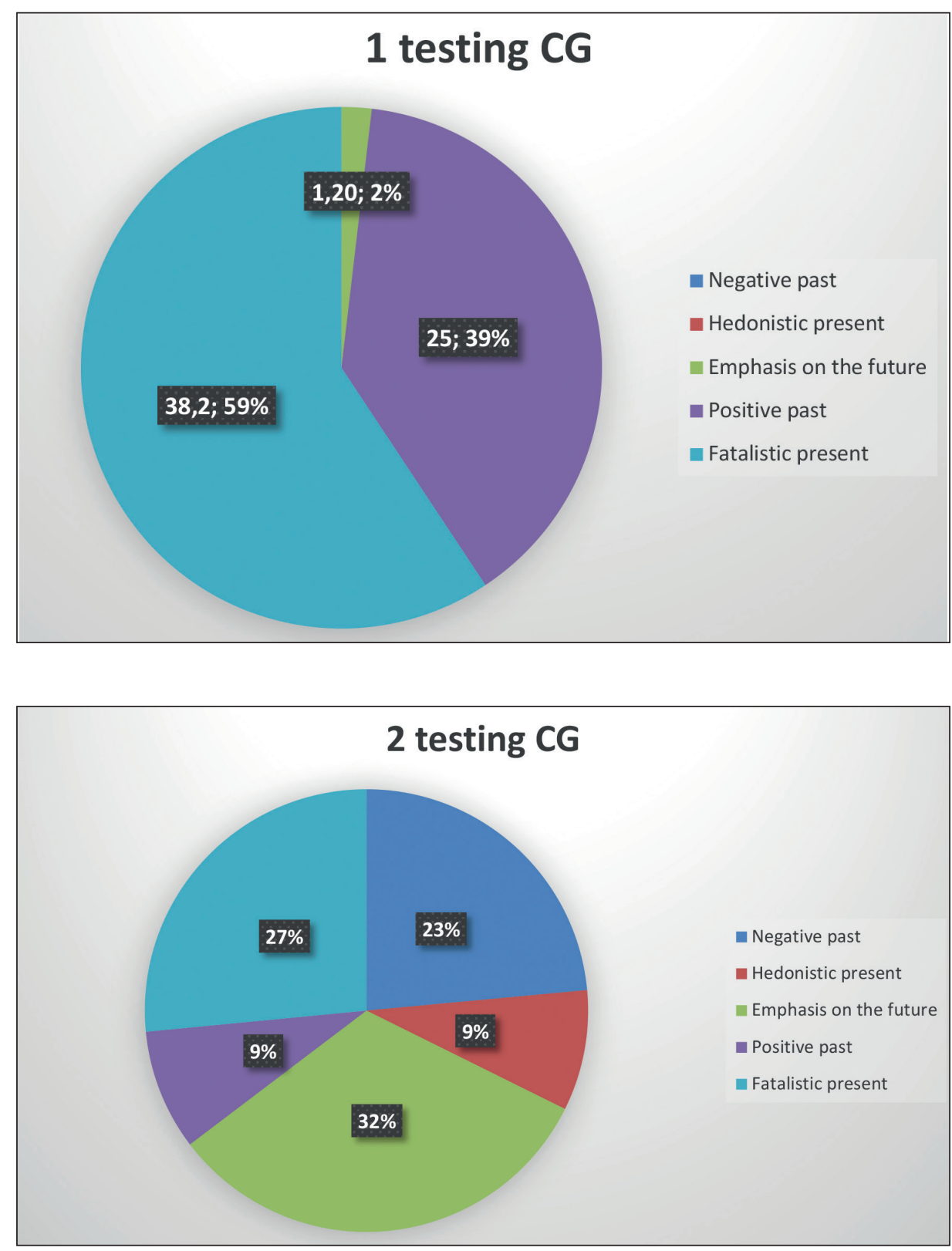

Fig. 3. First test in the control group

Fig. 4. First test in the control group steadily whereas the fatalistic attitude towards the present, along with positive or negative perception of the past, diminishes.

During the retest, the indicators for orientation towards the 'negative past' changed by $12.5 \%$ and $23.5 \%$ respectively (Figure 2, Figure 4).

Negativism is usually associated with guilt as well as an 'unrealised life' or individual subjective reconstruction of events (did not pay enough attention, did not like, did not go fishing, etc). During the retest, orientation towards the 'hedonistic present' was observed in $18.75 \%$ of the respondents in the EG and $8.8 \%$ in the CG (Figure. 2, Figure. 4). The ones who orient themselves towards the 'hedonistic present' have the ability to have fun 'here and now', or in the current moment. This may be viewed as a positive return to life.

'Emphasis on the future', in the retest, is seen in $28.1 \%$ of the respondents in the EG and $32.3 \%$ in the CG (Figure
2, Figure 4). It is the ability to plan and succeed but also a source of anxiety. The future affects decision-making and the choice of action.

The focus on the 'positive past' changed for respondents in the EG from $15.6 \%$ to $25 \%$, and from $25 \%$ to $8.8 \%$ for those in the CG (Figure 2, Figure 4). Thus, the indicators decreased in one group and increased in the other. The past has an emotional colouration since it relates to subjective reality rather than an objective reconstruction of past events - it provides an escape from reality. A harmonious combination of future orientation and a positive perception of the past is interpreted as the search of own resources for achieving goals.

During the retest, the indicators for an orientation towards the 'fatalistic present' changed significantly - it was observed in $15.6 \%$ of respondents in the EG and $26.5 \%$ in the CG (Figure. 2, Figure. 4). Those oriented towards the 'fatalistic present' have a high risk of personal pathology, 
such as depression or anxiety. This shows that a significant number of women have now ceased to consider themselves disadvantaged and given up 'obeying fate'.

We would also like to emphasise that $5 \%$ of the respondents had a balanced time perspective.

\section{DISCUSSION}

This study examined the perception of subjective time after the loss of a loved one and charted the change in perception for a year after the loss, with psychological support and through independent experience.

In our research, we assume that the loss of a loved one is an especially debilitating experience that affects the overall perspective of life and mental health. Perhaps the perception of one's future is associated with the general ability to adapt when experiencing difficult life situations. However, we did not set ourselves the goal of studying the relationship between the level of adaptation, perception of subjective time, peculiarities of the coping strategies chosen when experiencing loss and transformation of the concept of self $[5,6]$. Instead, we observed the changes that took place and evaluated the effectiveness of the psychological intervention.

Once again, we focus on the value of psychological intervention in the first few months after the loss. The magnitude of impact of the loss, manifested by the grief symptoms, is usually less, and calls into question the value of the results [2]. However, even minor positive trends give the hope that people who are experiencing bereavement will be able to shift their focus from the past to the future, with systemic psychological support. At the same time, they will be able to turn their attention to the present, thus reducing the level of influence of external factors on the perception of one's life and its fatality. They will eventually regain control over their lives and find resources for setting goals and building a future perspective.

\section{CONCLUSIONS}

A break caused by a loss, especially that of a loved one, disrupts a holistic view of life. It results in mental health problems, which in turn impact social relations and social realization. Timely psychological assistance helps solve problems of legitimising behavioural change and accumulating resources for adapting to changed life scenarios.

\section{REFERENCES}

1. Bury M. R. Chronic illness as biographical disruption. Sociological Health IIIn. 1982; 4:167-182. doi: 10.1111/1467-9566.ep11339939.
2. Johannsen M., Damholdt M.F., Zachariae R. et al. Psychological interventions for grief in adults: A systematic review and meta -analysis of randomized controlled trials. J Affect Disord. 2019; 253:69-86. doi: 10.1016/j.jad.2019.04.065.

3. Kazberov P., Novikov A. Characteristics of temporaryprospects at personsconvicted for extremist and terrorist activity. Modern problems of science and education. 2015; 2(2):47.

4. Pittman A.L., Rantell K., Moran P. et al. Support after severe loss of suicide and other sudden deaths: a cross-sectional study of 3432 young people who lost loved ones, in the UK. BMJ Open. 2017; 7 (5): e014487. doi: 10.1136/bmjopen-2016-014487.

5. Rybyk L. Analysis of the transformation of the self-concept of wives of dead law enforcement agents in case of experience of loss. Naukovyi visnyk publichnoho ta pryvatnoho prava. 2018;6 (1):54-61.

6. Rybyk L. Psychological help during the loss - can we help people to survive grief? Psychological Journal: Scientific Review. 2018; 20:61-77.

7. Wong P.T.P.Transformation of grief through meaning: Meaning-centered counseling for bereavement. Existential and spiritual issues in death attitudes. New York, NY: Lawrence Erlbaum Associates. 2008, 375p.

\section{ORCID and contributionship:}

Larysa A. Rybyk: 0000-0002-3280-1406 ${ }^{A-D, F}$

Olha Sandal: 0000-0002-4171-4814 ${ }^{E, F}$

Kateryna S. Honcharenko: 0000-0003-1162-9464 E,F

Oleksandra Manzii: $0000000264802307^{E, F}$

Olha Podilchak: 0000-0002-9654-1914 E,F

Stanislav Andreichuk: $0000000332267300^{E, F}$

Monica Paduraru: 0000-0002-0068-5885 E,F

\section{Conflict of interest:}

The Authors declare no conflict of interest

\author{
CORRESPONDING AUTHOR \\ Larysa A. Rybyk \\ National academy of internal affairs \\ 1 Solomianska Square, 03035 Kyiv, Ukraine \\ tel: +380982456619 \\ e-mail:2217953@gmail.com
}

Received: 10.05.2021

Accepted: 22.09.2021

A - Work concept and design, B - Data collection and analysis, C - Responsibility for statistical analysis, D-Writing the article, $\mathbf{E}$-Critical review, $\mathbf{F}$ - Final approval of the article 


\title{
EMOTIONAL POTENTIAL IN THE CHILDREN'S TEAM
}

DOI: 10.36740/WLek202111110

\author{
Tatiana I. Svatenkova, Alexander V. Svatenkov \\ MYKOLA GOGOL NIZHYN STATE UNIVERSITY, NIZHYN, UKRAINE
}

\begin{abstract}
The aim: To investigate the group psychological work influence on the children emotional intelligence development and the processes of psychological stability and cohesion in a sport team.

Materials and methods: We used the comprehensive diagnosis of the child's personality and status in the group ( $n=622$ ). The main accent was made on the level of emotional intelligence (EQ) and sociometric status of the child. The main hypothesis: the higher the child 's EQ level, the higher its sociometric status. The standard PASW Statistics method was used to process the statistics.

Results: Sociometric tests: 223 children had a low sociometric status (36\%); 242 - satisfactory and within the norm limits (39\%), 75 - above the average (12\%), and only 81 had a high sociometric status (13\%). The EQ level indicators (integrative level): 317 respondents had a low EQ level (51\%); 218 - the average level (35\%) and only 87 respondents had a high El level (14\%).

Conclusions: The hypothesis is confirmed. After the implementation of the author's program for adaptation and the child emotional intelligence development, we have results: Sociometric test: only 56 children have lower sociometric status (9\%); 144 - satisfactory and average (23\%); 223 - above average (36\%) and 199 - high sociometric status (32\%). EQ level (integrative level), we also have positive changes: only 111 respondents remained with a low level of emotional intelligence (18\%); 386 developed the level of emotional intelligence to the average (62\%) and 125 had a high level of emotional intelligence (20\%).
\end{abstract}

KEY WORDS: emotional intelligence, interpersonal relationships, cohesion, mental health

Wiad Lek. 2021;74(11 p.l):2738-2742

\section{INTRODUCTION}

Increased interest in the study various groups that perform joint activities in social, organizational, economic, sports psychology and work psychology nowadays. The urgency is $[1-8]$ :

- the fast changing forms of work organization based on the high economic interest and responsibility all members of the group;

- relative production-economic and organizational-managerial independence of labor collectives, which contributes to the self-organization development and self-government forms improvement;

- the team fitness issue is becoming more and more relevant.

The sport team is a small group united by the purpose, traditions, meanings and system of individuals` behavior. This is manifested especially brilliantly in the sports team because of the psychological characteristics of a team member, his status, the volitional component, etc. Interpersonal relationships may form a different psychological climate depending the formed group. We understand the more or less stable prevailing team mood under this notion. Each member takes part in shaping the psychological climate. Positive or negative team mood is induced from one person to another, determining the emotional mood, behavior, and efficiency.
The problem of optimizing the athletes' interactions in the team has a special place among the socio-psychological problems working with the group. The development of stable and adequate interpersonal relationships is one of the sports psychologist tasks. The intra-group relations development and the individual group members' emotional intelligence development helps to increase the effectiveness and coherence in the sports team. It is best to develop this in junior and children's teams.

Daniel Goleman believes that there are five compulsory components of emotional intelligence [1]:

Self-awareness. The ability to recognize and understand your own emotions is an important part of emotional intelligence.

Self-regulation or Self-management. Self-regulation implies the emotions expression in an adequate manner. Self-management skills relate to the emotions you feel at any given time or in any given circumstance and how well you manage them. Self-control is a fundamental part, but other aspects relate to what you do then: whether you behave in a way which is recognized as 'good' or 'virtuous' or not.

Communication skills or social skills. The ability to interact positively with other people. Here are some important social skills: active listening, verbal communication skills, non-verbal communication skills, leadership and ability to persuade. 
Empathy. Empathy helps us to develop a stronger understanding of other people's situations.

Self-motivation. Self-motivation includes our personal drive to improve and achieve, commitment to our goals, initiative, or readiness to act on opportunities, and optimism and resilience. Self-motivation and personal time management are key skills in this area.

\section{THE AIM}

The aim is to highlight the problem of development and correction the child emotional intelligence by involving in temporary children's environment (the recreation program "Children's Camp "Zefir"). The work organization is based on the competent approach, taking into account the individual and socio-psychological peculiarities of the child development in accordance with age and carried out under the psychologist supervision. This approach deserves special attention due to the unique combination of socio-pedagogical and individual-psychological approach and 17-year experience working with children the heads of the program: the Ph.D. (psychological sciences) Tatiana I. Svatenkova and Ph.D. (social-pedagogical sciences) Alexander V.Svatenkov.

\section{MATERIALS AND METHODS}

The special approach to the work organization with children is implemented within three years (2016-2019) on the base of the recreation program "Children's Camp" Zefir ". It is based on the harmonious combination of physical, psychological, creative, intellectual, emotional, social, individual methods influencing the child's personality development. During these years 622 children took part in the research, including 263 junior school age (6-10 years). Pre-trained psychologists and social workers who are selected during the year and receive special training in mentor courses worked with children. The diagnostic toolkit consists of the following techniques:

1. Sociometric survey [2].

2. Diagnosis of "emotional intelligence" (N. Hall) [3].

3. Methodology for diagnosing the aggressiveness level [4].

4. The child's self-esteem diagnostic method "Stages" [4].

5. The child emotional state diagnostic "Cactus" [4].

6. An integrated method for diagnosing the child's psychological characteristics "Constructive drawing of men from geometric shapes" [4].

The study was conducted with the parents written consent. An agreement on non-disclosure of children's personal data has been signed. We show only the general results of the study and the children age. Other data is encrypted.

\section{STAGE FIRST}

Psychological diagnostics. Psychological peculiarities research. It was the second day the children's stay in the team. We used the above tests.

\section{STAGE TWO}

Analytical. We selected each team appropriate psychological exercises and tasks corresponding to age for the psychological characteristics development. We compiled psychological and pedagogical recommendations for tutors how to work individually with each child and in group interaction.

\section{STAGE THIRD}

Forming. The tutors, together with the psychologist, organized special planed work throughout the stay period. We used training in teams, individual counseling, exercises on creativity development, cohesiveness, increasing communicative and emotional competence, mutual support - all important competences of the child.

\section{STAGE FOUR}

Control. Child's psychological characteristics diagnosis using the methods described above. We conduct it in the last day staying children in a temporary team. The results give us an opportunity to evaluate the quality of the work performed.

\section{STAGE FIFTH}

Analytical and correctional. Analyze the tests results and the work done. We adjust the further program working with children.

The basic method of diagnostics was sociometric testing. It gives an opportunity to show the sociometric status of each child in the team, the preferences and antipathies in group, identify leaders and outsiders. It is known that the level of emotional intelligence $[1,89]$ has a decisive influence on the level of human adaptability in a team and the quality of its social contacts $[1,90]$. We used the PASW Statistics method to process and compare the results.

\section{EXPERIENCE REPORT}

The diagnosis results of the emotional intelligence level are the basis for individual approach to organize work with the child. Other methods provide information about the child 's emotional state, the self-esteem level, abilities, orientation and overall child's personality development level. We gathered results working with different ages children for three years -27 periods in the camp.

It is appropriate to reveal the results using sociometry and emotional intelligence (EQ) level diagnosis. The testing procedure took place at the beginning of work (on the 2nd day of arrival) and on the last day a child staying on rest (11 or 12 day). The first testing procedure results for three years $(n=622)$ :

1. Sociometric tests: 223 children had a low sociometric status (36\%); 242 - satisfactory and within the norm limits (39\%), 75 - above the average (12\%), and only 81 had a high sociometric status (13\%). 
2. The EQ level indicators (integrative level): 317 respondents had a low EQ level (51\%); 218 - the average level (35\%) and only 87 respondents had a high EI level $(14 \%)$.

The adaptation training program included the 5 EQ components development based on the model D. Holman. Self-awareness developed in the individual work with the child and through the children's participation in forum theaters and psychodrama presentations. Develop and correct the child's emotions self-control, self-motivation, empathy and expand the communication skills range easier in-group settings.

We provided specially created socio-psychological games for children (based on the game "Mafia"), which motivate children to control emotions, identify the emotional state of another. Children develop emotional intelligence, communicative competence, general intelligence and empathy using co-operations and interactions, observation, verbal and non-verbal means in communication.

The "Candle" is the children 's daily group dialogs - the day results. They have held in a comfortable, trusting form, which gives the opportunity to have heard and not convicted to anyone. The tutor manages the conversation process and motivates the emotion manifestation, teaches to recognize and identify their own emotions and express them in right way to be able to reveal abilities and talents in the group.

\section{RESULTS}

The optimal adaptation training program developing the children's EQ level was formed on the basis diagnostic data. This program consists of 3 lessons -9 hours in general ( 3 hours each) - spent in the first three days the child's staying in a new team. Individual consultations with the psychologist and the optimal group work were based on the general group EQ level and the test results [5]. We have significant changes after the competence approach program implementation. The second testing procedure results for the three years:

1. Sociometric test: only 56 children have lower sociometric status (9\%); 144 - satisfactory and average (23\%); 223 - above average (36\%) and 199 - high sociometric status (32\%).

2. EQ level (integrative level), we also have positive changes: only 111 respondents remained with a low level of emotional intelligence (18\%); 386 developed the level of emotional intelligence to the average $(62 \%)$ and 125 had a high level of emotional intelligence (20\%).

Imagine the results graphically.

The positive dynamics, confirmed by the three years results, helped to develop a training program for working with children during the year, the purpose is to harmonize the all child 's competences development. The "Alternative" training program consists of four main blocks, which have aimed at both self-knowledge and the acquisition the necessary knowledge, skills and abilities. In particular:

1. Self-knowledge and professional self-determination
This block gives knowledge about human - the nervous system, temperamental features, psychological qualities and character, memory, thinking, etc. This enable each participant not only to understand who he is, but also to clearly imagine who he wants to be in the future and how to do it.

\section{Communication and self-presentation}

The participants master the knowledge, skills and abilities in establishing interpersonal contact, finding mutual understanding, overcoming communication barriers, conflicts and ways their solution, etc. Participants learn self-presentation techniques in various social communities and groups, public speaking skills etc.

\section{Leadership and organizational abilities}

Knowledge about the leader`s functions, his personality traits, the group dynamics, the basis for the interaction in the group establishment, the group decisions development; analyze fears and obstacles on the way to leadership. They determine the current level of organizational skills, design and implement a program for their own self development.

4. Time and transpersonal life path perspectives [6]

This block devotes to the personal safe behavior development, familiarity with the gender roles peculiarities and the family relationships harmony. They learn to take responsibility for their own actions and words, think positively, structure their free time, plan their lives and engage in self-development.

\section{DISCUSSION}

Scientists recognized the role of emotional intelligence in our life and society by the long psychological research and experiments since the end of the twentieth century [7]. Emotional intelligence is the ability to recognize, use, understand and manage emotions in a positive way to reduce stress, communicate effectively, identify empathy with others, and be able to respond to life challenges and conflict resolution.

The EQ developing group method for children - training - combines the group influence practice, the group relationships and imitation development, etc. The most effective is the child's observation and attention development, the use art therapeutic methods, non-violent communication as a personal interaction direction and the effective form of correction the emotional and behavioral features, verbal therapy, respiratory practices and the empathy development through the creation a special communication atmosphere in group.

Helen Langer the professor of psychology at Harvard University, said that attentiveness is an active process of marking new things for the child $[6,398]$. It helps to be in present and makes you to be more sensitive to contexts and perspectives. High EQ and attentiveness leads to the life fullness in its external and internal manifestations.

The emotional intelligence control assisted by the fact that the emotional intelligence itself becomes an intellectual ability to understand their own and others' 

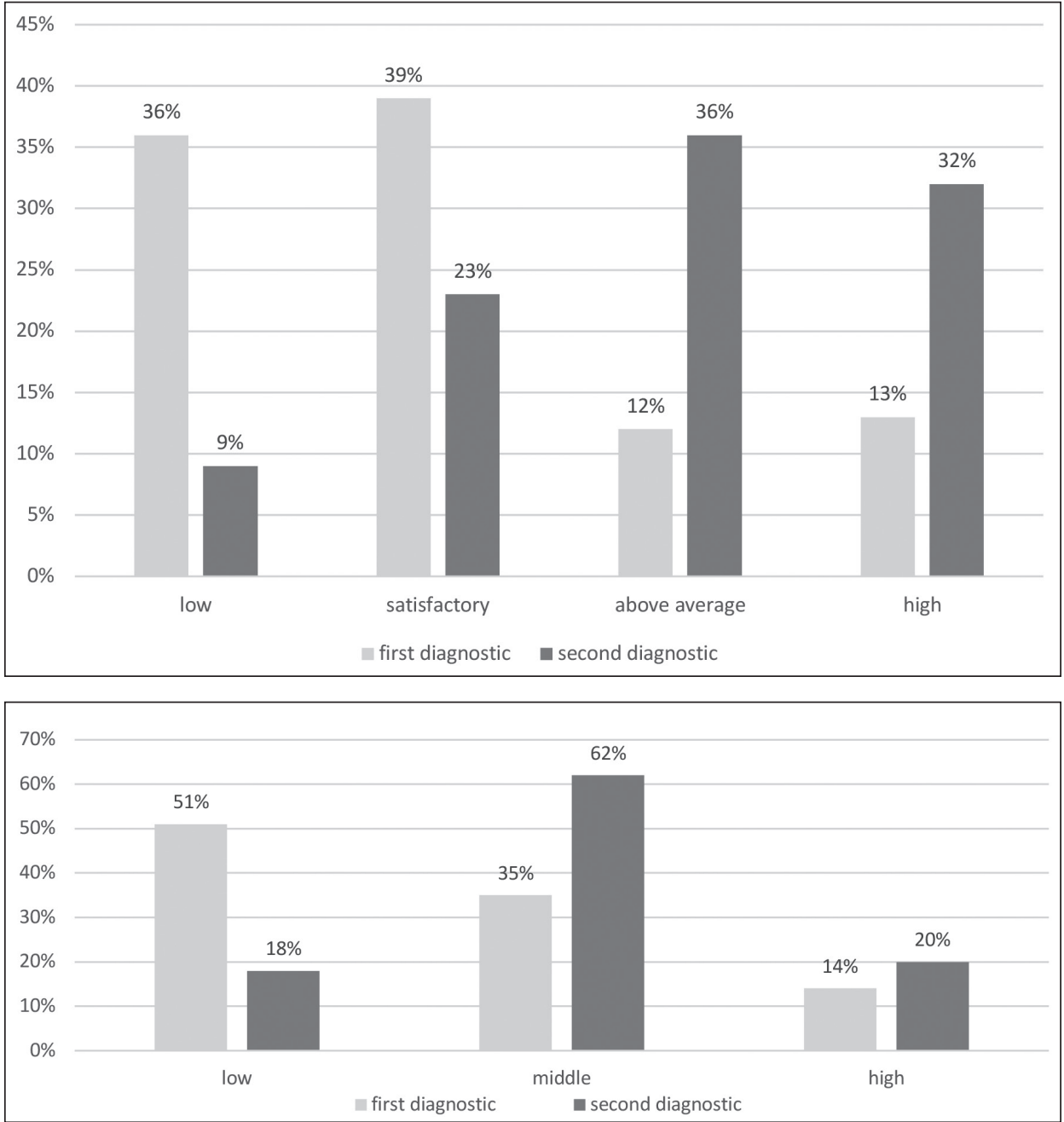

Fig. 1. Diagnosis of the child's social status

Fig. 2. Diagnosis of the level of emotional intelligence feelings, to rely on others and build relationships with them on the basis of trust and empathy. Abilities and skills can develop through learning. The EQ can also be the ability to combine rational and emotional to move forward effectively.

The child`s EQ plays an important role in the sports team unification and successful team is a consequence of the emotional development all group. The post-traumatic stress management issues, the sports team development dynamics, individual work with the players and the motivation for success formation remain open.

The EQ helps to regulate conflict situations in team, yet the practical psychologist work in the sport field is not limited only to the issue of group rallying [8].

The children's emotional intelligence development, along with the physical potential development through sports, helps to harmonize the right and left hemispheres activities of the brain [9]. This enables the child to be not only physically active, but also to develop as a person, improving the quality of mental health and the level of adaptation in society. A high mental health level, developed emotional intelligence, a high level of adaptation and motivation for personal development are the key to the child's potential successful realization.

\section{LIMITATIONS AND STRENGTH OF THE STUDY}

Our research was conducted within the strict timeframe and the summer period of children's rest. That is why it is important to say that the regular sports ' psychologist work with a children team remains unexplored.

\section{CONCLUSIONS}

The several factors combination in working with children 's junior sport teams are actual.

First: the preliminary systematic mentors ' training according to the aim - harmonious combination of child 's physical and psychological development - is very important.

Second: the socio-pedagogical and individual psychological approaches combination in working with a person and a team.

Third: the successful combination of different methods influencing the personality (group and individual) and the use of different forms and methods working with children; competent approach and use diagnostic methods in work.

Fourth: teaching through playing, using nature skills and desire to be the first, with nonviolent communication and according the psychological age period of a child - all 
this help to be the very important trainer influencing the personality and group development.

All this allows us to record the results of our work, to respond promptly to the person's individual needs, his development peculiarities in the sport team, to develop dynamically and adjust the program in accordance with the time and features of the group requirements. This helps to keep in focus the individual harmonious development and to help each child on the path to self-realization.

It is important to take into account optimism in the practical psychologist work, his ability to feel emotions foremost well, desire to maintain a positive Self-image. Also important to be objective, responsible and demanding of themselves. Care should be taken on the harmony between what children want, what they claim (assessment, attitude, etc.), and their real actions, that is the meaning and way of life activity manifestation. The desire to change, to imitate, to learn is most clearly and emotionally only in child age. It is necessary to construct the practical psychologist work so that this age requirement becomes a reality and became the basis for further transformation of it into a stable personality quality.

\section{REFERENCES}

1. Goleman D. Emotsional'nyy intellekt. [Emotional Intelligence]. Vladimir: VKT. 2009, 478p. (in Russian)

2. Moreno J.L. Sotsiometriya. Eksperimental'nyy metod i nauka ob obshchestve. Izdatel'stvo "Zarubezhnaya literatura" [Sociometry. Experimental method and science about society]. Moskow. 1958, 135p. (in Russian)

3. Sergienko E., Mayyer J., Salovey P., Karuzo D. Emotsional'nyy intellekt (MSCEIT v.2.0.). [Emotional Intelligence]. Moskva: Izd-vo «Institut psikhologii RAN». 2010, 118p. (in Russian)

4. Grinova 0.M., Tereshchenko L.A. Dytyacha psykhodiahnostyka: navchal'nyy posibnyk. [Child psychodiagnostics: educational manual]. Vinnytsya: Nilan LTD. 2015, 227p. (in Ukrainian)

5. Svatenkova T.I. Development of emotional intelligence of a child. The experience of practical psychologist. SIA OmniScriptum Publishing. 2018, 140p.
6. Mayer J.D. Models of emotional intelligence. JR. Sternberg. Handbook of Intelligence. Cambridge: Cambridge University Press. 2000, 420p.

7. Salovey P., Mayer J.D. Emotional intelligence. Imagination, Cognition, and Personality. 1999; 9: 185-211.

8. Svatenkova T.I. Development and correction of emotional intelligence of children of elementary school age in conditions of temporary children's group. Social Work \& Education, Scientific Papers. 2018; 5 (2): 107-117.

9. Tyurina T., Stavkova, S. Harmonization of the Activity of the Left and Right Cerebral Hemispheres - an Important Component of the Spiritual and Mental Health of Individual and Humanity. Mental Health: Global Challenges Journal. 2020;3(2): 45-49. doi: https://doi.org/10.32437/ mhgcj.v4i2.84

\section{ORCID and contributionship:}

Tetyana I. Svatenkova: 0000-0003-1494-6000 A,B,D-F

Oleksandr V. Svatenkov: 0000-0001-5898-7088 ${ }^{C, E}$

\section{Conflict of interest:}

The Authors declare no conflict of interest.

Received: 12.05 .2021

Accepted: 07.10 .2021

A - Work concept and design, B - Data collection and analysis, C - Responsibility for statistical analysis, D-Writing the article, $\mathbf{E}$-Critical review, $\mathbf{F}$ - Final approval of the article 


\title{
YOUTH HEALTH MANAGEMENT SPHERE
}

DOI: 10.36740/WLek202111111

\author{
Antonina I. Kononchuk ${ }^{1}$, Alexander V. Svatenkov ${ }^{1}$, Tatiana I. Svatenkova ${ }^{1}$, Danylo I. Kononchuk ${ }^{1}$, Mitzi Waltz $^{2}$ \\ 'MYKOLA GOGOL NIZHYN STATE UNIVERSITY, NIZHYN, UKRAINE \\ ${ }^{2}$ ATHENA INSTITUTE, VRIJE UNIVERSITEIT, AMSTERDAM, THE NETHERLANDS
}

\begin{abstract}
The aim: To study the youth awareness level in the health field; to create a youth health center model.

Materials and methods: An extensive literary review of relevant articles and youth health research reports for the period 2009-2020, was performed using Medline, PubMed and Google Scholar databases, with the following key words: "Ukrainian youth health state", "number of chronically ill among Ukrainian youth", "bad habits spread in the Ukrainian youth environment", "youth for a healthy lifestyle". We used a descriptive cross-sectional survey with open-ended and closed-ended questions about attitude to a healthy lifestyle $(n=688)$.

Results: Youth consider the health as the most comprehensive definition, which is enshrined in the scientific literature $(67,7 \%)$. Family remains the most influential social institution for young people today. Unemployment, low medical care level and high HIV/AIDS rates are the most important health concerns.

Conclusions: Influencing the safe behavior formation factors is defined, the young people attitude the healthy lifestyle and the mentioned factors have been described. The model of the Youth Health Support and Conservation Centre is presented.
\end{abstract}

KEY WORDS: Educational management, safe behavior, healthy lifestyle, the model of Health Centre, city community

Wiad Lek. 2021;74(11 p.l):2743-2749

\section{INTRODUCTION}

Health at $10 \%$ depends on the medicine level, $20 \%$ - on the environment state, $20 \%$ - on heredity and $50 \%$ - on lifestyle [1]. The healthy lifestyle is forming by:

- value awareness, conscious attitude, health support;

- healthy lifestyle;

- spirituality development;

- saving and promotion health life [2].

Ukrainian adolescents' health self-assessment is lower than their peers in Europe:

- Every five teenager consider his health mediocre or bad (27\%).

- Every third teenager has smoking experience. One in ten teenagers first smoke a cigarette at 11 or earlier, $7 \%$ smoke every day.

- One in seven among 11-year-old and 76\% 17-year-old have alcoholic drinking experience.

- Every nine teenagers (aged from 11 to 13 years) tries cannabis at least once.

- Among 12 million reported sexually transmitted diseases 3 million occur among adolescents [3].

Issue topicality prompted scientists to develop the health concept that can take into account and reconcile the provisions of the three concepts with the modern scientific paradigm. They created holistic and integrative approach to study such a phenomenon as health (Brehman, I., Vasilyeva, O., M., Fromm, E. etc.) [4].

"Health is a complete physical state, social and mental well-being, not just the disease or physical disabilities absence" (WHO Statute) [5]. Health considered as a multidimensional socio-cultural phenomenon that combines different elements and reflects fundamental aspects of human existence in today\&apos;s globalized world. Gusak, P., Zimivets, N., Petrovich, V. define “...as the individual position, which determines the reactions regulation and the volitional activity realization regarding the health factors for the optimal personal and environmental opportunities combination for well-being" [6]. Responsible attitude to health takes place in a systematic planed activity: assessing the health attitude level; analysis health improvement factors; developing the improve situation action plan; implementation the action plan; results evaluation.

Charlton Annie generalized the health education experience programs implementation [7]. The researcher defined the following health education models: information and cognitive, mastering knowledge and skills, value and logical, social changes, actions for the health benefit [6]. The Ukrainian practice of youth responsible attitude to health creation has experience in several models implementation. Currently, the State Target Social Program "Youth of Ukraine" for 2016-2020 defined healthy lifestyle as one of the priority areas in the state youth policy [8].

\section{THE AIM}

The aim of the article is to study the youth awareness level in the health field; to create a youth health center model. 


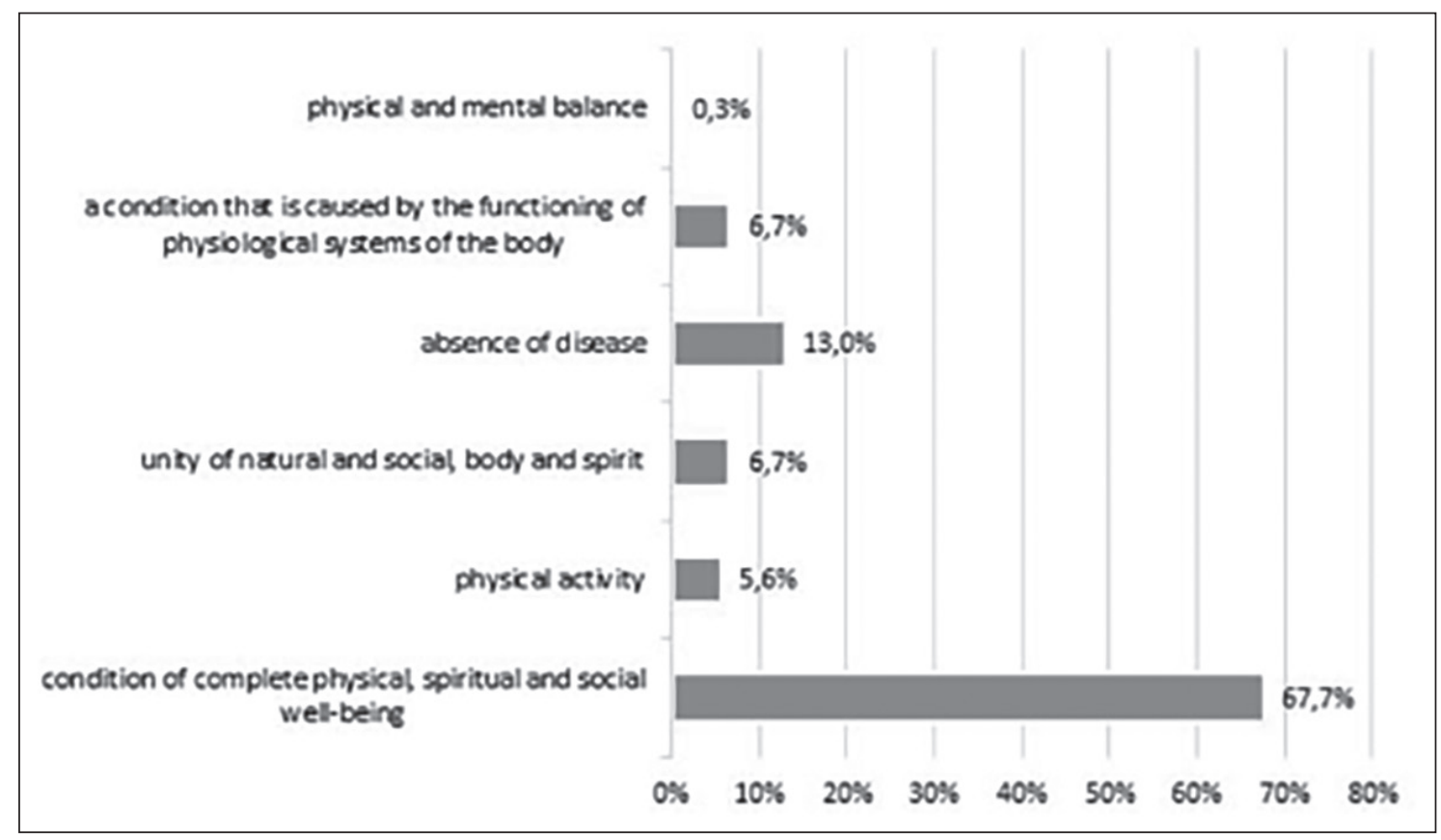

Fig.1. The respondents answers to the question "What is health for you?"

\section{MATERIALS AND METHODS}

The first stage. The research analysis in the youth health preserving field in Ukraine over the past 10 years: the number of "relatively healthy" youth decreased by $28 \%[1,24]$. Assessment resources and potential the youth health social sphere: the volunteers number among youth has decreased by $37 \%$ since 2010 ; the youth centers number can meet the needs of only $48 \%$ [8]. The chronic diseases number among young people has increased by $63 \%$ [1].

The second stage. Conducted discussions with students on ideas about health and ways to preserve it $(n=415)$ within the teaching scientific disciplines: "Social work in Ukraine", "Technologies of work with different groups population in Ukraine", "Psychology of youth deviant behavior". The study was anonymous and show only the generalized point of view most respondents. According to the analysis, 148 hours of group discussions were as follows: $87 \%$ of respondents are well informed about health and ways to maintain it, but in reality only $30 \%$ of respondents lead a healthy lifestyle (sports, no alcohol, drugs and tobacco, healthy food).

The third stage. We created the anonymous questionnaire to get information about the young people lifestyle, identify factors and assess their impact extent on the creation a healthy behavior. We used a descriptive cross-sectional survey with open-ended and closed-ended questions for young people about their attitude to a healthy lifestyle $(n=688)$.

Than we made a ranking assess young people awareness in social problems and the youth environment in particular. It is essential to have a full idea of young people\&apos;s perception the state\&apos;s health policy vectors and the main problems in the health preservation field to formulate the Centre\&apos;s work goals and objectives.

\section{RESULTS AND DISCUSSION}

The total respondents number was 688 young people, including 210 boys and 478 girls (16-18-years old). The conversation, statistics and observation methods were also used. It gave ground to formulate appropriate conclusions and recommendations for local self-government bodies, social services, and public city organizations to improve social youth policy, organize activities, develop and implement relevant direction projects. The research conducting was approved by the Nizhyn Mayor (Chernihiv region, Ukraine) and the Mykola Gogol Nizhyn State University Commission on Social and Psychological Research Ethics.

Young people consider the health as the most comprehensive definition, which is enshrined in the scientific literature (67,7\%) (Fig. 1).

Such a comprehensive approach to understanding health among young people can be a starting point for the development and implementation the Centre's (Youth Health Support and Conservation Centre) integrated programs in partnership with local authorities, social services, public organizations at the municipal level.

Solving such cultural and social problems like unemployment, creating opportunities for sports, organizing meaningful leisure for young people should be the programs ' aim. The developed countries experience in the such programs implementation has shown their preventive effectiveness in health preservation. Particular attention should be paid to cooperation with the family and the environment because cultural, mental and national characteristics are based on the family values priority and social ties [9].

Figure 2 presents the respondents\&apos; answers to the question "Which of the following factors influence the safe behavior creation in the youth health preservation 


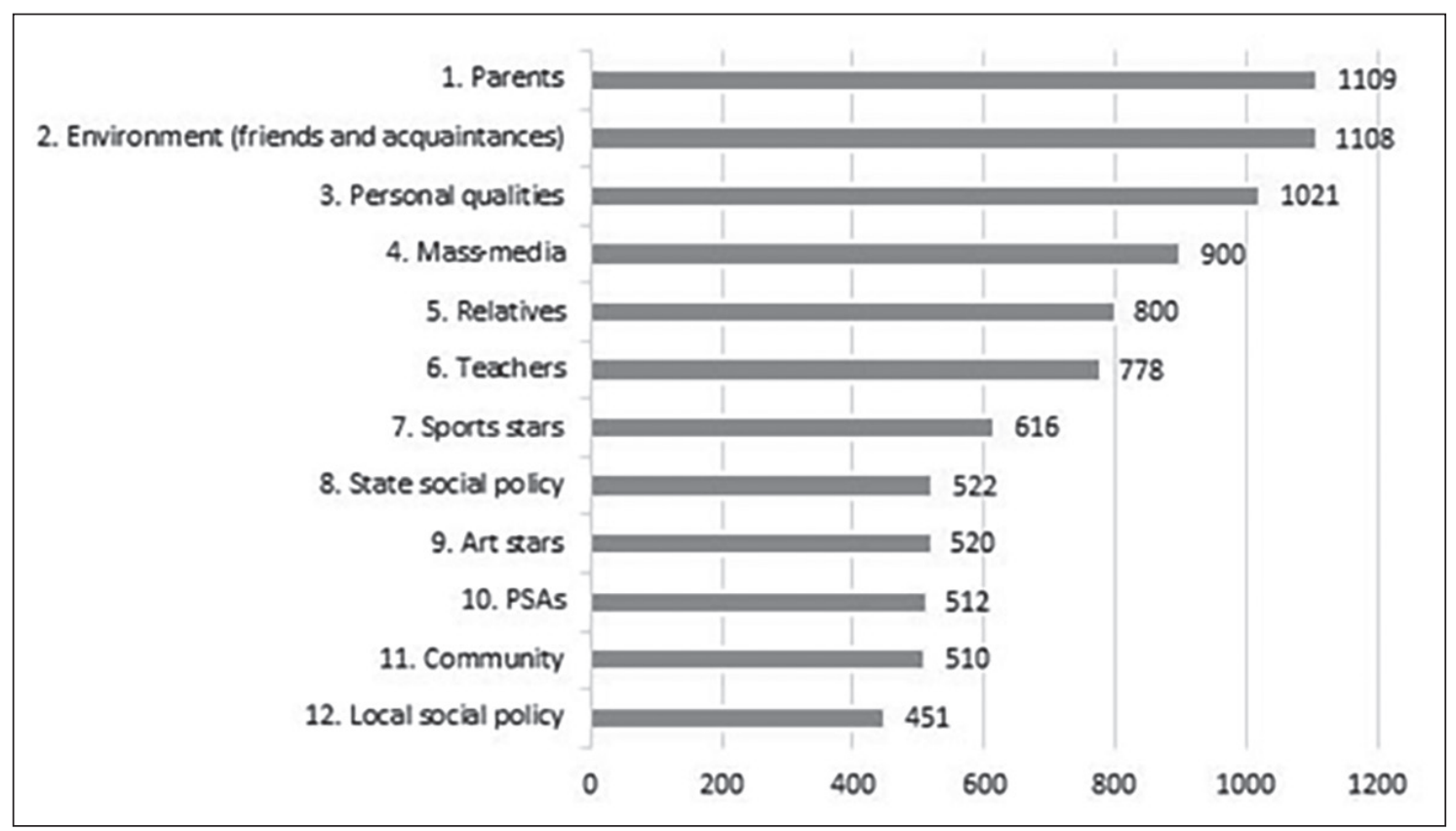

Fig. 2. Results of the respondents answers to the question "Which of the following factors influence the creation of safe behavior in the field of preservation and support of youth health?"

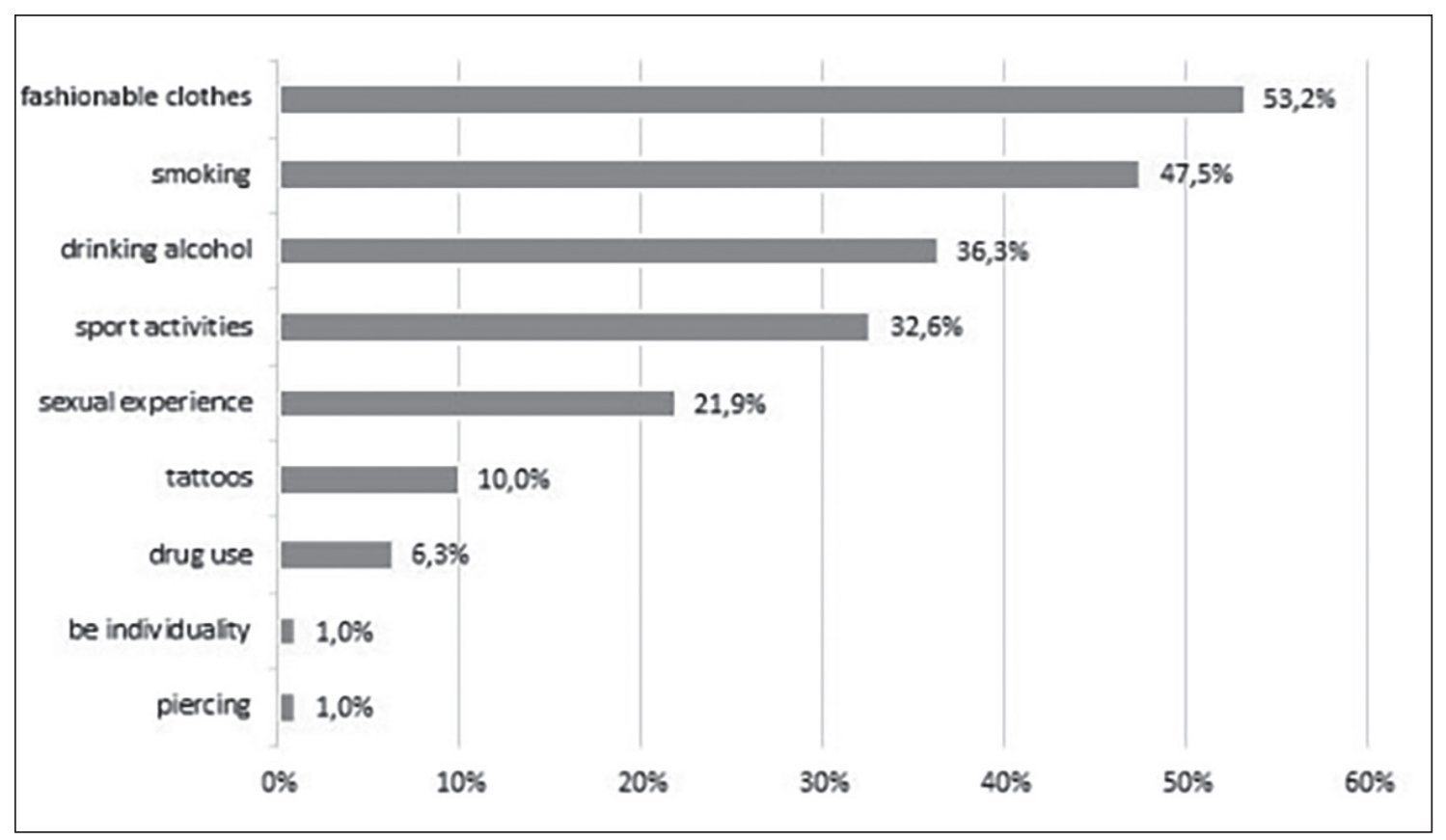

Fig. 3. Results of the respondents answers to the question "What is popular among peers nowadays?"

and support?". The respondent had to choose one of the answer options: "Absolutely unaffected," "Impact to a small extent", "Impact to a great extent," and "Hard to answer" for each factor.

We introduced scale indicators to determine the proposed factors relevance. The response "Impact to a great extent" was 2 points, "Impact to a small extent" - 1 point, "Absolutely unaffected" and "Hard to answer "- 0 points. We obtained the number that determined the place for each social problem in the overall ranking.
Family remains the most influential social institution for young people in the health sector. It is the family communication, interaction, parents example plays decisive role in forming the young people safe behavior.

We would like to understand a unique youth behavior and appearance style. It was respondents' answers to the question "What is popular among peers nowadays?" (Fig.3).

Respondents were offered nine options to answer this question: fashionable clothes, smoking, drinking, sexual experience, sports, drugs, tattoos, piercing and individu- 


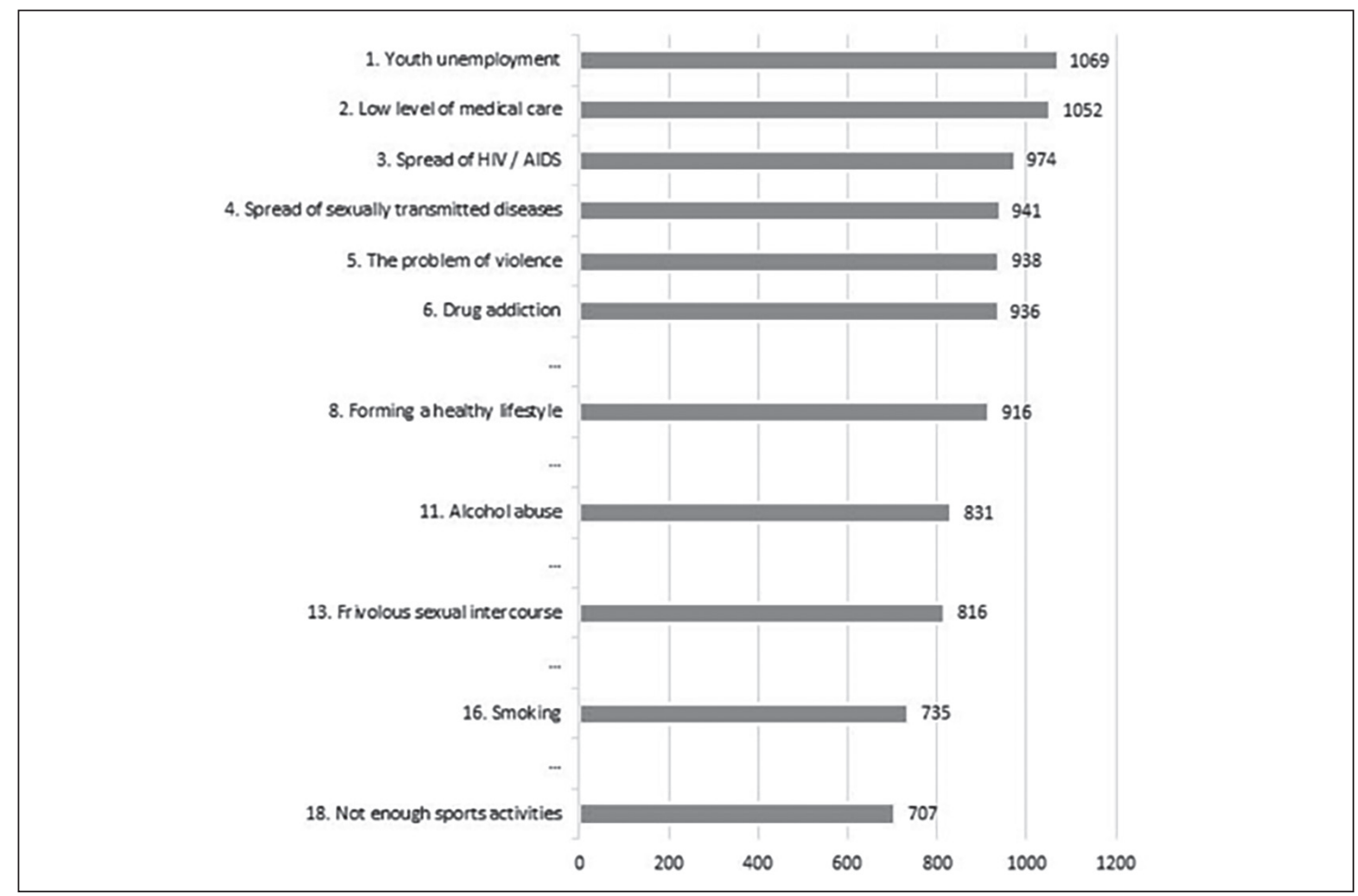

Fig. 4. Results of the respondents answers to the question "To what extent do you concern about the following issues?"

Table I. The results of the respondents answers to the question "What are you most often talking about ...with..."

\begin{tabular}{ccccc}
\hline Theme & Parents & Teachers & Peers & Nobody \\
\hline Education & $44.1 \%$ & $13.3 \%$ & $40.6 \%$ & $2.0 \%$ \\
\hline Health & $76.5 \%$ & $0.9 \%$ & $11.8 \%$ & $10.8 \%$ \\
\hline Food & $58.7 \%$ & $0.5 \%$ & $13.1 \%$ & $27.7 \%$ \\
\hline Own behavior & $21.8 \%$ & $11.3 \%$ & $44.2 \%$ & $22.7 \%$ \\
\hline Relationships & $13.3 \%$ & $0.6 \%$ & $70.2 \%$ & $15.9 \%$ \\
\hline Puberty & $10.1 \%$ & $1.2 \%$ & $47.1 \%$ & $41.6 \%$ \\
\hline Intimate relationship & $8.4 \%$ & $0.5 \%$ & $47.8 \%$ & $43.3 \%$ \\
\hline
\end{tabular}

ality. The respondents were able to choose several options, so the total percentage exceeds $100 \%$.

We can conclude that fashion is a significant factor in creating a youth lifestyle. Growing the fashion trends are essential to young people. We can control it throw the involving youth leaders in community activities, working with media and developing social advertising.

Figure 4 presents the answers ' results: "How are you concerned about the following problems?". Respondent had to choose «High,» «Middle,» «Low».

Unemployment, low medical care level and high rates of HIV / AIDS among young people are the most important health concerns.

Awareness the importance does not always lead to introduction the spreading individual health models into one's behavior, as statistics show. The healthy behavior promotion should be not only among young people but also among all population segments. It should be the priority task at all state functioning levels. The following question was directed at their identification: "What do you talk about most often ...with...?”(Table I).

The results allow us to conclude that there are specific patterns:

- the youth high level interests in sexual life and the low adults ' participation in sexual education, which may be one of the leading factors in the HIV / AIDS and STDs significant spread;

- low parents 'involvement in the youth behavior models formation and private (sexual) discussion only with peers, it can be a significant factor in forming misconceptions, landmarks;

- the considerable adults 'involvement in health preservation and the lack youth discussions the environment, it hinders the innovations and determines the low health issues attractiveness for young people.

Youth health is affected by several reasons:

- emotional discomfort by educational difficulties;

- relationships complexity in system "young person - 


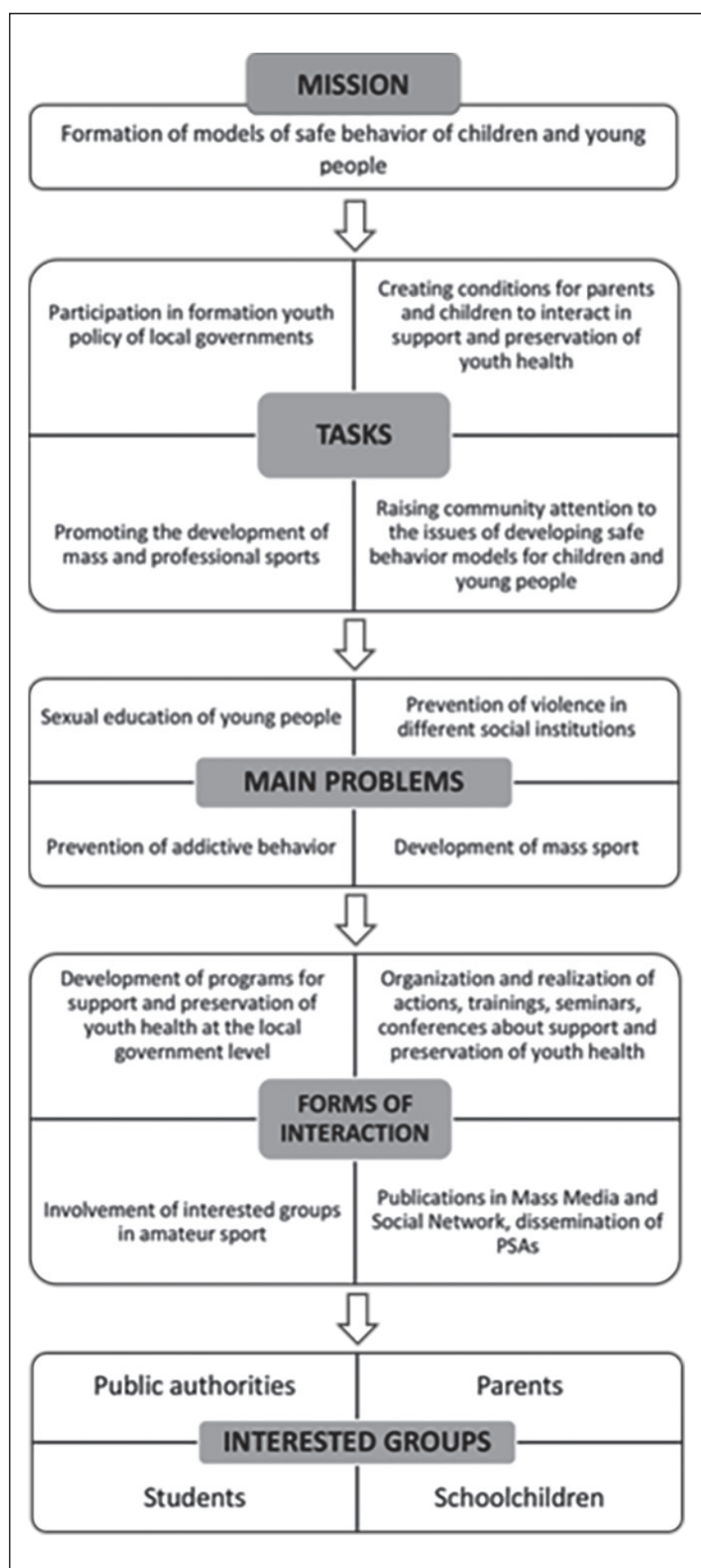

Fig. 5. Model of the Youth Health Support and Conservation Centre

teacher - parents";

- intense negative environment impact;

- growing sense of insecurity, dissatisfaction with oneself and the world.

The results give rise to develop the Youth Health Support and Conservation Centre model (Fig. 5).

The primary stakeholder engagement forms are:

- development youth health preservation programs at the local government level;
- organization and realization social events, training, and workshops on youth health support with parents and schoolchildren;

- involvement into amateur sport groups;

- publications in mass media and social networks.

The primary condition for the effectiveness is to initiate interaction between all interested groups: public authorities, parents, student population, and schoolchildren. According to the mission and tasks the model of Centre's management (Fig. 6).

The Center director is appointed to the position and dismissed by the founder (competitive basis, contract).

Center director:

1) organizes the Center work, personally responsible for the Center tasks implementation, determines the Center employees' responsibility degree;

2) appoints and dismisses Center employees according to established procedure;

3) controls the employees ' duties completeness and quality;

4) approves the Center organizational structure, Center\&apos;s employees job descriptions, the Center rules procedure and control their implementation;

5) makes the staff list and submits it for approval in manner law prescribed;

6 ) issues orders, instructions in accordance with its competence, organizes and controls the execution;

7) concludes agreements, acts on the Center behalf and represents its interests, monitors the Center mission implementation;

8) disposes the Center funds and property by the approved budget;

9) opens and closes the Center accounts in the banking institutions;

10) develops and submits for the founder approval the Center work plans and implementation reports;

11) provides the Center activities information at the expert council request established by the Center;

12) organizes the Center accounting and reporting;

13) organizes the expenditures planning necessary for the Center work, reports on the implementation;

14) promotes the Center employees ' advanced training; An advisory body - an expert council - established at the Center in order to ensure the young people participation in the effective Center work. The Expert Council is formed with active young people, who lead the Center work together with the Center employees, implement the Center tasks and mission. The main expert council tasks:

1) public control over the Center work, including the property and funds use, and at the director's work, ensuring its transparency, legality, expediency;

2) promoting the public opinion consideration during the Center\&apos;s work;

3) preparation proposals for defining tasks, perspective development and Center\&apos;s work main directions, control over implementation;

4) preparation proposals for the Center's work plan, control its implementation;

5) analysis the Center's inspections results. 


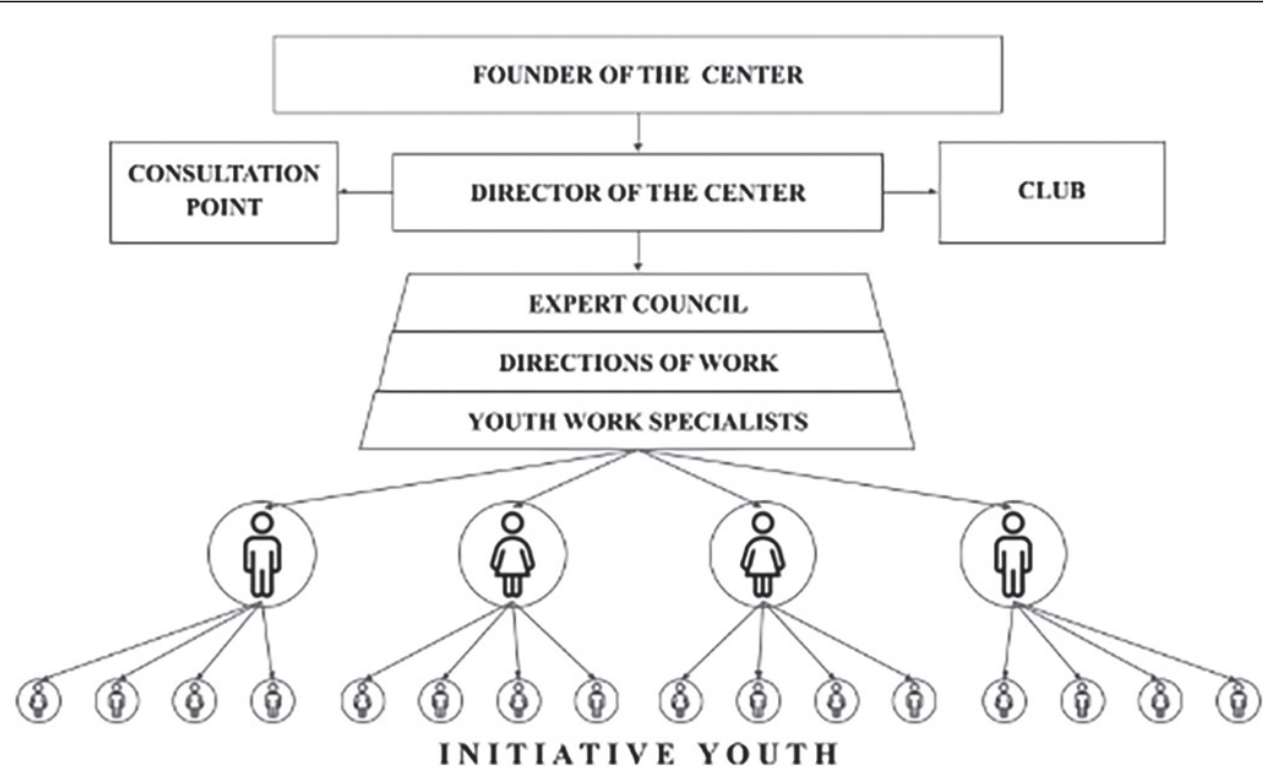

Fig. 6. Model of the Youth Health Support and Conservation Centre's management

Youth professionals work with different age and social youth categories. The purpose is socialization and active inclusion young people in the country public life. It can be realized involving young people in the decision-making processes and implementing participation in certain community activities. Specialists in youth work perform certain functions:

preventive - prevent the social problems possibility in the youth environment;

diagnostic - diagnostic the youth environment, problems and needs to properly and effectively organize the work;

health - preserving and strengthening the youth health; organizational - organization, establishment and coordination the Center\&apos;s specialists joint work, local authorities, volunteers, youth organizations, institutions and departments, various social institutions, community residents; planning and distribution different types of work in the joint activities process;

activation - development and support youth initiatives, volunteer movement; work with youth leaders;

animation - the young people leisure organization, which involves communication and interaction, the new discovery, creative development;

advocacy - the youth rights protection; the youth policy implementation to improve the youth development conditions in society;

educational - providing the necessary information access to knowledge, consulting, information campaigns, teaching young people the safe behavior skills, communication, conflict resolution, etc.;

advertising and propaganda - informational and educational activities, promoting the youth social protection ideas, healthy lifestyles, etc.

The psychological and legal issues counseling center and the young parents club work in the Center. Specialists-vol- unteers are involved in the consultation point work. A professional psychologist helps with family relationships, addictions, helps to form a productive attitude to adverse life situations and develop a socially acceptable life strategy. A professional lawyer provides qualified advice on the rights protection, including benefits for education, employment, housing, etc.

The Center's work includes:

- physical improvement through the health-preserving skills and abilities formation, organization sports and ecological-tourist work, using folk and modern preserving and strengthening health methods;

- psychological screening and correction the youth mental state, their adaptation;

- educate a spiritually healthy person by artistic and technical creativity;

- providing friendly relations and creating a positive microclimate as the youth social health basis.

The Center\&apos;s activities to promote a healthy lifestyle are as follows:

- Youth public organizations and volunteer groups meetings;

- Thematic volunteer summer camps;

- Trainings for teenagers and young people on the safe behavior formation;

- «Public Reception» work;

- Thematic preventive youth discos;

- Street play libraries;

- Youth club-cafe;

- Work with youth crisis categories.

The youth initiative group participates in the preventive materials development. Their tasks are: development, layout and publication information materials, shooting preventive videos. 


\section{CONCLUSIONS}

Conversation with youth on ways to optimize the health situation and the personal data statistical processing priority areas in the study. The general conclusions after the conversation:

- first, the youth healthy lifestyles problem remains urgent and requires immediate solutions at the state and regional levels;

- secondly, to involve many specialists into the education sphere is very important;

- thirdly, we must pay youth' attention to it at all social and education levels.

The safe behavior creation factors in youth health preservation and maintenance:

- personal abilities (problems awareness, the preventing importance);

- parents and immediate surroundings (behavior examples, discussing opportunities, informational influence);

- media and fashion trends.

We associate new approaches to youth value formation with the activities of youth centers. These are new institutions that ensure the development and implementation of youth policy in the local community following the needs of the youth, support for self-realization, and integration of youth into the modern democratic society.

New approaches to youth health value formation are youth centers. They should must provide health education, recognizing it as main social mechanism that promotes public safety and the healthy society development. It requires the following steps:

- to create a public health state program;

- to restore the state priority influence on the physical education development;

- to attach a healthy lifestyle standard as the Ukrainian society integral progress indicator.

To establish links between psychological counselling centers at universities with a mental health institutions network is very important (crisis centers, social support centers, neurological psych dispensaries, human rights institutions etc.). It is comprehensive client care and facilitating the appropriate competencies formation.

Further research is the development and implementation comprehensive programs for the youth safe behavior formation based on the Youth Centre systematic approach. Sufficient Centre's work is possible in the stakeholders ' interaction (public authorities, parents, students and schoolchildren) while implementing programs and projects.

\section{REFERENCES}

1. Balakireva 0.M., Bondar T.V. et al. Pokaznyky sotsial'noyi pidhotovky ta zdorov'ya pidlitkiv ta molodi: za rezul'tatamy sotsiolohichnoho doslidzhennya v ramkakh mizhnarodnoho proektu «Zdorov"ya ta povedinkovi oriyentatsiyi student-s'koyi molodi» [Social conditioning and health indicators of adolescents and young people: according to the results of a sociological study within the international project «Health and behavioral orientations of student youth"]. UNICEF, NGO Ukr. Inst. of Soc. research. 0. Yaremenko. Kyiv: Foliant Printing Center. 2019, 130p. (In Ukrainian).
2. Alekseenko T. Sotsial'na pedahohika: slovnyk [Social pedagogy: a dictionary]. Vinnytsia: Planer. 2009, 548p. (In Ukrainian).

3. Abramova I.G. Do problemy ukrayins'koyi mental'nosti [To the problem of Ukrainian mentality]. Bulletin of Zaporizhia National University. 2008; 2: 7-11. (In Ukrainian).

4. World Health Organization. Mental health: strengthening our response. 2018. https://www.who.int/news-room/fact-sheets/detail/mentalhealth-strengthening-our-response [date access 20.08.2020]

5. Statut Vsesvitn'oyi orhanizatsiyi okhorony zdorov\&apos;ya [Charter of the World Health Organization]. 1948. http://zakon5.rada.gov.ua/laws/ show/995_599 [date access 20.08.2020]

6. Gusak P.M., Zimivets N.V., Petrovich V.S. Vidpovidal'ne stavlennya do zdorov'ya: teoriya ta tekhnolohiyi [Responsible attitude to health: theory and technologies]. Lutsk: 0JSC «Volyn Regional Printing House». 2009, 219p. (In Ukrainian).

7. Charlton A. Osnovnyye printsipy obucheniya zdorovomu obrazu zhizni. [Basic principles of teaching a healthy lifestyle]. Questions of psychology. 1997; 2; 3-14. (In Russian)

8. Pro zatverdzhennya Derzhavnoyi tsil'ovoyi sotsial'noyi prohramy “Molod' Ukrayiny" na 2016-2020 roky: Postanova Kabinetu Ministriv Ukrayiny [On approval of the State target social program "Youth of Ukraine" for 2016-2020: Resolution of the Cabinet of Ministers of Ukraine]. 2016. https://zakon3.rada.gov.ua/laws/show/148-2016-\%D0\%BF [date access 20.08.2020]

9. Dramnescu M. Mental Health and Ethical Issues in Cultural and Organizational Change. Mental Health: Global Challenges Journal. Special Issue-MHGCProceeding. 2020; 2: 56-64. doi: 10.32437/mhgcj.v4i2.

\section{ORCID and contributionship:}

Antonina I. Kononchuk: 0000-0001-9986-00374,D,E

Alexander V. Svatenkov: 0000-0001-5898-7088 B-D

Tatiana I. Svatenkova: 0000-0003-1494-6000

Danylo I. Kononchuk: 0000-0002-5401-6660

Mitzi Waltz: 0000-0002-9089-2545

\section{Conflict of interest:}

The Authors declare no conflict of interest.

\section{CORRESPONDING AUTHOR}

\section{Tatiana I. Svatenkova}

Mykola Gogol Nizhyn State University

2 Grafska Street, 16600 Nizhyn, Ukraine

tel: +380673394539

e-mail: tatianasvatenkova@gmail.com

Received: 08.06.2021

Accepted: 11.10 .2021
A - Work concept and design, B - Data collection and analysis, C - Responsibility for statistical analysis, D - Writing the article, $\mathbf{E}$ - Critical review, $\mathbf{F}$ - Final approval of the article 


\title{
THE QUALITY OF LIFE FOR STUDENTS IN EDUCATIONAL INSTITUTIONS: CURRENT SITUATIONS AND BASIC PRINCIPLES OF PSYCHOHYGIENIC IMPROVEMENT
}

DOI: 10.36740/WLek202111112

\author{
Oksana V. Tymoshchuk', Roman Z. Han', Iryna Y. Makoida', Olha B. Molodovets', Iryna B. Romash', \\ Nataliia Yermakova ${ }^{2}$, Valentina Vitale ${ }^{3}$ \\ 'IVANO-FRANKIVSK NATIONAL MEDICAL UNIVERSITY, IVANO-FRANKIVSK, UKRAINE \\ 2SUMY STATE PEDAGOGICAL UNIVERSITY NAMED AFTER A.S. MAKARENKO, SUMY, UKRAINE \\ ${ }^{3}$ ROMA TRE UNIVERSITY, ROME, ITALY
}

\begin{abstract}
The aim: To develop the key principles of psychohygienic improvement of the processes of personality formation and enhancement of the quality of life of pupils and students of modern educational institutions of various types.

Materials and methods: While working out the basic principles of psychohygienic correction of the processes of personality development and improvement of the quality of life of pupils and students of modern educational institutions of various types, we have conducted surveys of the adolescent boys and girls studying at five modern educational institutions in Ivano-Frankivsk city, namely Vasyl Stefanyk Precarpathian National University, Ivano-Frankivsk Finance Commercial Cooperative College named after Stepan Hranat, Ivano-Frankivsk State Music School named after Denys Sichynskyi, Ivano-Frankivsk Vocational Lyceum of Road Transport and Construction No. 15, and Ivano-Frankivsk Boarding Lyceum for Gifted Young People from Rural Areas. A total of 420 pupils and students studying at different types of educational institutions took part in the survey. They were in both natural and preformed conditions due to application of the program of psychophysiological effects on the body, psychohygienic correction of personality development processes and improvement of the quality of life of pupils and students.

Results: While conducting the research, we have noted that the practical application of the program of psychophysiological effects on the body, psychohygienic correction of personality development processes and improvement of the quality of life of pupils and students occurs at mental, personal and psychophysiological levels of the adolescent boys and girls, anticipating correction of emotional, motivational and behaviour-based key characteristics of personality, psychophysiological adaptation and quality of life, thus being a platform for development of creative potential, self-analysis, self-expression and self-control skills, as well as discovery of positive landmarks and meaning of life of the boys and girls.

Conclusions: The obtained data demonstrate that implementation of the program of psychophysiological effects on the body, psychohygienic correction of personality development processes and improvement of the quality of life of pupils and students, which includes: study of the level of development of psychophysiological functions, personality characteristics and indicators of the quality of life in each of the participants as well as taking into account the leading areas of their development within certain frameworks of educational process (the milestone of psychodiagnostics and assessment of the level of development of psychophysiological functions and personality traits); performing a set of exercises to relieve muscle spasms, isometric and respiratory gymnastics, as well as exercises of asymmetric gymnastics (the milestone of physical impact); application of psychophysiological component (the milestone of psychophysiological influence); introduction of a psychohygienic component (the milestone of psychohygienic correction) serves the basis for creating the foundation for activating positive changes in the peculiarities of psychophysiological and mental adaptation and characteristics of the quality of life of modern youth at educational institutions of various types.
\end{abstract}

KEY WORDS: quality of life, pupils, students, modern educational institutions, psychohygienic correction, personality characteristics

Wiad Lek. 2021;74(11 p.l):2750-2754

\section{INTRODUCTION}

According to the WHO definition, "quality of life" is an individual's perception of their personality and position in life in the context of the culture and value systems, as well as attitude to the meaning of life, expectations and reality, difficulties and problems. Quality of life is a subjective feeling of happiness (emotional component) and personal well-being as well as of life satisfaction (cognition-and-perception component) [1]. These days, there exist numerous researches investigating characteristic features of the quality of life of our country's either adult population or children and youth with acute or chronic diseases of various origin. Yet, only a small part of scientific works is aimed at studying the quality of life of healthy or apparently healthy pupils and students [2-5]. Moreover, our scientists' investigations often lack clear research algorithms and protocols, that being a significant obstacle to an objective assessment of the impact of a certain factor on the quality of life of pupils and students, who comprise a special social group that shapes the future of our state. 
Young people's lifestyle has a significant impact on learning activity, academic performance and working capacity and is closely connected with their physical and mental health [6-8]. Thus, low physical activity causes a decrease in the body's resistance to the development of various diseases and deterioration of physical and mental performance due to lack of training loads on all the systems and functions of the body [9]. However, at the present point of time, the study of the effects of physical activity on the quality of life of pupils and students of modern educational institutions of various types is insufficient [10].

In Ukraine, at present, there are no specific questionnaires that can be applied to study the quality of life, so in most cases, researchers use the Ukrainian-language questionnaire Medical Outcomes Study Short Form 36 (MOS SF-36) [11]. This questionnaire performs effectively and shows good results in the study of the level of general and social well-being, health status, success level, etc. Its significant advantage is the possibility of application in the study of indicators of the quality of life of healthy population, as well as young people over 14 years old, whereas the vast majority of similar questionnaires are designed to study the quality of life of individuals with specific acute or chronic diseases $[2,6]$. Nowadays, no monitoring studies with the use of SF-36 questionnaire are conducted in Ukraine, and the level of mental and social well-being has been usually assessed in people over 25 years old. Of particular concern is the fact that though the quality of life of pupils and students of modern educational institutions of various types is relatively low, any actions of psychohygienic correction of the processes of personality development and improvement of the quality of life are virtually absent.

\section{THE AIM}

The aim of the study is to develop the key principles of psychohygienic correction of the processes of personality development and enhancement of the quality of life of pupils and students of modern educational institutions of various types.

\section{MATERIALS AND METHODS}

While working out the basic principles of psychohygienic correction of the processes of personality development and improvement of the quality of life of pupils and students of modern educational institutions of various types, we have conducted surveys of the adolescent boys and girls studying at five modern educational institutions in Ivano-Frankivsk city, namely Vasyl Stefanyk Precarpathian National University, Ivano-Frankivsk Finance Commercial Cooperative College named after Stepan Hranat, Ivano-Frankivsk State Music School named after Denys Sichynskyi, Ivano-Frankivsk Vocational Lyceum of Road Transport and Construction No. 15, and Ivano-Frankivsk Boarding Lyceum for Gifted Young People from Rural Areas. A total of 420 pupils and students studying at different types of educational institutions took part in the survey.
They were in both natural and preformed conditions due to application of the program of psychophysiological effects on the body, psychohygienic correction of personality development processes and improvement of the quality of life of pupils and students.

The program included anticipatory assessment of the peculiarities of the course of adaptation processes, taking into account the indicators of the quality of life with aplication of statistical models and methods of expert assessment. Taking into account different approaches to the organization of the educational process at the institutions under study, we have investigated the relationships between the functional state of the organism, the level of development of psychophysiological functions and personality characteristics, the quality of life and quantitative indicators of academic performance in basic and vocational disciplines; we have also developed, scientifically established and embedded in the educational establishment's practical activities the program of psychophysiological effects on the body, psychohygienic correction of personality development processes and improvement of the quality of life of pupils and students; we have also evaluated the degree of its implementation efficacy, and created approaches for anticipatory assessment of individual features of the processes of psychophysiological and psychological adaptation of pupils and students of modern educational institutions of various types taking into account the indicators of the quality of life based on the introduction of modern methods of multidimensional statistical analysis and anticipation.

The choice of the research objects, their grouping peculiarities and development of accounting classification characteristics took into account the indicators that enabled ensuring the qualitative and quantitative representativeness of the conducted research. To pursue the study and compare the obtained data adequately, it was necessary to take into account such indicators as age and gender, relative unity and absolute comparability of the basic characteristics of educational and extracurricular activities and environmental effects on the leading psycho-pedagogical indicators.

To determine the quality of life of the adolescent boys and girls, we have applied the questionnaire "SF-36 Health Status Survey", which is a non-specific questionnaire to achieve the goal set.

The criteria for the assessment of the quality of life included:

- the level of state of health according to the General Health (GH) grading scale;

- the level of physical functioning of the body (self-care, walking, carrying loads, etc.) according to the Physical Functioning (PF) grading scale;

- the impact of physical characteristics on role functioning (professional, educational and daily activities) according to the Role-Physical (RP) grading scale;

- the impact of emotional state on role functioning and the possibility of occurrence of difficulties in carrying out daily activities according to the Role-Emotional (RE) grading scale; 


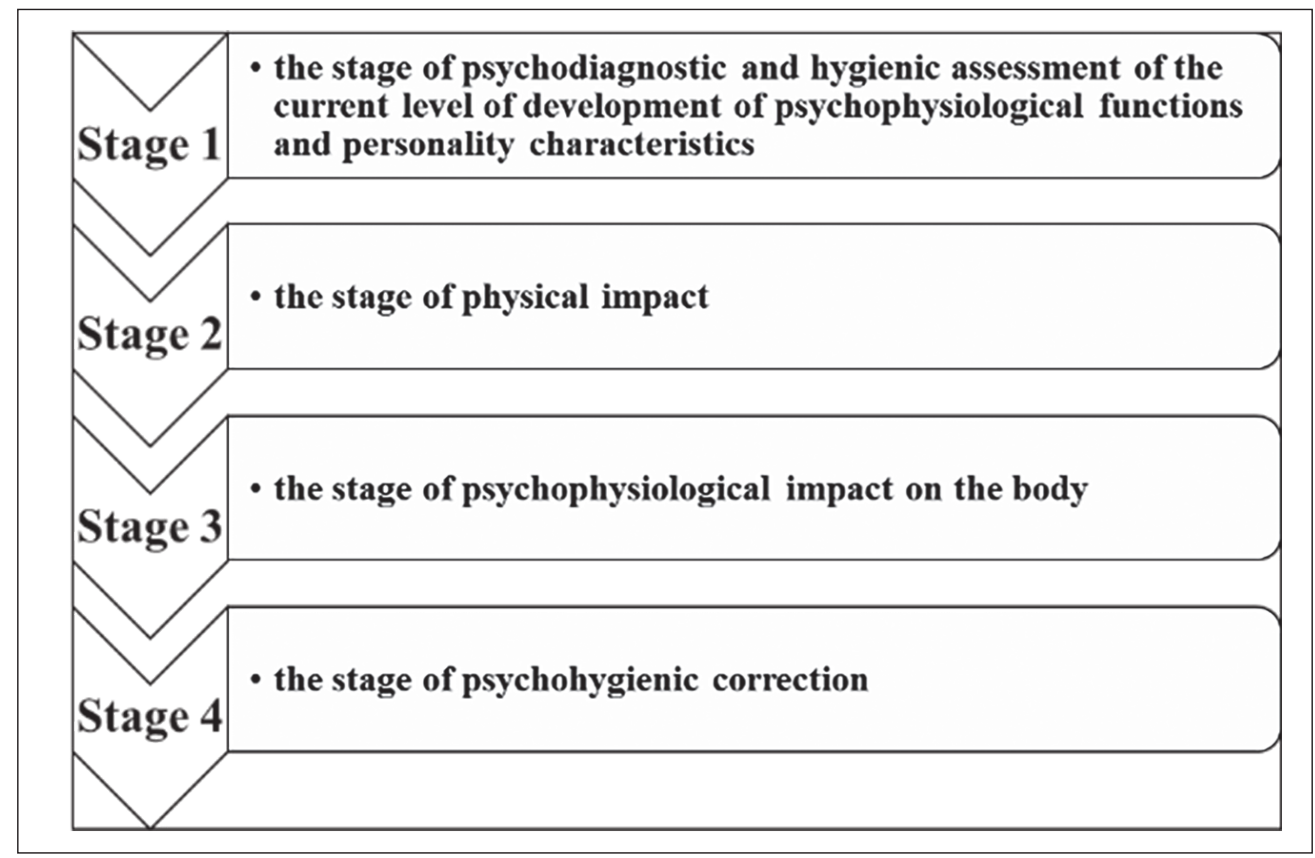

Fig. 1. The structure of the program of psychophysiological effects on the body, psychohygienic correction of personality development processes and improvement of the quality of life of pupils and students

- social functioning and social activity according to the Social Functioning (SF) grading scale;

- indicators of pain intensity, which can manifest themselves both in educational institutions and outside them, according to the Bodily Pain (BP) grading scale;

- manifestation of the level of viability indicators and the feeling of strength and energy according to the Vitality (VT) grading scale;

- mental health self-assessment in the presence of signs of depression or anxiety according to the Mental Health $(\mathrm{MH})$ grading scale.

In order to create conditions for the rational organization of educational and extracurricular activities of pupils and students, on the basis of a detailed study of the leading correlates of functional status and adaptive resources of boys and girls, we have developed a program of psychophysiological effects on the body, psychohygienic correction of personality development processes and improvement of the quality of life of young people, the main stages of practical implementation and the basic parts of which are: establishing the level of development of certain psychophysiological functions, personality characteristics and the quality of life individually in each of the adolescent boys and girls as well as anticipating the main directions of their development in certain conditions of educational process (the stage of psychodiagnostic and hygienic assessment of the current level of development of psychophysiological functions and personality characteristics); performing exercises to relieve muscle spasms, trainings of isometric gymnastics, and breathing exercises as well as introduction of classes of asymmetric gymnastics (the stage of physical impact); active practical engagement of the elements of the psychophysiological component of this program (the stage of psychophysiological impact); application of psychohygienic component of the program (the stage of psychohygienic correction) (Fig. 1).

\section{RESULTS AND DISCUSSION}

In the process of implementation of the developed program, an essential condition was a distinct, systematic performance of at least 2-3 exercises from each of the groups while organizing independent exercising in out-of-lesson time (as a special homework), which were independently adjusted by the boys and girls and were performed daily for 30-45 minutes, as well as a regular, systematic performance of the exercises carefully chosen as part of the mandatory set of exercises of morning hygienic and evening relaxation gymnastics, sports activities and sports games under the supervision of teachers.

Introduction of the program of psychophysiological effects on the body, psychohygienic correction of personality development processes and improvement of the quality of life of pupils and students was carried out on the basis of realization of such principles as the principle of rational application of physical and mental loadings and their sustainability at the time of influence; the principle of differentiated implementation; the feedback principle; the principle of systematicity, succession and stage-by-stage approach to the suggested exercises.

Implementation of the conceptual issues of the principle of rational application of physical and mental loadings and their sustainability at the time of the program application contributed to the creation of rational, in terms of hygiene, organization of daily learning and extracurricular activities at various types of modern educational institutions.

The program of psychophysiological effects on the body, psychohygienic correction of personality development 
processes and improvement of the quality of life of pupils and students of modern educational institutions of various types includes the following basic stages of practical implementation: assessment of the initial level of development of the basic psychophysiological functions, personality characteristics and the main characteristics of the quality of life in each of the adolescent boys and girls taking into account the leading directions of their development in different conditions of the educational process; actual performance of the trainings to relieve muscle spasms by application of exercises of isometric, asymmetric and breathing gymnastics; application of the psychophysiological and psychohygienic components of the developed program. The main components of the practical implementation of the program are: physical, psychophysiological and psychohygienic.

The physical component included exercises to relieve muscle spasms, isometric exercises, breathing exercises and asymmetric exercises. The psychophysiological component included a set of exercises for visual gymnastics, a series of exercises to improve cerebral circulation and exercises to relieve mental fatigue. The psychohygienic component was implemented through the introduction of psychophysical training exercises, psychotechnical games, various relaxation techniques, as well as exercises to overcome anxiety and increase self-control.

In the process of implementation and testing the effectiveness of the developed program, it has been provided the systematic performance of at least 2-3 exercises of each group in the process of independent training at extracurricular time, which the young people plan and adjust independently and perform for 30-45 minutes daily. These exercises had to be performed systematically, were included in the complex of exercises of morning hygienic and evening relaxation gymnastics, and were used as an element of sports action-oriented games and pastime at least 2-3 times a week.

While conducting the research, we have noted that the practical application of the program of psychophysiological effects on the body, psychohygienic correction of personality development processes and improvement of the quality of life of pupils and students occurs at the mental, personality and psychophysiological levels of the body of the adolescent boys and girls, thus providing correction of the basic emotional, motivational and behavioral personality characteristics, psychophysiological adaptation and the quality of life as well as being a platform for the development of creative potential, self-analysis, self-expression and self-control skills, and the discovery of positive landmarks and meaning of life of the youth.

The assessment of the effectiveness of implementation of the developed program has been carried out on the basis of defining the three key indicators of the level of development of personality characteristics: anxiety-neurotic, neuro-psychic and character-motivational components.

The positive impact at the final stage of the program implementation has been noted among both the adolescent boys and girls and statistically significant differences have been spotted in the comparison groups. First of all, these differences dealt with the indicators of the development of character accentuations in accordance with excitatory $(\mathrm{p}(\mathrm{t}) \mathrm{cg}-\mathrm{ig}<0.05-0.001)$, anxiety $(\mathrm{p}(\mathrm{t}) \mathrm{cg}-\mathrm{ig}<0.05-0.01)$ and dysthymia $(\mathrm{p}(\mathrm{t}) \mathrm{cg}-\mathrm{ig}<0.05)$ types as well as the indicators of the level of subjective control in the field of education$\mathrm{al}$ and health-disease relations $(\mathrm{p}(\mathrm{t}) \mathrm{cg}-\mathrm{ig}<0.05-0.001)$. The developed program had the greatest impact on such personality characteristics as character accentuations according to excitable type (first place in terms of the level of positive changes), the level of subjective control in the field of health and disease (second place in terms of the level of positive changes), and the level of subjective control in the field of educational relations (third place in terms of the level of positive changes).

While studying the peculiarities of changes in terms of the indicators of the quality of life according to the Social Functioning (SF) grading scale, the obtained Control Group data were characterized by almost unchanged data both among the adolescent boys, ranging from $51.43 \pm 3.51$ to $51.30 \pm 3.51$ points $(\mathrm{p}(\mathrm{t})>0.05)$, and among the girls, ranging from $43.36 \pm 2.71$ to $43.52 \pm 2.54$ points $(\mathrm{p}(\mathrm{t})>0.05)$. At the same time, the Intervention Group changes in the level of manifestations of the studied data were marked by an increase in their values from $50.63 \pm 3.43$ to $62.22 \pm 3.63$ points $(\mathrm{p}(\mathrm{t})<0.05)$ among the boys and from $44.49 \pm 2.71$ to $58.46 \pm 2.65$ points $(\mathrm{p}(\mathrm{t})<0.001)$ among the girls. At the beginning of the study, no statistically significant differences were found between the representatives of the comparison groups $(\mathrm{p}(\mathrm{t}) \mathrm{cg}-\mathrm{ig}>0.05)$; at the end of the surveys, statistically significant differences were registered only among the girls $(\mathrm{p}(\mathrm{t}) \mathrm{cg}-\mathrm{ig}<0.001)$.

The values of the Mental Health (MH) grading scale in conventional learning conditions (Control Group) and in Intervention Group were also marked by the presence of quite similar to the mentioned above trends. The indicators of the quality of life according to this grading scale in Control Group slightly increased from $71.16 \pm 2.98$ to $71.44 \pm 2.73$ points $(\mathrm{p}(\mathrm{t})<0.05)$ among the adolescent boys and slightly decreased from $61.03 \pm 3.16$ to $60.28 \pm 3.47$ points $(\mathrm{p}(\mathrm{t})>0.05)$ among the girls. However, in Intervention Group, the changes in the level of manifestation of the studied indicators increased from $70.59 \pm 3.34$ to $82.31 \pm 3.84$ points $(\mathrm{p}(\mathrm{t})<0.05)$ among the boys and from $60.52 \pm 3.46$ to $74.33 \pm 3.27$ points $(\mathrm{p}(\mathrm{t})<0.05)$ among the girls. At the initial stage of observations, no statistically significant differences among the participants in the comparison groups were observed $(\mathrm{p}(\mathrm{t}) \mathrm{cg}$-ig>0.05); at the final stage of the surveys, statistically significant differences were observed only among the girls $(\mathrm{p}(\mathrm{t}) \mathrm{cg}-\mathrm{ig}<0.05)$.

\section{CONCLUSIONS}

As a result of evaluating the effectiveness of the program of psychohygienic correction of personality development processes and improvement of the quality of life of pupils and students, positive changes in the key indicators of the quality of life of pupils and students have been noted. 
Besides, it stands to mention, that the highest values of positive impact were both in the adolescent boys and girls according to the Social Functioning (SF) grading scale $(\mathrm{p}(\mathrm{t})$ $c g-i g<0.05-0.001)$ and the Mental Health $(\mathrm{MH})$ grading scale $(\mathrm{p}(\mathrm{t}) \mathrm{cg}-\mathrm{ig}<0.05-0.001)$. It should be noted that this program had the highest positive impact on the indicators of the quality of life according to the Social Functioning (SF), Mental Health (MH) and General Health (GH) grading scales.

The obtained data demonstrate that implementation of the program of psychophysiological effects on the body, psychohygienic correction of personality development processes and improvement of the quality of life of pupils and students, which includes: study of the level of development of psychophysiological functions, personality characteristics and indicators of the quality of life in each of the participants as well as taking into account the leading areas of their development within certain frameworks of educational process (the milestone of psychodiagnostics and assessment of the level of development of psychophysiological functions and personality traits); performing a set of exercises to relieve muscle spasms, isometric and respiratory gymnastics, as well as exercises of asymmetric gymnastics (the milestone of physical impact); application of psychophysiological component (the milestone of psychophysiological influence); introduction of a psychohygienic component (the milestone of psychohygienic correction), forms the basis for creating the foundation for activating positive changes in the peculiarities of psychophysiological and mental adaptation and characteristics of the quality of life of modern youth at educational institutions of various types.

\section{REFERENCES}

1. Pavlova Ir.D., Vynogradskyi B.I., BorekZ.F. et al. Life quality and physical activity of Ukrainian residents. Journal of Physical Education and Sport. 2015;15(4):809-814.

2. Prystupa E.A., Pavlova lu.D. Evaluation of Health in Context of Life Quality Studying. Advances in Rehabilitation. 2015;29(2):33-38.

3. Hopman W.I., Towheed T.R., Anastassiades T.V. et al. Canadian normative data for the SF-36 health survey. Canadian Medical Association Journal. 2000;163(3):265-271.

4. Kowalski K.C., Peter R.E., Crocker R.M. et al. The Physical Activity Questionnaire for Older Children (PAQ-C) and Adolescents (PAQ-A). University of Saskatchewan. 2004, 37p.

5. Flaherty M.P., Sikorski E., Klos L. et al. Peacework and mental health: From individual pathology to community responsibility. Intervention. 2020;18(1):28-36. doi: 10.4103/INTV.INTV_59_18.

6. Kostyuchenko 0 . Recreational potential of metaphorization in mental self-regulation of the students. Mental Health: Global Challenges Journal. 2020;3(2):28-37. doi: 10.32437/mhgcj.v4i2.78.

7. Romash I. The nature of the manifestation of procrastination, level of anxiety and depression in medical students in a period of altered psycho-emotional state during forced social distancing because of pandemic COVID-19 and its impact on academic performance. Mental Health: Global Challenges Journal. 2020; 3(2): 6-11. doi: 10.32437/ mhgcj.v4i2.92.
8. Wilson I. Linking clinical variables with health-related quality of life. 1995;273(1): 59-65.

9. Tymoshchuk 0.V. Special aspects of the efficient daily routine of students at modern educational establishments of different types. Wiadomosci lekarskie. 2020; 73(7):1516-1520.

10. Moeijes J.S., Busschbach J.G., Bosscher R.E. Sports participation and health-related quality of life: a longitudinal observational study in children. J Qual. Life Res. 2019;28(9):2453-2469.

11. Salvini M.S., Gall S.U., Müller I.T. et al. Physical activity and healthrelated quality of life among schoolchildren from disadvantaged neighbourhoods in Port Elizabeth, South Africa. Qual. Life Res. 2018;27(1):205-216.

12. Vus V., Syurina E., Brückner T., et al. Youth and Mental Health: life satisfaction, wellbeing, and societal participation in the context of a transitioning state. Wiadomosci Lekarskie, 2021;74(7):1687-1694. doi: 10.36740/WLek202107123.

Relationship work with scientific programs, plants, topics. The work is a fragment of the research work "Study of the psychophysiological state of children, adolescents and students of the Carpathian region during the introduction of educational innovations" (2012-2018, № state registration 0112U006018), Department of Hygiene and Ecology of Ivano-Frankivsk National Medical University.

\section{ORCID and contributionship:}

Oksana V. Tymoshchuk: 0000-0001-9179-9951 $1^{A, B, D}$

Roman Z. Han: 0000-0002-7601-3065

Iryna Y. Makoida: 0000-0002-8258-2643 ${ }^{\mathrm{C}}$

Olha B. Molodovets: 0000-0003-0482-3760

Iryna B. Romash: 0000-0002-9749-778

Nataliia Yermakova: 0000-0001-6163-8313 ${ }^{F}$

Valentina Vitale: 0000-0001-7771-5379

\section{Conflict of interest:}

The Authors declare no conflict of interest.

\section{CORRESPONDING AUTHOR} Oksana V. Tymoshchuk

Ivano-Frankivsk national medical university

2 Galyckaya st., 76493 Ivano-Frankivsk, Ukraine

tel: + 38-099-163-35-29

e-mail: oksanavorob4ak@gmail.com

Received: 05.06 .2021

Accepted: 27.09.2021

A - Work concept and design, B - Data collection and analysis, C - Responsibility for statistical analysis, D -Writing the article, E-Critical review, $\mathbf{F}$ - Final approval of the article 


\title{
CITIZENS OBTAINING PSYCHOSOCIAL SUPPORT DURING THE COVID-19 PANDEMIC IN UKRAINE: A CROSS-SECTIONAL STUDY
}

DOI: 10.36740/WLek202111113

\author{
Tetiana M. Tytarenko ${ }^{1}$, Maryna S. Dvornyk ${ }^{1}$, Tetiana 0. Larina ${ }^{1}$, Kateryna V. Myronchak', Volodymyr V. Savinov ${ }^{1}$, \\ Julia D. Hundertaylo ${ }^{1}$, Giuseppe Vella ${ }^{2}$ \\ ${ }^{1}$ INSTITUTE OF SOCIAL AND POLITICAL PSYCHOLOGY NATIONAL ACADEMY OF EDUCATIONAL SCIENCES OF UKRAINE, KYIV, UKRAINE \\ ${ }^{2}$ AZIENDA SANITARIA PROVINCIALE DI AGRIGENTO, AGRIGENTO, SICILIA, ITALY
}

\begin{abstract}
The aim: To investigate the obtaining of psychosocial support by citizens during the COVID-19 pandemic in Ukraine using a cross-sectional study assessing the socio-demographic characteristics of the respondents.

Materials and methods: It was developed and used the authors' questionnaire "Socio-psychological support during the COVID-19 pandemic in Ukraine". Data processing used Nonparametric Mann-Whitney analysis of variance and one-way Kruskal-Wallis analysis of variance (SPSS 26.0).

Results: The study was conducted from 0ctober 2020 to May 2021 and sampled 100 individuals. Significant differences in the studied features are revealed. Gender: women have a more prosperous and broader range of contacts to discuss fears and anxieties during quarantine; suffer more from emotional loss; have more need to be heard and to be taken care of, with no criticism; are more experienced in professional psychological help obtaining; communicate with internal migrants more often. Age: young respondents (19-24 y.0.) suffer more from pandemic losses in the areas of spirituality and friendship; however, more often and more effectively use the means of online psychological support; older respondents are more likely to receive support from an important community and through meditation. Living conditions: living alone, citizens experience more pandemic stress, suffer from losses in personal life and friendship, and consider participation in challenge activities as the most convenient form of support. Place of residence: living in the rural areas is associated with a narrow circle of citizens' contacts to discuss their plans for leisure; more significant damage from pandemic losses in health; lack of support in the form of understanding themselves and their conditions. Education: higher education affects a broader circle of communication; more minor financial losses; willingness to share traumatic stories for art therapy. Financial satisfaction promotes the exchange of ideas between users of online psychological support.

Conclusions: The identified conditionality of psychosocial support obtaining by socio-demographic indicators can be used in the development of psychosocial support interventions during a pandemic for Ukrainian citizens by the public and private sectors, particularly in creating specialized smartphone applications, adapting playback theatre in the online space, creating gender-sensitive online programs to integrate IDPs into local communities.
\end{abstract}

KEY WORDS: mental health, telehealth, sex differences, art therapy, community participation

Wiad Lek. 2021;74(11 p.l):2755-2761

\section{INTRODUCTION}

The daily lives of people in the context of the COVID-19 pandemic have undergone inevitable changes. For some, these changes proved to be cardinal and destructive, and for others, temporary and insignificant. However, for most people, pandemic losses and quarantine restrictions have actualized fears, confusion, and the search for support [1]. There has been an increase in stress, anxiety, panic, depression, sleep disturbances, and symptoms of post-traumatic stress disorder [2]. The value of freedom in individual decisions ceased to dominate because the life and health of those around them have become dependent on the daily behavior of everyone [3]. During the pandemic, there has increased the need to expand social capital, to use community and family resources to promote psychosocial well-being [4]. Accordingly, the role of psychosocial support became crucial.

UNICEF defines psychosocial support as assistance to individuals and communities in treating psychological wounds, the restoration of social structures after an emergency or critical event. Timely and adequate psychosocial support prevents the transformation of distress into disorders and diseases, helps people cope with everyday challenges, restore normal life, meet the community's needs [5].

Most protocols in various psychological fields emphasize the importance of psychosocial support during the COVID-19 pandemic [6, 7]. In particular, it is about adaptating traditional means of psychological work (such as art therapy) to the online format $[8,9]$. An example of such work in Ukraine is the volunteer project "Art Vitamins" implemented by the NGO "Art Therapeutic Association" [10].

In Ukraine, the pandemic deployment appeared alongside the continuing crisis consequences of the hybrid war. In particular, vulnerable groups, including internally displaced persons (IDPs), lacked financial and social resources. During the quarantine restrictions and social isolation, there was a spread of initiatives for the population's remote psychological support, primarily in the education system 
Table I. Empirical values by Mann-Whitney U test, Kruskal-Wallis H test block of questions "Communicative field of personality during the COVID-19 pandemic."

\begin{tabular}{|c|c|c|c|c|c|c|}
\hline \multirow[b]{2}{*}{ Dependent variables } & \multicolumn{6}{|c|}{ Grouping variables } \\
\hline & $\begin{array}{l}\text { Sex, } \\
U(p)\end{array}$ & $\begin{array}{l}\text { Age, } \\
H(p)\end{array}$ & $\begin{array}{l}\text { Place of } \\
\text { residence, } \\
H(p)\end{array}$ & $\begin{array}{l}\text { Living } \\
\text { condition, } \\
\text { H (p) }\end{array}$ & $\begin{array}{l}\text { Education, } \\
\qquad H(p)\end{array}$ & $\begin{array}{c}\text { Financial } \\
\text { satisfaction, } \\
\text { H (p) }\end{array}$ \\
\hline $\begin{array}{l}\text { Social contacts to discuss fears and anxieties } \\
\text { in the field of study/work }\end{array}$ & $\begin{array}{l}474,5 \\
(0,042)\end{array}$ & & & & & \\
\hline $\begin{array}{c}\text { Social contacts to discuss plans for vacation } \\
\text { and leisure activities }\end{array}$ & & & $\begin{array}{l}14,635 \\
(0,006) \\
\end{array}$ & & $\begin{array}{c}9,497 \\
(0,023)\end{array}$ & \\
\hline $\begin{array}{l}\text { Feelings about studying/working during } \\
\text { adaptive quarantine }\end{array}$ & & & & & $\begin{array}{c}8,002 \\
(0,046)\end{array}$ & \\
\hline
\end{tabular}

$[11,12]$. There were also made attempts to systematize different approaches to provide psychological assistance during a pandemic in Ukraine [13]. However, to build effective strategies for psychosocial support of Ukrainian citizens in the context of the COVID-19 pandemic, there is still a lack of research on the specifics of obtaining such support.

\section{THE AIM}

To investigate the obtaining of psychosocial support by citizens during the COVID-19 pandemic in Ukraine using a cross-sectional study assessing the socio-demographic characteristics of the respondents.

\section{MATERIALS AND METHODS}

The study is based on the concept of personality's socio-psychological support by T.M. Tytarenko [14]. It is developed the online authors' questionnaire "Socio-psychological support during the COVID-19 pandemic in Ukraine" (Google Forms) using modifications of standardized methods for the following block of questions [15]: 1. Communicative field of personality during the COVID-19 pandemic

2. Loss experience support

3. Online psychological support

4. Psychological support by playback theatre

5. Community support

Many studies of psychosocial support trace certain trends in the relationship between the level of its obtaining and demographic indicators, so they were included in the questionnaire: gender; settlement; education; living conditions; occupation/ profession; level of financial satisfaction. Answer options were added to all indicators (except occupation).

The data was collected randomly via the Internet and by the "snowball" method. Original (interval, nominal) scales were recoded into the appropriate ordinal scales; the unreadable data were excluded from the analysis. The normality of the distribution of the collected data was not confirmed, so we used the nonparametric Mann-Whitney analysis of variance and one-way Kruskal-Wallis analysis of variance (are not related to the characteristics of the variables' distribution). Data processing used the statistical software SPSS 26.0.

\section{RESULTS}

The study was conducted from October 2020 - May 2021. The sample consisted of 100 individuals, 84 women and 16 men. The largest age group was $19-24$ y.o. (44\%) and $25-45$ y.o. (41\%), the rest (46-70 y.o.) - 15\%. Almost half of the respondents (45\%) indicated that they live in Kyiv, about $37 \%$ are city residents from different regions, and the rest (almost 19\%) were residents of villages and urban-type settlements. Most respondents have a complete higher education (51\%), almost $38 \%$ have an incomplete higher/secondary special education, $5 \%$ have only secondary education, and $7 \%$ have a scientific degree. Almost $30 \%$ of respondents live with their parents; about 19\% live only with a partner; $17 \%$ - in full families, with a partner and a child/ children; $12 \%$ live alone; the rest live with cohabitants/ friends $(10 \%)$, with a large family $(8 \%)$, or with a child/ children (6\%). Almost $28 \%$ of the sample are rather dissatisfied with their finances, and the other 25\% are rather satisfied, almost an equal number of absolutely satisfied (13\%) and dissatisfied (14\%) with their current financial condition.

As a result of non-parametric analysis of variance, we obtained statistically significant differences in the level of expression of the ordinal variable (questionnaire scales) and key socio-demographic indicators .

Following Block 1. Communicative field of personality during the COVID-19 pandemic (Tab. I), women have a more intense and expanded communication environment than men to discuss their fears and anxieties caused by quarantine restrictions. Residents of villages and urban-type settlements and respondents with secondary and secondary special education have a narrower communication environment to discuss their own recreation/ leisure plans. Respondents with higher education are also more likely to report positive feelings about studying/ working during quarantine restrictions. 
Table II. Empirical values by Mann-Whitney U test, Kruskal-Wallis H test block of questions "Loss experience support."

\begin{tabular}{|c|c|c|c|c|c|c|}
\hline \multirow[b]{2}{*}{ Dependent variables } & \multicolumn{6}{|c|}{ Grouping variables } \\
\hline & $\begin{array}{l}\text { Sex, } \\
U(p)\end{array}$ & $\begin{array}{l}\text { Age, } \\
H(p)\end{array}$ & $\begin{array}{c}\text { Place of } \\
\text { residence, } \\
H(p)\end{array}$ & $\begin{array}{c}\text { Living } \\
\text { condition, } \\
\mathbf{H}(\mathrm{p})\end{array}$ & $\begin{array}{l}\text { Education, } \\
\qquad \text { H (p) }\end{array}$ & $\begin{array}{c}\text { Financial } \\
\text { satisfaction, } \\
\text { H (p) }\end{array}$ \\
\hline Stress & $\begin{array}{l}360^{* *} \\
(0,003) \\
\end{array}$ & & & $\begin{array}{l}12,714^{*} \\
(0,048)\end{array}$ & & \\
\hline Emotional sphere & $\begin{array}{c}426^{*} \\
(0,019) \\
\end{array}$ & & & & & \\
\hline Health sphere & & & $\begin{array}{l}9,478^{*} \\
(0,05)\end{array}$ & & & \\
\hline Spiritual sphere & & $\begin{array}{l}7,456^{*} \\
(0,024) \\
\end{array}$ & & & $\begin{array}{l}9,335^{*} \\
(0,025)\end{array}$ & \\
\hline Financial sphere & & & & & $\begin{array}{l}7,945^{*} \\
(0,047) \\
\end{array}$ & $\begin{array}{l}13,3^{*} \\
(0,01)\end{array}$ \\
\hline Friendship sphere & & $\begin{array}{l}6,081^{*} \\
(0,048)\end{array}$ & & $\begin{array}{l}14,291^{*} \\
(0,027)\end{array}$ & $\begin{array}{l}9,425^{*} \\
(0,024)\end{array}$ & \\
\hline Personal growth sphere & & & & & $\begin{array}{l}9,074^{*} \\
(0,028)\end{array}$ & \\
\hline Intellectual sphere & & & & $\begin{array}{l}13,31^{*} \\
(0,038) \\
\end{array}$ & & \\
\hline Personal life, love relationships & & & & $\begin{array}{l}19,09 * * \\
(0,004)\end{array}$ & & \\
\hline Professional activity (work) & & & & & & $\begin{array}{l}9,578^{*} \\
(0,048)\end{array}$ \\
\hline Professional psychological help & $\begin{array}{l}326^{* *} \\
(0,001)\end{array}$ & & & & & \\
\hline Help and support of mentors, coaches & & & & $\begin{array}{l}13,593^{*} \\
(0,035)\end{array}$ & & \\
\hline Support from a meaningful community & & $\begin{array}{l}6,494^{*} \\
(0,039) \\
\end{array}$ & & & & \\
\hline $\begin{array}{l}\text { Opportunity to mourn openly, without } \\
\text { condemnation and instructions }\end{array}$ & $\begin{array}{c}307 \\
\left(0,000^{* *}\right)\end{array}$ & & & & & \\
\hline Face-to-face consultation with specialists & $\begin{array}{c}411 \\
\left(0,012^{*}\right) \\
\end{array}$ & & & & & \\
\hline Online support & $\begin{array}{c}450,5 \\
\left(0,031^{*}\right) \\
\end{array}$ & & & & & \\
\hline $\begin{array}{c}\text { Participation in the group or individual } \\
\text { challenges }\end{array}$ & & & & $\begin{array}{l}14,524^{*} \\
(0,024)\end{array}$ & & \\
\hline Meditation & & $\begin{array}{c}8,06^{*} \\
(0,018)\end{array}$ & & & & \\
\hline $\begin{array}{l}\text { The need to understand me and my states by } \\
\text { close people }\end{array}$ & $\begin{array}{l}355^{* *} \\
(0,002) \\
\end{array}$ & & & & & \\
\hline The need to be heard & $\begin{array}{l}436,5^{*} \\
(0,021) \\
\end{array}$ & & & & & \\
\hline $\begin{array}{l}\text { The need to show negative emotions without } \\
\text { condemnation }\end{array}$ & $\begin{array}{l}351,5^{* *} \\
(0,002)\end{array}$ & & & & & \\
\hline The need to be around and not being lectured & $\begin{array}{l}398,5^{* *} \\
(0,007)\end{array}$ & & & & & \\
\hline The need for love & $\begin{array}{l}411^{* *} \\
(0,008)\end{array}$ & & & & & \\
\hline The need to be believed in & $\begin{array}{l}425,5^{*} \\
(0,015) \\
\end{array}$ & & & & & \\
\hline $\begin{array}{l}\text { The need to be surrounded by attention and } \\
\text { care }\end{array}$ & $\begin{array}{c}468^{*} \\
(0,047)\end{array}$ & & & & & \\
\hline
\end{tabular}




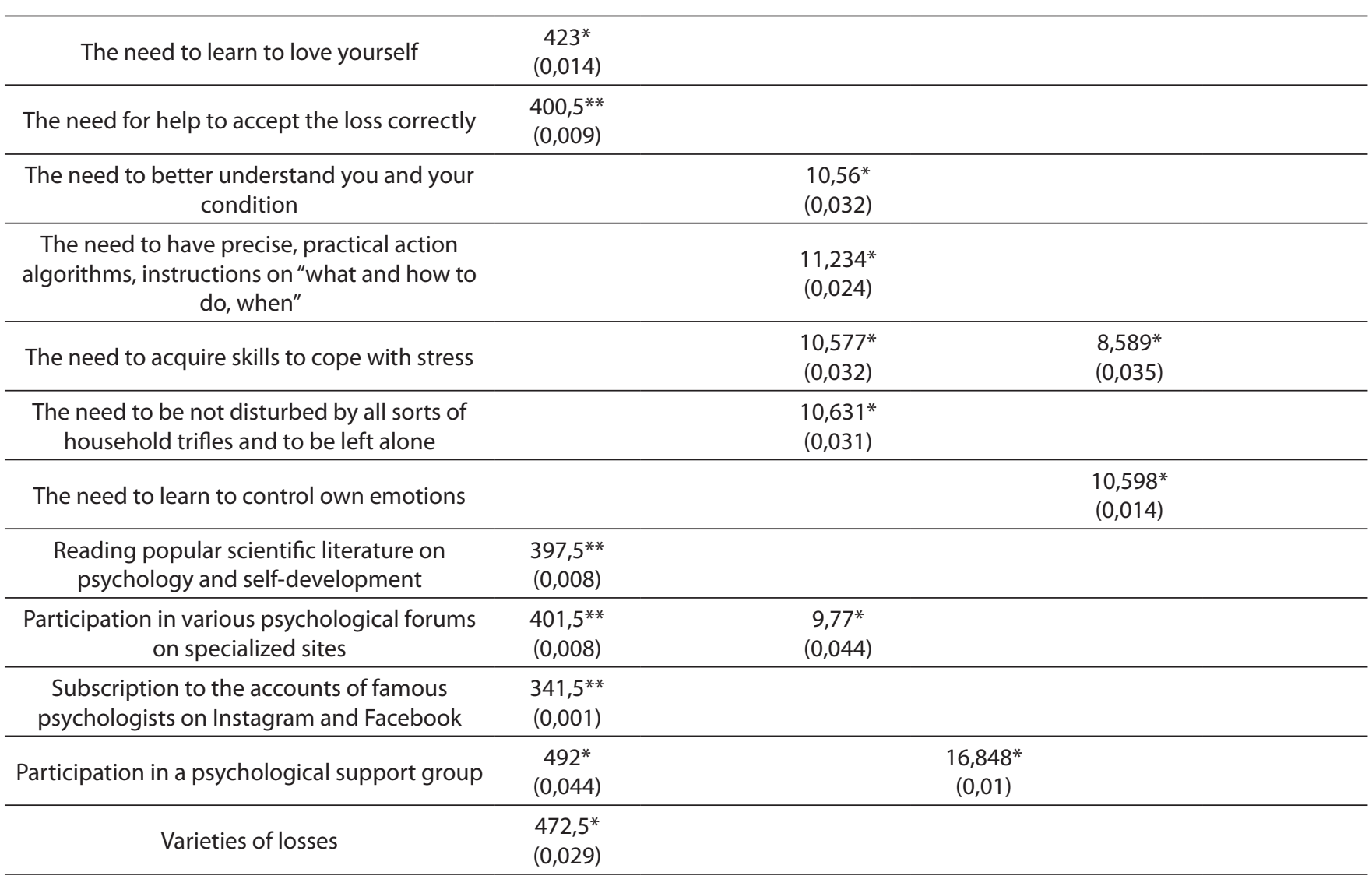

${ }^{*} p \leq 0,05 ;{ }^{* *} p \leq 0,01$.

According to Block 2. Loss experience support (Tab. II), women during pandemic quarantine are more stressed than men; are more likely to suffer from emotional loss; have more significant variability and the number of losses in general [16]. Women, if they had the opportunity, are more likely to seek professional psychological help and have more experience in this, in particular in the following forms: reading popular science literature on psychology and self-development, participation in psychological forums on specialized sites, subscription to the accounts of famous psychologists on Instagram and Facebook, participation in psychological support groups. Women find the following forms of support more convenient and necessary while loss experiencing: the opportunity to mourn openly, without condemnation and criticism (crying, shouting, screaming, swearing, whining), face-to-face consultation with specialists (nurse, psychologist, social worker), and online support (specialized applications, chats, Internet services, YouTube channels). Women also need more of their loved ones to understand them better and their condition and desire to be heard and listened to. They have a greater need to express "negative emotions" without fear or condemnation. Women need their loved ones to be around, love, believe in them, surround them with attention and care, calm them down and give hope, teach them to love themselves, and help them accept the loss correctly.

Respondents living in villages and urban-type settlements are more affected by the loss of health than those living in cities. Respondents from rural areas and regional centers are more focused on the result of support as an understanding of themselves and their state. Village residents also need more practical, precise algorithms of action, instructions on "what and how to do when..." during the experience of loss. Respondents living in rural areas and regional centers have more requests for stress management skills obtaining. Whereas the representatives of the capital and regional centers, compared to the periphery residents, expect more support during the loss experiencing by not being disturbed in all sorts of household chores and by being left alone.

Among the representatives of the youngest group (1924 y.o.), the spiritual sphere and the sphere of friendly relations turned out to be more damaged by losses than among the representatives of the older age groups. Meanwhile, the oldest respondents (46-70 y.o.) prefer to receive support when experiencing the loss from an important community (church, organization, significant group). Also, for the older generation, in comparison with the younger, the most convenient, practical, and necessary during the loss period is outlined such support as meditation (seeking support in their internal resources).

Respondents living alone or with children experience more stress than those living with partners, parents, or family. Also, those living alone suffered the most from losing friendship and personal life (love relationship). Those who live alone or with their parents were more sensitive to losses in the intellectual sphere. Singles and those living with children are more likely to seek the support and assistance 
Table III. Empirical values on (by) Mann-Whitney U test, Kruskal-Wallis H test block of questions "Online psychosocial support."

\begin{tabular}{|c|c|c|c|c|c|c|}
\hline \multirow[b]{2}{*}{ Dependent variables } & \multicolumn{6}{|c|}{ Grouping variables } \\
\hline & $\begin{array}{l}\text { Sex, } \\
U(p)\end{array}$ & $\begin{array}{l}\text { Age, } \\
H(p)\end{array}$ & $\begin{array}{l}\text { Place of } \\
\text { residence, } \\
H(p)\end{array}$ & $\begin{array}{l}\text { Living } \\
\text { condition, } \\
\text { H (p) }\end{array}$ & $\begin{array}{l}\text { Education, } \\
\qquad \mathbf{H}(\mathbf{p})\end{array}$ & $\begin{array}{c}\text { Financial } \\
\text { satisfaction, } \\
\text { H (p) }\end{array}$ \\
\hline $\begin{array}{l}\text { How often do you get the advice you } \\
\text { really need using the online means of } \\
\text { psychosocial support? }\end{array}$ & $\begin{array}{c}441^{*} \\
(0,022)\end{array}$ & & & & $\begin{array}{l}9,768^{*} \\
(0,021)\end{array}$ & $\begin{array}{l}11,123^{*} \\
(0,025)\end{array}$ \\
\hline $\begin{array}{l}\text { How often do you get suggestions in an } \\
\text { online community about how to deal with } \\
\text { personal problems? }\end{array}$ & $\begin{array}{c}396^{* *} \\
(0,006)\end{array}$ & $\begin{array}{l}8,463^{*} \\
(0,015)\end{array}$ & & & $\begin{array}{l}10,521^{*} \\
(0,015)\end{array}$ & \\
\hline $\begin{array}{l}\text { I am glad to be in an online community } \\
\text { where I get psychosocial support. }\end{array}$ & & $\begin{array}{c}10,693^{* *} \\
(0,005)\end{array}$ & & $\begin{array}{l}14,587^{*} \\
(0,024)\end{array}$ & & \\
\hline $\begin{array}{l}\text { How often do you confide about your } \\
\text { problems with other members in an online } \\
\text { community? }\end{array}$ & & $\begin{array}{c}11,915^{* *} \\
(0,003)\end{array}$ & & & & $\begin{array}{l}9,605^{*} \\
(0,048)\end{array}$ \\
\hline $\begin{array}{l}\text { How often do you use the means of online } \\
\text { psychosocial support you have mentioned? }\end{array}$ & & $\begin{array}{l}6,591^{*} \\
(0,037)\end{array}$ & & & & \\
\hline
\end{tabular}

${ }^{*} p \leq 0,05 ; * * 0,01$.

Table IV. Empirical values by Mann-Whitney U test, Kruskal-Wallis H test block of questions "Psychological support by playback theatre."

\begin{tabular}{|c|c|c|c|c|c|c|}
\hline \multirow[b]{2}{*}{ Dependent variables } & \multicolumn{6}{|c|}{ Grouping variables } \\
\hline & $\begin{array}{l}\text { Sex, } \\
U(p)\end{array}$ & $\begin{array}{l}\text { Age, } \\
H(p)\end{array}$ & $\begin{array}{l}\text { Place of } \\
\text { residence, } \\
\text { H (p) }\end{array}$ & $\begin{array}{c}\text { Living } \\
\text { condition, } \\
\text { H (p) }\end{array}$ & $\begin{array}{c}\text { Education, } \\
\text { H (p) }\end{array}$ & $\begin{array}{c}\text { Financial } \\
\text { satisfaction, } \\
\text { H (p) }\end{array}$ \\
\hline Desire to tell a story to an audience & & & $\begin{array}{l}12,524 \\
(0,014) \\
\end{array}$ & & $\begin{array}{c}9,546 \\
(0,023) \\
\end{array}$ & \\
\hline Having a specific story & & & & & $\begin{array}{c}8,536 \\
(0,036)\end{array}$ & \\
\hline
\end{tabular}

${ }^{*} p \leq 0,05$.

Table V. Empirical values by Mann-Whitney U test, Kruskal-Wallis H test block of questions "Community support."

\begin{tabular}{|c|c|c|c|c|c|c|}
\hline \multirow[b]{2}{*}{ Dependent variables } & \multicolumn{6}{|c|}{ Grouping variables } \\
\hline & $\begin{array}{l}\text { Sex, } \\
U(p)\end{array}$ & $\begin{array}{l}\text { Age, } \\
H(p)\end{array}$ & $\begin{array}{c}\text { Place of } \\
\text { residence, } \\
\text { H (p) }\end{array}$ & $\begin{array}{c}\text { Living } \\
\text { condition, } \\
\text { H (p) }\end{array}$ & $\begin{array}{l}\text { Education, } \\
\qquad H(p)\end{array}$ & $\begin{array}{c}\text { Financial } \\
\text { satisfaction, } \\
\text { H (p) }\end{array}$ \\
\hline $\begin{array}{l}\text { Communication of community residents } \\
\text { with internally displaced persons }\end{array}$ & $\begin{array}{c}445^{*} \\
(0,024)\end{array}$ & & & & & \\
\hline $\begin{array}{l}\text { Reasons for changing the place of residence } \\
\text { of community residents }\end{array}$ & & & & & & $\begin{array}{l}10,148^{*} \\
(0,038)\end{array}$ \\
\hline
\end{tabular}

${ }^{*} p \leq 0,05$.

of mentors or coaches. The same two categories of respondents (single and with children) more often than those living with families, consider the most convenient, practical, and necessary during the period of loss such a form of support as participation in group or individual challenges (accepting challenges, completing new, complicated, non-standard, original tasks to test yourself). Respondents living in complete families with partners and children have more experience participating in a psychological support group (for example, a support group for people whose relatives have died, who have lost their job, betrayed, or so).

Respondents without higher education suffer more from losses in the spiritual sphere, friendly relations, and person- al growth; financially dissatisfied respondents - from losses in the financial sphere and professional activity (sphere of work). The category of respondents with a scientific degree, compared to others, differs in that their financial sphere is the least damaged by the pandemic losses. During the loss period, respondents with secondary education seek psychological support as more skills to cope with stressful situations and learn to control their emotions.

Block 3. Online psychological support (Tab. III). The youngest respondents (19-24 y.o.), more often than the respondents of older age groups, use online psychological support in general. They also more often find solutions to their problems through online means of psychological 
support, listen more often to the problems of other users, and are more willing to visit the community where they receive online psychological support.

Women are more likely to get the ideas they needed and find solutions to their problems through online psychological support.

Unlike respondents who live in a large family, single people are more likely to visit the community of online psychological support.

Respondents with secondary, secondary special education more often find solutions to their problems and get the ideas they needed due to online psychological support.

In online psychological support, more financially satisfied respondents are also more likely to get the ideas they needed and listen to other users' problems.

Block 4. Psychological support by playback theatre (Tab. IV). Residents of cities are more willing to tell stories from their own lives at a playback theatre performance than residents of villages and small towns. Respondents with higher education are more willing to tell a story to an audience and are more likely to have a specific story to play on stage.

Block 5. Community support (Tab. V). Women are more likely to communicate with IDPs than men, which confirms intensive communication between women and internally displaced persons. Respondents who are unsatisfied with their finances more often consider changing the place of residence of community members as a positive life strategy.

\section{DISCUSSION}

The COVID-19 pandemic and socio-demographic indicators are a particular background for the opportunities for Ukrainian citizens to receive psychosocial support. The factors of female gender and elder age are partially confirmed as in the study on increasing fears of COVID-19 [17].

The part of gender in psychosocial support obtaining is quite significant; however, since women predominate in the sample composition (84\%), it is necessary to pay attention to the limited reliability of results distribution. In this case, supportive interventions should be adapted to the female audience but create conditions for greater involvement of men.

Age is also an influential factor in obtaining psychosocial support during a pandemic. Trends for youth in online involvement, and focus on personal and community resources in older respondents must also be considered when organizing face-to-face and remote psychosocial interventions.

Respondents' living conditions and residence status are also crucial for psychosocial support obtaining. The audience of people living alone or with children should be focused on by non-governmental civic initiatives to develop structured and exciting group activities for better social integration. Better ability to use information resources in an urban environment can be a factor that improves the overall performance of citizens to receive psychosocial support, so psychosocial interventions should be directed primarily to the periphery citizens, becoming the prerogative of the public sector.
Separately, we can talk about the importance of education and financial satisfaction factors in psychosocial support obtaining. The data on the needs during pandemic losses experiencing in people without higher education can be interpreted as a request to develop precise algorithms for self-help, which the governmental and public sectors can disseminate. Better involvement in online interventions for those satisfied with their finances can be provided by monetizing procedures.

\section{CONCLUSIONS}

Segregation of the sample in obtaining psychosocial support during the COVID-19 pandemic by socio-demographic characteristics of sex, age, place, and residence status, education, satisfaction with financial security contains valuable material for building a strategy of supportive interventions by public and governmental sectors for various categories of Ukrainian citizens. The selected most sensitive to psychosocial interventions socio-demographic groups should be regarded as those ready to be involved in supportive environments at the workplaces and outside them. Particular attention should be paid to the identified psychological requests of the population to receive various forms of psychosocial support in both online and offline formats. The prospect of implementing the obtained results can be the creation of specialized smartphone applications, an online adaptation of playback theatre, development of gender-sensitive online programs for the IDPs' integration into local communities.

\section{REFERENCES}

1. Stern A. Recomendaciones psicológicas para afrontar la pandemia COVID-19. Universidad de Buenos Aires, 2020. https://www.academia. edu/42406940/. [date access 02.09.2020]

2. Wang C., Pan R., Wan X. et al. Immediate psychological responses and associated factors during the initial stage of the 2019 coronavirus disease (COVID-19) epidemic among the general population in China. International Journal of Environmental Research and Public Health. 2020:17:1729.

3. Brooks S.K., Webster R.K., Smith L.E. et al. The psychological impact of quarantine and how to reduce it: rapid review of the evidence. The Lancet. 2020;395:912-920.

4. Aluh D.0., Onu J. The need for psychosocial support amid COVID-19 crises in Nigeria, TPGTa. Psychological Trauma:Theory, Research, Practice, and Policy. 2020;12(5):557-558.

5. UNICEF. Mental Health \& Psychosocial Support (MHPSS). 2019. https:// www.unicef.org/media/73726/file/UNICEF-MH-and-PS-TechnicalNote-2019.pdf. [date access 02.09.2020]

6. Sim H.S., How C.H. Mental health and psychosocial support during healthcare emergencies-COVID-19 pandemic. Singapore medical journal. 2020;61(7):357.

7. Rao S.R., Spruijt 0., Sunder P. et al. Psychosocial aspects of COVID-19 in the context of palliative care - A quick review. Indian Journal of Palliative Care. 2020;26(1):116.

8. Martorella G., Fredericks S., Sanders J., Wynne R. Breaking pandemic chain reactions: telehealth psychosocial support in cardiovascular disease during COVID-19. European Journal of Cardiovascular Nursing. 2021;20(1):1-2. 
9. Potash J.S., Kalmanowitz D., Fung I. et al. Art therapy in pandemics: Lessons for COVID-19. Art Therapy. 2020;37(2):105-107.

10. Voznesenska 0.L. et al. Prostir art-terapii. Zbirnyk naukovykh prats. Kyiv: Kropyvnytskyi. 2020, 58 p. (in Ukrainian).

11. Sliusarevskyi M.M. "Onlain-kolo": dosvid psykholohichnoi pidtrymky i dopomohy naselenniu pid chas pandemii COVID-19.Visnyk Natsionalnoi akademii pedahohichnykh nauk Ukrainy. 2020;2(1):1-5. (in Ukrainian).

12. Sliusarevskyi M.M., Naydionova L.A., Voznesenska O.L. et al. Dosvid perezhyvannya pandemiyi COVID-19: dystantsiyni psykholohichni doslidzhennya, dystantsiyna psykholohichna pidtrymka: materialy onlayn-seminariv 23.04.2020 "Dosvid karantynu: dystantsiyna psykholohichna dopomoha i pidtrymka" ta 15.05.2020 "Dystantsiyni psykholohichni doslidzhennya v umovakh pandemiyi COVID-19 i karantynu", Kyiv: ISPP NAPN Ukrayiny. 2020, 406p. (in Ukrainian).

13. Velykodna M.S. Modeli i metody nadannia psykholohichnoi dopomohy pid chas pandemii COVID-19: zarubizhnyi dosvid. Psykholohichnyi chasopys. 2020;6(4):229-237. (in Ukrainian).

14. Tytarenko T.M. Posttravmatychne zhyttietvorennia: sposoby dosiahnennia psykholohichnoho blahopoluchchia: monohrafiia. Kropyvnytskyi: Imeks-LTD. 2020, 54p. (in Ukrainian).

15. Tytarenko T.M., Zlobina 0.H., Dvornyk M.S. et al. Porodzheni viinoiu spilnoty yak sotsialni donory i retsypiienty: materialy mizhdystsyplinarnoho naukovoho seminaru 25.03.2021, Kyiv: ISPP NAES, IS NAS. 2021, 72 p. (in Ukrainian).

16. Myronchak K. Vtraty pid chas pandemii: riznovydy ta osoblyvosti perezhyvannia. Scientific Studios on Social and Political Psychology. 2020;46(49):51-58. (in Ukrainian).

17. Parlapani E., Holeva V., Voitsidis P. et al. Psychological and behavioral responses to the COVID-19 pandemic in Greece. Frontiers in psychiatry. 2020;11(821). doi:10.3389/fpsyt.2020.00821.

\section{ORCID and contributionship:}

Tetiana M. Tytarenko: 0000-0001-8522-0894 A, F

Maryna S. Dvornyk: 0000-0003-1505-0169 A, D, F

Tetiana O. Larina: 0000-0001-8975-3348 ${ }^{\text {B-D }}$

Kateryna V. Myronchak: 0000-0002-1378-0494 ${ }^{\text {B, D, E }}$

Volodymyr V. Savinov: 0000-0001-5830-2333 ${ }^{\text {B, C, } E}$

Julia D. Hundertaylo: 0000-0001-6959-663X $X^{B, C}$

Giuseppe Vella: 0000-0002-3441-7598 ${ }^{F}$

\section{Conflict of interest:}

The Authors declare no conflict of interest

\section{CORRESPONDING AUTHOR Maryna S. Dvornyk}

Institute of Social and Political Psychology National Academy

of Educational Sciences of Ukraine

15 Andriivska st., 04070 Kyiv, Ukraine

tel: +380668144949

e-mail: dvornyk.marina@gmail.com

Received: 30.05 .2021

Accepted: 27.09 .2021

A - Work concept and design, B - Data collection and analysis, C - Responsibility for statistical analysis, D-Writing the article, $\mathbf{E}$-Critical review, $\mathbf{F}$ - Final approval of the article 


\title{
CULTURAL AWARENESS IN CONTEMPORARY MENTAL HEALTH PRACTICE
}

D0I: 10.36740/WLek202111114

\author{
Svitlana L. Fedko ${ }^{1}$, Alona Kurbatova ${ }^{2}$, Natalya Remesnyk ${ }^{3}$, Iryna Matviienk0 ${ }^{4}$, Alina Parasiei-Hocher ${ }^{5}$, \\ Nataliia Kryvda ${ }^{6}$, Fatma Elzahraa Hussin ${ }^{7}$ \\ 'KYIV NATIONAL LINGUISTIC UNIVERSITY, KYIV, UKRAINE \\ 2OPEN INTERNATIONAL UNIVERSITY OF HUMAN DEVELOPMENT «UKRAINE» KYIV, UKRAINE \\ ${ }^{3}$ NATIONAL ACADEMY OF EDUCATIONAL SCIENCES OF UKRAINE, KYIV, UKRAINE \\ ${ }^{4}$ NATIONAL UNIVERSITY OF LIFE AND ENVIRONMENTAL SCIENCES OF UKRAINE, KYIV, UKRAINE \\ ${ }^{5}$ UKRAINIAN INSTITUTE OF ARTS AND SCIENCES, KYIV, UKRAINE \\ ${ }^{6}$ TARAS SHEVCHENKO NATIONAL UNIVERSITY OF KYIV , KYIV, UKRAINE \\ ${ }^{7}$ AIN SHAMS UNIVERSITY, CAIRO, EGYPT
}

\begin{abstract}
The aim: To analyze cultural conditionality of mental health care practice; to explore the relationship between cultural awareness of mental health practitioners, their professional experience and professional status.

Materials and methods: It was hypothesized that cultural competence is expected to emerge with professional experience of mental health practitioners. The Sociocultural Awareness Questionnaire was administered to mental health care practitioners - counselors, clinicians, and therapists - $(\mathrm{N}=62)$, aged 27 to 65 , with professional work experience from 1 to 25 years. The majority of the respondents were from Kyiv (Ukraine).

Results: There is no significant correlation between the duration of the period of professional activity of mental health care practitioners and their ideas concerning cultural awareness $(r=-0.084, p=0.515)$. In the same way there is no statistically significant differences $(U=397.500, p=0.866)$ in cultural awareness between two groups of Mental Health care practitioners based on a professional status criterion.

Conclusions: No professional experience, nor status are the basis for the sociocultural awareness of mental health practitioners. The assumption that cultural competence is expected to emerge with experience has not been confirmed during the pilot study.
\end{abstract}

KEY WORDS: Mental health, psychotherapy, culture, cultural awareness, socio-cultural competence

Wiad Lek. 2021;74(11 p.l):2762-2767

\section{INTRODUCTION}

This study has explored the issue that lies at the intersection of culture and mental health. It consists of theoretical overview and empirical evaluation of problems relating to cultural awareness of contemporary mental health practitioners.

The cultural and ethnic factors which tend to influence the diagnosis and treatment of mental disorders are of paramount clinical significance these days. Culture is increasingly becoming an important issue that should be taken into consideration when providing mental health service. A challenging area in the field of mental health care is the relationship between ethnic / cultural factors and knowledge about mental health issues. It has now been suggested that the key factors that may influence perceptions of mental illness are: personal experiences, educational level and ethnicity [1]. This paper explores the cultural/ethnic component in contemporary mental health service.
Generally, culture refers to the "cumulative deposit of knowledge, experience, beliefs, values, attitudes, meanings, hierarchies, religion, notions of time, roles, spatial relations, concepts of the universe, and material objects and possessions acquired by a group of people in the course of generations through individual and group striving" [2]. In psychological terms, culture is "the set of attitudes, values, beliefs, and behaviors shared by a group of people, but different for each individual, communicated from one generation to the next ... Individual differences in culture can be observed among people in the degree to which they adopt and engage in the attitudes, values, beliefs, and behaviors that, by consensus constitute their culture" [3]. Thus, it is quite obvious that cultural factors play a crucial role in both experience and treatment of mental health disorders.

Theoretical framework of this research is based on the following considerations: 1) cultural relativism in the assessment of mental normality and abnormality [3-5]. 2) 
the differences in the clinical manifestations of the most common mental illnesses depending upon the specific cultural context [5-7]. 3) culturally-specific syndromes as mental disorders which occur in certain cultures and result in abnormal behavior [8-11].

More recent evidence highlights four ways culture can impact mental health. They are: cultural stigma (the specific way of looking at mental health, pathology etc.); comprehension of symptoms (culture can influence how people describe and feel about their symptoms); community support (family and social assistance); resources (the mental health treatment options) [12].

The primary research that refers to the mental disorders in relation to the cultural context was carried out by E. Kraepelin [8]. This scientific field was defined as "Comparative Psychiatry". Later, the concept of "Ethnopsychiatry" was introduced by J. Devereux [9]. At the same time E. Wittkover proposed the term "Transcultural Psychiatry" [13].

A fundamental issue for all above-mentioned research fields is to explain the influence of ethnic and cultural peculiarities to the etiology, pathogenesis and clinical manifestations of psychopathological phenomena, as well as their therapy and prevention.

A few relevant examples from the related field. According to clinicians, such a mental disorder as schizophrenia has a more favorable course for patients from less economically developed countries (Colombia, India and Nigeria) than for those living in more civilized countries [14]. Reactive psychoses are more common in Africa than in Europe [15]. In addition, there has been a huge amount of research on the problem of ethnocultural differences in the experience of depression and the assessment of depressive symptoms $[6,16,17]$.

The methodological framework of current research is based on the Lev S. Vygotsky\&apos;s sociocultural theory that explains human development as a socially mediated process [18]. The formation of the psyche as a process of cultural appropriation is the main thesis of the cultural-historical concept. According to Vladimir. D Mendelevich, the main issue of ethnocultural research in psychiatry is "... the influence of ethnic, national, cultural features of man on the etiology, pathogenesis, clinical manifestations and patterns of psychopathological phenomena, as well as on the formation of the outcome of mental illness, their therapy and prevention" [15]. Mendelevich's understanding of this phenomenon is fully endorsed by experience.

The main problem on the way to a culture-oriented approach is the rejection of universal models of psychological assistance and the search for culturally consistent models that would correspond to the client\&apos;s cultural background. The situation is complicated by the fact that, as mentioned by N. Gopalkrishnan, much of the theory and practice of mental health, including psychiatry and mainstream psychology, have emerged from Western cultural traditions and Western understandings of the human condition [19]. So, many experts now contend that mental health practice cannot be universal for people from different cultures or ethnic groups $[20,21,22]$. Moreover, as was mentioned by $\mathrm{O}$. Zinoviev, who regarded the terms Westernization, Americanization, and Globalization as synonymous: "The evolutionary process of mankind has taken on a form that is generally characterized by the concepts of "Westernization", "Americanization", and "globalization". All these concepts denote the same process, only considered from different points of view. This process is in reality the conquest of all mankind by the Western world as a whole" [23].

The solution to this problem is the specific professional feature of a mental health practitioner - socio-cultural awareness. This is exactly what explains our idea for an empirical study of the chosen issue.

\section{THE AIM}

The objective of the current study is to analyze cultural conditionality of mental health care practice; to explore the relationship between cultural awareness of mental health practitioners, their professional experience and professional status.

\section{MATERIALS AND METHODS}

\section{SETTINGS}

The present study was designed to explore the relationship between cultural awareness of mental health practitioners, their professional experience and professional status. A distinctive feature of this study is the focus on professional consciousness of mental health care practitioners.

The study consisted of 2 steps: data collection and data analysis.

\section{DATA COLLECTION TOOLS}

In accordance with the specifics of the study, the task of selection of the appropriate data collection tools was solved by applying a Sociocultural Awareness Questionnaire, that was previously used in research on social cultural reflection of counseling psychologists [24]. It was the first attempt to obtain results that would reflect the degree of sociocultural competence of mental health practitioners focused on psychologists and counselors was reported in 2017.

In order to differentiate the respondents by age, professional experience, status etc. some additional basic demographic questions (including gender and age) were asked. The data were collected by in-person interviews as well as absentia (by using Internet).

\section{PARTICIPANTS}

The sample included the professionals from Mental Health institutions in Ukraine, both public and private. The majority of the respondents were from Kyiv (Ukraine).

In order to provide reliable and valid empirical data, we sought to achieve reasonable composition of experimental sample in terms of age, professional experience and professional status. 
The study involved 62 mental health care practitioners: counselors, clinicians, and therapists, aged 27 to 65 . As shown in Table I, the mean age of the respondents was 39.16 years $(S D=9.23)$. Our experimental sample covered a wide range of work experience (from 1 to 25 years). The mean professional experience was 11.16 years $(S D=5.68)$. The above indicators are very important in the context of this study, since they allow us to ensure the comprehensiveness of the study and the correspondence of the experimental sample to the characteristics of the general population.

In terms of professional status, the percentage of mental health care practitioners with academic degree is 30,6\% of the total sample, as indicated in Table II.

Due to the fact that our study is preliminary, the experimental sample group is rather small. For that reason, we made the effort to bring it into line with features of the general population.

\section{DATA ANALYSIS}

The Quantitative Analysis was used for data processing. For this purpose, the empirical data was subjected to the coding procedure that enabled its further processing using statistical methods. The Descriptive Statistics, Spearman Rank Correlation Coefficient and Mann-Whitney U Test were used. The significance level was set to 0.05 or $5 \%$ (the $\mathrm{p}$-value $\leq 0.05$ was considered significant). All statistical calculations were performed using SPSS (PASW) Statistics 23.0 .

\section{RESULTS}

Based on research tasks, a special algorithm for was formed for data processing.

The first purpose of the empirical part was to test the possible correlation between professional experience and cultural awareness. Since the variables showed a non-normal distribution, Spearman's correlation analysis was used to identify the correlation between the professional experience and cultural awareness of the mental health care practitioners. Results of the analysis are reported in Table III.

Table III shows that Sig.(2-tailed) $=0.515$. This value is higher than 0.05, indicating that there is no significant relationship between the duration of the period of professional activity and ideas concerning cultural awareness. Spearman's rho (r) was found to be -0.084 . This value indicates a weak relationship or no relationship.

The second attempt of revealing the basis of sociocultural awareness of mental health care practitioners was to compare the groups based on a status criterion. So, we ran non-parametric Mann-Whitney $U$ Test for this purpose.

The table above indicates that for Status category Mental Health Care Practitioners we have 43 observations whose total sum of ranks is 1343.50 . This results in a mean rank of 31.24. At the same time for category Mental Health Care Practitioners with $\mathrm{PhD}$ or Doctorate degree we have 19 observations whose total sum of ranks is 609.50 . This results in a mean rank of 32.08. So, as we can see, both groups can be considered as having almost the same mean ranks and thus tends to take the similar values.

Here we see that actual Sig.(2-tailed) is $0.866(\mathrm{p}=0.866)$. We therefore have significant evidence to argue that the difference between the medians of two subgroups is not statistically significant. The research results, therefore, showed no statistically significant differences in the cultural awareness between two groups of mental health care practitioners.

\section{DISCUSSION}

Our study shows that no professional experience, nor status are the basis for the sociocultural awareness of mental health practitioners. The disclosure of its true reasons is the fundamental task for the future research since the knowledge of these reasons will serve as a support for the development of socio-cultural competence of psychotherapists and other mental health practitioners.

In the meantime, we can make some assumptions based on the results of studying the relevant sources. Thus, the key systemic factors shaping the cultural awareness of contemporary mental health practitioners presumed to be as following.

1. Work experience with people from other cultures / work experience in a multicultural environment. The encounter with a representative of a different mentality is already a kind of challenge for a professional. All of these are, no doubt, factors contributing to the cultural awareness development.

2. The development of sociocultural competence in the process of mastering the specialty. The disciplines which develop cultural competence and cultural sensitivity of students are widely represented in the training program for mental health practitioners in the Western countries. Few examples: the discipline called "Culture And Mental Health" at University of California, USA [25]; "Cultural Psychiatry” at UC Davis School of Medicine, USA [26]; "Multicultural Mental Health" at Henderson State University, [27]; "Cultural Competence And Multicultural Mental Health Care" at University of Toronto, Canada [28], "Culture and mental health in global perspective" at University of Edinburgh, Scotland [29]. All these courses cover social and cultural determinants of mental health and disorders as well as mental health of indigenous populations, ethnocultural minorities, immigrants, and refugees [27].

3. Personal non-professional cultural experience, experience of communication with representatives of different cultures, spiritual and personal development, experience of emigration, adaptation to a new cultural environment etc. In such situations, individual acquires the effective ways of social interaction with people of various cultural backgrounds. Gaining cultural competence is a lifelong process of increasing self-awareness, developing social skills and behaviors around diversity, and gaining the ability to advocate for others $[30 ; 31]$. 
Table I. Demographic Characteristics of Sample Members (age, professional experience)

\begin{tabular}{ccccccc}
\hline & N & Minimum & Maximum & Mean & Std. Deviation \\
\hline Age (yr.) & 62 & 27 & 65 & 39,16 & 9,226 \\
\hline Professional Experience (yr.) & 62 & 1 & 25 & 11,16 & 5,681 \\
\hline Valid N (listwise) & 62 & & & & \\
\hline
\end{tabular}

Table II. Distribution of sample by professional status (\%)

\begin{tabular}{cccccc}
\hline & & Frequency & $\%$ & Valid \% & Cumulative \% \\
\hline \multirow{3}{*}{ Valid } & Mental Health Care Practitioner & 43 & 69,4 & 69,4 & 69,4 \\
\cline { 2 - 6 } & $\begin{array}{c}\text { Mental Health Care Practitioner } \\
\text { (PhD or Doctorate degree) }\end{array}$ & 19 & 30,6 & 30,6 & 100,0 \\
\cline { 2 - 6 } & Total & 62 & 100,0 & 100,0 \\
\hline
\end{tabular}

Table III. Spearman's correlation analysis

\begin{tabular}{|c|c|c|c|c|}
\hline & & & $\begin{array}{l}\text { Professional } \\
\text { experience }\end{array}$ & $\begin{array}{c}\text { Cultural } \\
\text { awareness }\end{array}$ \\
\hline \multirow{6}{*}{ Spearman\&apos;s rho } & \multirow{3}{*}{$\begin{array}{l}\text { Professional } \\
\text { experience }\end{array}$} & Correlation Coefficient & 1,000 &,- 084 \\
\hline & & Sig. (2-tailed) & . & ,515 \\
\hline & & $\mathrm{N}$ & 62 & 62 \\
\hline & \multirow{3}{*}{$\begin{array}{c}\text { Cultural } \\
\text { awareness }\end{array}$} & Correlation Coefficient &,- 084 & 1,000 \\
\hline & & Sig. (2-tailed) & ,515 & . \\
\hline & & $\mathrm{N}$ & 62 & 62 \\
\hline
\end{tabular}

Table IV. Mann-Whitney U test

\begin{tabular}{|c|c|c|c|c|}
\hline & Status & $\mathbf{N}$ & Mean Rank & Sum of Ranks \\
\hline \multirow{3}{*}{ Cultural Awareness } & Mental Health Care Practitioners & 43 & 31,24 & 1343,50 \\
\hline & $\begin{array}{l}\text { Mental Health Care Practitioners (PhD or } \\
\text { Doctorate degree) }\end{array}$ & 19 & 32,08 & 609,50 \\
\hline & Total & 62 & & \\
\hline \multicolumn{5}{|c|}{ Test Statistics $^{\mathrm{a}}$} \\
\hline \multicolumn{5}{|c|}{ Cultural Awareness } \\
\hline Mann-Whitney U & 397,500 & & & \\
\hline Wilcoxon W & 1343,500 & & & \\
\hline Z &,- 168 & & & \\
\hline Asymp. Sig. (2-tailed) & ,866 & & & \\
\hline
\end{tabular}

${ }^{a}$ Grouping Variable: Status

Undoubtedly, this is not a complete list of possible factors which may contribute to the of the socio-cultural competence of mental health professionals.

\section{CONCLUSIONS}

The effective mental health practice should be directly associated with the specific cultural environment it is provided in. The scientific provisions relating to cultural awareness in mental health practice are reflected in the wide array of scientific theories. The cornerstone of all those theories is Lev Vygotsky\&apos;s Cultural Historical Theory of devel- opment and determination of human mental life. This, in turn, goes back to the origins of the cultural anthropology.

Our assumption that cultural competence is expected to emerge with experience has not been confirmed during the pilot study. This study showed, that no professional experience, nor status are the basis for the sociocultural awareness of mental health practitioners It can be assumed that some other factors give rise to the emergence and development of professional skill under consideration.

Despite the theoretical relevance of the culture-oriented approach in mental health system, the practical issues of its development have not been sufficiently studied to date. 


\section{LIMITATIONS OF THE STUDY}

This study has its own limitations, including the fact that it is based on self-reported data that is difficult to verify. An unfortunate reality is the current unavailability of another effective method to measure the cultural awareness of mental health care practitioners. Another concern is related to the relatively small sample size, at first sight. Due to the novelty of our research field, it is better to test a new research hypothesis in a small sample group first. Measures to increase the sample size have to be taken in future, such as involvement of respondents from different countries and cultural backgrounds.

\section{STRENGTHS OF THE STUDY}

Our study addressed relevant research topic. Currently there has been a very few research into the cultural awareness in psychology and psychotherapy, particularly for mental health practitioners. Despite the fact, the cultural conditioning of the human psyche is disclosed in psychology quite comprehensively, the representation of the principle of cultural appropriateness in the professional consciousness of mental health practitioners had not been sufficiently explored.

\section{REFERENCES}

1. Palmer E., Douglass A., Smith T. et. al. Evaluation of perceptions and knowledge of mental illness in the United States through crowdsourcing. Mental Health Clinician. 2018; 8(5): 227-234. doi:10.9740/mhc.2018.09.227.

2. Hofstede G. Cultures and Organizations: Software of the mind. New York: McGraw Hill. 1997, 201p.

3. Matsumoto D. Culture and Psychology. CA: Brooks/Cole Publishing Company, Pacific Grove. 1996, 114p.

4. Alarcon D. Culture, cultural factors and psychiatric diagnosis: review and projections. World Psychiatry. 2009; 8(3): 131-139.

5. Lehti A., Hammarström A., Mattsson B. Recognition of depression in people of different cultures: a qualitative study. BMC Family Practice. 2009; 10(1): 53. doi:10.1186/1471-2296-10-53.

6. Kleinman A. Culture and Depression. The New England Journal of Medicine. 2004; 35(10): 951-953. doi: 10.1056/NEJMp048078.

7. Viswanath B., Chaturvedi S. Cultural Aspects of Major Mental Disorders: A Critical Review from an Indian Perspective. Indian Journal of Psychological Medicine. 2012; 34(4): 306-312. doi: 10.4103/02537176.108193.

8. Kraepelin E. Psychiatrisches aus Java. Zentralblatt Nervenheilkd Psychiatr. 1904; 27: 468-469.

9. Devereux J. Ethnopsychanalyse complémentariste. Paris: Flammarion. 1972, 85p.

10. Furlong A. The Japanese Hikikomori Phenomenon: Acute Social Withdrawal Among Young People. The Sociological Review. 2008; 56(2): 309-325. doi: 10.1111/j.1467-954X.2008.00790.x.

11. Frank B. The Geography of Madness: Penis Thieves, Voodoo Death, and the Search for the Meaning of the World Strangest Syndromes. Melville House, Boston. 2016, 63p.

12. National Council for Mental Wellbeing. Mental Health First Aid USA. (2019, July 11). Four Ways Culture Impacts Mental Health. Mental Health First Aid USA. https://www.mentalhealthfirstaid.org/2019/07/ four-ways-culture-impacts-mental-health/. [date access 06.05.2020]
13. Wittkower D., Fried J. Some problems of transcultural psychiatry. Culture and Mental Health. New York: The Macmillan Company. 1959, 71p.

14. Matsumoto D. Human, culture, psychology. Incredible mysteries, research and discoveries. SPb: Piter. 2008, 302p. (in Russian).

15. Mendelevich V.D. Psihiatricheskaya propedevtika: prakticheskoe rukovodtsvo. M.: GEOTAR-Media. 2014, 61p. (in Russian).

16. Leong F., Kalibatseva Z., Molchanova E. The culture and depression: definition, diagnostic difficulties and recommendations. 2012; 6(17). http://medpsy.ru [date access 06.05.2020]

17. Hourani L., Williams J., Forman-Hoffman V. et. al. Influence of spirituality on depression, posttraumatic stress disorder, and suicidality in active duty military personnel. Depress Res Treat. 2012; 5: 425-463. doi: $10.1155 / 2012 / 425463$.

18. Vygotsky L.S. Sobranie sochinenij: $v 6$ t. T. 3: Problemy razvitija psihiki. M.: Pedagogika. 1983, 106p. (in Russian).

19. Gopalkrishnan N. Cultural Diversity and Mental Health: Considerations for Policy and Practice. Frontiers in public health. 2018; 6: 179. doi: 10.3389/fpubh.2018.00179.

20. Bondarenko A.F. Ethical Personalism: Culturally-Oriented tradition in Psychological Counselling. Med. psihol. Ross. 2015;2(31). http://mprj. ru [date access 06.05.2020]

21. Henrich J., Heine J., Norenzayan A. The weirdest people in the world? Behavioral and Brain Sciences. 2010; 33(2-3): 61-83. doi: 10.1017/ S0140525X0999152X.

22. Kim U. Understanding human potential, creativity and achievement: Indigenous, cultural and psychological perspectives. Progress in Psychological Science around the World. London: Routledge. 2019, 348p. doi: 10.4324/9781315793184-22.

23. Zinoviev A.A., Zapad. Mental Health. M: Algorithm. 2007, 46p. (in Russian).

24. Bondarenko A.F, Fedko S.L. Socio-cultural competence of a present-day counselor: current prospects and future challenges. Psycholinguistics. 2017; 21(1):23-40.

25. Culture and mental health: Curriculum. University of California. 2012. https://dornsife.usc.edu/assets/sites/210/docs/PSYC_462 LOPEZ 20123.pdf [date access 06.05.2020]

26. Cultural psychiatry: Curriculum. UC Davis School of Medicine. 2021. https://health.ucdavis.edu/psychiatry/specialties/diversity/curriculum. html [date access 06.05.2020]

27. Multicultural mental health: Curriculum. Henderson State University. 2021. http://www.travislangley.info/?page_id=1465 [date access 06.05.2020]

28. Cultural competence and multicultural mental health care: Curriculum. University of Toronto. Coursera. 2020. https://www.coursera.org/ lecture/mental-health/4-6-cultural-competence-and-multiculturalmental-health-care-NPBD3 [date access 06.05.2020]

29. Culture and mental health in global perspective: postgraduate course curriculum. The University of Edinburgh. 2020. http://www.drps.ed.ac. uk/20-21/dpt/cxpgsp11563.htm [date access 06.05.2020]

30. Guzman M.R., Durden T.R., Taylor S.A. et al. Cultural Competence: An Important Skill Set for the 21st Century. Youth \& Families. 2016. https:// extensionpublications.unl.edu/assets/html/g1375/build/g1375.htm [date access 06.05.2020]

31. Fradelos E., Alikari V., Vus V. et al. Assessment of the relation between religiosity, anxiety, depression and psychological resilience in nursing staff. Health Psychology Research. 2020; 8(1): 30-34. doi: 10.4081/ hpr.2020.8234. 
ORCID and contributionship:

Svitlana L. Fedko: 0000-0003-3473-7417 ${ }^{A-D}$

Alona Kurbatova: 0000-0003-4173-0504 ${ }^{E, F}$

Natalya Remesnyk: 0000-0001-5885-6942 ${ }^{E, F}$

Iryna Matviienko: 0000-0002-0606-0544 ${ }^{E, F}$

Alina Parasiei-Hocher: 0000-0002-2340-5903 ${ }^{E, F}$

Nataliia Kryvda: 0000-0001-7429-769

Fatma Elzahraa Hussin: 0000-0002-9331-9373 E,F

\section{Conflict of interest:}

The Authors declare no conflict of interest.

\section{CORRESPONDING AUTHOR}

Svitlana L. Fedko

Kyiv National Linguistic University

73, Velyka Vasylkivska st., 03150 Kyiv, Ukraine

tel: +380974887217

e-mail: svitlana.fedko@knlu.edu.ua

Received: 17.05 .2021

Accepted: 06.10 .2021

A - Work concept and design, B - Data collection and analysis, C - Responsibility for statistical analysis,

D-Writing the article, $\mathbf{E}$-Critical review, $\mathbf{F}$ - Final approval of the article 


\title{
INTELLECTUAL DISABILITIES IN PRESCHOOLERS: MENTAL HEALTH DETERMINANTS DURING THE PERINATAL PERIOD OF DEVELOPMENT
}

DOl: 10.36740/WLek202111115

\author{
Oksana V. Boriak', Anna V. Chobaniann', Oleksandr V. Kolyshkin' ${ }^{1}$, Yurij Y. Kosenko ${ }^{1}$, Tetiana M. Dehtiarenko ${ }^{1}$, \\ Alla P. Kolyshkina', Galina Itskovich ${ }^{2}$ \\ 'SUMY STATE PEDAGOGICAL UNIVERSITY NAMED AFTER A.S. MAKARENKO, SUMY, UKRAINE \\ 2INTERDISCIPLINARY COUNCIL ON DEVELOPMENT AND LEARNING, NEW YORK, USA
}

\begin{abstract}
The aim: The aim of the study is to identify correlations between mental health indicators for preschoolers with intellectual disabilities and specifics of their prenatal, natal and postnatal development.

Materials and methods: Analysis of special medical, psychological and pedagogical literature; comparison and systematization of research material to determine mental health indicators for preschoolers with mild and moderate degrees of intellectual disability; mathematical methods of statistics.

Results: Empirical research, delineating formation of mental health indicators for senior preschoolers with intellectual disabilities, specified in low level of formation of both criteria, has been conducted. In general, we can conclude that the formation of mental health against the background of intellectual disability of preschool children is associated with low levels of self-awareness as a member of a social group; below age expectations' ability to perceive self and produce information about themselves, their preferences and meaningful adults; inability to adhere to social norms and values in behavior; high levels of anxiety; aggressive tendencies; lack of independence; helplessness concerning helping others; expectation of help from adults; content inappropriate emotional outbursts accompanied by frequent mood swings; and desire for solitude.

Conclusions: The obtained results confirm the conditionality of intellectual disability on negative factors in the perinatal period of development and strong correlation with mental disorders. It is important to correctly diagnose the existing manifestations of comorbid mental health disorders at preschool age and earlier, in order to implement appropriate measures for intervention and development.
\end{abstract}

KEY WORDS: mental health, preschool age, intellectual disability, neurodevelopmental disorders, comorbidity

Wiad Lek. 2021;74(11 p.l):2768-2773

\section{INTRODUCTION}

Mental health of children with neurodevelopmental disorders continues to present an acute problem. In modern publications, the interpretation of mental health of an individual is limited to successful performance of psychological functions resulting in productive activity, establishing relationships with other people, ability to adjust to changes and cope with adverse life circumstances [1]. The issues of mental health in toddlers and preschoolers with impaired development have been critical for a long time for both scientists and practitioners [2-4].

Research on the selected subject confirms and complements the data on conditional mental health of intellectually disabled children (IDC). Recent studies have concluded that there are three most common categories of mental disorders comorbid with intellectual developmental disorder (IDD): hyperkinesis (ADHD), anxiety disorders, and conduct and externalizing disorders [4].

According to the results of the systematic(psychological/ pharmacological) review of mental health problems in children (and adults) with severe intellectual impairments, mental and behavioral disorders and their key symptoms were classified as follows: attention deficit disorders, tic disorders, mood disorders, anxiety disorders, somatoform disorders, dissociative disorders, eating disorders, adaptation disorders [5]. The authors emphasize that ways in which behavior and behavioral problems may be associated with mental disorders or indicate them are complex.

Coexistence of mental disorders with intellectual disability in children aged 3 to 18 years is described in literature [6]. Research on the integration of social, psychological, and genetic influences on children's intellectual disabilities and their impact on parental mental health [7] has proved that the indicators of parental physical health are an important predictor of mental health of children.

However, these studies were conducted on a different methodological basis, whereas the issue of preschoolers' mental health has been left out of consideration. Their psycho-neurophysiology is characterized primarily by deficits in higher cortical functions, inertia of mental processes, underdevelopment of higher-level cognition with pronounced persistent deficits in abstract thinking, 
processes of generalization and distraction [8]. Extremely vulnerable in this aspect is the age category of preschoolers, as during this period development arrives to an important crossroads for personality and social skills development. Psychological well-being is one of primary objectives of developmental and educational work with children of the presented nosological group [9-12].

\section{THE AIM}

The aim of this study is to determine correlation between mental health indicators of preschoolers with intellectual disabilities and distinguishing features of the prenatal, natal and postnatal stages of their development.

\section{MATERIALS AND METHODS}

The following methods were used: analysis of special medical, psychological and pedagogical literature to reveal the essence of mental health determinants/indicators for older preschoolers with ID; comparison and systematization of research material to determine the mental health indicators represented by the category of children; diagnostic complex to identify variables of mental health indicators - "Methods for assessment of the level of social development" [13] allowed to determine the degree of social intelligence, knowledge about oneself and one's place in the world, ideas about social norms, rules, understanding of social reality, cooperation; projective testing technique: "House, tree, man" [14], method "Joint sorting" [15], Pearson\&apos;s $x^{2}$ homogeneity criterion, calculation of Spearman\&apos;s rank correlation coefficient.

Survey sample consisted of 448 preschoolers, whereof 292 preschoolers had moderate ID and 156 - preschoolers had mild ID.

Check for homogenous distribution of preschoolers involved in the experimental study by the degree of ID using Pearson\&apos;s $x^{2}$ homogeneity criterion showed: during the experimental study, parameters of the group of mild IDC were as follows: $N=156 ; n_{1}=22 ; n_{2}=24 ; n_{3}=26 ; n_{4}=48$; $n_{5}=36$. Parameters of the group of children with moderate ID: $M=292 ; m_{1}=54 ; m_{2}=44 ; m_{3}=68 ; m_{4}=56 ; m_{5}=70$. For our case $L=5$ ( 5 age categories of preschoolers were categorized: early, junior, middle, senior (2 groups), so $x^{2} \kappa p=9.49$. Since critical area is right-handed, we can conclude from the inequality $x^{2} c \pi<x^{2} \kappa p$, that null hypothesis is accepted. We can state that at the experimental stage of the study at a given level of significance, the distribution of pupils according to the degree of ID is homogeneous.

Spearman's rank correlation coefficient: $\mathrm{Ho}$ - no significant rank correlation, i.e. certain prenatal, natal and postnatal periods do not correlate with certain indicators of mental health; $\mathrm{Hi}$ - a significant rank correlation between indicators and periods. $R$ exp was calculated for each child by the formula:

$$
R \text { exp. }=1-\frac{6 \mathrm{\Psi} \sum_{i=34}^{n} d_{i}}{n\left(n^{2}-1\right)}=1-\frac{6 \mathrm{Ч}\left(d 1+d 2+\ldots d_{n)}\right.}{n Ч\left(n^{2}-1\right)}
$$

To calculate $\mathrm{T}$ cr. there was used the formula: $T c r .=$

$$
T c r .=t c r . Ч(L, \mathrm{~K}) \cup \sqrt{\frac{1-R_{\text {експ. }}^{2}}{n-2}}
$$

where $\mathrm{n}$ - the sample size; $\mathrm{t} \mathrm{cr}$. $(\mathrm{L}, \mathrm{\kappa})$ - the critical point of the two-sided critical range, which is found in the Spearman's distribution table. By the level of significance $\mathrm{L}$ and $\kappa=\mathrm{n}-2$ degrees of freedom. As a result, $\mathrm{L}=0,05 ; \mathrm{n}=34$; $\kappa=32$; $\mathrm{t}$ cr. $(0,05 ; 32)$; tcr. $\approx 2,04$

Comparison of $\mathrm{R}$ exp. and $\mathrm{T} \mathrm{cr}$.: if the indicators $\mathrm{R}$ exp. are less than $\mathrm{T}$ cr., there is no reason to reject Ho, i.e., the correlation between the signs is insignificant; if the indicators R exp. are more than T cr. - Ho is rejected, so there is a significant correlation between qualitative characteristics.

\section{RESULTS}

The following results were obtained during the collection of medical history data: $17.5 \%$ had older siblings in their family, which were born from the first pregnancy; $45.7 \%$ of children were product of the second or third mother's pregnancy; $36.8 \%$ - from 4 th and more, yet in most cases, they were firstborn.

As a result of medical records review, the following was identified as risk factors for ID:

1. Interruption of pregnancy associated with toxicosis was common to all children in this group: in most cases, toxicosis accompanied the entire period of pregnancy with varying intensity (the most threatening - in the first trimester).

2. Complications of childbirth associated with cesarean section were present in $42.2 \%$ of cases.

3. Diseases of mothers in the first trimester of pregnancy (both viral and infectious), which were accompanied by high fever $-28.5 \%$ of cases.

4. Maternal age for the first pregnancy which exceeded the threshold of forty years $-18.9 \%$.

5. Concomitant complications of childbirth: intoxication (mostly medical) - 21.3\%, fetal hypoxia - 15.6\%, birth injuries $29.8 \%$, fetal asphyxia $-48.9 \%$, umbilical cord entanglement - $15.8 \%$; and other complications, including chronic toxoplasmosis during pregnancy, maternal hepatitis $\mathrm{B}$, neonatal jaundice, large fetus $-8 \%$.

Based on the retrospective analysis of medical histories, clinical findings, additional medical (neurological) examinations, anamnestic data of preschoolers, we have found a number of systemic disorders of early development: all children had more or less severe psychomotor delay, especially - developmental delay of gross motor functions.

While processing medical-psychological-pedagogical documentation, the following has been established:

In the etiology of intellectual, speech and other related disorders, pathological course of pregnancy and its complications is determined to make significant impact on mental health of children. Distribution of children by cooccurring disorders is presented in the diagram (Fig. 1). 


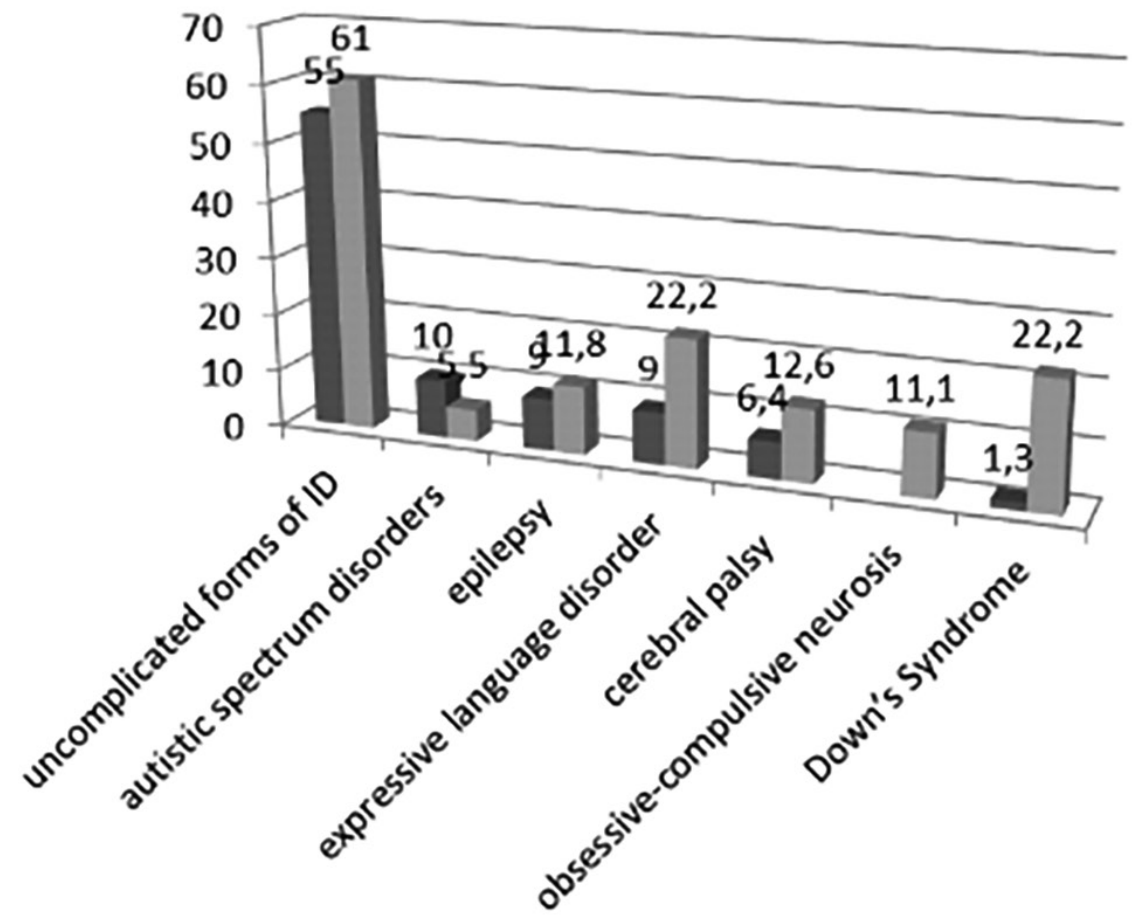

- Mild degree

Moderate degree

Fig. 1. The detection of cooccurring disorders in intellectually disabled preschoolers IDP (in \%)

Since IDD is characterized by inertia of mental processes [8], the experimental research involved 210 children with ID of senior preschool age: 84 - with mild and 126 - with moderate degrees of ID. Under the aim of our study and taking into account unique features of the studied category of children, the mental health of ID preschoolers is interpreted as a formed ability to appropriately express their individual desires and interests according to age (Table I).

The first studied criterion was socio-interpersonal according to the "Methods for assessment of the level of social development" [14]. The results show that children of both groups with ID have a low level of formation of socio-personal criteria ( moderate $\mathrm{ID}=52.8 \%$ vs mild $\mathrm{ID}=26.8 \%$; $\chi 2 \mathrm{emp} .=9.492$, which corresponds to $\rho \leq 0.01=\mathrm{H}_{1}$ ) due to low indicators of formation of: ideas of oneself (moderate $=23.7 \%$ against mild $=51.2 \%$; $\chi 2 \mathrm{emp} .=9.376$ at $\left.\rho \leq 0.01=\mathrm{H}_{1}\right)$, ideas of others (moderate $=16.9 \%$ against mild $=56.1 \%$; $\chi 2 \mathrm{emp} .=16.58$ at $\left.\rho \leq 0.01=\mathrm{H}_{1}\right)$, understanding of social activity based on cooperation ( moderate $=15.8 \%$ against mild $=39.1 \%$; $\chi 2 \mathrm{emp} .=9.058$ at $\left.\rho \leq 0.01=\mathrm{H}_{1}\right)$ (Table II).

The next stage of the study revealed correlations between the mental health indicators of IDP and distinguishing features of prenatal, natal and postnatal development (Table III).

The second criterion of the study was emotional and behavioral, the indicators of which were studied by the projective technique "House, tree, man" [14] and the method of "Joint sorting" [15].

Low formation of emotional and behavioral criteria of mental health indicators (zero level in moderate $=52.8 \%$ against mild $=20.7 \% ; \chi 2 \mathrm{emp} .=13.16$, which corresponds to $\rho \leq 0.01=\mathrm{H}_{1}$ ), as specified in low incidence of cooperation with others, presence of low self-esteem, increased anxiety and propensity to solitude (in moderate $64.1 \%$ against mild $=38,4 \%$; $\chi 2 \mathrm{emp} .=5.952$, which corresponds to $\rho \leq 0.05=\mathrm{H}_{1}$ ), inability to negotiate with others (in moderate $73.5 \%$ against mild $=39.6 \% ; \chi 2 \mathrm{emp} .=9.57$, which corresponds to $\rho \leq 0.05=\mathrm{H}_{1}$ ), high levels of aggression, negativism, lack of independence and helplessness when helping others, expectation of help from adults (in moderate $73.5 \%$ against mild $=39.6 \% ; \chi 2 \mathrm{emp} .=9.57$, which corresponds to $\rho \leq 0.05=\mathrm{H}_{1}$ ), inappropriate emotional outbursts, accompanied by frequent mood swings (in moderate $64.1 \%$ at $\rho \leq 0.01=\mathrm{H}_{1}$ ), manifestations of inappropriate behavior in unfamiliar conditions (in moderate $65 \%$ at $\rho \leq 0.01=\mathrm{H}_{1}$ ) have been established. Summary indicators of the study are given in the table (Table IV).

The next stage of the study revealed correlations between mental health indicators of IDP and distinguishing features of prenatal, natal and postnatal stages of their development (Table V).

These tables show that the events of, specifically, postnatal period have a significant impact on further emotional life of the child [16-18].

\section{DISCUSSION}

We can conclude that the formation of mental health against the background of intellectual disability of preschool children is associated with low levels of self-awareness as a 
Table I. Criteria and indicators of mental health of ID preschoolers

\begin{tabular}{|c|c|}
\hline \multicolumn{2}{|c|}{ Mental health indicators of IDP } \\
\hline \multicolumn{2}{|c|}{ Criteria } \\
\hline Social and interpersonal & Emotional and behavioral \\
\hline \multicolumn{2}{|c|}{ Indicators } \\
\hline $\begin{array}{l}\text { - formation of ideas about oneself and one place in the world } \\
\text { - formation of ideas about others } \\
\text { - understanding of social reality, basics of cooperation. }\end{array}$ & $\begin{array}{l}\text { - anxiety / proneness to conflict / aggression / negativism / } \\
\text { low self-esteem } \\
\text { - appropriate behavior in a familiar situation / unfamiliar } \\
\text { situation } \\
\text { - emotional attitude to joint activities }\end{array}$ \\
\hline
\end{tabular}

Table II. Results of the study of formation levels of social-personality criterion (in\%)

\begin{tabular}{ccc}
\hline Levels & Preschoolers with moderate ID & Preschoolers with mild ID \\
\hline High & - & 3.2 \\
\hline Average & 24.5 & 53.6 \\
\hline Low & 52.8 & 26.8 \\
\hline Null & 22.7 & 26,4 \\
\hline
\end{tabular}

Table III. Correlations between mental health indicators of IDP by socio-personal criteria and prenatal, natal and postnatal development

\begin{tabular}{|c|c|c|c|c|}
\hline $\begin{array}{l}\text { Pairs of development stages/ indicators of the social and } \\
\text { inter -personal criteria }\end{array}$ & $\begin{array}{l}\text { Value } \\
\text { R exp. }\end{array}$ & $\begin{array}{l}\text { Value } \\
\text { Tcr. }\end{array}$ & $\begin{array}{l}\text { Comparison } \\
\text { results of } \\
\text { R exp.and Tcr. }\end{array}$ & $\begin{array}{l}\text { Comparison } \\
\text { indicators of } R \\
\text { exp. and } T \mathrm{Cr} \text {. }\end{array}$ \\
\hline prenatal/natal development - formation of ideas about oneself & 0.0993 & 0.03 & R exp. $>\mathrm{T} c r$ & 0.97 \\
\hline prenatal/natal development - formation of ideas about others & 0.0993 & 0.03 & R exp. $>\mathrm{T} \mathrm{cr}$ & 0.97 \\
\hline $\begin{array}{l}\text { prenatal/natal development - formation of ideas about the } \\
\text { surrounding reality, appropriate use of surrounding objects }\end{array}$ & 0.0993 & 0.03 & R exp. $>\mathrm{T} c r$ & 0.97 \\
\hline $\begin{array}{c}\text { prenatal/natal development - situation appropriate } \\
\text { adjustment in unknown environment }\end{array}$ & 0.0993 & 0.03 & R exp. $>\mathrm{T} c r$ & 0.97 \\
\hline postnatal development - formation of ideas about oneself & 1.001 & 0.01 & R exp. $>\mathrm{T} \mathrm{cr}$ & 1 \\
\hline postnatal development - formation of ideas about others & 1.001 & 0.01 & R exp. $>\mathrm{T} c r$ & 1 \\
\hline $\begin{array}{l}\text { postnatal development - formation of ideas about the } \\
\text { surrounding reality, appropriate use of surrounding objects }\end{array}$ & 1.001 & 0.01 & R exp. $>\mathrm{T} c r$ & 1 \\
\hline $\begin{array}{c}\text { postnatal development - appropriate behavior in unknown } \\
\text { environment }\end{array}$ & 1.001 & 0.01 & R exp. $>\mathrm{T} c r$ & 1 \\
\hline
\end{tabular}

Table IV. Formation levels of emotional and behavioral criteria (in \%)

\begin{tabular}{ccc}
\hline Levels & Preschoolers with moderate ID & Preschoolers with mild ID \\
\hline High & - & - \\
\hline Average & 16.9 & 28.3 \\
\hline Low & 30.3 & 61 \\
\hline Null & 52.8 & 20.7 \\
\hline
\end{tabular}

member of a social group; below age expectations' ability to perceive self and produce information about themselves and meaningful adults, and express preferences; inability to adhere to social norms and values in behavior; high levels of anxiety; aggressive tendencies; lack of independence; helplessness concerning helping others; expectation of help from adults; content-inappropriate emotional outbursts accompanied by frequent mood swings; and desire for solitude. We make assumption about the predominance of postnatal period as the leading impactful factor in development of preschooler's mental health. There is an intricate connection between children of the selected category and their parents at different stages of ontogenesis, that lays foundation to future patterns of social behavior. In this aspect, increase in maternal (caregivers') psychoeducation becomes urgent. Our study confirms and complements the data on the importance of parental education $[19,20]$.

This article does not reveal the entire scope of mental health indicators associated with ID, since it presents results of the study covering senior preschool age only, while school-age children were not considered. It is also worth noting that we did not take into account such important 
Table V. Correlations between mental health indicators of IDP by emotional and behavioral criteria

\begin{tabular}{|c|c|c|c|c|}
\hline $\begin{array}{l}\text { Pairs of development stages/ indicators } \\
\text { of emotional and behavioral criteria }\end{array}$ & $\begin{array}{l}\text { Value } \\
\text { R exp. }\end{array}$ & $\begin{array}{l}\text { Value } \\
\text { Tcr. }\end{array}$ & $\begin{array}{l}\text { Comparison } \\
\text { results of } \\
\mathrm{R} \text { exp.and Tcr. }\end{array}$ & $\begin{array}{l}\text { Comparison } \\
\text { indicators of } R \\
\text { exp. and Tcr. }\end{array}$ \\
\hline prenatal/natal development - anxiety & 0.998 & 0.02 & R exp. $>$ Tcr & 0.98 \\
\hline prenatal/natal development - proneness to conflict & 0.999 & 0.02 & R exp. $>$ Tcr & 0.98 \\
\hline prenatal/natal development - aggression & 0.996 & 0.03 & R exp. $>$ Tcr & 0.97 \\
\hline prenatal/natal development - negativism & 0.996 & 0.03 & R exp. > Tcr & 0.97 \\
\hline prenatal/natal development - low self-esteem & 0.996 & 0.03 & R exp. $>$ Tcr & 0.97 \\
\hline $\begin{array}{l}\text { prenatal/natal development - appropriate behavior in a } \\
\text { familiar situation / unfamiliar situation }\end{array}$ & 0.996 & 0.03 & R exp. $>$ Tcr & 0.97 \\
\hline $\begin{array}{l}\text { prenatal/natal development - emotional attitude to } \\
\text { cooperation with others }\end{array}$ & 0.996 & 0.03 & R exp. $>$ Tcr & 0.97 \\
\hline postnatal development - anxiety & 1.001 & 0.01 & R exp. $>$ Tcr & 1 \\
\hline postnatal development -proneness to conflict & 1 & 0.11 & R exp. $>$ Tcr & 0.89. \\
\hline postnatal development - aggression & 1 & 0.11 & R exp. $>$ Tcr & 0.89 \\
\hline postnatal development - negativism & 1 & 0.11 & R exp. $>$ Tcr & 0.89 \\
\hline postnatal development - low self-esteem & 0.996 & 0.03 & R exp. $>$ Tcr & 0.96 \\
\hline $\begin{array}{c}\text { postnatal development - appropriate behavior in a familiar } \\
\text { situation / unfamiliar situation }\end{array}$ & 1.001 & 0.01 & R exp. > Tcr & 1 \\
\hline $\begin{array}{l}\text { postnatal development - emotional attitude to cooperation } \\
\qquad \text { with others }\end{array}$ & 1.001 & 0.01 & R exp. $>$ Tcr & 1 \\
\hline
\end{tabular}

predictor of child's mental health as maternal mental health and attitude towards the child with ID, as these can be a subject of the separate study.

\section{CONCLUSIONS}

Clinical manifestations of mental disorders are in part determined by negative factors at prenatal, natal and postnatal stages of development. The study revealed correlation between the mental health of IDP and distinguishing features of early development and found that children with ID are at risk for developing significant mental health problems. It's important to correctly diagnose the existing manifestations of mental health disorders exactly at the preschool age or earlier, in order to implement appropriate enrichment, therapy and development.

Further research should determine the relative contribution/interaction of ID, social/environmental, psychological and biological factors to the identified elevated indicators of mental health disorders. Based on the careful review and early monitoring of babies with history of adverse prenatal and natal events, it is necessary to introduce a comprehensive medical-psychological-pedagogical approach with experts from different disciplines and fields from as early as toddlerhood. Medical direction: monitoring general physical health of the toddler (pediatrician), increasing active participation in everyday life, development of motor and cognitive skills through sensorimotor integration (occupational therapist). Psychological-pedagogical direction: work with parents aimed at recognizing the need to understand child's emotional world, identifying strategies for effective reading of emotional signals and developing working alliance with specialists; for the child, formation of own motivation and initiative to interact on a systematic basis with specialists (pedagogical/medical workers); pedagogical direction (special teacher, occupational and speech therapists) - developmental interventions to maximize cognitive potential; psychological direction - improving self-image and self-esteem, enhancing interaction with peers and adults.

\section{REFERENCES}

1. Barling J. History of occupational health psychology. Handbook of occupational health psychology. [2nd ed.]. Washington, DC: APA Books. 2010, 102p.

2. Flaherty M., Sikorski E., Klos L. et al. Peacework and mental health: from individual pathology to community responsibility. Intervention Journal of Mental Health and Psychosocial Support in Conflict Affected Areas. 2020; 18 (1): 28-36 doi: 10.4103/INTV.INTV_59_18.

3. Einfeld S., Ellis L., Emerson E. Comorbidity of intellectual disability and mental disorder in children and adolescents: A systematic review. Journal of intellectual \& developmental disability. 2011;36. 137.

4. Buckley N., Glasson E., Chen W. et al. Prevalence estimates of mental health problems in children and adolescents with intellectual disability: A systematic review and meta-analysis. Australian \& New Zealand Journal of Psychiatry. 2020; 54(10): 970-984.

5. Vereenooghe L., Flynn S., Hastings R. P. et al. Interventions for mental health problems in children and adults with severe intellectual disabilities: a systematic review. BMJ. 2018; 2. doi:10.1136/ bmjopen-2018-021911.

6. Lakhan R. The Coexistence of Psychiatric Disorders and Intellectual Disability in Children Aged 3-18 Years in the Barwani District, India. Psychiatry. 2013; 1: 6-9 
7. Baker K., Devine R., Ng-Cordell E. et al. Childhood intellectual disability and parents'mental health: integrating social, psychological and genetic influences. IMAGINE-ID consortium and Claire Hughes The British Journal of Psychiatry. 2020; 2: 1-8.

8. Lebedinsky V.V. Disorders of mental development in childhood: textbook for students of the psychological faculty of higher educational establishments. M.: Akademiya. 2003, 60p.

9. Boriak 0., Pakhomova N., Okhrimenko I. et al. Psycholinguistic Research of Speech Activity of Junior Students with Intellectual Disorders. Applied Linguistics Research Journal. 2021; 5 (6): 104-112.

10. Chobanian A.V., Kolyshkina A.P. Theoretical substantiation of the model of psychological support of senior preschoolers with intellectual disabilities. Habitus. 2020; 18(2): 130-135.

11. Kolyshkin 0.V. Psychological features of the process of speech development of senior pupils with hearing loss in the process of motor activity. Habitus. 2020; 15: 148-152.

12. Kosenko Yu.M., Boriak 0.V., Korol 0.M. The use of computer didactic games in teaching history of the pupils with intellectual disabilities in inclusive environment. Information technologies and teaching aids. 2020; 77(3): 76-89.

13. Zakrepina A. Study of the peculiarities of social development of mentally retarded preschoolers. Preschool education. 2010. 1: 66-73.

14. Romanova E. Graphic methods in practical psychology. SPb.: Rech. 2001, $135 p$.

15. Asmolov A.G., Burmenskaya G.V., Volodarskaya I.A. How to design universal learning activities in primary school: from action to thought: teacher's guide. M.: Enlightenment. 2008, 204p.

16. The third scientific-practical symposium «Perinatal medicine and safe motherhood». Women's health. 2010; 5 (51): 15-16.

17. Siusiuka V.H., Kotlova Yu.V. Influence of anxiety of women during pregnancy on the condition of newborns and the course of their early neonatal period. Current issues of pediatrics, obstetrics and gynecology. 2014; 1: 117-120.

18. Staniszkis J. Patologie struktur organizacyjnych. Próba podejścia systemowego. Wydawnictwo Polskiej Akademii Nauk. Breslau: Ossolineum. 1972, 103p.

19. Miller J. S., Wanless S. B., Roger P. Parenting for Competence and Parenting with Competence: Essential Connections Between Parenting and Social and Emotional Learning. Weissberg School Community Journal. 2018; 28(2): 238-250.
20. Mohammadi F., Rakhshan M., Molazem Z. et al. Parental Competence among Parents with Autistic Children: A Qualitative Study. Nursing and Midwifery Studies. 2018; 7(4): 168-173.

21. Itskovich G. Infant and Parent Mental Health: Developmental trajectory as a communal concern. Mental Health: Global Challenges Journal. 2019; 1: 29-31. doi: 10.32437/mhgcj.v1i1.14.

\section{ORCID and contributionship:}

Oksana V.Boriak: 0000-0003-2484-1237 ${ }^{A-D, F}$

Anna V. Chobanian: 0000-0001-6191-1068 A-D,F

Oleksandr V. Kolyshkin: 0000-0002-1129-3254 A, D, E

Yurij M. Kosenko: 0000-0003-2723-2031 ${ }^{\text {D, E }}$

Tetiana M. Dehtiarenko: 0000-0001-7153-9706 D, E

Alla P. Kolyshkina: 0000-0001-9598-1830 D,E

Galina Itskovich: 0000-0002-1722-2203 A, E, F

\section{Conflict of Interest:}

The Authors declare no conflict of interest.

\section{CORRESPONDING AUTHOR Oksana. V. Boriak \\ Sumy State Pedagogical University \\ named after A.S. Makarenko \\ 87 Romenska St., 40002 Sumy, Ukraine \\ tel: +380668373379 \\ e-mail: oksana_boriak@ukr.net}

Received: 04.06.2021

Accepted: 14.10 .2021
A - Work concept and design, B - Data collection and analysis, C - Responsibility for statistical analysis, D -Writing the article, $\mathbf{E}$ - Critical review, $\mathbf{F}$ - Final approval of the article 


\title{
ISSUES OF EMOTIONAL INSTABILITY IN THE CONTEXT OF STUDENTS' EMOTIONAL HEALTH RESEARCH
}

DOI: 10.36740/WLek202111116

\author{
Oksana M. Mykytyuk ${ }^{1,2}$, Tamara G. Tiurina' ${ }^{1}$, Tereza M. Klymus' ${ }^{1}$ Marta Ya. Kozak', Ihor I. Yatsyshyn', \\ Natalia A.Umanets' ${ }^{1}$, Nina M. Hayduk' ${ }^{1}$ \\ 'LVIV POLITECHNIK NATIONAL UNIVERSITY, LVIV, UKRAINE \\ ${ }^{2}$ UKRAINIAN ACADEMY OF PRINTING, LVIV, UKRAINE
}

\begin{abstract}
The aim: The aim of the research was to investigate the issue of emotional health in the context of mental health of students, in particular, the emotional instability as a students\&apos; personal quality with regard to cognitive and empathic components.

Materials and methods: In a comparative analysis of the study, 104 3rd-year students of the Faculty of Management and Media Communications of the Ukrainian Academy of Printing, were divided into two groups on the basis of gender (group №1 - females; group №2 - males). In the study, undertaken in 2019-2020, two questionnaires, namely "Problems of Emotional Health" and "Assessment of Empathic Compassion", drawn up by a team of authors, were used. The comparative analysis was carried out with the use of the Mann-Whitney U test.

Results: The study of emotional instability and competence in the context of the student\&apos;s mental health allows us to conclude that the cognitive component is the basis that promotes the development of social, regulatory, and empathic components, and the latter is the main motivator of a person's activity.

Conclusions: The research showed that high school students do not always have enough opportunities for independent formation and emotional competence development, and have problems with emotional instability. These problems may be solved by the introduction of the educational component, in particular: introducing relevant special courses into the educational process, conducting psychological training aimed at the development of emotional professional competence in the context of the formation of personality's mental health.
\end{abstract}

KEY WORDS: emotions, mental health, cognitive and empathic components, emotional competence

Wiad Lek. 2021;74(11 p.l):2774-2778

\section{INTRODUCTION}

The functioning of modern society, complex social and economic transformations, as well as challenges, including the coronavirus pandemic, put forward significant requirements for the competence and professionalism of future specialists.

The emotional intensity of professional and personal life testifies to the urgency of studying emotional competence, emotional health in the context of mental health as an integral part of personal success. Competence in the field of emotions has become one of the most important components of the high professional level of students, their successful professional development. For the first time, emotional instability and research of emotional intelligence in the context of mental health were discussed at the end of the 90 years of the last century. In the early 1990s, American psychologists P. Salovey and J. Meyer emphasized not only the formation of self-consciousness, self-actualization, self-control, motivation, but also claimed that emotional phenomena affect the individual. In their writings, the scientists identified this complex as emotional intelligence and later they considered emotional intelligence as a set of features of general abilities [1].
Modern researchers, like philosophers and psychologists of the last century, have not reached a common point of view regarding the interpretation of the emotional component of health in the context of mental health. The most common position was the so-called intellectualist theory: organic manifestations are the result of psychic phenomena J. Herbart's concept in particular. [2].

Given the importance of emotions in human life, a number of scientists put forward a lot of theories, thus highlighting their understanding of emotional processes and states, the diversity of their functions and mechanisms of development $[3,4]$.

J. Dewey wrote about the importance of emotions. He noted that emotional arousal determinates the pattern of behavior, but emotion arises only when instinctive actions are inhibited. Psychologically, emotion is adaptation or tension [5].

Interesting research was presented in 1927 by the famous physiologist W. Cannon. In his research, the scientist presented reasoned evidence confirming his assumptions about bodily changes that occur in different emotional states. A number of scientists, including W. James and 
K. Lange, linked the emergence of emotions, emotional experiences with changes in the state of internal organs, which are hyposensitive structures [6].

As the review of psychological literature conducted by us showed, several areas of study of emotions in the context of mental health have been formed during the research of this phenomenon: interpretation of the essence of emotions, creation of theories in order to explain the nature of emotional states, identification of visual changes in appearance and so on. Many scientists (C. Darwin, P. Bard, W. James, K. Izard, K. Lange, S. Rubinstein, P. Simonov, P. Jacobson, etc.) note that emotions are among the most ancient mental states and processes [7-9].

However, despite the widespread representation of emotions in the human psyche, there is no clear generally accepted definition of them in terms of both emotional health and emotional instability in the literature today [10-13].

To date, the emotional sphere is deeply and comprehensively studied and presented in the works of both foreign and domestic psychologists (G. Breslav, V. Vilyunas, S. Maksymenko, S. Rubinstein, etc.). Many psychological theories explaining the nature of the phenomenon under study have been created (C. Darwin, W. James, K. Izard, K. Lange, S. Schechter, etc.), close connection of emotional sphere components with cognitive processes (L. Vygotsky, O. Leontiev, S. Rubinstein, O. Tikhomirov, etc.), motives, needs (K. Izard, O. Leontiev, J. Reykovsky, S. Rubinstein, S. Shekhter, etc.), volitional and regulatory processes (K. Abulkhanova-Slavska, L. Bozhovych, Z. Freud, O. Chebykin, etc.) has been studied. [14].

Psychological features of components of students\&apos; emotional sphere (B. Ananiev, V. Kolesnikov, etc.) are singled out, general aspects of the problem of emotional maturity are developed, methodological strategies for emotional sphere formation are highlighted (G. Breslav, O. Grebenyuk, O. Zaporozhets, S. Rubinstein and etc.). Understanding the role and special significance of emotions in people\&apos; s lives contributed to the emergence of the concepts of "emotional competence", "emotional intelligence" in psychology as the necessary components of successful functioning of the individual (G. Breslav, G. Gardner, D. Goleman, D. Lucin, D. Meyer, E. Nosenko, P. Selovey and others).

The student is considered as an active subject (K. Abulkhanova-Slavska, D. Leontiev, S. Stavytska, V. Tatenko, etc.), one of the characteristic features of which is the ability to self-regulation, that is the ability to manage his/ her own mental states, which is necessary to preserve mental, especially, emotional health, and harmonious coexistence with other people and the world around, as well as successful solution of life problems.

Most researchers consider the stability of the individual, the self-regulation of the subject as a conscious, purposeful process of achieving goals in solving personal meaningful tasks (R. Baumeister, I. Galyan, L. Dika, A. Katsero, O. Konopkin, D. Leontiev, N. Naumchik, O. Osnytsky and others) [15].

One of the types of psychic self-regulation is emotional self-regulation, which is an important component of men- tal health and at the same time is a process of optimizing the emotional state, including the ability to manage one's own emotions, feelings, experiences, thoughts and activities (J. Gross, R. Erber, V. Zarytska, etc.) [16]; management of cognitive activity (regulation of memory, attention and thinking processes), behavior, activity, communication (M. Bernstein, I. Leontiev, O. Osnitsky, V. Morosanova, H. Heckhausen, etc.) $[17,18]$.

In modern science special attention is paid to the problem of harmonization of the activity of the left and right cerebral hemispheres, that is, the formation of a holistic harmonious bioadequate thinking, contributing not only to individual's spiritual and mental recovery, but also to establishing harmonious, adequate relations with the world around, social and natural environment. [19].

The following types of self-regulation are analyzed in the psychological literature: personal (K. Abulkhanova-Slavska, D. Chizhma), volitional (V. Ivannikov, S. Maksymenko), axiological (S. Maksymenko), motivational (O. Xenofontova, Y. Kul, H. Heckhausen), emotional (R. Baumeister, J. Gross, S. Maksimenko).

Goleman D. indicates the existence of a number of objects of self-regulation and identifies, depending on the focus of the object, self-regulation of activities, behavior, mental processes, motivational sphere, etc. [17].

Emotional self-regulation in the structure of the individual is regarded as one of the varieties of mental self-regulation, which ontogenetically develops first in the form of basal emotional self-regulation aimed at ensuring psychological comfort and stability of the inner state of the individual. (D. Goleman) [17].

Theoretical analysis of the problem showed that the issue of the emotional sphere development is not new for both domestic and foreign psychologists. Considerable material has already been accumulated, many theoretical concepts have been created, and there is certain experience in the formation and development of individual components of the emotional sphere. [14-20].

However, in general, this problem is far from its final solution and still remains of great interest. Firstly, this is due to the ambiguity of the categorical apparatus of the emotional sphere of mental health and constant emergence of new terminology; secondly, the lack of diagnostic tools, which could be explained by the complexity of the study of the individual's emotional sphere in general.

\section{THE AIM}

The theoretical analysis of scientific papers showed insufficient presentation of thorough researches aimed at studying the development of emotional competence of students' mental health, in particular emotional instability and confirmed the relevance of our study, and also allowed to formulate our own approach to determining and studying emotional instability of students during the pandemic, to reveal the content and identify the structural elements of this phenomenon. 


\section{MATERIALS AND METHODS}

In our research, we studied the issues of emotional health of students of the Ukrainian Academy of Printing in the context of personality's mental health, in particular the study of emotional instability as a personal quality of students with regard to cognitive component (system of knowledge, emotional analysis skills, ability to emotional reflection, self-awareness, self-reflection, ability to correctly recognize, identify their own emotional states, emotions and feelings of others) and empathic component (understanding the emotional states of others in the form of compassion, empathy, ability to accept students\&apos; experiences, emotional sensitivity).

As part of our study, undertaken in 2019-2020, we used two questionnaires, namely "Problems of Emotional Health" and "Assessment of Empathic Compassion", compiled by a team of authors [5-7]. The comparative analysis of the obtained data was carried out with the use of the Mann-Whitney U test.

The results of the comparative analysis of the study, the respondents of which were 3rd year students of the Faculty of Management and Media Communications of the Ukrainian Academy of Printing are presented. A total of 104 students were included in our study. Since it is generally believed that females are more emotional than men, we decided to find evidence of this in the course of our study, and that is why the students were divided into two groups according to gender (group № 1 - female students; group № 2 - male students).

\section{RESULTS}

The question of the necessity of forming the emotional stability of the individual in the context of his/ her mental health through formation and development of the cognitive component (system of knowledge, emotional analysis skills, ability to emotional reflection, self-awareness, self-reflection, ability to correctly recognize, identify their own emotional states, emotions and feelings of others) and the empathic component (understanding the emotional states of others in the form of compassion, empathy, ability to accept the experiences of others, emotional sensitivity) arises. We believe that emotional instability is correlates with the dynamics of students moods and emotions in the emotional health of students.

According to the generalized results of our research, we can state that group №1 (female students) is more prone to emotional instability than group №2 (male students). Indicators 52.9 versus 47.1, in particular, show that it has problems in forming cognitive component (system of knowledge, emotional analysis skills, ability to emotional reflection, self-awareness, self-reflection, ability to correctly recognize, identify their own emotional states, emotions and feelings of others).

In this regard, we can conclude that female students in comparison with male students lack sufficient systemic knowledge, formed cognitive skills to analyze emotions, formed ability to rational emotional reflection. In group № 2 (males) the average indicators on the "emotional in- stability" scale prevail, i.e. 51\% of the subjects in this group have average emotional instability, $42 \%$ have low emotional instability and only $7 \%$ have high emotional instability.

With regard to the results of the study "Assessment of Empathic Compassion" in the context of the study of the empathic component as a component of mental health (understanding the emotional states of others in the form of compassion, empathy, ability to accept students\&apos; experiences, emotional sensitivity), after analyzing the obtained data we can state the following.

According to the generalized results of our research, it should be noted that group №1 (females) has higher indicators of empathic compassion - 63.2 than group №2 (males) - 36.8. In this regard, we can conclude that group № 1 (females) is more prone to high rates of empathic compassion, even in extreme situations, than group №2 (males).

In group №1 (females) average indicators of neuropsychological stability (79\%) dominate, high rates have $21 \%$ of the students; low and very high rates are not observed. As for the group №2 (males) the average rates of neuropsychological stability prevail (49\%), low rates have $40 \%$ of the students, and $11 \%$ - high rates.

To study emotional instability as a personal quality of students on the basis of gender specificities, we carried out a comparative analysis, using the Mann-Whitney U-test to compare two independent data samples.

According to the results of the comparative analysis between the sample of female and male students, statistically significant differences were found in the parameters of "Problems of Emotional Health" and "Assessment of Empathic Compassion".

Thus, emotional instability in the study of emotional health is significantly higher in group №1 (females) $(\mathrm{m}=$ 52.9), while in group №2 (males) this indicator is $\mathrm{m}=47.1$.

These results confirm the findings of other authors that emotional instability as a personal quality, in our case, of students is more pronounced in female students.

The rate of empathic compassion in group №1 (females) is higher $(\mathrm{m}=63.2)$ than in group №2 (males) $(\mathrm{m}=$ 36.8). The data suggest that female students have much higher empathic compassion than male students.

The emotional competence of the student's mental health includes the following components: cognitive component (system of knowledge, emotional analysis skills, ability to emotional reflection, self-awareness, self-reflection, ability to correctly recognize, identify own emotional states, emotions and feelings of others); social component (ability to establish emotional contacts, ability to recognize the emotions of others, have the skills to overcome emotional barriers in the communication process); regulatory component (ability to control and manage emotional states, emotional resistance, self-control of expression) and empathic component (understanding the emotional states of others in the form of compassion, empathy, ability to accept students\&apos; experiences, emotional sensitivity).

In our further work we plan to continue research on gender characteristics of emotional instability as personal quality of students in order to verify the results obtained. 
Table I. Results of Comparative Analysis on the Problems of Emotional Health and Empathic Compassion

\begin{tabular}{cccccc}
\hline $\begin{array}{c}\text { Parameters of cognitive and empathic } \\
\text { components research }\end{array}$ & $\begin{array}{c}\text { Group of students } \\
\text { (females) №1 }\end{array}$ & $\begin{array}{c}\text { Group of students } \\
\text { (males) №2 }\end{array}$ & $\mathbf{U}$ & $\mathbf{Z}$ & p-level \\
\hline Parameters «Problems of Emotional Health" & 52.9 & 47.1 & 23.5 & 3.7 & 0.005 \\
\hline $\begin{array}{c}\text { Parameters «Assessment of Empathic } \\
\text { Compassion» }\end{array}$ & 63.2 & 36.8 & 77 & 1.4 & 0.2 \\
\hline
\end{tabular}

\section{DISCUSSION}

The educational environment of a modern higher education institution is a student-centered. Researches in this area are carried out by many scientists [15-17]. L. Chernyavska, I. Krynytska, O. Myalyuk argue that "the formation of the future specialist's personality includes concern for health self-care, and the most acute problem is its serious deterioration in student youth. Therefore, it is advisable for students to develop and implement a personalized, individual, prospective wellness program, given the significant percentage of students is classified by health status as a "special medical group" [15]. In his research, S. Stein [11] studied aspects of the development and manifestation of emotional burnout of psychology students. In particular, the author states that "the first-year students have a minimal level of depression, whereas the fifth-year students have a moderate level of depression. Therefore, such depressive manifestations as apathy (state of indifference, disinterest to other people, events, future prospects), neurocirculatory hypotension (decrease in blood pressure, changes in the nervous system against the background of stressors), dysphoria (dissatisfaction, hostility towards others, irritability, resentment), anxiety, fear are less common in junior students than in 5th year students" [11]. S. Smirnov [10] in his research argues that "the level of formation of certain symptoms makes it possible to comprehend the indicators of the phases of emotional burnout syndrome - "stress", "resistance", "exhaustion". Master\&apos;s students have phases of "stress" and "exhaustion" at the formation stage, and the "resistance" phase is already formed.

These data resonate with our study of problems of emotional instability. Interesting researches in this area were carried out by such authors as O. Mykytyuk [6, 7], T. Tyurina S. Stavkova [19], Flaherty et al [20].

Emotional stability is manifested in patience and perseverance, endurance and self-control even in stressful situations, self-restraint and ability to behave adequately in negative emotional circumstances, and so on. It should be noted that in professional activities, emotional stability is a crucial feature for a specialist to successfully perform his functions, since the specialist requires considerable self-control and self-regulation efforts.

\section{CONCLUSIONS}

According to the results of our study, students of higher educational institutions need, especially now, in the face of the coronavirus pandemic, relevant knowledge on the development of emotional competence and formation of practical skills to overcome emotional instability.
In our opinion, introduction of appropriate special courses, seminars, psycho-trainings will contribute to the formation of resilience to stressful situations, self-sufficiency, improvement of students' mental health by forming positive feelings, constructive thinking, good will and conscious desire to harmonize the inner and outer worlds, establishing harmonious relationships with the social and natural environment, spiritual and social self-realization.

That is why we continue to work on the syllabus of an optional discipline "Psychology of Emotions" for students and development of trainings on preventing emotional burnout. Furthermore, we believe that it is timely to organize a special psychological assistance unit for individual students at the Lviv Academy of Printing.

Therefore, in our opinion, relevant research should be continued in the field of a comprehensive program aimed at the formation of emotional competence of students in the context of mental health of the individual.

\section{REFERENCES}

1. Kenon V. Psihologiya emocij [Physiology of emotions]. Moskow: 1927, 25p. (In Russian)

2. Lomov B.F. Metodologicheskie i teoreticheskie problemy psihologii [Methodological and psychological problems of psychology]. Kiev: 1990; 45p. (In Ukrainian)

3. Luk A. Emocii i lichnost [Emotions and personality]. Moskow: Znanie; 1982, 176p. (In Russian)

4. Lusin D. Novaya metodika izmereniya emocional\&apos;nogo intelekta [Anew method for measuring emotional intelligence: the "Emin" questionnaire]. Psychological diagnostics. Moskow: 2006;4:3-21. (In Russian).

5. Maslou A. Motivaciya i lichnost [Motivation and personality ]. Piter. 1999, 55p. (In Russian).

6. Mykytyuk 0. Teoretyko-metodologichni zacady formuvannya socioecologichnoi kompetentnosti uchyteliv w systemi pisladyplomnoi pedagogichnoi osvity [Theoretical and methodological principles of formation of socio-ecological competence of teachers in the system of postgraduate pedagogical education]: monograph. Lviv: Print on demand. 2013, 80p. (In Ukrainian)

7. Mykytyuk 0., Tyurina T.,Zachepa A. Doslidzenna problem emocional ’nogo vygoranna uchyteliv u osvitn 'omu seredovychi [ Research of the problem of emotional burnout of teachers in the educational environment]. East European Scientific Journal. Drogobych. 2020;9(61):48-54. doi: 10.31618/EESA.2782-1994. (In Ukrainian)

8. Simonov P. Emocional mozg [Emotional brain ]. Moskow; 2018, 215p. (In Russian)

9. Slobodyanuk I. Treninh partnerskoho spilkuvannia [Partnership training].Training and Methodological Center "Consortium for Improving Management Education in Ukraine Partnership training . Kyiv. 2010, 48p. (In Ukrainian) 
10. Smirnow S. Pedagogika i psihologiya vysshego obrazovaniya: ot deyatel k lichnosti [Pedagogy and psychology of higher education: from activity to personality]: Moskow: Publishing Center "Academy". 2019, 56p. (In Russian)

11. Stein S. Preimushchestvo EQ: emocional\&apos;nyj intelekt i vashi uspekhi [The advantage of $\mathrm{EQ}$ : Emotional intelligence and your success]. Balance Business Books. Moskow. 2017, 74p. (in Russian)

12. Festinger L. Teoria kognitywnogo disonansa [Cognitive dissonance theory]. Moskow: Speech. 2000, 318p. (in Russian)

13. Chrachewa N. Psihogimnastika v treninge [Psycho-gymnastics in training]. Moscow: Speech. 2018, 256p. (in Russian)

14. Chell L., Zinger D. Teoriya lichnosti [Personality theories]. Peter. 2018, 327p. (in Russian)

15. Chernawska L., Krinitska S., Maluk O. Stan zdorovia studentiv, problemy ta shlakhy yikh vyrishennya [Students\&apos; health, problems and solutions ]. Nursing, 2017;1:24-27. (In Ukrainian)

16. Di Stefano C., Heather D., Schutz P. Identifying patterns of appraising tests in first year college students: implications for anxiety and emotion regulation during test taking. Journal of Educational Psychology. 2018;100(4):942-960. doi: 10.1037/a0013096.

17. Goleman D. Emotional intelligence . New York: Bantam Books. 1995, $512 \mathrm{p}$.

18. Tyurina T. Dukhovne zdorovia systemy "liudyna" (u svitli suchasnoi informatsiino-enerhetychnoi paradyhmy) [Spiritual health of the "man" system (in the light of the modern information and energy paradigmy)]. Spirituality of personality: methodology, theory and practice: Collection of scientific works. Sewerodonetsk. 2018;6(87):164-175. (In Ukrainian)

19. Tyurina T., Stavkova S. Harmonization of the activity of the left and right cerebral hemispheres - an important component of the spiritual and mental health of individual and humanity. Mental Health: Global Challenges Journal. 2020;3(2):45-49. doi: 10.32437/mhgcj.v4i2.

20. Flaherty M., Sikorski E., Klos L. et al. Peacework and mental health: from individual pathology to community responsibility. Intervention Journal of Mental Health and Psychosocial Support in Conflict Affected Areas. 2020;18(1):28-36.doi: 10.4103/INTV.INTV_59_18.

\section{ORCID and contributionship:}

Oksana M. Mykytyuk: 0000-0002-7237-4007 A-F

Tamara G. Tiurina: 0000-0001-9421-9350 A-F

Tereza M. Klymus: 0000-0003-0954-7275

Marta Ya. Kozak: 0000-0002-8204-11OX

Ihor I. Yatsyshyn: 0000-0002-4629-234 ${ }^{B, C}$

Natalia A. Umanets: 0000-0002-1756-5695

Nina M. Hayduk: 0000-0003-3839-8192F

\section{Conflict of interest:}

The Authors declare no conflict of interest

\section{CORRESPONDING AUTHOR \\ Marta Ya. Kozak}

Lviv Polytechnic National University

12 Bandera st., 79013 Lviv, Ukraine

tel: +380985738350

e-mail:m_fedyk@yahoo.com

Received: 10.06 .2021

Accepted: 11.10.2021

A - Work concept and design, B - Data collection and analysis, C - Responsibility for statistical analysis,

$\mathbf{D}$-Writing the article, $\mathbf{E}$-Critical review, $\mathbf{F}$ - Final approval of the article 


\title{
MENTAL HEALTH OF TEACHERS IN UKRAINIAN EDUCATIONAL ORGANIZATIONS
}

DOI: 10.36740/WLek202111117

\author{
Tetiana M. Dziuba' ${ }^{1}$ Liudmyla M. Karamushka², Lyubov J. Halushko³, Iryna M. Zvyagolskaya ${ }^{4}$, Taras V. Karamushka5, \\ Ali Hamaidia ${ }^{6}$, Tetiana M. Vakulich ${ }^{7}$ \\ 'V. G. KOROLENKO POLTAVA NATIONAL PEDAGOGICAL UNIVERSITY, POLTAVA, UKRAINE \\ ${ }^{2}$ G. S. KOSTIUK INSTITUTE OF PSYCHOLOGY OF THE NAES OF UKRAINE, KYIV, UKRAINE \\ ${ }^{3}$ VOLODYMYR VYNNYCHENKO CENTRAL UKRAINIAN STATE PEDAGOGICAL UNIVERSITY, KROPYVNYTSKYI, UKRAINE \\ ${ }^{4}$ POLTAVA STATE MEDICAL UNIVERSITY, POLTAVA, UKRAINE \\ ${ }^{5}$ TARAS SHEVCHENKO NATIONAL UNIVERSITY OF KYIV, KYIV, UKRAINE \\ ${ }^{6}$ UNIVERSITE DE MOHAMED LAMINE DEBAGHINE-SETIF-2, SETIF, ALGERIA \\ ${ }^{7}$ INDEPENDENT RESEARCHER, UKRAINE
}

\begin{abstract}
The aim: To research the indicators of teachers' mental health in a destabilizing organization of professional activities.

Materials and methods: The study was conducted at the Poltava M. V. Ostrogradsky Regional Institute of Postgraduate Pedagogical Education, Poltava V. G. Korolenko National Pedagogical University, Volodymyr Vynnychenko Central State Pedagogical University and Poltava State Medical University in 2018-2020. The sample size of 1817 respondents (Ukraine) included 388 men and 1429 women aged 20 to 57 years. The following methods were used: "Scale of threats to occupational health" (Dziuba, 2015) and "Scale of subjective well-being" (Sokolova, 2007) adapted by T. Dziuba. The study used mathematical and statistical analysis (descriptive statistics, correlation analysis) using IBM SPSS Statistics (version 21.0).

Results: It was found that an unstable level of emotional comfort is dominant (57.2\%). This is shown by the following indicators: "self-assessment of mental health" $61.0 \%$, "tension and sensitivity" $54.3 \%$ and "signs of psychiatric symptoms" $53.0 \%$. Correlation analysis revealed a significant negative impact of the threat factors "daily and weekly overtime" ( $p<0.01$ ) and "overwork" ( $p<0.01)$ on mental health. There is an increase in emotional discomfort in a situation of daily and weekly overtime and overwork. There is a positive correlation between the teachers' mental health and the indicator "significance of the professional environment" $(p<0.01)$.

Conclusions: The study showed that teachers' mental health in Ukrainian educational organizations is characterized by unstable emotional comfort and increased emotional discomfort, which is a consequence of unbalanced (destabilizing) working conditions: overwork, overtime. The obtained data motivates the need to conduct targeted psychotherapeutic and corrective work with teachers who demonstrate professional distress.
\end{abstract}

KEY WORDS: mental health, psychological security in the educational organization, overwork, daily and weekly overtime

Wiad Lek. 2021;74(11 p.l):2779-2783

\section{INTRODUCTION}

Professional development and career growth of teachers can occur against the background of mental harmony, well-being, positive mood, creative activity (state of psychological safety), or vice versa - anxiety, excessive stress, low mood (state of psychological danger). The psychological safety of a teacher in educational space performs a stabilizing function as it "balances" the interaction of an employee with external environment. If educational environment does not contain threats, a teacher behaves freely and without compulsion. Under other conditions, the teacher\&apos;s behavior changes: it becomes "clamped" within the framework of professional conventions, there are vigilance and bias towards the existing organizational conditions, a state of "combat" readiness, and so on. In addition, in case of a violation of psychological security, there is a disintegration of professional interactions and psychological and somatic status [1].

Thus, organizational educational environment may contain some destabilizing features (threats), which under certain conditions violate the psychological safety of a teacher and negatively affect his/her mental health and well-being in general.

The complex and multifaceted problem of ensuring psychological security in educational organizations is associated primarily with studying the conditions of personal growth of the subjects in the educational process through their interaction that does not show psychological violence [2]. However, the effects of a destabilizing organization of professional activities on mental health and well-being have not been specifically studied, which necessitates appropriate research. 


\section{THE AIM}

The aim was to assess the level of the indicators of teachers' mental health in a destabilizing organization of professional activity.

\section{MATERIALS AND METHODS}

The study was conducted at the Poltava M. V. Ostrogradsky Regional Institute of Postgraduate Pedagogical Education, Poltava V. G. Korolenko National Pedagogical University, Volodymyr Vynnychenko Central State Pedagogical University and Poltava State Medical University in 2018-2020. The sample size of 1817 respondents (Ukraine) included 388 men and 1429 women aged 20 to 57 years. The sample is characterized by an uneven distribution by male gender. We define the uneven disintegration of the sample as an objective factor, given that most employees working in educational organizations in Ukraine are women.

The following methods of theoretical analysis and empirical research were used:

1. "Scale of threats to occupational health" [3]. Its items representatively cover the aspects of professional activity in educational organizations that are perceived and understood by teachers as possible threat factors in the context of professional activity, business communication and professional career realization.

2. "Scale of subjective well-being" by M. Sokolova adapted by T. Dziuba. It allowed to determine the levels of professional well-being as a basic indicator of teachers' mental health in educational organizations [4].

"Scale of threats to occupational health" contains four scales: "Destroying communications", "Destabilizing organization of professional activity", "Destructions of professional self-affirmation" and "Demotivators of work performance". Each scale is formed by eight threat factors, which, in our opinion, in one way or another affect the mental health of the teacher. In this publication, we focus only on the threat factors of the scale "Destabilizing organization of professional activity" that includes chronic fatigue; performing several tasks at once; overtime working day and week; negative working conditions; professional activity is physically exhausting; professional activity is morally exhausting; excessive load; frequency of changes and reconstructions.

"Scale of subjective well-being" by M. V. Sokolova adapted by T. Dziuba used as an indicator of teachers' subjective well-being in professional activities. The scale is based on screening method, which allows a teacher to assess own psychological state in professional activities, professional behavior, and individual physical symptoms by six indicators: "tension and sensitivity"; "signs that accompany main psycho-emotional symptoms"; "mood swings"; "significance of professional environment"; "mental health self-assessment"; "degree of satisfaction with professional activity".

The results were subjected to mathematical and statistical analysis using IBM SPSS Statistics (version 21.0). The correlation analysis was used to identify the relationships among the obtained indicators.

\section{RESULTS}

The indicators of teachers' mental health in educational organizations (Table I) show that in general, an unstable level of emotional comfort is dominant (57.2\%).

The data presented in Table 1 shows that there are no serious problems in the professional sphere for most respondents, but we cannot talk about emotional comfort and its rapid recovery. Also, slightly higher values were obtained in terms of "self-assessment of mental health" (61.0\%), "tension and sensitivity" (54.3\%) and "signs of psychiatric symptoms" (53.0\%) at the level of unstable emotional comfort. At the same time, almost a third of the respondents stated the high importance of their professional environment for them (26.4\%. the level of "complete emotional comfort").

One cannot ignore the fact that only $1.8 \%$ get complete emotional comfort. These teachers do not complain about various ailments, act effectively under stress, are confident in their abilities, have a set of personal resources that act as regulators of psycho-emotional tension and psycho-physiological activation. $40.5 \%$ of respondents show moderate emotional comfort in the educational organization. These teachers do not experience serious emotional problems, they are quite active, confident, and adequately direct their behavior. However, if we compare the unstable and general total indicator of moderate and complete emotional comfort ( 40.5 and $1.8 \%$. respectively), we can see that the unstable level of emotional comfort significantly prevails (57.2\% of the total quantity).

The results of correlation analysis showed that there are significant correlations between the factors that threaten mental health, which formed the scale "Destabilizing organization of professional activity" and the level of teachers' mental health that impairs the psychological safety of the educational environment (Table II).

From the eight threat factors significant correlations with the level of mental health of teachers were formed by the factors: "daily and weekly overtime" $(p=-0.738, p<0.01)$ and "overload" ( $p=0.659, p<0.01)$. It is important to emphasize that the data indicate the presence of respectively negative and positive statistically significant correlations.

The threat factor of "daily and weekly overtime" was a negative predictor of teachers' mental health, which may indicate the presence of high professional requirements, work overload, and therefore unfavorable organizational and psychological conditions in the educational environment (Table III).

The results of the correlation analysis show that the threat factor "daily and weekly overtime" violates the teachers' mental health on such indicators as "mood swings" $(\mathrm{p}=-0.792, \mathrm{p}<0.01)$, "mental health self-assessment" $(\mathrm{p}=-0.500, \mathrm{p}<0.05)$, "professional satisfaction" $(\mathrm{p}=-0.340$, $\mathrm{p}<0.01)$, "signs of psychiatric symptoms" ( $\mathrm{p}=-0.110$. $\mathrm{p}<0.01)$ and "significance of the professional environment" $(\mathrm{p}=0.141, \mathrm{p}<0.01)$. At the same time, there is positive correlation $(\mathrm{p}=0.141, \mathrm{p}<0.01)$ for the indicator "significance of the professional environment" that indicates a positive influence on mental health. 
Table I. The level of mental health indicators

\begin{tabular}{|c|c|c|c|c|}
\hline \multirow[b]{2}{*}{ Indicators of mental health } & \multicolumn{4}{|c|}{$\begin{array}{l}\text { The level of manifestation, } \\
\text { number of subjects, in \% }\end{array}$} \\
\hline & $\begin{array}{l}\text { complete } \\
\text { emotional } \\
\text { comfort }\end{array}$ & $\begin{array}{l}\text { moderate } \\
\text { emotional } \\
\text { comfort }\end{array}$ & $\begin{array}{c}\text { unstable } \\
\text { emotional } \\
\text { comfort }\end{array}$ & $\begin{array}{l}\text { emotional } \\
\text { discomfort }\end{array}$ \\
\hline Tension and sensitivity & 3.5 & 18.3 & 54.3 & 23.9 \\
\hline Signs of psychiatric symptoms & 3.4 & 40.1 & 53.0 & 3.5 \\
\hline Mood swings & 5.5 & 65.5 & 28.3 & 0.7 \\
\hline Significance of professional environment & 26.4 & 59.1 & 12.5 & 2.0 \\
\hline Self-assessment of mental health & 2.7 & 34.5 & 61.0 & 1.8 \\
\hline Satisfaction with professional activities & 4.2 & 55.3 & 36.8 & 3.7 \\
\hline Overall indicator of mental health & 1.8 & 40.5 & 57.2 & 0.5 \\
\hline
\end{tabular}

Table II. The relationship between the level of teachers' mental health and risk factors

\begin{tabular}{cc}
\hline Mental health risk factors & $\begin{array}{c}\text { Level of } \\
\text { mental } \\
\text { health }\end{array}$ \\
\hline $\begin{array}{c}\text { Scale "Destabilizing organization of } \\
\text { professional activity" }\end{array}$ & $-0.601^{* *}$ \\
\hline "chronic fatigue" & -0.012 \\
\hline "perform multiple tasks at once" & 0.036 \\
\hline "daily and weekly overtime" & $-0.738^{* *}$ \\
\hline "negative working conditions" & 0.117 \\
\hline "professional activity exhausts physically" & -0.041 \\
\hline "professional activity exhausts morally" & 0.094 \\
\hline "overload" & $0.659^{*}$ \\
\hline "frequency of changes and reconstructions" & 0.107 \\
\hline
\end{tabular}

Notes: ${ }^{*}-p<0.05{ }^{* *}-p<0.01$.

Next we analyze the threat factor "overload" (Table IV).

The results of the correlation analysis showed the presence of a positive statistically significant correlation with the overall level of mental health $(\mathrm{p}=0.659, \mathrm{p}<0.01)$.

It is noteworthy that there is a negative correlation between teachers\&apos; assessment of the threat factor "overload" and mental health indicators "tension and sensitivity" ( $p=-0.236, p<0.01)$, "signs of psychiatric symptoms" $(\mathrm{p}=-0.287, \mathrm{p}<0.01)$ and "significance of the professional environment" $(p=-0.660, p<0.05)$, while the indicator "mental health self-assessment" $(p=0.236$. $p$ $<0.01$ ) shows weak but statistically significant correlation, which is positive and identical to the value for the indicator "tension and sensitivity".

\section{DISCUSSION}

The dominance of the level of unstable emotional comfort among teachers may indicate they tend to unnecessary emotional experiences and dramatization of the situation including those related to health or professional activities: "my work puts pressure on me...", "it is hard at work morally and physically...", etc. It may also indicate certain psychosomatic symptoms (excessive response to professional situations and failures, violation of sleep cycle, decreased overall activity, etc.). This trend shows that the high level of professional requirements causes stress and can lead to a variety of negative symptoms: burnout, dissatisfaction with work results, stress, health problems [5].

The identified trend also indicates the presence of destabilizing organizational threat factors in pedagogical activities which can be manifested in unclear chaotic organization and planning, poorly structured and vague information, excessive and often recurring information pressure, inflated requirements for current activities, etc. This conclusion is consistent with the results of studies that have identified certain psychological problems: increasing workload increases the level of stress and role responsibility [6]; overtime (on average from 41 to 50 hours per week) spent on current professional tasks [7]; physical health problems associated with overload, lack of exercise, bad sleep, time constraints and high professional requirements [8].

Decrease of the general level of mental health of Ukrainian teachers in the situation of daily and weekly overtime causes them feeling difficulties in controlling emotions (indicators: "mood swings", "signs of psychiatric symptoms", "self-assessment of mental health"), constant worries about real and imagined professional situations (indicators: "self-assessment of mental health" and "satisfaction with professional activities"). Similar results of the relationship between physical health and overloaded roles were found by J. Ilmarinen who showed that as teachers\&apos; workload increases, their physical health deteriorates and as their workload decreases, their physical health improves. Learning is not considered as a physically demanding activity and an overload of professional roles is usually associated with injuries such as foot and back pain [9].

Manifestations of the so-called "conditional comfort" in a situation of excessive professional workload were also discovered. "Overload" is perceived by a teacher as 
Table III. Indicators of mental health of teachers according to the threat factor "daily and weekly overtime"

\begin{tabular}{cc} 
Indicators of mental health & $\begin{array}{c}\text { The threat factor } \\
\text { "daily and weekly } \\
\text { overtime" }\end{array}$ \\
\hline Tension and sensitivity & -0.011 \\
\hline Signs of psychiatric symptoms & $-0.110^{* *}$ \\
\hline Mood swings & $-0.792^{* *}$ \\
\hline Significance of professional environment & $0.141^{* *}$ \\
\hline Self-assessment of mental health & $-0.500^{*}$ \\
\hline Satisfaction with professional activities & $-0.340^{* *}$ \\
\hline Overall indicator of mental health & $-0.738^{* *}$ \\
\hline
\end{tabular}

Notes: ${ }^{* *} p<0.01 ;{ }^{*} p<0.05$.

Table IV. Indicators of teachers' mental health according to the threat factor" overload"

\begin{tabular}{cc}
\hline Indicators of mental health & $\begin{array}{c}\text { The threat factor } \\
\text { "overload" }\end{array}$ \\
\hline Tension and sensitivity & $-0.236^{* *}$ \\
\hline Signs of psychiatric symptoms & $-0.287^{* *}$ \\
\hline Mood swings & -0.008 \\
\hline Significance of professional environment & $-0.660^{*}$ \\
\hline Self-assessment of mental health & $0.236^{* *}$ \\
\hline Satisfaction with professional activities & -0.012 \\
\hline Overall indicator of mental health & $0.659^{*}$ \\
\hline
\end{tabular}

Notes: ${ }^{* *} p<0.01 ;{ }^{*} p<0.05$

a compensatory mechanism when he/she wants by any means to reduce emotional stress and overcome disorganization in behavior, consciousness and psyche while being in a situation of professional psycho-emotional overload. The "illusive relaxation" in teachers\&apos; perceptions of stress in the educational environment allows them to better concentrate and mobilize efforts to carry out current professional task. We explain this pattern by the fact that the absence of negative indicators in the organization of educational space plays a less significant role than the presence of positive ones. Positive indicators expand the repertoire of personal and professional resources, opportunities and actions for a teacher and consequently affect the overall assessment of mental health indicators by oneself.

Daily and weekly overtime encourage teachers to seek stability: they aim to assert themselves in the chosen profession, to ensure a stable position in the professional field, to try different professional statuses and roles while focusing on their real professional opportunities. High rates of emotional discomfort indicate the crises of professionalization and burnout. The identified trend is consistent with other studies which emphasize that the high level of professional requirements is a cause of stress and can cause a variety of negative symptoms: occupational burnout, psychological stress, health problems [10]; dissatisfaction with the work results due to insufficient understanding of the relationship between the realization of creative abilities and mental health [11]; excessive anxiety under uncertainty [12].

The main result of this study is that professional environment is extremely important for teachers' mental health. This demonstrates the importance of the psychological microclimate in the team, necessity of support from colleagues to maintain emotional comfort and a sense of professional well-being. Professional support is a resource for activating and realizing the professional potential of teachers, optimization of intensive interpersonal interactions, making optimal decisions in situations of excessive professional and time stress. The results are consistent with studies by foreign scholars which show that high levels of protection correlate with low levels of psychological stress in uncontrolled situations involving threats to the individual [13].

\section{CONCLUSIONS}

Our research has shown that most educators demonstrate unstable emotional comfort. This is due to unbalanced (destabilizing) working conditions (overload, daily and weekly overtime) in Ukrainian educational organizations which worsen the psychological security in educational environment. The concept of "destabilizing organization of professional and pedagogical activities" is defined by the authors of the study as a set of organizational (external) threat factors (harmful and dangerous circumstances in the organizational educational environment) that adversely affect the health of educational organization personnel.

Destabilizing threat factors in educational organizations lead to a violation of the dynamic balance between a teacher and a professional environment and cause a slowdown in professional development, reduced productivity, a concentration of mental energy of an employee on personal experiences. Destabilizing factors affect mental health, cause crisis and frustration, inadequate perception of feedback from other participants. The obtained data allow to specify the meaning of the threat factors for the teachers' professional health in situations of excessive overload and justify the need for targeted psychotherapeutic and corrective work with teachers who have manifestations of professional distress. It is also necessary to increase the awareness among teachers about the value of maintaining and developing mental health.

\section{REFERENCES}

1. Reimann M., Guzy J. Psychological contract breach and employee health: The relevance of unmet obligations for mental and physical health. Revista de Psicología del Trabajo y de las Organizaciones. 2017;33(1):111. doi:10.1016/j.rpto.2016.11.001.

2. Espelage D., Anderman E. M., Brown V. E. et al. Understanding and preventing violence directed against teachers: Recommendations for a national research. practice. and policy agenda. American Psychologist. 2013;68(2):75. doi:10.1037/a0031307.

3. Dziuba T. M. Oznaky' destrukcij profesijnogo samostavlennya pedagoga v umovax prolongovanogo stresu. [Signs of destruction of professional self-esteem of a teacher in conditions of prolonged stress]. Teorety' chni i pry`kladni problemy’ psy`xologiyi. 2019;2:104-115. (In Ukraine). 
4. Sokolova M.V. Shkala sub`ektivnogo blagopoluchiya [The scale of subjective well-being (M. V. Sokolova)]. Nikiforov G. S. Diagnostika zdorov`ya. Psikhologicheskij praktikum [Health diagnostics. Psychological workshop]. SPb. : Rech`. 2007; 6:376-378. (In Russian).

5. Bakker A. B., Hetland J., Olsen 0. K. Daily strengths use and employee well-being: The moderating role of personality. Journal of 0ccupational and Organizational Psychology. 2019; 92(1):144-168. doi:10.1111/ joop.12243.

6. Beckley J. The wellbeing a New Zealand teachers: the relationship between health. stress. job demand teacher efficacy. 2011. http://hdl. handle.net/10179/3067 [date access 11.06.2020]

7. Ingvarson L., Kleinhenz E., Beavis A. et al. Secondary teacher workload study: report. Teacher Workforce and Careers. 2005. https://research. acer.edu.au/workforce/2. [date access 11.06.2020]

8. Vus V., Omelchenko L. Interdependent: Mental Health, Social Development, Youth'Socially-Oriented Activity (on the example of a country in transition). Mental Health: Global Challenges Journal. 2018;1(1): 86-87 doi: 10.32437/mhgcj.v1i1.37.

9. In Snel J., Cremer R., Kemper H. C. G. et al. Work and health. Work and Aging: a European perspective. London: CRC Press. 1994, 64 p. doi:10.1201/9781003062622.

10. Baeva I. A. Psikhologicheskaya bezopasnost`obrazovatel 'noj sredy’ v strukture kompleksnoj bezopasnosti obrazovatel noj organizaczii [Psychological security of the educational environment in the structure of complex security of the educational organization]. Kazanskij pedagogicheskij zhurnal. 2017; 6:12-17. (In Russian).

11. Lu J. Creativity and Mental Issues-Behavioral Patterns in Higher Education. Mental Health: Global Challenges Journal. 2018;1(1):59-59. doi: https://doi.org/10.32437/mhgcj.v1i1.23.

12. Greco V., Roger D. Coping with uncertainty: The construction and validation of a new measure. Personality and individual differences. 2001; 31(4): 519-534. doi:10.1016/S0191-8869(00)00156-2.

13. Glynis M. Coping with threatened identities. Psychology Press. 2015. doi:10.4324/9781315733913.

\section{ORCID and contributionship}

Tetiana M. Dziuba: 0000-0002-5950-7741 A-F

Liudmyla M. Karamushka: 0000-0003-0622-3419 A,E

Lyubov J. Halushko: 0000-0001-6323-5307 ${ }^{F}$

Iryna M. Zvyagolskaya: 0000-0001-7531-3966 ${ }^{\mathrm{F}}$

Taras V. Karamushka: 0000-0003-4813-8327 ${ }^{F}$

Ali Hamaidia: 0000-0002-5104-7381 ${ }^{\mathrm{F}}$

Tetiana M. Vakulich: 0000-0002-5700-5035 ${ }^{\mathrm{F}}$

\section{Conflict of interest:}

The Authors declare no conflict of interest.

\section{CORRESPONDING AUTHOR}

\section{Tetiana M. Dziuba}

V. G. Korolenko Poltava National

Pedagogical University

2 Ostrogradskoho St., 36000 Poltava, Ukraine

tel:+380974343775

e-mail: tatjanadzuba@gmail.com

Received: 01.06 .2021

Accepted: 07.10.2021

A - Work concept and design, B - Data collection and analysis, C - Responsibility for statistical analysis, D-Writing the article, $\mathbf{E}$-Critical review, $\mathbf{F}$ - Final approval of the article 


\title{
MOTIVATION FOR ALCOHOL CONSUMPTIONS BY ADULTS: TRADITIONS OR AN ATTEMPT TO SOLVE MENTAL HEALTH PROBLEMS (EXEMPLIFIED BY THE CITY OF LVIV AND LVIV REGION, UKRAINE)
}

D0I: 10.36740/WLek202111118

\author{
Maryna B. Klimanska', Larysa D. Klymanska², Halyna Z. Herasym², Janusz Sierosławski ${ }^{3}$, Viktor Ye. Savka², \\ Olha I. Herus ${ }^{2}$ \\ 'IVAN FRANKO NATIONAL UNIVERSITY OF LVIV, LVIV, UKRAINE \\ 2NATIONAL UNIVERSITY“LVIVSKA POLITEKHNIKA", LVIV, UKRAINE \\ ${ }^{3}$ INSTITUTE OF PSYCHIATRY AND NEUROLOGY, WARSZAWA, POLAND
}

\begin{abstract}
The aim: To clarify motivation trends of alcohol consumption by adults in the city of Lviv and Lviv region and their mental health risk factors as compared to the specificity of motivation for alcohol consumption by the representatives of other European countries.

Materials and methods: The study is based on the data of the representative survey of Lviv region residents (1,200 persons) following the methodology RARHA adjusted for Ukraine and its statistical processing.

Results: The results of the study point to the prevalence of social and recreational, traditional motives for alcohol consumption by Lviv region residents (consumption during solemn ceremonies and celebrations). Extremely important, as compared to other European countries, are social motives (the sense of belonging to an important social group). The importance of social factors for the respondents decreases a bit with age and considerably depends on the specific features of religious practices. A wide-spread motive is the striving for changing the emotional state, combined with higher abuse risk as compared to the people who drink on social occasions.

Conclusions: The results of the study characterize the specificity of the motivational structure of alcohol consumption by Ukrainians as compared to the general European trends and can be used for the development of targeted regional prevention programs.
\end{abstract}

KEY WORDS: alcohol consumption, motivation, mental health, social motives of alcohol consumption, motives of changing emotional state, prevention

Wiad Lek. 2021;74(11 p.l):2784-2788

\section{INTRODUCTION}

The topicality of the problem of alcohol consumption and its motivation does not need to be proven. According to the data of the World Health Organization, some 3 million people die annually as the result of alcohol consumption, which is $5.3 \%$ of all deaths; alcohol constitutes the cause of about 200 types of diseases and traumas [1]. In Europe alcohol is the third factor among the causes of disease and mortality, and this requires logical steps towards research and prevention. One of such steps was a three-year program (2014-2017) - The Joint Action on Reducing Alcohol Related Harm (RARHA), coordinated by the Portuguese governmental agency SICAD (General Directorate for Intervention on Addictive Behaviours and Dependencies) [2]. The goals of the program include establishment of the common system of monitoring of alcohol consumption patterns and alcohol-related harm in the countries of Europe. In 2019, within the research project implemented by the Praesterno Foundation (Poland) and the Department of Social Science and Social Work of the National
University "Lvivska Politekhnika", funded by the State Agency for the Prevention of Alcohol-Related Problems (Państwowa Agencja Rozwiązywania Problemów Alkoholowych) PARPA (Poland, Warsaw), a representative survey of the residents of the city of Lviv and Lviv region was conducted, using RARHA methodology adjusted to Ukrainian reality. The survey results $[3,4]$ have shown that the figure of alcohol consumption among adult residents of Ukraine is high. Only $15.3 \%$ of the respondents have claimed that they have completely or almost completely rejected alcohol, $59.1 \%$ of the respondents have claimed that they have people close to them who drink alcohol in excessive amounts on a regular basis, among whom $8.9 \%$ are their family members. The scope of alcohol-related problems requires paying special attention to a detailed analysis of the key motives for alcohol consumption among the residents of the city of Lviv and Lviv region: the reasons people drink can be related both to the cultural characteristics of the society and to the mental health problems of a concrete individual. This data may become 
a well-grounded basis for alcohol dependence prevention programs, with due account of the regional specificity.

Alcohol consumption is a form of conscious behaviour aimed at achieving a specific effect known to the individual. Realization of this effect, possible consequences of consumption develops in childhood while following adult behaviour and is considerably culture-stipulated. As the person grows up and gains his/her own experience of contacting alcohol, (s)he develops his/her personal vision of the effects and the causes of alcohol consumption. According to the research data $[5,6]$, the motivation for alcohol consumption constitutes the mediator between the expectations and the amount of alcohol consumed. Four key motivational categories are distinguished, with a different source (internal or external stimulators) and valency (positive and negative expectations): consumption for the sake of getting positive mood and good well-being, getting social approval, reducing the level of negative emotions, and avoiding social isolation. The degree of motivation for alcohol consumption is directly related to the consumption rate. The specificity of motivation considerably depends on age (domination of one generalizing motive in the teenage years is replaced with a complex motivational structure as the experience of consumption comes) and gender. Alcohol consumption for the sake of getting positive mood and reducing the level of negative emotions is directly related to alcohol abuse [6].

\section{THE AIM}

The aim of the paper is to clarify motivation trends of alcohol consumption by the adults in the city of Lviv and Lviv region and their mental health risk factors as compared to the peculiarities of alcohol consumption by the representatives of other European countries.

\section{MATERIALS AND METHODS}

The study of motivation trends of alcohol consumption was performed using RARHA methodology [7]. All in all, 1,200 persons have participated in the study, with 400 of them being the residents of the city of Lviv and 800 - the residents of the region. The study was conducted through interviewing based on the principles of informed consent, voluntary participation, anonymousness, and confidentiality.

The individuals who have not consumed alcohol over the recent year have not been asked the question about consumption motivation. As the result, a part of respondents who probably belong to those who abstain from alcohol has been excluded. Still a part of respondents has been excluded due to missing of many answers in the motivation block. As the result, 904 respondents have been analyzed in this paper (416 men and 488 women).

Participants were asked to report how often they drank for the particular reasons in the past 12 months when they drank. Ten possible reasons were suggested to measure motives of drinking using a 5 grade scale (from 1 - Never and 5 - Always).
The data was processed using STATISTICA-12 program. Descriptive statistics method, a chi-squared test, cluster analysis of data (k-means clustering) were applied.

\section{RESULTS}

At the first stage of data processing analysis of the means and percentage of "always" (4) or "most of the time" answers was performed (5) for the sake of determining the prevailing motives for alcohol consumption and the degree of their manifestation. All in all, the level of manifestation of all motives was moderate and did not even reach 3 points (of 5 possible). The data obtained has shown that most frequently the respondents consume alcohol since it "md_3 improves parties and celebrations" $(\mathrm{M}=2.86, \mathrm{SD}=1.1,32.7 \%)$ and " $m$ d_2 because it's fun" ( $M=2.51, S D=1.14,22 \%)$. Further on by the degree of manifestation come such motives as "md_5. to fit in the group you like" $(\mathrm{M}=2.19, \mathrm{SD}=1.13$, 16.4\%), "MD_6. so you won't feel left out [with others]" $(\mathrm{M}=1.87, \mathrm{SD}=1.12,12.8 \%)$, "md_1. Because you like the feeling after having a drink" ( $\mathrm{M}=1.84, \mathrm{SD}=1.02,10.1 \%)$, and "md_7. Because it helps you when you feel depressed" $(\mathrm{M}=1.67, \mathrm{SD}=0.95,6.7 \%)$.

The least important motives are the beliefs that " $m d \_8$. Because you think it is healthy" $(\mathrm{M}=1.5, \mathrm{SD}=0.78,4.0 \%)$, "md_4. Just to get drunk" ( $\mathrm{M}=1.35, \mathrm{SD}=0.75,3.5 \%)$, "md_9. To forget about everything" $(\mathrm{M}=1.35, \mathrm{SD}=0.73$, $2.9 \%)$, and "md_10. Because it is a part of good diet" $(\mathrm{M}=1.15, \mathrm{SD}=0.53,1.3 \%)$.

Analysis of the motivational structure of alcohol consumption has proven a relative insignificance of some reasons for alcohol consumption. Here one may mention the ones which scored less than $4 \%$ and fewer answers "always" or "most of the time": "md_8. Because you think it is healthy" (4.0\%), "md_4. Just to get drunk" (3.5\%), "md_9. To forget about everything" (2.9\%), and "md_10. Because it is a part of good diet" (1.3\%). Hence, the next step in result analysis was identification of groups with different motivation types as far as alcohol consumption reasons are concerned, with exclusion of the variables that are not important when decision concerning alcohol consumption is passed. Cluster analysis of cases (using $\mathrm{k}$-means clustering) was performed for the sake of subgroup identification, and as the result three groups of respondents were outlined (Fig.1.). Analysis of variance has proven availability of considerable differences between clusters by all scales $(\mathrm{p} \leq 0.001)$.

The most numerous is the third cluster of persons having low manifestation of all motives (555 individuals, or $61.4 \%$ ) and, respectively, characterized by lower frequency of alcohol consumption (Cluster "Low Alcohol Consumption Level"). The first and the second clusters are almost the same in size (174 persons in the first cluster and 175 persons in the second cluster, which is $19.3 \%$ from all those under study each). For the first cluster the reason for alcohol consumption most frequently is getting a nice feeling after having a drink (md_1), creating good mood (md_2) and reducing the feeling of depression (md 7) - a cluster 
with the conditional name "Changes in the Emotional State". The second cluster which has got the conditional name "Social Approval" is characterized by the prevailing motives of belonging to the group (md_5 and md_6).

Analysis of the composition of clusters by the peculiarities of alcohol consumption has helped identify considerable divergences ( $\left.\chi^{2}=107.038, p \leq .001\right)$ Fig. 2 .

The share of persons consuming alcohol on a weekly basis is three times higher among those who consume alcohol for changing their emotional state (36.21\%) and twice higher among those who consume alcohol for social approval $(26.29 \%)$ as compared to the cluster with low level of alcohol consumption (11.53\%), which proves the appearance of the risk of alcohol abuse in the background of its use as a means of changing the mood.

Analysis of the composition of each cluster testifies to the availability of divergences between clusters by gender $\left(\chi^{2}\right.$ $=35,89, \mathrm{p} \leq .001)$. The cluster with low alcohol consumption level includes more women $(61.8 \%)$ than men $(38.2 \%)$, while the first and the second clusters, respectively, include more men $(60.34 \%$ men and $39.66 \%$ women in the cluster "Changes in the Emotional State"; $56.57 \%$ men and $43.43 \%$ women in the cluster "Social Approval"). Of interest are the results characterizing changes in the cluster composition depending on the age of respondents $\left(\chi^{2}=20.96, p \leq .01\right)$. Thus, the cluster with low alcohol consumption level consists only of some $20.54 \%$ of people aged $18-30$, while among those who consume alcohol for the sake of experiencing positive emotions there are $32.76 \%$ of such people, and the percentage of senior people $(61+)$ is definitely insignificant in this cluster (only $10.92 \%$ ), while in the cluster with low alcohol consumption level is $23.6 \%$ (Fig.3.).

The results obtained testify to a considerable decrease in the importance of the motive for alcohol consumption for the sake of changing one's emotional state in the older age. Instead, for other age groups emotional motivation is more important. Consumption for the sake of social approval in the senior age group is also lower, but the difference is not that clearly expressed.

It would also be expedient to compare the composition of clusters depending on the peculiarities of the respondent's attitude to religion since religious beliefs constitute an integral part of the world outlook for the residents of Western Ukraine (only $6.8 \%$ of all the respondents have indicated that they are atheists, $32.4 \%$ have said that they are believers, and $60.8 \%$ are practicing believers). It has been identified that the percentage of people who are not just believers but the ones who actively attend liturgies dominates is all clusters, but their share is larger in the cluster "Low Consumption Level" and comparatively lower in the two other ones $\left(\chi^{2}\right.$ $=16.44, p \leq .001$ ), and this proves that observance of religious values and religious practice following constitutes a factor of restraint for alcohol consumption.

\section{DISCUSSION}

The data obtained in Ukraine can be compared to the data received as the result of the similar survey held in 11 Euro- pean countries over 2014-2016 (Bulgaria, Croatia, Estonia, Hungary, Iceland, Italy, Lithuania, Poland, Portugal, Spain, Portugal, and Sweden), with the participation of 16,223 respondents [7]. While comparing the level of expression of the motives among the representatives of different countries, it has been traced that priority motives for alcohol consumption by the residents of Lviv region "improves parties and celebrations" and "because it's fun" are on the moderate level by their numerical figures and more or less correspond to the level of the neighbouring Poland. At the same time, as far as the indicators of social motives that are in the third and fourth places in the motivation structure for alcohol consumption are concerned, Ukrainians considerably outpace most European countries. Thus, the frequency of motive "To fit in the group you like" varies in different European countries from about 1\% (Spain) to almost $17 \%$ (Bulgaria, Lithuania). As compared to other countries, the residents of Lviv region would be in the first positions on this list, with the figure of $16.4 \%$. The situation with "So you won't feel left out" is similar. This motive is the most frequent in the same countries as the previous one and ranges from $16.7 \%$ (Bulgaria) to $0.7 \%$ (Spain). Ukraine would take the second position in this ranking, with the figure of $12.8 \%$.

Of importance for Ukrainians are alcohol-based solutions for mental health problems - the change in the emotional state as the result of alcohol consumption: by their figures for "Because it helps you when you feel depressed" Ukrainians $(6.7 \%)$ would have to be in the second or third place in the ranking side by side with Bulgaria and Poland.

The residents of Lviv region, as compared to the representatives of other countries, rarely drink for the sake of just getting drunk and almost do not consider it to be a part of a good diet. This can be accounted for by the absence of the tradition to drink wine in Ukraine (unlike other European countries). Here people normally drink stronger beverages which traditionally are not included into the daily diet.

The results of the survey show prevalence of social and recreational motives in alcohol consumption by the residents of Lviv region. The importance of those social factors decreases with the age of respondents and depends on the peculiarities of their attitude to religion. An important motive of drinking - changing one's emotional state. Individuals consuming alcohol mainly for this purpose in order to solve their mental health problems run a higher risk of abuse as compared to those who drink for social purposes. This motivation is particularly manifested at a young age.

Comparison of the results obtained with the figures from other countries proves the impossibility of associating the motivation structure of alcohol consumption by Ukrainians with the representatives of a specific country. Alcohol has the same, or similar effect on individuals, while motivation for consumption is different for different people, as well as identifies specific peculiarities within specific cultures. However, the problem of alcohol abuse is, in fact, available in all countries, and this causes topicality of comparative 


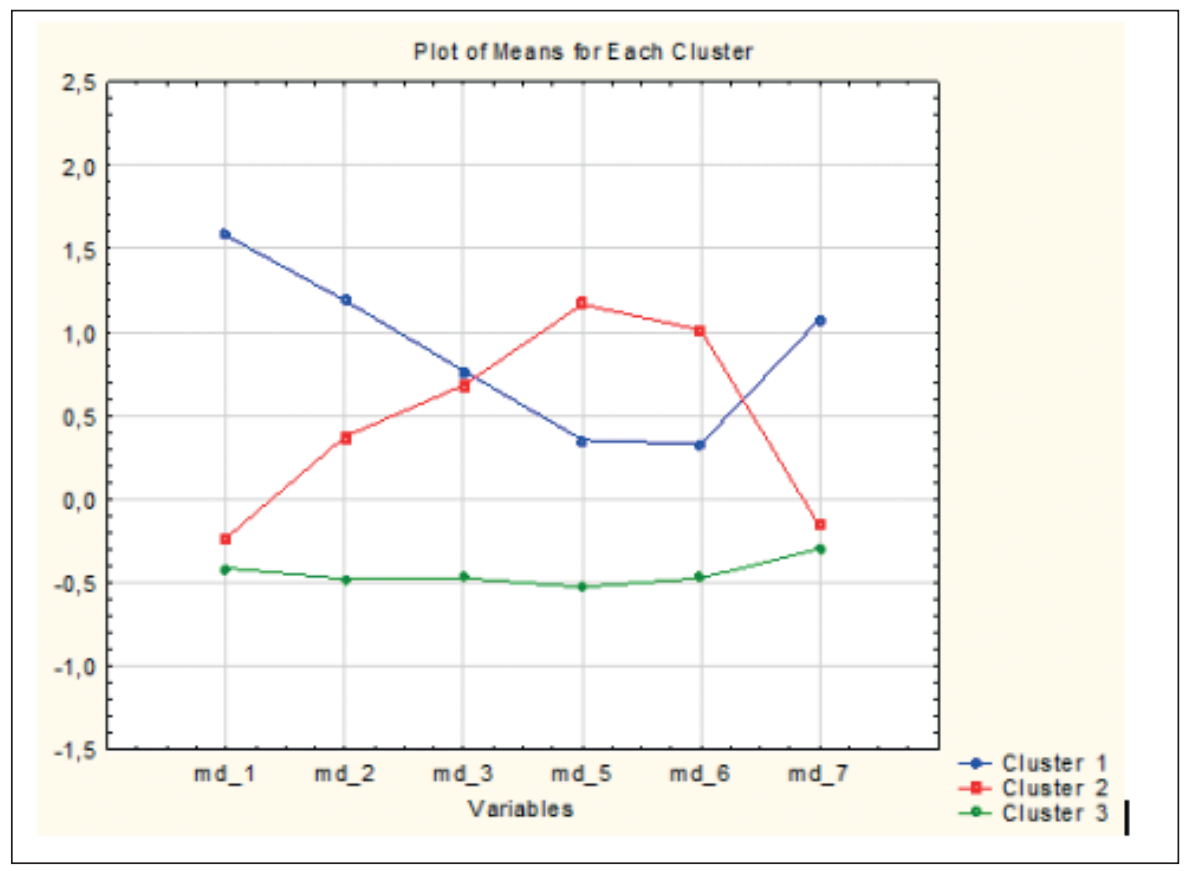

Fig.1. The results of cluster analysis of alcohol consumption motivation

("md_1. Because you like the feeling after having a drink, "md_2. Because it's fun" "md_3. Improves parties and celebrations", "md_5. To fit in the group you like", "md_6. So you won't feel left out [with others]", "md_7. Because it helps you when you feel depressed")

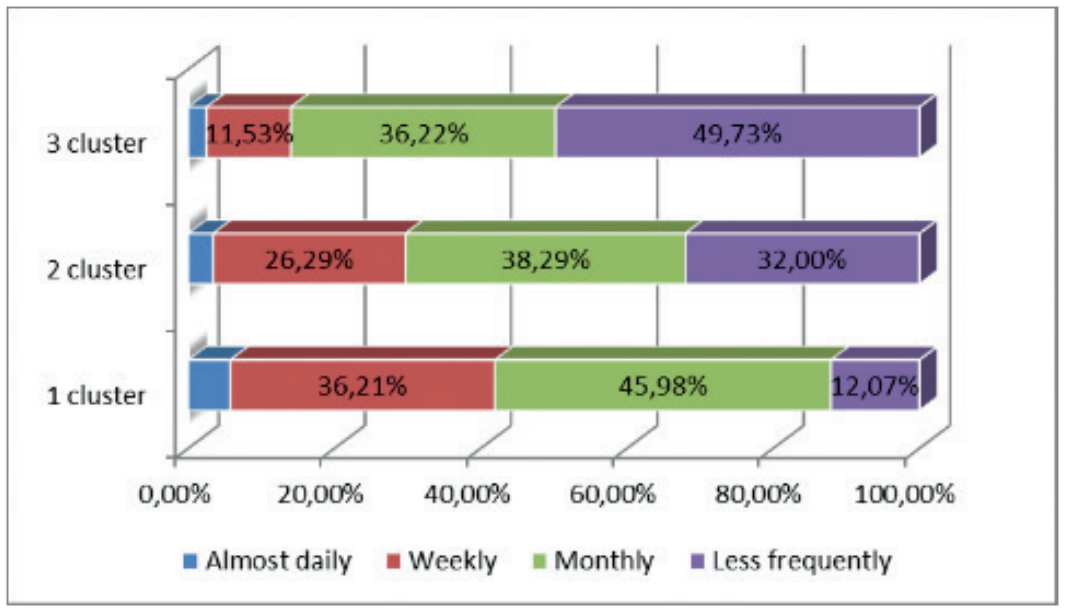

Fig.2. Peculiarities of alcohol consumption by the representatives of different clusters (cluster 1 "Changes in the Emotional State", cluster 2 "Social Approval", cluster 3 "Low Alcohol Consumption Level")

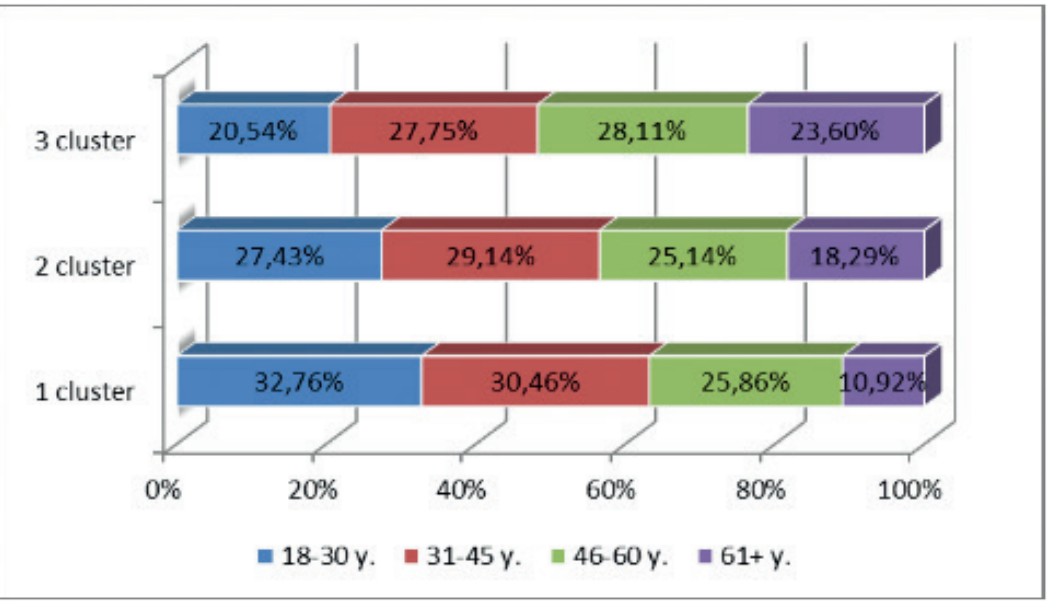

Fig.3. Age composition of clusters (cluster 1"Changes in the Emotional State", cluster 2"Social Approval", cluster 3"Low Alcohol Consumption Level")

analysis of both motivation for consumption in specific cultures, and of the connection between consumption motivation and alcohol abuse manifestations. As far as some indicators are concerned, the results in Lviv region coincide with the data from Poland, which is obviously caused by geographical and cultural proximity. Thus, for Ukrainians of importance are improved celebration motives, getting nice feelings after having a drink and relieving negative emotions. At the same time, as far as social motives are concerned, Ukrainians outpace Polish 
people and show higher dependence on the group. One of the limitations in the results obtained may be regional specificity. According to the data of surveys [8], the west of Ukraine is characterized by lower level of alcohol consumption as compared to the centre and the east, therefore, the results obtained should be applied to the residents of Ukraine in general with caution.

In our opinion, dominating motivations for alcohol consumption, recorded in the present study, make the situation with development and implementation of prevention programs more complicated. This is accounted for, on the one hand, by the idea many Ukrainians have that alcohol consumption has become almost an obligatory component of the culture of spending time together with friends. On the other hand, consumption of alcohol as a means of "relieving" psychological tension, and though temporary, but "distancing" from reality, proves that alcohol addiction is rooted in the complex social problems of the modern Ukrainian society, and, thus, the needs for their priority regulation. And prevalence of strong alcoholic beverages in the consumed alcohol range aggravates the problem of excessive alcohol drinking. That is why the problem of alcohol abuse is a derivative one and requires prior normalization of the current tense social situation.

\section{CONCLUSIONS}

The results obtained in the course of the research have enabled to characterize the specificity of the motivation structure of alcohol consumption by Ukrainians as compared with the general European trends. Uniform coverage of different age groups enables to plan, on the basis of this data, anti-alcohol prevention programs and communicative campaigns for different target groups using the arguments that would be suitable for those groups.

\section{REFERENCES}

1. World Health Organization. Alcohol. 2018. https://cutt.ly/5bZUi3u [date access 03.09.2020]

2. Joint Action on Reducing Alcohol Related Harm (RARHA). 2020. https:// cutt.ly/ubZUj6S [date access 03.09.2020]

3. Herasym H., Herus 0., Klymanska L. et al. The problem of alcohol consumption in Lviv in the sociological dimension (by the materials of empirical research). Mental Health: Global Challenges Journal. 2019. doi: 10.32437/MHGCJ-2019(0).66.

4. Herasym H., Herus 0. , Klos L. et al. Spozhyvannia alkoholnykh napoiv yak sotsialna problema: stvorennia stratehii protydii alkoholizmu u Lvivskii oblasti. Monohrafiia [Alcohol consumption as a social problem: creating a strategy to combat alcoholism in the Lviv region. Monograph]. Lviv: Panorama. 2020, 154p. (In Ukrainian)
5. Cox W. M., Klinger E. A Motivational model of alcohol use. Journal of Abnormal Psychology. 1988; 97(2):168-180. doi: 10.1037/0021843x.97.2.168.

6. Kuntsche E., Knibbe R., Gmel G., Engels R. Why do young people drink? A review of drinking motives. Clinical Psychology Review. 2005; 25(7): 841-861. doi: 10.1016/j.cpr.2005.06.002 .

7. Moskalewicz J., Room R., Thom B. Comparative monitoring of alcohol epidemiology across the EU Baseline assessment and suggestions for future action. Synthesis report. Warsaw: RARHA. 2016, 204p.

8. Rating Group Ukraine. Zdorovia ta samopochutiia ukrainciv. [Health and well-being of the Ukrainians]. 2017. https://cutt.ly/BbxKfto [date access 03.09.2020] (In Ukrainian)

The study has been performed within the project of the State Agency for the Prevention of Alcohol-Related Problems "Cooperation with Ukraine in the Field of Solving Alcohol-Related Problems in the Local Environment" (funded by the National Health Program for 2016-2020. Assignment 47/3.5/18/DEA Period of implementation: from 03.09.2018 to 31.08.2020)

\section{ORCID and contributionship:}

Maryna B. Klimanska: 0000-0002-3047-2346 A-D.F $^{-1}$

Larysa D. Klymanska: 0000-0002-3693-7503

Halyna Z. Herasym: 0000-0003-3254-438X $X^{B, E}$

Janusz Sieroslawski: 0000-0001-9775-6127 $7^{B, C, E}$

Victor E. Savka: 0000-0002-1751-7562 ${ }^{\mathrm{E}}$

Olha I. Herus: 0000-0003-1780-3793 ${ }^{B, C}$

\section{Conflict of interest:}

The Authors declare no conflict of interest

\section{CORRESPONDING AUTHOR Maryna B. Klimanska \\ Ivan Franko National University of Lviv \\ 1 Universytetska st., 79000 Lviv, Ukraine \\ tel: +380503716453 \\ e-mail: marina.klimanska@gmail.com}

Received: 18.06 .2021

Accepted: 15.10 .2021

A - Work concept and design, B - Data collection and analysis, C - Responsibility for statistical analysis, D-Writing the article, $\mathbf{E}$-Critical review, $\mathbf{F}$ - Final approval of the article 


\title{
ORGANIZATIONAL FACTORS OF PSYCHOLOGICAL SAFETY IN THE WORKPLACE
}

DOI: 10.36740/WLek202111119

\author{
Iryna B. Volevakha' ${ }^{1}$, Nataliia V. Kolomiiets ${ }^{2}$, Tetiana V. Kukhar ${ }^{1}$ \\ ${ }^{1}$ ACADEMY OF THE STATE PENITENTIARY SERVICE, CHERNIHIV, UKRAINE \\ ${ }^{2}$ CHERNIHIV POLYTECHNIC NATIONAL UNIVERSITY, CHERNIHIV, UKRAINE
}

\begin{abstract}
The aim: To reveal the organizational factors of psychological safety in the workplace.

Materials and methods: Methods of psychological survey, statistical assessment and analysis of the received data were used.

Results: Psychological safety is regarded in the paper as a state of preservation of mind that involves maintaining a balance between the negative effects of the environment and a person's resilience, that is, the ability to overcome such effects. In the structure of the psychological safety of the organization member three components were identified and explored: cognitive, emotional and "confidence in the future". The results of the survey study confirmed that such organizational factors as level of organizational culture, working team cohesion, working team self-organization, management style of the immediate supervisor, work autonomy, role ambiguity have positive effect on psychological safety. Conclusions: The results imply the importance of purposeful implementation of company policies aiming to improve the revealed factors: providing autonomy to employees and work groups within the organization, establishing clear job descriptions, work performance requirements and interaction principles, improving works design, internal communications.
\end{abstract}

KEY WORDS: worker psychological safety, corporate culture, work autonomy, team cohesion, role ambiguity, team self-organization

Wiad Lek. 2021;74(11 p.l):2789-2793

\section{INTRODUCTION}

The mental state of employees of the organization, their feeling protected from various negative influences, is a necessary guarantee of successful professional duties performance, realization of their creative potential, and ensuring a strong desire to continue working and developing in the organization. Hence, forecasting external and internal threats and risks, regulating the conditions and factors of the organizational environment to minimize risks, and creating conditions for the formation of a feeling of psychological safety are important tasks of every modern organization.

In order to build an optimal organizational environment purposefully in which the potential of employees can be fully realized for the benefit of the organization, managers need to have a clear understanding of the factors that affect the psychological safety of employees and, consequently, their efficient performance at workplace. Psychological safety is associated with improved team performance $[1,2]$, job involvement $[3,4]$, sharing information and knowledge [5].

It also should be noted that psychological safety is a basic human need and it should be a priority and integral part of organization policy, based on the principles of humanism and the value of human life quality. Feeling safe at the workplace reduces risks of employees' burnout that in turn may have a significant effect on various mental health disorders occurring [6]. All these factors justify the importance of research aimed to determine the socio-psychological factors of psychological safety.

\section{THE AIM}

The aim of the research is to reveal the organizational factors of psychological safety in the workplace, i.e. to answer the question what characteristics of inner organizational environment influence employees' perceptions of feeling safe at workplace.

\section{MATERIALS AND METHODS}

\section{THEORETICAL BACKGROUND}

In building a model of psychological safety, the approach of I. Baeva (2006) was followed, who considers psychological safety as a state of preservation of mind that involves maintaining a balance between the negative effects of the environment and a person's resilience, that is, the ability to overcome such effects [7].

Thus, in the structure of the psychological safety of the organization member three components were identified.

The cognitive component includes beliefs of employees arising from the perception and intellectual processing of information about: 
1. parameters of the professional environment in terms of real and potential risks and threats that cause, or may cause, feeling not safe.

2. own abilities to cope with the risks and threats of the professional environment. That is, self-assessment of own professional and social competence, flexibility in responding to difficult circumstances, and self-confidence in situations of professional activity.

At the heart of the emotional component is a feeling of being protected from the threats that come from the professional environment. It is the result of perception of the situation and cognitive processing of information about the state and threats of the environment, as well as about his coping abilities. The resulting assessment has emotional shades and can be characterized by dichotomies such as "safe-dangerous", "good-bad", "comfortable-uncomfortable" etc.

Psychological safety in the workplace should be considered both in terms of current professional situation and also worker's expectations for the future. In order to feel safe, it is not enough to perceive the environment as safe and the own ability to cope with all the challenges successfully today, but also the confidence that the current state of affairs will be maintained tomorrow is important. So, we include "confidence in the future" component to the model of psychological safety.

\section{PARTICIPATION}

The research involved 322 representatives who were selected randomly from 29 different organizations of two types: 169 employees of educational organizations (schools and universities) and 153 employees of business organizations (enterprises, banks, etc.). The distribution by sex is as follows: 287 women, 135 men. The minimum length of service in the organization -1 year, the maximum - 41 years.

\section{TOOLS}

The participants were offered the research questionnaire consisting of two sections: section A which focused on biographical information: age, gender, years of service, years of service in the current organization, type of organization and section B which consisted of such measuring scales:

1. "Questionnaire of personal psychological safety of organization member" that was constructed according to the model of psychological safety described above on the basis of "Psychological safety of the educational environment scale". Respondents\&apos; assessments of the level of psychological safety were assessed on ten components: "general assessment of safety at work", "relationship with the management", "relationship with the colleagues", "job tasks complexity and volume", "working conditions", "reward", "ability to cope with troubles caused by the management", "ability to cope with troubles caused by the colleagues", "ability to cope with the job tasks", "confidence in the future".

On the basis of the literature analysis we hypothesise that the following factors of the organization inner environment influence the psychological safety of employees: level of organizational culture, working team development, management style of the immediate supervisor, work autonomy, role ambiguity. The following Surveys (2-6) were aimed to measure such factors.

2. Survey "Assessment of the level of corporate culture" [8]. 3. Survey "Pulsar" - the socio-psychological level of a working team development is assessed by its member based on its main socio-psychological states: readiness for activity, orientation, self-organization, activity, cohesion, integrity [8].

4. The Blake Mouton Managerial Leadership Grid. Employee Questionnaire. Two behavioural dimensions - "concern for people" and "concern for results" of the participants' immediate supervisors were explored [9].

5. "Work Autonomy Scale" [10].

6. "Six-item role ambiguity scale" [11].

Influence of the selected organization's characteristics on psychological safety of employees was checked by using statistical method of regressive analysis. Impact of the type of organization on the psychological safety of participants was analyzed by comparing the results of two samples - members of educational institutions and members of business organizations by using Mann-Whitney U-test.

\section{RESULTS}

The empiric research data analysis showed the influence the number of organizational factors on the psychological safety of the employees (table I).

"Emotional safety" measures to what extent an employee regards his work as a source of trouble, if he is likely to experience anxiety, sadness and discomfort during performing of professional duties. It was found out that the employees are more likely to feel safe in the organizations with characteristics such as: less "role ambiguity" $(\beta=0,545, p \leq 0,001)$, higher "corporate culture level" $(\beta=0,231, p \leq 0,002)$ and higher "team cohesion" $(\beta=0,149, p \leq 0,026)$.

The component of psychological safety "relationship with the management" is based on the employees' perception of level of pressure and coercion from the management. The tension is higher among the employees who think that their organizations have high "team cohesion" $(\beta=-$ $0,387, p \leq 0,001)$, lower "team activity" $(\beta=0,312, p \leq 0,003)$, lower "level of corporate culture" $(\beta=0,293, p \leq 0,02)$ and their managers demonstrating less "concern for people" $(\beta=0,301, p \leq 0,001)$.

"Relationship with the colleagues" (trusting one's colleagues, perceiving them as those who don't bring threats and troubles) has one predictor - "role ambiguity" $(\beta=0,219, p \leq 0,008)$.

Both components of psychological safety "job tasks complexity and volume" (from the point of view of causing employees feeling significant discomfort) and "ability to cope with the job tasks" has influence of the parameter of "team self-organization" $(\beta=0,314, p \leq 0,001)$ and $(\beta=0,235$, $\mathrm{p} \leq 0,003)$, respectively. 
Table I. The revealed affecting factors influencing the psychological safety components

\begin{tabular}{|c|c|}
\hline $\begin{array}{l}\text { The psychological safety } \\
\text { components }\end{array}$ & $\begin{array}{l}\text { The affecting factors } \\
\text { revealed }\end{array}$ \\
\hline Emotional safety & $\begin{array}{c}\text { Role ambiguity } \\
\text { Corporate culture level } \\
\text { Team cohesion } \\
\text { Type of organization }\end{array}$ \\
\hline $\begin{array}{l}\text { Relationship with the } \\
\text { management }\end{array}$ & $\begin{array}{c}\text { Team cohesion } \\
\text { Team activity } \\
\text { Level of corporate culture } \\
\text { Concern for people }\end{array}$ \\
\hline Relationship with the colleagues & $\begin{array}{c}\text { Role ambiguity } \\
\text { Type of organization }\end{array}$ \\
\hline Job tasks complexity and volume & Team self-organization \\
\hline Ability to cope with the job tasks & Team self-organization \\
\hline Working conditions & Level of corporate culture \\
\hline $\begin{array}{l}\text { Ability to cope with troubles } \\
\text { caused by the management }\end{array}$ & Level of corporate culture \\
\hline Confidence in the future & $\begin{array}{c}\text { Autonomy } \\
\text { Type of organization }\end{array}$ \\
\hline
\end{tabular}

"Working conditions" (confidence that the workplace has safe and healthy conditions) and "ability to cope with troubles caused by the management" (communication with the supervising managers as a source of stress, having problems in establishing a normal working relationship with management) have also one and the same for both of them predictor - "level of corporate culture" $(\beta=0,356$, $p \leq 0,006)$ and $(\beta=0,335, p \leq 0,001)$, respectively.

Higher "confidence in the future" is predicted by higher "autonomy" rates $(\beta=0,238, \mathrm{p} \leq 0,01)$.

As for the components: "reward" (level of concern about the low amount of payment for the work) and "ability to cope with troubles caused by the colleagues" - no contributors were found.

By comparing the results of two samples - members of educational institutions and members of business organizations - significant differences in three components of psychological safety were revealed. Indexes of "emotional safety" ( $\mathrm{p} \leq 0,01)$, "relationship with the colleagues" $(p \leq 0,05)$ are significantly higher in the sample of the teachers and professors, and "confidence in the future" $(\mathrm{p} \leq 0,01)$ is higher in business organizations employees.

\section{DISCUSSION}

The results indicate that a number of explored organizational factors affect workers' perceptions of safety.

General assessment of the level of their psychological safety ("emotional safety") is influenced by role ambiguity. In our opinion, such result can be explained by the fact that the working environment with clear requirements, duties and responsibilities of employees reduces such potential threats to psychological safety as uncertainty and likelihood of role conflicts, both interpersonal and intrapersonal. Also we revealed statistically the significant positive impact of a high level of corporate culture development on this component. By high level of corporate culture the authors of the test mean a good works organization, developed internal communications, the use of various methods of positive incentives for personnel, and a high level of morality. The positive influence of higher team cohesion can be explained by the fact that in a highly cohesive work groups with a strong desire of its members to work together employees receive emotional support from colleagues and friendly attitude towards themselves; active exchange of knowledge and mutual assistance between members in such groups also remove threats to feeling safe and promoting the job satisfaction that is proved by the other researches $[12,13]$.

Interestingly, a high level of "team cohesion" turned out to have a negative influence on "Relationship with the management" - employees of highly cohesive teams are more inclined to feel a higher level of pressure and coercion from the management. Presumably, this can be explained by the greater desire of high cohesive teams to defend their interests before the leadership and even by trying to take over some of the powers. In contrast, members of teams with a high "team activity" feel less threatened by management. Obviously, this is due to their acceptance of the organization\&apos;s goals and an interest in performing effectively, that aligns with the intentions of the leaders. The positive influence of the supervisors' management style in the part of "Concern for people", in our opinion, was quite expected - the leader\&apos;s neglect of the interests of employees usually causes tension in relations at the "boss-subordinate" level. On the contrary, it was proved that job satisfaction has been associated with employees who perceive their managers as supportive and caring [14]. The positive influence of "level of corporate culture" on both "relationship with the management" and "ability to cope with troubles caused by the management" should also be noted. As already discussed, a high level of corporate culture development contributes to "emotional safety", i.e. feeling safe in general. Organizational culture is usually treated as a product, first of all, of the leaders' activities, therefore, such managers are perceived by employees positively and they are more likely to build productive relationships with subordinates. The research data show that organizational culture is significantly positively correlated with leadership behaviour and job satisfaction [14].

The results of the research show that employees of organizations with a clearer distribution of roles and responsibilities state a lesser threat to their psychological safety from the colleagues. We think, this can be explained by the fact that a higher definition of roles reduces the likelihood of conflicts between employees, which may arise as a result of diverging expectations and real practice.

Perception of the complexity and volume of the work tasks as causing less significant discomfort and higher estimation of one's ability to cope with the job tasks are more likely to occur in the members of working groups with high rates of "team self-organization", i.e. the ability to organize its work itself without the intervention 
of higher authorities. This can be explained by the fact that the "self-organized team" creates an acceptable and understandable job design for its members itself. In the decision-making process methods of performing tasks, algorithms of interactions are being worked out, the experience and knowledge of employees are shared. The result is that the complexity and volume of the tasks causes less discomfort for the self-organized team members.

"Working conditions" (confidence that the workplace has safe and healthy conditions and the work shall not cause loss of health) is contributed by "level of corporate culture". In organizations with a high level of corporate culture, as a rule, sufficient attention is paid to ensuring a safe working environment for employees. M. Aluko (2003) measures culture against the ability of the organization to guarantee, among the other their needs, job security of the employees [15].

Employees with a higher degree of autonomy are more confident in their ability to cope with future challenges in the professional environment. Since they have a greater freedom in planning, organizing and controlling their work and are accustomed to relying primarily on their own strengths, as a result, they value themselves higher as professionals and, therefore, are more confident in their professional future.

The statistically significant differences of the results of the two types organizations representatives, in our opinion, can be explained as follows:

- "emotional safety" - the business environment is less stable, the number of challenges and adverse situations that arise during a given period of time and can affect the sense of safety in organizations of these type is higher;

- "relationship with the colleagues" - a higher level of internal competition between employees of business organizations. In some of them, maintenance this kind of competition may even be part of the adopted personnel policy;

- "confidence in the future" - the differences can be explained by the influence of the crisis of recent years in the field of education in Ukraine and it affects organizations of the participating teachers and professors.

Similar results of contributing of the described factors to psychological safety were received by other researchers: good interpersonal relationships $[3,4,16,17,18]$, various workplace contexts $[6,11]$, team characteristics [1], leaders' behaviour and supportive management style [3, 18, 20,21], role ambiguity [22], job autonomy and communication quality [21], job security [23].

\section{CONCLUSIONS}

Psychological safety of organization member is considered by the authors as the feeling of being protected from the threats of the professional environment. The source of this feeling is an estimation of the professional environment threats' intensity (strength) and one's ability to cope with them. The findings of this research reveal a number of organizational factors that have statistically significant relationships to the employees' perception of safety. The results imply that the psychological safety of the employees can be improved by implementation the following organizational policies:

1) providing autonomy to employees and work groups within the organization in making decisions regarding planning and organization of their work, the choice of methods for completing tasks, encouraging self-organization, internal cohesion and leadership within work groups;

2) establishing clear job descriptions, work performance requirements and interaction principles inside the organization;

3) correcting of management style of those chiefs who demonstrate lack of concern for personnel;

4) developing corporate culture components such as works organization, internal communications, positive incentives, morality.

The further prospects of research are seen in conducting empirical research of the other factors that potentially affect the psychological safety, adding to the sample the representatives of other types of organizations.

\section{REFERENCES}

1. Newman A., Donohue R.., Eva N. Psychological safety: a systematic review of the literature. Human Resourse Management Review. 2017; 27: 521-535.

2. Edmondson A. Psychological safety and learning behavior in work teams. Administrative Science Quarterly. 1999; 44: 350-383.

3. Kahn W.A. Psychological conditions of personal engagement and disengagement at work. Academy of Management Journal. 1990; 33: 692-724.

4. May D.R., Gilson R.L., Harter L.M. The psychology condition of meaningfulness, safety andavailability and the engagement of the human spirit atwork. Journal of Occupational and Organizational Psychology. 2004; 77: 11-37.

5. Siemsen E., Roth A.V., Balasubramanian S., Anand G. The influence of psychological safety and confidence in knowledge on employee knowledge sharing. Manufacturing \& Service Operations Management. 2009; 11(3): 429-447.

6. Tsaras K., Malliarou M., Kotrotsiou S. et al. Impact of job burnout on mental health among social workers in public and private sector in Greece. Mental Health: Global Challenges Journal. 2019; 2(1): 30. doi:10.32437/mhgcj.v2i1.47.

7. Baeva I.A. Psikhologiya bezopasnosti kak napravleniye psikhologicheskoy nauki i praktiki. Natsionalnyy psikhologicheskiy zhurnal. 2006; 1: 66-68. (in Russian).

8. Istratova 0.N., Eksakusto T.V. Spravochnik psikhologa-konsultanta organizatsii. Rostov-na-Donu. 2006, 638p. (in Russian).

9. Karamushky L.M. Tekhnolohiyi roboty orhanizatsiynykh psykholohiv: Navch. posib. dlya studentiv vyshch. navch. zakl. ta slukhachiv in-tiv pislyadyplom. Osvity. K.: Firma «INKOS». 2005, 366p. (in Ukrainian)

10. Breaugh J. A. The measurement of work autonomy. Human Relations. $1985 ; 38,551-570$.

11. Rizzo J. R., House R. J., Lirtzman S. I. Role conflict and ambiguity in complex organizations. Administrative Science Quarterly. 1970; 15: 150-163.

12. Edmondson A. Psychological Safety, Trust and Learning: A Group-level Lens. In Trust and Distrust in Organizations: Dilemmas and Approaches. New York: Russell Sage Foundation. 2004, 272p. 
13. Urien B., Osca A., García-Salmones L. Role ambiguity, group cohesion and job satisfaction: A Demands-Resources Model (JD-R) Study from Mexico and Spain. Revista Latinoamericana de Psicología. 2017; 49(2): 137-145.

14. Tsai Y. Relationship between Organizational Culture, Leadership Behavior and Job Satisfaction. BMC Health Services Research. 2011; 11: 98. doi: 10.1186/1472-6963-11-98.

15. Aluko M.A.O. The impact of culture on organizational performance in selected textile firms in Nigeria. Nordic Journal of African Studies. 2003; 12 (2): 164-179.

16. Edmondson A.C., Lei Z. Psychological safety: the history, renaissance, and future of an interpersonal construct. Annual Review of Organizational Psychology and Organizational Behavior. 2014; 1:23-43.

17. Appelbaum N.P., Dow A., Mazmanian P.E. et al. The effects of power, leadership and psychological safety on resident event reporting. Medical Education. 2016; 50: 343-350.

18. Aranzamendez G., James D., Toms R. Finding antecedents of psychological safety: a step toward quality improvement. Nursing Forum. 2015; 50: 171-178.

19. Singer S., Edmondson A. Confronting the tension between learning and performance. Reflections: The SoL Journal. 2012; 11:34-43.

20. Walumbwa F.0.,SchaubroeckJ.Leader personality traits and employee voice behavior: Mediating roles of ethical leadership and work group psychological safety. Journal of Applied Psychology. 2009; 94(5): 1275-1286.

21. Parker S. K., Axtell C. M., Turner N. Designing a safer workplace: Importance of job autonomy, communication quality, and supportive supervisors. Journal of Occupational Health Psychology. 2001; 6(3): 211-228.

22. Schmidt S., Roesler U., Kusserow T., Rau R. Uncertainty in the workplace: Examining role ambiguity and role conflict, and their link to depression - a meta-analysis. European journal of work and organizational psychology. 2014; 23: 91-106.
23. Idrees D., Hafeez M., Kim J.-Y. Psychological Factors Affecting the Perception of Personal Safety of Construction Workers in a Developing Country. International Journal of Scientific Engineering and Research (IJSER). 2017; 5(10): 94-98.

\section{ORCID and contributionship:}

Iryna B. Volevakha: 0000-0002-7525-0878 A, D-F

Nataliia V. Kolomiiets: 0000-0002-5770-4805 B-E

Tetiana V. Kukhar: 0000-0002-2352-323X B, D, E

\section{Conflict of interest:}

The Authors declare no conflict of interest.

\section{CORRESPONDING AUTHOR \\ Iryna B. Volevakha}

Academy of the state penitentiary service

34 Honcha st. 14000 Chernihiv, Ukraine

tel: +380663031812

e-mail:volevalha_iryna@ukr.net

Received: 02.06 .2021

Accepted: 14.10 .2021

A - Work concept and design, B - Data collection and analysis, C - Responsibility for statistical analysis,

D-Writing the article, $\mathbf{E}$ - Critical review, $\mathbf{F}$ - Final approval of the article 


\title{
PERSONALITY FACTORS OF EMOTIONAL RESILIENCE IN THE CHALLENGING ENVIRONMENTS FOR MENTAL HEALTH
}

DOI: 10.36740/WLek202111120

\author{
Oleksandr R. Malkhazov', Iryna V. Zhadan', Svitlana I. Poznyak', Giuseppe Vella² \\ 'INSTITUTE OF SOCIAL AND POLITICAL PSYCHOLOGY NATIONAL ACADEMY OF EDUCATIONAL SCIENCES OF UKRAINE, KYIV, UKRAINE \\ ${ }^{2}$ AZIENDA SANITARIA PROVINCIALE DI AGRIGENTO, AGRIGENTO, SICILIA, ITALY
}

\begin{abstract}
The aim: The article presents the results of an empirical study aimed at identifying individual typological profiles of people with different potential for emotional resilience development.

Materials and methods: The authors identify a set of characteristics that determine emotional resilience development and suggest standardized methodologies to measure their intensity level (Eysenck Personality Inventory (EPI), Strelau Temperament Inventory (STI), Thurstone Temperament Schedule adapted by Khainovski, and the LeonhardSchmieschek questionnaire). The outcomes of the data processed in the R environment have allowed the determination of the parameters of the psychological profile of an average client and identification of the traits that have the strongest impact on emotional resilience development.

Results: The constructed factor-correlation-cluster model based on the mean data values for each of the respondents' psychological profiles contains three superclusters: 1) orientation at outer/inner world, 2) behavioral determination stability, 3) reflectivity. Accordingly, six types of psychological profiles of individuals with different potential for emotional resilience development have been determined. The six types are: 1) outward-oriented (looking) type; 2) inward-oriented type; 3) stable behavioral determination type; 4) unstable behavioral determination type; 5) reflectivity-oriented type; 6) reflectivity- non-oriented type. The authors describe the structure and peculiarities of manifestation of the individual psychological characteristics within each supercluster. The behavioral manifestations that facilitate or hinder the development of emotional resilience of individuals belonging to certain profiles are also described.

Conclusions: The implementation prospects of the developed typology of psychological profiles of individuals with different emotional resilience resources are related to providing client-oriented support of emotional resilience development. Further research will address the development, piloting and implementation of the socio-psychological strategies of emotional resilience development support based on the suggested psychological profile typology.
\end{abstract}

KEY WORDS: individual typological profile, superclusters, emotional resilience, development potential, diagnostic markers

Wiad Lek. 2021;74(11 p.l):2794-2798

\section{INTRODUCTION}

People repeatedly experience threats to their safety and find themselves in environments that challenge their psychological health. The consequences of such experiences are reduced resilience, rejection of common social practices, taking conspiracy theories for granted, readiness to sacrifice one's rights and freedoms for the feeling of safety, and the spread of dependency syndrome. The Ukrainian society has been enduring a military conflict for years, the annexation of part of its territory, and problems with the adaptation of temporarily displaced people. In addition, the threats posed by the Covid-19 pandemic have caused growing anxiety, emotional tension, and a lack of feelings of security, actualizing the issue of the factors of mental health protection and creating a social demand for their identification.

Recently, scientists have accumulated empirical data that can help establish an understanding of the individual psychological characteristics and abilities that determine people's behavior in problem situations. One of the factors that influence the choice of effective behavioral strategies in challenging environments for mental health is personality emotional resilience. Even though the issue of emotional control is being investigated in different contexts and scientific paradigms, there is still a lack of research focused on exploring the individual psychological determination of emotional resilience. Theoretical conceptions of personality styles of emotional self-regulation have not been supported with sufficient empirical data. At the same time, there is a strong demand for such studies among consultants and practitioners as research findings can effectively facilitate emotional resilience development support, and therefore, provide for mental health protection.

The empirical research results obtained by Ukrainian and foreign scientists $[1-8]$ prove that an individual's confidence in their ability to control emotions and emotional manifestations, which makes it easier to accept new circumstances, find new meanings and adapt to social reality demands, is one the most important factors of emotional resilience development. In addition, studies of the psychological mechanisms of emotional resilience [1] have revealed strong associations between emotional resilience 
and stability, sensitivity to emotional stimuli (neuroticism), optimism, self-control, high level of obstinacy, resentfulness, isolation, irascibility, behavior control, restraint, moodiness, acute sensing of pleasant and unpleasant impressions, timidity and phobia, inability to enjoy life, restlessness, thoughtfulness, concentration, ability to control asthenic emotions, emotional reactivity (agitation), a tendency to frequent change of emotions, sociability, extra- and introversion, and anxiety. Special attention has been paid to the associations between the peculiarities of peoples' reactions to emotionally significant situations and extra-/introversion level, cognitive style of behavior, locus control, psychological endurance (resilience) and self-judgment, level of anxiety, impulsive rigidity, and avoidance [2]. The studies of sportsmen's psychological resilience personality determinants used the Eysenck Personality Inventory (EPI), the Strelau Temperament Inventory (STI), the Thurstone Temperament Schedule adapted by Khainovski, and the Leonhard-Schmieschek questionnaire suggest that resource self-evaluation and typological personality characteristics have a considerable influence on psychological resilience [9]. Research methods on personality, including those of emotional resilience diagnostics, have been thoroughly described [10]. The argument that the ability of an individual to resolve emotionally challenging situations provides for their survival and flourishing in the changing and competitive environment has also been empirically confirmed. [11].

Synthesizing the study results mentioned above and the findings of the authors' investigations has allowed determining 24 personality traits that influence the development of emotional resilience. The most frequently mentioned correlations are those between emotional resilience and indicators of nervous processes balance (strength of excitation $\div$ strength of inhibition), endurance, reflectivity, and hyperthymity.

\section{THE AIM}

The article aims to empirically determine and rationalize individual psychological profiles of individuals with different potential for emotional resilience development.

The research methods used to obtain the empirical data were chosen in consideration of the identified characteristics. The sample included 485 male respondents aged 18 to 36 who took part in the survey. All of them saw a psychologist because of emotional self-regulation problems.

\section{MATERIALS AND METHODS}

To measure the intensity of the traits that determine personality emotional resilience development, the authors applied the Eysenck Personality Inventory (EPI), the Strelau Temperament Inventory (STI), the Thurstone Temperament Schedule adapted by Khainovski, and the Leonhard-Schmieschek questionnaire. The data were processed with the help of the $\mathrm{R}$ statistical computing software [13-14]. Statistical computing and construction of

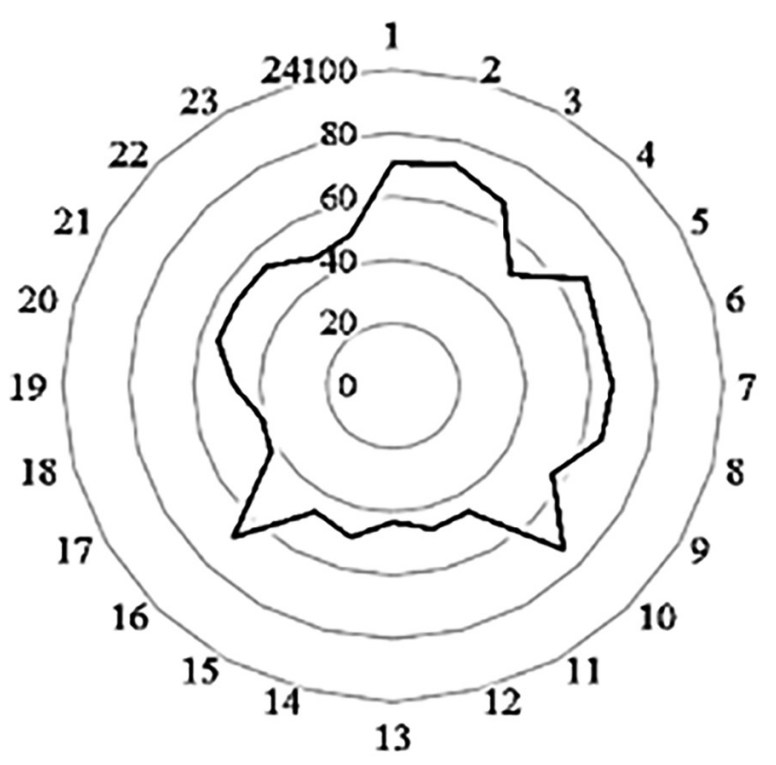

Fig. 1. Psychological profile of an average individual

Symbols: Questionnaires: Strelau: 1 - strength of excitation, 2 - strength of inhibition, 3 - mobility of nervous processes, 4 - balance of nervous processes by strength of excitation; Thurstone: 5 - active, 6 - vigorous, 7 - impulsive, 8 - dominant, 9 - stable, 10 - sociable, 11 - reflective; Leonhard-Schmieschek: 12 - demonstrative, 13 - pedantic, 14 - stuck, 15 - excitable, 16 - hyperthymic, 17 - distimical, 18 - anxious $19-$ cyclothymic, 20 - exalted, 21 - emotive; H. Eysenck: 22 - extraversionintroversion, 23 - neuroticism, 24 - falsification scale.

the factor-correlation-cluster model in the R environment allowed hierarchization and verification of the database to identify the most significant traits of those under study.

\section{RESULTS}

To unify the raw data scales for each of the five trait intensities, levels have been determined: low (L) - $0 \%$ to $20 \%$ of the maximum possible score, below average (BA) - $21 \%$ to $40 \%$, average ( $\mathrm{Av}$ ) $-41 \%$ to $60 \%$, above average (AA) $-61 \%$ to $80 \%$, and high level $(\mathrm{H})-81 \%$ to $100 \%$. The radar chart below (Fig. 1) presents the parameters of the psychological profile of an average individual.

As can be seen in Figure 1, the prior identified traits that have the strongest impact on emotional resilience development have an above-average (balance of nervous processes, endurance (strength of excitation/inhibition) and hyperthymity) or a below-average (reflectivity) intensity level. In addition, the intensity level of the data on activity, dominance and sociability turned out to be above average. The three traits appear to be worth including in the list of characteristics that significantly affect individuals' emotional resilience.

The next step of the statistical analysis was to construct a factor-correlation-cluster model based on the mean data values for each psychological profile (Fig. 2). With a view to that, all the data have been grouped and hierarchically 


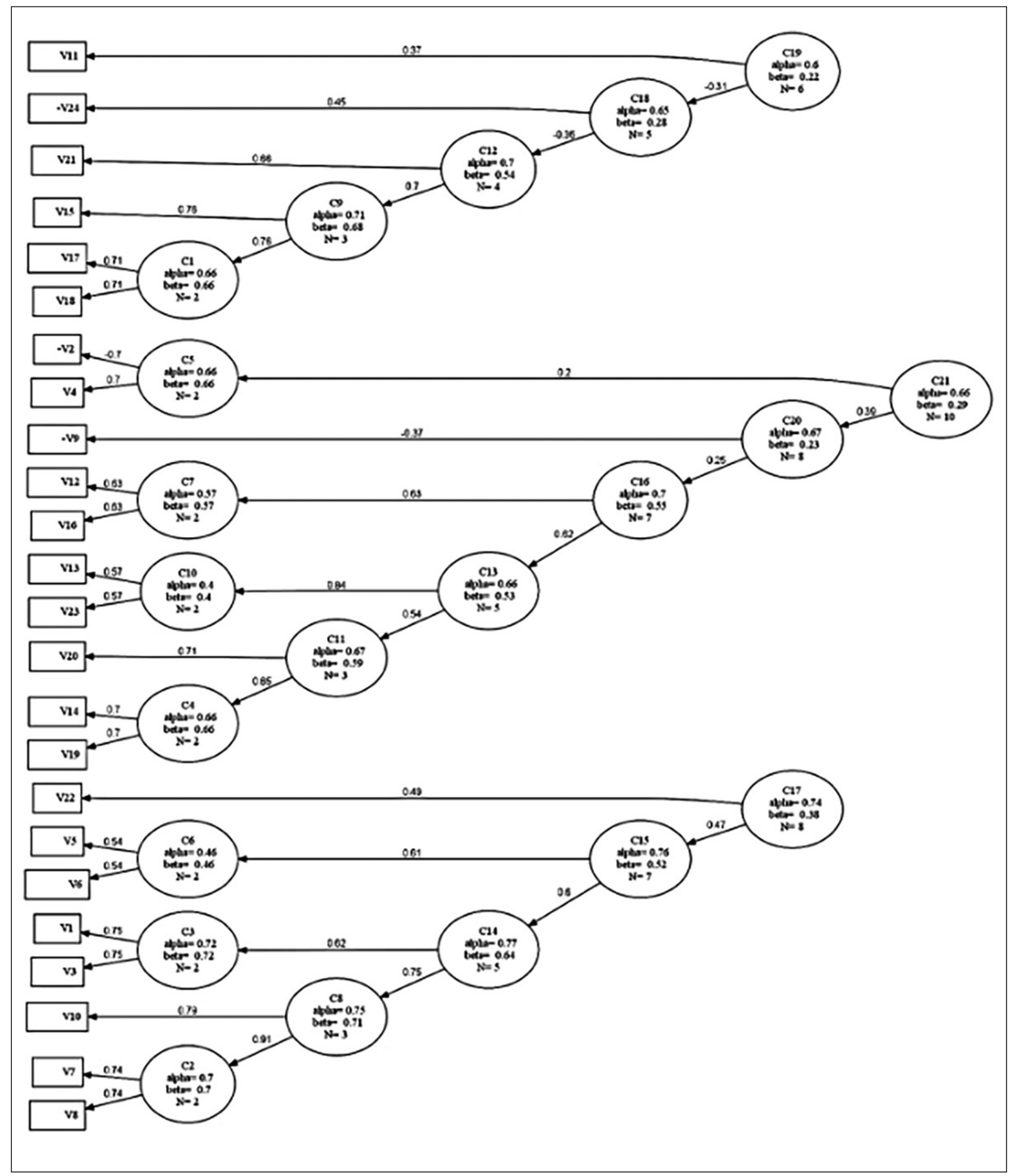

Fig. 2. Factor-correlation-cluster model based on the mean data values $(n=485)$.

Note that factor-correlation-cluster model has been built after Revelle, W. (1997) and Revelle, W. and Zinbarg, R. E. (2009).

Symbols: C1 - C21 - cluster numbers; $a$ - Cronbach\&apos;s alpha; $\beta$ - risk ratio; 0,74 above the arrows that lead, for instance, to V7, V8 - correlation coefficient $(r)$, r reliability level is not lower than $\mathrm{P}<0,05 ; \mathrm{N}$ - number of traits constituting a corresponding cluster; questionnaires: . Strelau: 1 - strength of excitation, 2 - strength of inhibition, 3-mobility of nervous processes, 4 - balance of nervous processes by strength of excitation; Thurstone: 5 - active, 6 - vigorous, 7 - impulsive, 8 - dominant, 9 - stable, 10 - sociable, 11 - reflective; Leonhard - Schmieschek: 12 - demonstrative, 13 - pedantic, 14 - stuck, 15 - excitable, 16 - hyperthymic, 17 - distimical, 18 - anxious 19 - cyclothymic, 20 - exalted, 21 - emotive; H. Eysenck: 22 - extraversion- introversion, 23 - neuroticism, 24 - falsification scale. 
ordered in three superclusters: I - orientation at outer/inner world (C17), II - behavioral determination stability (C21), and III - reflectivity (C19). The superclusters were used to identify six psychological profiles of individuals with different potential for emotional resilience development. They are: 1 ) outward-oriented (looking) type; 2) inward-oriented type; 3 ) stable-behavioral-determination type; 4) unstable-behavioral-determination type; 5) reflectivity-oriented type; 6) reflectivity-non-oriented type. A more detailed structure and the peculiarities of manifestation of the individual psychological characteristics within each supercluster are presented below.

The first supercluster (C17 - orientation to outer/inner world) includes eight traits and three clusters of different orders:

- seven traits of AA intensity level (V1 - strength of the excitation nervous processes, $\mathrm{V} 3$ - mobility of nervous processes, V5 - active, V6 - vigorous, V10 - sociable, V7 - impulsive, V8 - dominant) and one trait of Av intensity level (V22 - extraversion-introversion);

- three first-order clusters (C2, C3, C6);

- one second-order cluster (C8);

- one third-order cluster (C14);

- one fourth-order cluster (C15).

The second supercluster (C21 - behavioral determination stability) comprises ten traits and eight clusters of different orders:

- two traits of AA intensity level (V2 - strength of inhibition nervous processes, V16 - hyperthymic) and eight traits of Av intensity level (V4 - balance of nervous processes by strength of excitation, V9 - stable, V12 - demonstrative, V13 - pedantic, V23 - neurotic, V20 - exalted, V14 - stuck, V19 - cyclothymic);

- four first-order clusters (C5, C7, C10, C4);

- one second-order cluster (C11);

- one third-order cluster (C13);

- one fourth-order cluster (C16);

- one fifth-order cluster (C20).

The third supercluster (C19 - reflectivity) consists of six traits and four clusters:

- traits of Av intensity level (V11 - reflective, V15 - excitable, V17 - distimical, V21 - emotive, V24 - falsification scale, V18 - anxious);

- one first-order cluster (C1);

- one second-order cluster (C9);

- one third-order cluster (C12);

- one fourth-order cluster (C18).

\section{DISCUSSION}

The underlying point of the study is that the emotional resilience of an individual is significantly determined by the traits whose intensity level goes beyond average. Following the same logic and having analyzed the content components of each supercluster, we have identified the behavioral manifestations that either facilitate or hinder the development of emotional resilience of individuals with relevant profiles.

The emotional resilience of the individuals with the profile type related to the first supercluster (orientation to outer/inner world) is facilitated by:
- long-term endurance in situations of frequently repeated stimuli;

- ability to quickly switch from one type of activity to another, quickly adapt to a new situation, readiness and willingness to interact with new people and deal with new objects;

- readiness to perform physically strenuous activities;

- inclination to manage others, take responsibility, take the initiative, willingness to speak in public and organize civic actions.

The following behavioral manifestations hinder the development of emotionalresilience of the individuals with this profile:

- inclination for affective reactions in the situations that demand a vigorous action;

- strong reactions to external stimuli;

- inclination to work in haste even if it is not necessary for the given situation;

- lack of patience even when it is necessary to keep calm;

- inclination for obtrusiveness, loquacity, intemperance, impulsiveness, graphomania;

- carelessness and flippancy, the inclination for hasty and thoughtless decisions.

The development of emotional resilience of the people with the individual profile referring to the second supercluster (behavioral determination stability) is supported by:

- ability to cope with complex coordinated movements, actions, activities, delicate and tedious work;

- optimistic attitude to life, ability to overcome distress easily;

- mental activity facilitating progress making;

- open-mindedness, the intention to be an interesting interlocutor by suggesting new ideas.

The obstacles for emotional resilience development of the individuals with such profiles are:

- light-minded attitude to complex situations, which prevents comprehension of the reasons why such situations have emerged and inhibits emotional resilience development as a whole;

- intention to be in the spotlight;

- inclination to repress unpleasant memories, get into a chosen role, falsify information about oneself in the course of communication and believe that the given information is true;

- adventurous behavior;

- resort to ready-made restrictions (rules, traditions, rituals) as a means of protection in challenging situations.

The emotional resilience of the respondents with the profile types within the reflectivity supercluster is based on:

- inertia of behavior (inclination for listening rather than expressing one's opinion, which only happens from time to time after a long pause);

- seriousness manifested in ethical rigidity;

- concentration on the dark rather than light sides of life;

- inclination for slow thinking and careful and timid behavior;

- truthfulness in situation analysis and adequate evaluation of one's actions and the actions of other people.

The behavioral manifestations that hinder the development of emotional resilience of the people with such profiles are: 
- sensitivity, deep reactions to subtle emotional stimuli, softheartedness, excessive responsiveness, vulnerability;

- irritability (as a defensive mechanism);

- lack of reasoning about why one is in an emotionally charged situation, and difficulty acknowledging one's mistakes.

\section{CONCLUSIONS}

The typology of the psychological profiles of individuals with different emotional resilience resource built on empirical research data opens new prospects for developing client-oriented support for emotional resilience development.

The behavioral manifestations facilitating and hindering emotional resilience development identified for different profile types can be used as diagnostic markers to determine a person's profile. Analyzing the behavioral manifestations of a client belonging to a certain profile type allows identifying the problem zones, vectors and means of emotional resilience development.

The prospects for further research are related to developing, piloting, and implementing the socio-psychological strategies of the emotional resilience development support based on the suggested psychological profile typology.

\section{REFERENCES}

1. Abolin L.M. Psihologicheskie mehanizmyi emotsionalnoy ustoychivosti cheloveka [Psychological mechanisms of human emotional stability]. Kazansk ij universitet. 1987; 262p. (in Russian).

2. Bodrov V.A. Lichnostnaya determinatsiya razvitiya i preodoleniya psihologicheskogo stressa [Personal determination of development and overcoming psychological stress]. In Sovladayushcheye povedeniye. Sovremennoye sostoyaniye i perspektivy. Institut psihologii RAN. 2008, $256 \mathrm{p}$. (in Russian).

3. Malkhazov 0.R. Chynnyky neirotyzmu i tryvozhnosti osobystosti v sotsialno-psykholohichnomu suprovodi rozvytku emotsiinoi stiikosti [The Causes of Neuroticism and Anxiety of an Individual in Social Psychological Assistance of the Development of Emotional Resilience]. Psykholohichni nauky: problemy i zdobutky». K. KyMU. 2019; 2(14):274-297. (in Ukrainian).

4. Malkhazov 0.R. Samovladannia u sotsialno-psykholohichnomu suprovodi rozvytku emotsiinoi stiikosti osobystosti [Self-control in the socio-psychological support of the development of emotional stability of the individual]. Naukovyi visnyk KhDU Seriia Psykholohichni nauky. 2020;3: 155-162. doi:10.32999/ksu2312-3206/2020-3-19. in Ukrainian).

5. Shydelko A.V. Emotsiina stiikist osobystosti: naukovi rozvidky [Emotional resilience of the individual: scientific research ]. Nauka i osvita. 2017; (3):85-89. (in Ukrainian).

6. Kocherhina I. Types of emotional self-regulation of women who have suffered from psychological abuse in a family. Journal of Education, Culture and Society. 2018; (9)2: 81-92.

7. Lebrecht S., Bar M., Feldman Barrett L. et al. Micro-valences: Perceiving affective valence in everyday objects. Frontiers in Psychology. 2012;3:107.

8. Raja M., Azzoni A. The impact of obsessivecompulsive personality disorder on the suicidal risk of patients with mood disorders. Psychopathology. 2007; 40 (3):184-190.
9. Dementeva I.M. Lichnostnyie determinantyi psihologicheskoy ustoychivosti u sportsmenov vyisokoy kvalifikatsii, zanimayuschihsya regbi-7. [Personal determinants of psychological stability in highly qualified athletes involved in rugby-7]. Aktualnyie voprosyi fizicheskoy kulturyi i sporta. Kubanskiy gosudarstvennyiy universitet fizicheskoy kulturyi, sporta i turizma. Krasnodar. 2019; 21:85-92. (in Russian).

10. Craik K.H. Personality research methods: An historical perspective. Journal of personality. 2007; 54:18-51.

11. Wong P. T. P. The resource-congruence model of coping and the development of the Coping Schema Inventory. Handbook of Multicultural perspectives on stress and coping. New York, NY: Springer. 2006, 283p.

12. Kokun 0.M., Pishko I.0., Lozinska R.S. et al. Zbirnyk metodyk dlia diahnostyky psykholohichnoi hotovnosti viiskovosluzhbovtsiv viiskovoi sluzhby za kontraktom do diialnosti u skladi myrotvorchykh pidrozdiliv: Metodychnyi posibnyk. K.: NDTs HP ZSU. 2011, 281p. (in Ukrainian).

13. Revelle W. Hierarchical Cluster Analysis and the Internal Structure of Tests. Multivariate Behavioral Research. 1979;14:57-74.

14. Revelle W., Zinbarg R.E. Coefficients alpha, beta, omega and the glb: comments on Sijtsma. Psychometrika, RePEc: spr: psycho: 2009; 74:i:1:145-154. doi: 10.1007 / s11336-008-9102-z.

The work is a fragment of the research projects: Socio-psychological factors of student youth's citizenship competence developemnt, state registration No. 0119U000138; Socio-psychological support of the victims of war in the period of transition to peacful life, state registration No. 0119U000141.

\section{ORCID and contributionship:}

Oleksandr R. Malkhazov: 0000-0001-7312-5830 B-D

Iryna V. Zhadan: 0000-0001-5274-574X ${ }^{A, B, D}$

Svitlana I. Poznyak: 0000-0003-0646-4933

Giuseppe Vella: 0000-0002-3441-7598

\section{Conflict of interest:}

The Authors declare no conflict of interest.

\section{CORRESPONDING AUTHOR} Iryna V. Zhadan

Institute of Social and Political Psychology National Academy

of Educational Sciences of Ukraine

15 Andriivska St., 04070 Kyiv, Ukraine

tel: +380673251308

e-mail: Iryna_zhadan@ukr.net

Received: 20.06 .2021

Accepted: 15.10 .2021

A - Work concept and design, B - Data collection and analysis, C - Responsibility for statistical analysis,

D-Writing the article, $\mathbf{E}-$ Critical review, $\mathbf{F}$ - Final approval of the article 


\title{
TESTING IN MENTAL HEALTH RESEARCH: PROFESSIONAL HARDINESS QUESTIONNAIRE (ENGLISH-LANGUAGE VERSION)
}

DOI: 10.36740/WLek202111121

\author{
Oleg Kokun \\ G.S. KOSTIUK INSTITUTE OF PSYCHOLOGY OF NATIONAL ACADEMY OF EDUCATIONAL SCIENCES OF UKRAINE, KYIV, UKRAINE
}

\begin{abstract}
The aim: To develop and validate the English-language version of the Professional Hardiness Questionnaire (PHQ).

Materials and methods: A total of 425 skilled English-speaking respondents ( 188 men, 237 women; aged 19-75 years, $M=34.12 \pm 13.18$ years) from different countries of various professions participated in a remote online survey. The results were used to validate the English-language version of the PHQ. English-language versions of six other measures were also used to check the PHQ's competitive validity.

Results: The 24-item PHQ determines eight indicators of professional hardiness: general level of professional hardiness; professional commitment; professional control; professional challenge; and the emotional, motivational, social and namely professional aspects of professional hardiness. We calculated means and standard deviations for each indicator and determined normative data (in points) for general level of professional hardiness, sorted into five levels: low, below average, average, higher than average and high. The PHQ had sufficiently high internal consistency $(a=0.76-0.90)$ and competitive validity. General level of professional hardiness was significantly correlated $(r=$ $0.17-0.45 ; p<0.001$ ) with the scales of all of the additional six measures used.

Conclusions: The professional hardiness of specialists in different professions should be examined, both to strengthen specialists' hardiness and to prevent negative consequences of occupational stress on their mental health. It is also necessary to test the $\mathrm{PHQ}$ in various professional fields to clarify the quantitative indicators of professional hardiness for skilled people in various professions.
\end{abstract}

KEY WORDS: occupational stress, mental health, public health, social medicine, hardiness assessment

Wiad Lek. 2021;74(11 p.l):2799-2805

\section{INTRODUCTION}

The concept of «hardiness» came into scientific circulation after the publications of Kobasa S. and Maddi S. examining telephone company managers' «hardiness» were presented in the late 1970s and early 1980s [1-3]. Subsequent studies on hardiness were actively initiated and are now widespread in other professional fields, including education, health, sports and law enforcement. Special attention has been paid to the important role of hardiness in servicemembers' successful military training and work as well as its ability to prevent negative mental health consequences after severe stress. Such studies have been conducted under the supervision of Bartone P. T. [4, 5], Hystad S. W. and Thomassen A. G. [6, 7], among many other scientists.

The exceptional and multifaceted significance of hardiness for people's mental health in various activities and fields has been confirmed by many studies. Duquette A. et al. [8] examined hardiness as a prerequisite for preventing professional burnout in various occupations. Analogous studies have been conducted with nurses $[9,10]$, schoolteachers [11], university lecturers [12] and journalists [13]. Hardiness has also been confirmed to have an impact on psychological well-being and various aspects of adaptability among students [14-17] and Paralympic athletes [18]. In addition, research has shown that people with higher levels of hardiness are less prone to high blood pressure [19], heart disease [20], anxiety [21] and depressive disorders [22].

Many examination tools have been developed to study hardiness over the last four decades. The most well known are the Personal Views Survey (Kobasa S., Maddi S. et al.), the initial version of which contained 101 items; the Hardiness Survey (Maddi S. et al.), whose first version contained 65 items; and the Dispositional Resilience Scale (Bartone P. T. et al.), whose first version contained 45 items. These measures have numerous modifications and have been adapted into various languages.

In the past decade alone, many publications have appeared proposing new methods for studying hardiness, including the Psychological Hardiness Questionnaire with 27 items [21], the Connor-Davidson Resilience Scale with 25 items [23], the Resistant Personality Questionnaire with 21 items [24], the Academic Hardiness Scale with 18 items [25] and the Brief Resilience Scale with 21 items [26], among others. This evidences the gradual tendency to use a decreased number of items (15-25 items) in the examination of hardiness.

Although the phenomenon of hardiness was initially identified based on research in the professional field (managers at Illinois Bell Telephone), the variety of chosen 
samples in later studies led to the use of the 'professional' content of hardiness in a more general sense, and existing methods examining hardiness did not focus clearly on professional aspects. However, in our opinion, such generalised representations of hardiness are not entirely correct, as its levels in different areas can vary significantly for the same person. For example, a person can have high hardiness in a professional sphere and relatively lower hardiness in everyday life or alternatively may cope well with adverse learning factors while remaining completely helpless in interpersonal relationships (and so on). Hardiness can include different elements in various conditions; for example, the hardiness of an imprisoned person is determined by different qualities and manifestations than that of someone working at a large corporation. In particular, Skomorovsky A. and Sudom K. A. [27] substantiated the concept of 'military-specific hardiness', which was a more accurate predictor of military personnel's psychological well-being and effectiveness than general hardiness, and proposed developing specific examination tools for this population.

\section{THE AIM}

The aim of our study was to develop and validate the English-language version of the Professional Hardiness Questionnaire (PHQ).

\section{MATERIAL AND METHODS}

\section{MEASURES}

The development of the English-language version of the PHQ (provided in the Annex 1) was based on its initial Ukrainian-language version (http://prof-diagnost.org). The accuracy of its translation into English was checked and corrected by 12 bilingual specialists with degrees in medicine and/or psychology.

The PHQ is a 24-item self-report measure. All questions are directly related to a specialist's occupational activities. In addition to the 'traditional' components of hardiness (commitment, control, and challenge), we also highlighted four more specific aspects for each: emotional, motivational, social and namely professional.

Respondents were asked to rate each item on a 5-point Likert scale ranging from $A$ to $E$. For each answer, option A was worth 0 points, option $B 1$ point, option $C 2$ points, option D 3 points and option $\mathrm{E} 4$ points. We improved the traditional version of the Likert scale to take into account the specifics of possible answers to various questions.

Thus, the PHQ provides an opportunity to examine not only the traditional commitment, control and challenge components but also the emotional, motivational, social and content-professional aspects of professional hardiness within a clear professional context. The method for calculating these figures is given in Table I.

As the table indicates, each of the three components of professional hardiness (commitment, control and chal- lenge) in the PHQ is evaluated with eight questions: two questions each for the emotional, motivational, social and namely professional aspects. Due to this progressive approach, the 24-item PHQ identifies eight indicators of professional hardiness.

To check the PHQ's competitive validity, we used English-language versions of six methods: the Personal Orientation Inventory (Shostrom E., adapted by Alioshyn Yu. et al.), the General Self-Efficacy Scale (Schwarzer R. and Jerusalem M.), the Motivation for Professional Activities inventory (Zamfir C.'s technique with Rean A.s modification), the questionnaire identifying satisfaction with a profession and a job (Zhurin N. and Ilyin E.), the Maslach Burnout Inventory (Maslach C. and Jackson S. E., adapted by Poliakova O.) and the Professional Self-Fulfilment Questionnaire (Kokun O.).

\section{DATA COLLECTION}

We conducted a remote online survey using the trilingual website http://prof-diagnost.org.

\section{PARTICIPANTS}

In total, 1,024 skilled English-speaking respondents from different countries, representing various ages and professions, participated in the remote online survey. Only 425 respondents (188 men, 237 women; aged 19-75 years, $M=34.12 \pm 13.18$ years) filled out all proposed questionnaires and were thus ultimately selected for data processing.

\section{ETHICS}

The author asserts that all procedures contributing to this work comply with the ethical standards of the relevant national and institutional committees on human experimentation and with the Helsinki Declaration of 1975, as revised in 2008. All participants were informed that their participation in the study was voluntary and that they could refuse to participate or withdraw from the study at any time. Participants were informed that there were no right or wrong answers and were encouraged to respond candidly. Complete confidentiality was assured. Only de-identified data were used in the statistical analysis. We recorded only general data about respondents, such as gender, age and profession. Participants were motivated to participate in the study by the automatic presentation of their results, which was accompanied by a psychological and professional interpretation.

\section{STATISTICAL ANALYSIS}

The software package SPSS version 22.0.0 was used to conduct the statistical analysis. Descriptive statistics (means and standard deviations), independent sample $t$-tests, Pearson's correlation coefficient and Cronbach's alpha were used to analyse the data. The data were normally distributed according to the one-sample Kolmogorov-Smirnov test. 
Table I. Calculation of PHQ quantitative indicators

\begin{tabular}{|c|c|c|c|}
\hline Indicator & $\Sigma$ points for associated questions & $\begin{array}{c}\text { Number of } \\
\text { items }\end{array}$ & $\begin{array}{c}\text { Score range } \\
\text { (min-max) }\end{array}$ \\
\hline General level of professional hardiness & $1-24$ & 24 & $0-96$ \\
\hline Professional commitment & $1,4,7,10,13,16,19,22$ & 8 & $0-32$ \\
\hline Professional control & $2,5,8,11,14,17,20,23$ & 8 & $0-32$ \\
\hline Professional challenge & $3,6,9,12,15,18,21,24$ & 8 & $0-32$ \\
\hline Emotional component & $1,2,3,13,14,15$ & 6 & $0-24$ \\
\hline Motivational component & $4,5,6,16,17,18$ & 6 & $0-24$ \\
\hline Social component & $7,8,9,19,20,21$ & 6 & $0-24$ \\
\hline Namely professional component & $10,11,12,22,23,24$ & 6 & $0-24$ \\
\hline
\end{tabular}

Table II. Means and standard deviations for the English-language version of the PHQ $(\mathrm{N}=425)$

\begin{tabular}{ccc}
\hline Indicator & M & SD \\
\hline General level of professional hardiness & 62.33 & 9.52 \\
\hline Professional commitment & 19.88 & 4.12 \\
\hline Professional control & 21.35 & 3.40 \\
\hline Professional challenge & 21.10 & 3.98 \\
\hline Emotional component & 15.15 & 3.05 \\
\hline Motivational component & 16.78 & 2.99 \\
\hline Social component & 15.12 & 2.75 \\
\hline Namely professional component & 15.28 & 3.15 \\
\hline
\end{tabular}

Table III. Normative data for general level of professional hardiness (in points)

\begin{tabular}{ccc}
\hline $\begin{array}{c}\text { General level of } \\
\text { professional hardiness }\end{array}$ & Points & $\begin{array}{c}\text { Cumulative } \\
\text { percentage } \\
(\mathbf{N = 4 2 5 )}\end{array}$ \\
\hline Low & $0-54$ & $0-20 \%$ \\
Below average & $55-60$ & $21-40 \%$ \\
Average & $61-64$ & $41-60 \%$ \\
Higher than average & $65-70$ & $61-80 \%$ \\
High & $71-96$ & $81-100 \%$ \\
\hline
\end{tabular}

\section{RESULTS}

We developed and validated the English-language version of the PHQ using the general scheme of test development [28]. Tables II and III show the results of test standardisation for the English-language version of the PHQ. The independent sample $t$-tests for the questionnaire scores did not reveal significant differences between men and women; therefore, means, standard deviations and normative data are presented without gender differentiation. Some significant differences between men and women $(p<0.05)$ were obtained only for the professional challenge scale and the scale representing the emotional component of professional hardiness but were not significantly expressed in absolute terms.

Cronbach's $a$ for the scales of professional commitment, control and challenge was $0.76 ; 0.80$ for the emotional, motivational, social and namely professional aspects of pro- fessional hardiness scales; and 0.90 for all scales together. Thus, the results indicated that the internal consistency of the PHQ was sufficiently high.

For normalisation, to determine the quantitative limits of the five professional hardiness levels, we used a step of $20 \%$ of the obtained distribution for the general level of professional hardiness indicator for the total sample (Table III).

The PHQ thus has sufficiently high competitive validity. For the same sample that was used for PHQ standardisation $(N=425)$, significant correlations were obtained between the general level of professional hardiness and the following scales:

- the Personal Orientation Inventory $(r=0.17-0.45$; $p<0.001$ );

- the General Self-Efficacy Scale $(r=0.31 ; p<0.001)$;

- motivation for professional activities ('internal motivation'; $r=0.26 ; p<0.001$ );

- the questionnaire identifying satisfaction with a profession and a job $(r=0.36 ; p<0.001)$;

- the Maslach Burnout Inventory $(r=-0.18--0.30$; $p<0.001$ ); and

- the Professional Self-Fulfilment Questionnaire $(r=$ 0.22-0.34; $p<0.001)$.

\section{DISCUSSION}

The important task of strengthening modern specialists' professional hardiness and maintaining their mental health $[13,29]$ undoubtedly necessitates the development of specific and informative professional tools examining professional hardiness. The PHQ was developed on the basis of three well-known interrelated components of hardiness: commitment, control and challenge [1, 19]. For each of these, we highlighted four additional aspects: emotional, motivational, social and namely professional. Through this progressive approach, the 24-item PHQ identifies eight indicators of professional hardiness. The number of questions in the PHQ fully corresponds to the modern trend of significant reductions in the amount of questions, from 50-100 in the first measures examining hardiness to 15-25 in more recent measures [23-26].

The English-language version of the PHQ was standardised according to the generally accepted procedure, and normative data were defined. The testing results 
showed that the quantitative impact of professional commitment as a component of professional hardiness is somewhat less than that of professional control and challenge. As for the four aspects of professional hardiness, the motivational aspect was the most pronounced and the social aspect the least.

PHQ testing also showed sufficiently high levels [28] of internal consistency $(\alpha=0.76-0.90)$ and competitive validity. General level of professional hardiness was correlated significantly $(r=0.17-0.45 ; p<0.001)$ with the scales of all six additional measures used.

\section{CONCLUSIONS}

We should again emphasise the importance of professional hardiness examinations for skilled people in different professions, both to purposefully strengthen their hardiness and to prevent negative consequences of occupational stress on their mental health.

The presented normative data (see Table 3) are rather conditional and can be used only for preliminary orientation, as they may differ quite significantly for those in different professions. Accordingly, the obvious direction of further research is PHQ testing for various professional fields with the aim of clarifying the quantitative indicators for a more accurate examination of professional hardiness for skilled people in different professions.

\section{REFERENCES}

1. Kobasa S. Stressful life events, personality and health: An inquiry into hardiness. Journal of Personality and Social Psychology. 1979;37(1):111. doi: 10.1037/0022-3514.37.1.1.

2. Kobasa S., Hilker R.R.J., Maddi S. Who stays healthy under stress? Journal of Occupational Medicine. 1979;21(9):595-598.

3. Kobasa S., Maddi S., Kahn S. Hardiness and health: A prospective study. Journal of Personality and Social Psychology. 1982;42(1):168-177. doi: 110.1037/0022-3514.42.1.168.

4. Bartone P.T., Kelly D.R., Matthews M.D. Psychological hardiness predicts adaptability in military leaders: A prospective study. International Journal of Selection and Assessment. 2013;21(2):200-210. doi: 10.1111/ijsa.12029.

5. Bartone P.T., Homish G.H. Influence of hardiness, avoidance coping, and combat exposure on depression in returning war veterans: A moderatedmediation study. Journal of Affective Disorders. 2020;265:511-518. doi: 10.1016/j.jad.2020.01.127.

6. Hystad S.W., Olsen 0.K., Espevik R. et al. On the stability of psychological hardiness: a three-year longitudinal study. Military Psychology. 2015;27(3):155-168. doi: 10.1037/mil0000069.

7. Thomassen Å.G., Hystad S.W., Johnsen B.H. et al. The effect of hardiness on PTSD symptoms: A prospective mediational approach. Military Psychology. 2018;30(2):142-151. doi: 10.1080/08995605.2018.1425065.

8. Duquette A., Kérouac S., Sandhu B.K. et al. Psychosocial determinants of burnout in geriatric nursing. International Journal of Nursing Studies. 1995;32(5):443-456. doi: 10.1016/0020-7489(95)00006-J.

9. McCranie E.W., Lambert V.A., Lambert C.E. Work stress, hardiness, and burnout among hospital staff nurses. Nursing Research. 1987;36(6):374-378.
10. Simoni P.S., Paterson J.J. Hardiness, coping, and burnout in the nursing workplace. Journal of Professional Nursing. 1997;13(3):178-185. doi: 10.1016/S8755-7223(97)80069-5.

11. Chan D.W. Hardiness and its role in the stress-burnout relationship among prospective Chinese teachers in Hong Kong. Teaching and Teacher Education. 2003;19(4):381-395. doi: 10.1016/S0742051X(03)00023-4.

12. Azeem S.M. Personality hardiness, job involvement and job burnout among teachers. International Journal of Vocational and Technical Education. 2010;2:36-40.

13. Cerezo A.G., Galian A.D., Tarroja M.C. et al. Breaking news: How hardiness moderates the impact of burnout on the psychological well-being of Filipino journalists covering disasters and emergencies. Philippine Journal of Psychology. 2015;48(2):175-194.

14. Chincholikar S.V., Kulkarni S. An insight into hardiness status of medical undergraduates. Indian Journal of Community Health. 2017;29(2):191-193.

15. Kokun 0., Korobeynikov G., Mytskan B. et al. Applied aspects of improving pupils' and students' adaptive capacity. Ido Movement for Culture. Journal of Martial Arts Anthropology. 2019;19(3):38-45. doi: 10.14589/id0.19.3.5.

16. Ndlovu V., Ferreira N. Students' psychological hardiness in relation to career adaptability. Journal of Psychology in Africa. 2019;29(6):598604. doi: 10.1080/14330237.2019.1689468

17. Vus V., Omelchenko L. 2019. Interdependent: mental health, social development, youth' socially oriented activity (on the example of a country in transition). Mental Health: Global Challenges Journal. 2018;1(1):86. doi: https://doi.org/10.32437/mhgcj.v1i1.37.

18. Kokun 0., Serdiuk L., Shamych O. Personal characteristics supporting Paralympic athletes' self-realization in sports. Journal of Human Sport and Exercise. 2021;16(2):435-444. doi: 10.14198/jhse.2021.162.17.

19. Maddi S.R. The personality construct of hardiness: I. Effects on experiencing, coping, and strain. Consulting Psychology Journal: Practice and Research. 1999;51(2):83-94. doi: 10.1037/1061-4087.51.2.83.

20. Contrada R. Type A behavior, personality hardiness, and cardiovascular response to stress. Journal of Personality and Social Psychology. 1989;57(5):895-903. doi: 10.1037/0022-3514.57.5.895.

21. Azarian A., Farokhzadian A., Habibi E. Relationship between psychological hardiness and emotional control index: A communicative approach. International Journal of Medical Research \& Health Sciences. 2016;5(5S):216-221.

22. Ghasemi Z., Kajbaf M. The relationship of mindfulness, psychological hardiness and spirituality with depression in mothers. Social Behavior Research \& Health. 2019;3(1):287-297. doi: 10.18502/sbrh.v3i1.1033.

23. Bahadorikhosroshahi J., Habibi-Kaleybar R. The comparison of psychological hardiness and resilience against educational stressors among veterans and non-veterans students. Pajoohande. 2017;22(1):e11.

24. Calvo J.A., García G.M. Hardiness as moderator of the relationship between structural and psychological empowerment on burnout in middle managers. Journal of Occupational and Organizational Psychology. 2018;91(2):362-384. doi: 10.1111/joop.12194.

25. Creed P.A., Conlon E.G., Dhaliwal K. Revisiting the Academic Hardiness Scale: Revision and revalidation. Journal of Career Assessment. 2013;21(4):537-554. doi: 1069072712475285.

26. Mazerolle S.M., Eason C.M., Goodman A. An examination of relationships among resiliency, hardiness, affectivity, and work-life balance in collegiate athletic trainers. Journal of Athletic Training. 2018;53(8):788795. doi: 10.4085/1062-6050-311-17. 
27. Skomorovsky A., Sudom K.A. Psychological well-being of Canadian Forces officer candidates: The unique roles of hardiness and personality. Military Medicine. 2011;176(4): 389-396. doi: 10.7205/ MILMED-D-10-00359.

28. Lane S., Raymond M.R., Haladyna T.M. Handbook of test development (2nd ed.). London: Routledge. 2015. doi: 10.4324/9780203102961.

29. Flaherty M.P., Sikorski E., Klos L. et al. Peacework and mental health: From individual pathology to community responsibility. Intervention. 2020;18(1):28-36. doi: 10.4103/INTV.INTV_59_18.

\section{ORCID and contributionship:}

Oleg Kokun: 0000-0003-1793-8540 A-F

\section{Conflict of interest:}

The Author declare no conflict of interest.

\section{CORRESPONDING AUTHOR}

\section{Oleg Kokun}

G.S. Kostiuk Institute of Psychology

2 Pankivska st., 01033 Kyiv, Ukraine

tel: +380677993520

e-mail:kokun@ukr.net

Received: 03.06.2021

Accepted: 13.10 .2021

A - Work concept and design, B - Data collection and analysis, C - Responsibility for statistical analysis,

D-Writing the article, $\mathbf{E}$-Critical review, $\mathbf{F}$ - Final approval of the article 


\section{ANNEX 1.}

The Professional Hardiness Questionnaire (blank form)

Age__Sex__ Profession

Instructions: Please answer the questions below by circle appropriate answers (only one, the most appropriate answer for each question).

\begin{tabular}{|c|c|c|c|c|c|c|}
\hline \multirow{2}{*}{ № } & \multirow{2}{*}{ Question } & \multicolumn{5}{|c|}{ Answer Options } \\
\hline & & A & B & C & D & $\mathbf{E}$ \\
\hline 1 & $\begin{array}{l}\text { How often do you enjoy the } \\
\text { process of your work? }\end{array}$ & Never & Rarely & $\begin{array}{l}\text { From time to } \\
\text { time }\end{array}$ & Often & Always \\
\hline 2 & $\begin{array}{l}\text { Do you like to be constantly } \\
\text { aware of your work? }\end{array}$ & No & Rather not & $\begin{array}{l}\text { From time to } \\
\text { time }\end{array}$ & Rather so & Yes \\
\hline 3 & $\begin{array}{l}\text { Do you feel exalted when you } \\
\text { solve non-standard work tasks? }\end{array}$ & Never & Rarely & $\begin{array}{l}\text { From time to } \\
\text { time }\end{array}$ & Often & Always \\
\hline 4 & $\begin{array}{l}\text { To what extent do you have a } \\
\text { strong desire to be constantly } \\
\text { aware of all your work? }\end{array}$ & Not at all & $\begin{array}{l}\text { To a small } \\
\text { extent }\end{array}$ & Partly & Substantially & Fully \\
\hline 5 & $\begin{array}{l}\text { Do you think clear work planning } \\
\text { is needed? }\end{array}$ & No & Rather not & $\begin{array}{l}\text { From time to } \\
\text { time }\end{array}$ & Nearly always & Always needed \\
\hline 6 & $\begin{array}{l}\text { To what extent does an unusual } \\
\text { work situation increase your } \\
\text { professional responsibility? }\end{array}$ & Not at all & $\begin{array}{l}\text { To a small } \\
\text { extent }\end{array}$ & Partly & Substantially & Fully \\
\hline 7 & $\begin{array}{l}\text { How much do you enjoy } \\
\text { interacting with colleagues when } \\
\text { solving tasks? }\end{array}$ & Not at all & $\begin{array}{l}\text { To a small } \\
\text { extent }\end{array}$ & Partly & Substantially & Fully \\
\hline 8 & $\begin{array}{l}\text { Do you think that constant } \\
\text { mutual control over colleagues' } \\
\text { activities (within reasonable } \\
\text { limits) is good for work? }\end{array}$ & No & Rather not & Perhaps & Rather so & Yes \\
\hline 9 & $\begin{array}{l}\text { In your opinion, what should } \\
\text { a team's natural reaction be to } \\
\text { abnormal situations? }\end{array}$ & Confusion & $\begin{array}{l}\text { Complete } \\
\text { peace }\end{array}$ & $\begin{array}{l}\text { Depends on } \\
\text { the circum- } \\
\text { stan-ces }\end{array}$ & Mobilisation & $\begin{array}{c}\text { Full } \\
\text { mobilisation }\end{array}$ \\
\hline 10 & $\begin{array}{l}\text { How often do you return to } \\
\text { professional work outside of your } \\
\text { work place? }\end{array}$ & Never & Rarely & $\begin{array}{l}\text { From time to } \\
\text { time }\end{array}$ & Often & Always \\
\hline 11 & $\begin{array}{l}\text { How often do you check the } \\
\text { compliance of the set tasks with } \\
\text { their fulfilment? }\end{array}$ & Never & Rarely & $\begin{array}{l}\text { From time to } \\
\text { time }\end{array}$ & Often & Always \\
\hline 12 & $\begin{array}{c}\text { Do you agree that effective } \\
\text { professional growth is impossible } \\
\text { without the constant solution of } \\
\text { non-standard and responsible } \\
\text { tasks? }\end{array}$ & Disagree & $\begin{array}{l}\text { Somewhat } \\
\text { disagree }\end{array}$ & $\begin{array}{l}\text { Somewhat } \\
\text { agree }\end{array}$ & Mostly agree & Fully agree \\
\hline 13 & $\begin{array}{c}\text { How often do you come across } \\
\text { something interesting or } \\
\text { noteworthy in the course of your } \\
\text { work? }\end{array}$ & Never & Rarely & $\begin{array}{l}\text { From time to } \\
\text { time }\end{array}$ & Often & Always \\
\hline 14 & $\begin{array}{l}\text { How often do you feel anxiety } \\
\text { when, for some reason, you are } \\
\text { not able to predict the specifics } \\
\text { of your work in advance? }\end{array}$ & Never & Rarely & $\begin{array}{l}\text { From time to } \\
\text { time }\end{array}$ & Often & Always \\
\hline
\end{tabular}




\begin{tabular}{|c|c|c|c|c|c|c|}
\hline 15 & $\begin{array}{c}\text { Are you in a bad mood when you } \\
\text { have to deal with an unforeseen } \\
\text { situation at work? }\end{array}$ & $\begin{array}{l}\text { Very strong } \\
\text { bad mood }\end{array}$ & Bad mood & $\begin{array}{l}\text { To some } \\
\text { extent }\end{array}$ & Not really & Not at all \\
\hline 16 & $\begin{array}{l}\text { How often do the circumstances } \\
\text { of your work make you } \\
\text { constantly focus on your work? }\end{array}$ & Very rarely & Rarely & $\begin{array}{l}\text { From time to } \\
\text { time }\end{array}$ & Often & Always \\
\hline 17 & $\begin{array}{l}\text { Do you think you need constant } \\
\text { monitoring of (your own, } \\
\text { colleagues', organisational) work } \\
\text { progress? }\end{array}$ & No & Rather not & Perhaps & Rather so & Yes \\
\hline 18 & $\begin{array}{c}\text { Do you notice a decreased desire } \\
\text { to work in the case of increased } \\
\text { responsibility for end work } \\
\text { results? }\end{array}$ & Always & Often & $\begin{array}{l}\text { From time to } \\
\text { time }\end{array}$ & Rarely & Never \\
\hline 19 & $\begin{array}{c}\text { Are you aware of your colleagues' } \\
\text { work and non-work activities? }\end{array}$ & No & Rather not & $\begin{array}{l}\text { From time to } \\
\text { time }\end{array}$ & Rather so & Yes \\
\hline 20 & $\begin{array}{c}\text { How easy is it for you to work } \\
\text { with colleagues who are not } \\
\text { completely open about the } \\
\text { course and results of their work } \\
\text { or joint work? }\end{array}$ & Always easy & Rather easy & $\begin{array}{l}\text { To some } \\
\text { extent easy }\end{array}$ & Difficult & Very difficult \\
\hline 21 & $\begin{array}{l}\text { How does your interaction with } \\
\text { colleagues change when you } \\
\text { have to solve unusual problems? }\end{array}$ & Deteriorates & $\begin{array}{l}\text { Sometimes } \\
\text { deteriorates }\end{array}$ & $\begin{array}{l}\text { Does not } \\
\text { change }\end{array}$ & $\begin{array}{l}\text { Sometimes } \\
\text { improves }\end{array}$ & Improves \\
\hline 22 & $\begin{array}{l}\text { How easily are you distracted } \\
\text { while working with unusual } \\
\text { tasks? }\end{array}$ & Very easily & Easily & Sometimes & Not easily & $\begin{array}{c}\text { Not dis-tracted } \\
\text { at all }\end{array}$ \\
\hline 23 & $\begin{array}{l}\text { In your opinion, will the end } \\
\text { result be improved if you double- } \\
\text { check your work? }\end{array}$ & No & Rather not & Perhaps & Rather so & Yes \\
\hline 24 & $\begin{array}{l}\text { Do you agree that every } \\
\text { employee should be able to work } \\
\text { in conditions of uncertainty? }\end{array}$ & No & Rather not & Perhaps & Rather so & Yes \\
\hline
\end{tabular}




\title{
THE ABILITY OF YOUNG PEOPLE TO SELF-REGULATE EMOTIONS AS MENTAL HEALTH SIGN
}

DOI: 10.36740/WLek2021111 22

\author{
Mariia S. Kanibolotska ${ }^{1}$, Marharita A. Dergach ${ }^{2}$, Neonila V. Partyko ${ }^{3}$, Anastasiia Cherkasova ${ }^{4}$, Oleg Blinov $^{5}$, \\ Olga Litvinova6 ${ }^{6}$ Daniela Dumitru \\ IINSTITUTE OF SOCIAL AND POLITICAL PSYCHOLOGY NATIONAL ACADEMY OF EDUCATIONAL SCIENCES OF UKRAINE, KYIV, UKRAINE \\ 2KHORTYRSIA NATIONAL EDUCATIONAL REHABILITATION ACADEMY, ZAPORIZHZHIA, UKRAINE \\ 'LVIV POLYTECHNIC NATIONAL UNIVERSITY, LVIV, UKRAINE \\ ${ }^{4}$ BORYS GRINCHENKO KYIV UNIVERSITY, KYIV, UKRAINE \\ ${ }^{5}$ NATIONAL AVIATION UNIVERSITY, KYIV, UKRAINE \\ ${ }^{6}$ KREMENCHUK MYKHAILO OSTROHRADSKYI NATIONAL UNIVERSITY, KREMENCHUK, UKRAINE \\ ${ }^{7}$ BUCHAREST UNIVERSITY OF ECONOMIC STUDIES, BUCHAREST, ROMANIA
}

\begin{abstract}
The aim: To determine the differences in the ability of young people with low and high economic statuses towards emotional self-regulation, and characterize their frame of mind by analyzing functional and dysfunctional emotions in healthy and unhealthy states.

Materials and methods: Theoretical - analysis, generalization, interpretation of the collected data; a set of empirical methods — "Attitude to health" by Berezovskaya, the scale "Quality of life" in the adaptation by Vodopyanova, self-assessment income scale and validated questionnaire "Subjective economic well-being" by Khashchenko. The author has applied Pearson's chi-squared test, Student's t-test, and Kruskal-Wallis test.

Results: The affective component of health manifests in the predominance of happiness $(t=0.3, p \leq 0.01)$ and peace $(t=1.7, p \leq 0.1)$ as components of a positive frame of mind among young people with high economic status. Such emotions such as fear $(t=2.1, p \leq 0.03)$, anxiety $(t=2, p \leq 0.04)$ and irritability $(t=1.8$, at $p \leq 0.07)$ are more common among young people with low economic status. Young people who have high economic status show stronger ability to emotional self-regulation in comparison to the ones with low economic status $\left(x^{2}=11.9, p \leq 0.001\right)$.

Conclusions: In this research, we have found a statistically significant difference in the ability towards emotional self-regulation between young people with low and high economic status: the latter group is able to control dysfunctional emotions such as anger and resentment more when communicating with others; they are more likely to find internal psychological resources. When the health deteriorates, the young people with high economic status are prone to show independence, and manage their own time and life, which is a sign of stable mental health.
\end{abstract}

KEY WORDS: caring attitude to health, emotional stability, mood/frame of mind, healthy state, unhealthy state

Wiad Lek. 2021;74(11 p.l):2806-2811

\section{INTRODUCTION}

Today the vectors of social development are filled with humanistic sense - the value of human life and mental health is a top priority worldwide. There is a bulk of useful health advice aimed at physical, mental and psychological well-being. Health-caring attitude is recognized to be the most important issue in all governmental programs for children and youth. At the same time, there is still a permanent threat to human life - COVID-19. This exacerbates the problem of socio-economic differentiation, and causes the effect of fluctuations in the labour market. These factors altogether cause a number of mental problems such as distress, sleep disorder, exhaustion, apathy, etc. People of all ages are at risk, but it is the able-bodied young people who are just starting their professional and personal lives that are most sensitive to the above mentioned external issues.
Young people present such a category of the population that actively responds to all social, political and cultural transformations, and at the same time are drivers of these changes, who facilitate acceptance of innovations within their groups.

There are some differences in the mental health of young people, depending on their level of economic welfare. On one hand, young people with high economic well-being are more health-wise, and are generally satisfied with their lives. However, they tend to use the natural potential of health to build a rapid career and achieve a higher financial level that can lead to emotional breakdowns and burnouts, which negatively affect their relationships with referent others $[1,2]$.

On the other hand, young people with low economic status do not think much about maintaining their physi- 
cal and mental health. They are socially passive, prone to addictive behaviour and unfavourable environments, and follow dangerous health patterns. Thus, these two extreme socio-economic categories of youth may not always be able to maintain their own mental health and monitor the emotions they are experiencing.

Emotions are multifaceted subjective feelings that reflect expected, current, or past interactions with the environment. They involve sets of interrelated psychological processes, encompassing affective, cognitive, motivational, physiological, and behavioural components. It's well known that emotions play a fundamental role in human adaptation by improving detection of relevant stimuli, readiness for behavioural responses, decision-making, and interpersonal interactions $[3,4]$. Young people with different economic well-being possess certain differences in their ability to regulate functional (positive) and dysfunctional (negative) emotional states. However, there has been little discussion on the ability towards emotional self-regulation of young people with different levels of subjective and objective well-being.

\section{THE AIM}

In this paper, we determine the differences in the ability of young people with low and high economic statuses towards emotional self-regulation, and characterize the youth's frame of mind, by analyzing functional and dysfunctional emotions in healthy and unhealthy states.

\section{MATERIALS AND METHODS}

This work was carried out as part of the research project "Socio-psychological factors in overcoming poverty as a lifestyle" (state registration number 0111U001263), conducted by the laboratory of psychology of masses and communities, Institute of Social and Political Psychology, National Academy of Pedagogical Sciences of Ukraine.

\section{METHODS}

Presentation of the differences in the ability of young people towards emotional self-regulation is divided into four sections, as shown below.

1. Demographic information: Socio-demographic status (student or unemployed), age, and gender.

2. Respondent's mood in healthy or unhealthy state was measured by the validated questionnaire "Attitude to health" [5].

3. Emotional self-regulation: In order to measure the level of emotional balance of the respondents, we used the scale "Quality of life" in the adaptation by Vodopyanova [6]. The adapted scale contains 36 questions, which are distributed in the areas - study/job satisfaction, personal achievements, health, communication with close people (friends, relatives), support (internal and external - social), optimism, tension (physical and psychological), discomfort, self-control, and negative emotions (mood).
4. The distribution of respondents into the groups was as follows: on one hand, the group with low economic status included those young people whose level of subjective indicator was low or medium [7], while the objective indicator was also low or medium. On the other hand, the group with high economic status included those having high or average subjective and objective indicators.

\section{INSTRUMENT}

We used a combination of open and closed questions to specify negative and positive emotions during the deterioration of physical and mental health in order to analyse the satisfaction level with various aspects of life and the ability to manage emotions; as well as to distribute respondents into the groups with different economic statuses.

\section{STATISTICS}

The following statistics has been applied - Pearson's chisquared test, Student's t-test, and Kruskal-Wallis test. Data processing and statistical significance were analysed using IBM SPSS Statistics 20 software package.

\section{SAMPLE}

The sample $(\mathrm{n}=315)$ consisted of $45.1 \%$ males, and $54.9 \%$ females, among which $55.6 \%$ were students who studied in higher educational institutions of Ukraine, and $44.4 \%$ were unemployed young people who were registered in employment service. Two groups of the respondents - with low $(n=108)$ and high economic statuses $(n=119)$ were taken under for further analysis.

\section{RESULTS}

First of all, we divided our respondents into three groups with different levels of the subjective indicator of economic status: low $-29.2 \%$, medium $-39.7 \%$, and high $-31.1 \%$. According to the objective indicator of economic status, the sample was also divided into three groups: low $-27 \%$, medium $-45.4 \%$, and high $-27.6 \%$. Respondents who had averages on both the objective and subjective indicators of economic status $(n=65)$, as well as young people $(n=23)$ with a "contradictory" combination of these indicators (one of them at a high level of manifestation, and the second low or on the contrary) were labeled to the intermediate ( $n=88$ ) group. This group was excluded from further research due to the lack of statistically significant differences compared to other experimental groups.

Thus, only two experimental groups were included under the final analysis: low $(n=108)$ and high $(n=119)$ economic status. The procedure of experimental groups formation is presented in the table below (Tab. I), where: 1 - low economic status; 2 - intermediate group; 3 - high economic status, the acronym SEB stands for subjective and economic well-being.

As a result of statistical processing of the obtained data, we found that the group with low economic status consisted 
Table I. The combination of the objective and subjective indicators of economic status

\begin{tabular}{cccc}
\hline $\begin{array}{c}\text { Objective indicator } \\
\text { (criterion - income level) }\end{array}$ & low & Subjective indicator (criterion - SEB level) & high \\
\cline { 2 - 4 }$\left(\begin{array}{c}\text { Low } \\
(\leq 1000 \text { UAR/month) }\end{array}\right.$ & $\mathbf{1}$ & $\mathbf{1}$ & 2 \\
\hline $\begin{array}{c}\text { medium } \\
(1000-2000 \text { UAR/month) }\end{array}$ & $\mathbf{1}$ & 2 & $\mathbf{3}$ \\
\hline $\begin{array}{c}\text { high } \\
(\geq 2000 \text { UAR/month) }\end{array}$ & 2 & $\mathbf{3}$ & $\mathbf{3}$ \\
\hline
\end{tabular}

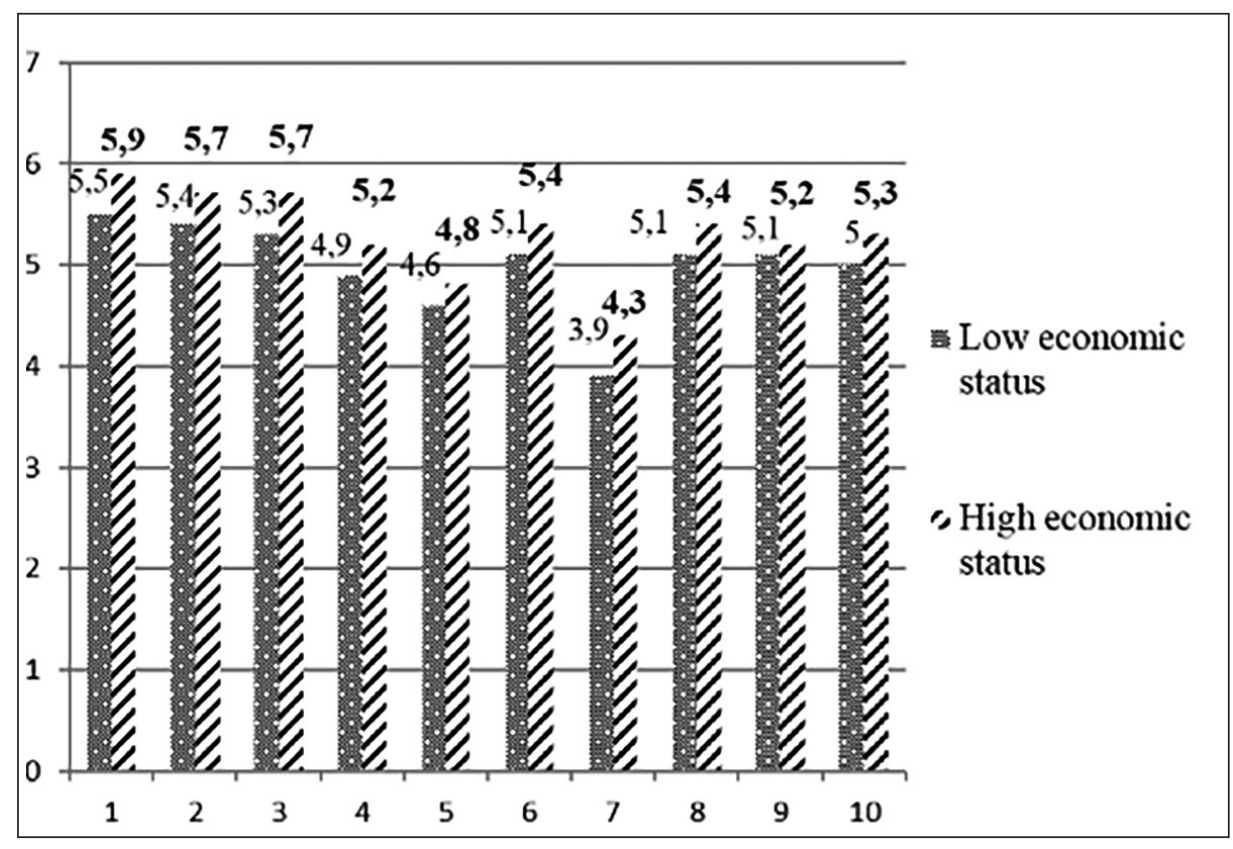

Fig. 1. The differences in the youth's mood in healthy state (mean value) of $53.7 \%$ female and $46.3 \%$ of male respondents, and the group with high economic status $-42.9 \%$ and $57.1 \%$ of males and females respectively. The use of non-parametric Kruskal-Wallis test suggested that gender did not affect the affiliation of young people to groups with low, high economic status or to the intermediate group ( $\mathrm{p} \geq 0.8)$.

The conducted theoretical analysis states that socially deprived groups tend to have bad habits more frequently than the other groups of people [8]. We decided to check this hypothesis in our sample using Pearson $\chi^{2}$ test. The procedure revealed that the occurrence of bad habits is higher among young people with low economic status compared to the ones with high economic status (42.8\% vs. $30.2 \%$ ), that is, $p \geq 0.01$. This result actually confirms the previous findings in the literature: representatives from the group of low economic status are indeed vulnerable in the context of maintaining mental and physical health.

During the next stage of our research, we wanted to compare youth's frame of mind in a healthy and unhealthy state, specifically how they react emotionally to health changes. The anxiety level in situations associated with deteriorating health is above the norm in both groups, but young people with low economic status tend to show more negative, dysfunctional emotions $(\mathrm{M}=42.5, \mathrm{SD}=13)$ than youth with high economic status $(\mathrm{M}=38.7, \mathrm{SD}=10)$, which is confirmed at a statistically significant level $(t=2.4$, at $\mathrm{p} \leq 0.02$ ).

The affective component of the attitude to health manifests through different emotions. Figure 1 details the data on functional emotions of youth in a healthy state, where: 1 - calm; 2 - pleasure; 3 - happiness; 4 - joy; 5 - a sense of absence of any threat; 6 - indifference; 7 - lack of anxiety; 8 - self-confidence; 9 - freedom; 10 - inner satisfaction.

Statistically significant differences in the groups studied are observed among such emotions as happiness $(t=0.3$, $\mathrm{p} \leq 0.01)$ and $\mathrm{calm}(\mathrm{t}=1.7, \mathrm{p} \leq 0.1)$, which are more common for young people with high economic status.

It was also important for us to find out what emotions characterize the youth during the deterioration of physical and mental health. Mean values of each emotion is shown in Figure 2, where: 1 - lack of peace; 2 - feeling sorry; 3 - concern; 4 - guilt; 5 - sadness; 6 - fear; 7 - irritability; 8 - depression; 9 - anxiety and nervousness; 10 - shame.

The presented data demonstrates that youth tend to lack peace, and feel anxiety and sadness frequently when their health deteriorates. These emotions manifest in both study groups of young people at a high level. However, statistically significant differences between the groups with low and high 

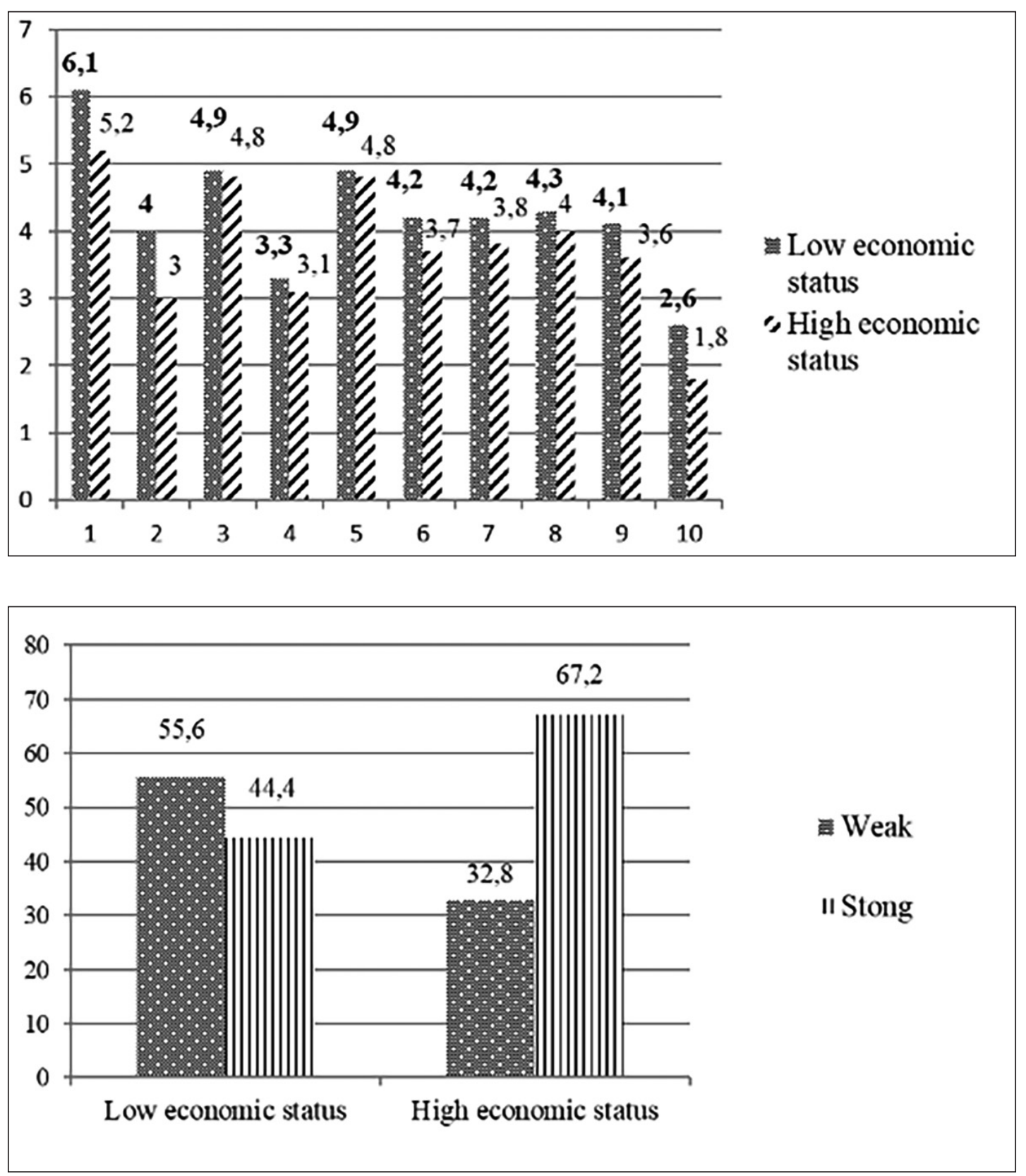

Fig. 2. The differences in the youth's mood in unhealthy state (mean value)

Fig. 3. Manifestation of emotional self-regulation of the youth with low and high economic status (\%) economic status were found for the emotions of fear $(\mathrm{t}=2.1$, $\mathrm{p} \leq 0.03)$, anxiety $(\mathrm{t}=2, \mathrm{p} \leq 0.04)$, and irritability $(\mathrm{t}=1.8, \mathrm{p} \leq 0.07)$.

The figure below demonstrates the differences in the manifestation of emotional self-regulation of youth with different economic statuses (Fig. 3).

It is apparent from Fig. 3 that $67.2 \%$ of respondents with high economic status have a fairly high tendency to emotional self-regulation, which is significantly different from the level at which it is manifested in the group with low economic status $-44.4 \%$. Conversely, slightly more than a half (55.6\%) of respondents with low economic status tends to have problems with emotional self-regulation while interacting with others; for the purpose of comparison, only $32.8 \%$ of young people with high economic status have a low tendency to do so. These differences between the experimental groups are confirmed at a statistically significant level $\left(\chi^{2}=11.9, \mathrm{p} \leq 0.001\right)$.

\section{DISCUSSION}

In the recent years, there has been a considerable interest in terms of maintaining mental health [2-4, 8, 9]. Muzdybaev, Krueger, and some co-workers investigated the role of economic factor in a person\&apos;s attitude towards health. They demonstrated the effect of objective and subjective determinants of the psychological well-being of an individual $[10,11]$. In particular, it was found that young people with a high status, being freed from any financial or economic difficulties, had a number of interpersonal problems.

According to a survey conducted by E. Shinyaeva O. and A. Padiarova, such personal qualities as being practical, networking, entrepreneurial, communicative, and easy-going were among the most important features that helped the respondents to achieve rapid economic growth. The lowest ranks were assigned to the following qualities: 
hard-working, talented, and physically healthy [12]. In our view, these findings indicate that young people with high economic well-being tend to have an exploitative and instrumental attitude towards their own health as they ignore the simple benefits from being healthy. This contradictory attitude to health actually forced us to get into the details of the problem of emotional self-regulation of young people with low and high economic statuses.

According to the results of our research, the mood (frame of mind) in healthy and unhealthy state differs in two experimental groups. The emotional aspect of health (mood) of the young people with high economic status is characterized by the predominance of positively marked, functional emotions, while young people with low economic status concentrate more on negative emotions, which usually accompany their unhealthy physical state. Moreover, young people with low economic status have a wider range of dysfunctional emotions. In the affective sphere, the attitude to health of young people with high economic status is marked by the predominance of positive emotions over the negative ones, even when the state of health is stable and there is no reason for any concern. Despite the results obtained, we still lack explanations such as why young people with low economic status tend to fix on negative emotions and if there is a correlation between their skill to recognize and verbalize these emotions, and their ability to manage emotional balance.

The extent to which a person is able to care about his/her health on the physical, intra and interpersonal levels can be an indicator of his/her emotional self-regulation. It is often manifested in communication, when a person can control anger, irritation, cope with mood swings when interacting with others, find internal resources in a changing situation, show independence in making important decisions, and manage his/her own time and life in general. The complexity of these abilities is a direct sign of stable mental health. As shown by our survey, the ability towards emotional self-regulation among youth with low economic status is weak - members of this group find it hard to cope with resentment, and are more likely to blame others for their troubles, rather than looking for a reason in themselves, which in fact evokes feelings of helplessness and loss of control over the situation.

\section{CONCLUSIONS}

The economic status of youth is understood as a socio-psychological construct formed by the combination of objective and subjective indicators, the criterion of which, respectively, is the income level and the level of subjective economic well-being of youth. The frame of mind that accompanies healthy or unhealthy state indirectly characterizes the ability of young people to cope with their affective manifestations. Young people with high economic status demonstrate more positive, functional emotions about their health than the opposite group. Conversely, young people with low economic status tend to get more embarrassed, anxious or irritated when their health deteriorates.
We have revealed statistically significant differences in the ability towards emotional self-regulation between young people with low and high economic status - the latter group is able to control anger and resentment when communicating with others; they are more likely to find internal psychological resources. When their health deteriorates, they are prone to show independence, and manage their own time and life, which is indicative of stable mental health.

\section{REFERENCES}

1. Adler N., Ostrove J. Socioeconomic status and health: what we know and what we don't. Psychological Review. 1999;896:3-15.

2. Armenta Ch., Ruberton P., Lyubomirsk S. Subjective well-being, Psychology of International Encyclopedia of the Social and Behavioral Sciences. 2016;2:648-653.

3. Gross J. The extended process model of emotion regulation: elaborations, applications, and future directions. Psychological Inquiry. 2016;26:130137. doi: 10.1080/1047840X.2015.989751.

4. Wojnarowska A., Kobylinska D., Lewczuk K. Acceptance as an Emotion Regulation Strategy in Experimental Psychological Research: What We Know and How We Can Improve That Knowledge. Frontiers in Psychology. 2020;11:1-5. doi: 10.3389/fpsyg.2020.00242.

5. Berezovskaya R. Issledovaniya otnosheniya k zdorov yu: sovremennoe sostoyanie problemy` v otechestvennoj psikhologii [Studies of health attitudes: the current state of the problem in native psychology]. Bulletin of Saint-Petersburg State University. 2011;1:222-226. (in Russian)

6. Vodop 'yanova N. Izmerenie kachestva zhizni [Quality life measurement]. Workshop on health psychology. Saint-Peterburg: Piter; 2015, 288 p.. (in Russian)

7. Khashhenko V. Sub`ektivnoe e konomicheskoe blagopoluchie i ego izmerenie: postroenie oprosnika i ego validizacziya [Subjective economic well-being and its measurement: construction of a questionnaire and its validation]. E’ ksperimental 'naya psikhologiya. 2011;1:106-127. (in Russian)

8. Korobka L. Metodychni zasady sotsialno-psykholohichnoho doslidzhennia stavlennia do zdorovia osib z riznym rivnem psykholohichnoho tiazhinnia do bidnosti [Methodical bases of sociopsychological research of the attitude to health of people with different level of psychological tendency to poverty]. Ukrainian scientific journal «Education of the region». 2013;3:286-290. (in Ukrainian).

9. Fradelos E., Kapsiocha E., Neroliatsiou A. at al. Assessment of psychological distress in university students: A Quantitative study. Mental Health: Global Challenges Journal. 2019;2(1): 14. doi:10.32437/ mhgcj.v2i1.42.

10. Muzdy 'baev K. Zhiznenny`e strategii sovremennoj molodezhi: mezhpokolencheskij analiz [Life strategies of modern youth: intergenerational analysis]. Journal of Sociology and Social Anthropology. 2004;7(1):175-189. (in Russian)

11. Krueger A., Mueller A. Time Use, Emotional Well-Being, and Unemployment: Evidence from Longitudinal Data. American Economic Review. 2012;3:594-599.

12. Shinyaeva E., Padiarova A. Soczial 'noe neravenstvo izdorov`e molodogo pokoleniya rossiyan [Social inequality and health of the young generation of Russians]. UI yanovsk: UIGTU. 2010, 168 p. (in Russian)

The work is a fragment of the research project "Socio-psychological factors in overcoming poverty as a lifestyle", state registration No. 0111 U001263. 
ORCID and contributionship:

Mariia S. Kanibolotska: 0000-0002-3608-3958 A-D, F

Marharita A. Dergach: 0000-0001-6740-3689, ${ }^{E, F}$

Neonila V. Partyko: 0000-0002-2904-2760 ${ }^{\text {B,E }}$

Anastasiia Cherkasova: 0000-0002-5416-5631 E,F

Oleg Blinov: 0000-0002-9523-0233 E,F

Olga Litvinova: 0000-0001-5261-6358 E,F

Daniela Dumitru: 0000-0003-1440-0403 ${ }^{E, F}$

Conflict of interest:

The Authors declare no conflict of interest.

\section{CORRESPONDING AUTHOR}

Mariia S. Kanibolotska

Institute of Social and Political

Psychology NAES of Ukraine,

15 Andriivska St., 04070 Kyiv, Ukraine

tel: +38095-9349046

e-mail:mariakanib@gmail.com

Received: 24.05 .2021

Accepted: 08.10.2021

A - Work concept and design, B - Data collection and analysis, C - Responsibility for statistical analysis,

D-Writing the article, $\mathbf{E}$-Critical review, $\mathbf{F}$ - Final approval of the article 


\title{
SOCIAL TENSION AS A MACRO INDICATOR OF THE PSYCHOLOGICAL WELL-BEING OF SOCIETY
}

D0I: 10.36740/WLek202111123

\author{
Mykola M. Slyusarevskyy' ${ }^{1}$, Svitlana Chunikhina' ${ }^{1}$, Maureen Flaherty ${ }^{2}$ \\ 'INSTITUTE OF SOCIAL AND POLITICAL PSYCHOLOGY NATIONAL ACADEMY OF EDUCATIONAL SCIENCES OF UKRAINE, KYIV, UKRAINE \\ ¿UNIVERSITY OF MANNITOBA, WINNIPEG, CANADA
}

\begin{abstract}
The aim: This article aims to determine the prospects of studying social tension as a macro indicator of the psychological well-being of society. Materials and methods: A total of 1,200 respondents were included in face-to-face interviews: 548 men and 652 women. The sample represents Ukraine's adult population at or above the age of 18 . We used a 16 -item questionnaire developed based on a theoretical model of necessary and sufficient indicators of social tension.

Results: This comprehensive study indicates that over the past 15 years, the national elections constituted the most significant factor in reducing social tensions in Ukraine, and the most potent stressor was the global financial crisis of 2008. Contrary to expectations, the COVID-19 pandemic has not provoked the rising social tension; rather, there has been a noticeable decrease. Based on empirical research data, the prospects of scaling the psychological well-being model of an individual to a broader social context are analyzed. In particular, the study of social tension makes it possible to identify and interpret the psychological effects associated with the projection of outwardly displaced individual reactions to complex social situations.

Conclusions: We explain how the social tension model can be applied as a macro indicator of psychological well-being at the level of a society. The prospects of creating more valid and reliable indicators of psychological well-being for any given socio-cultural, socio-economic, political context are also identified.
\end{abstract}

KEY WORDS: social tension, psychological well-being, social situation, monitoring, Ukraine

Wiad Lek. 2021;74(11 p.l):2812-2817

\section{INTRODUCTION}

It is now common to understand psychological well-being (PW) as a combination of affective and activity markers of a person psychological state: a steady predominance of positive feelings (joy, pleasure, happiness) in the emotional palette of the individual and the ability to carry out productive, effective, and purposeful activities in one's private and social life [1-4]. Nowadays, the theories and models of PW consider PW to be an environmentally or situationally conditioned state of personality. Nevertheless, most of them develop a narrow, purely subjectivist view of $\mathrm{PW}$ in isolation from broader social contexts. Therefore, it is quite promising to view $\mathrm{PW}$ as a characteristic of a "subject-environment" interaction, not of a single subject, and to identify the associations between PW and social, economic, and political phenomena more accurately. In our opinion, one of the indicators of $\mathrm{PW}$ at the societal level may be the extent of social tension, which is due to the psychological effects of social situations.

Social tension (ST) is now is studied by sociologists, economists, psychologists, and interdisciplinary research teams [5-9]. Because of a specific methodological diversity due to the interdisciplinary nature of the issue, it is necessary to define what we mean by ST. In particular, we separate social tension from such notions as social well-being, social discontent, and protest moods [9]. Although all these phenomena are individual or group reactions to certain socio-economic or political circumstances, the nature of these reactions is fundamentally different. For instance, social ill-being manifests in reducing the extent of group tension and vitality necessary to overcome unfavorable situations; in contrast, social discontent mobilizes resources of individual or collective resistance, as do protest moods. Social tension arises from people\&apos;s dissatisfaction with living conditions that hinder the satisfaction of their needs, the achievement of goals, or the fulfilment of expectations, or contradict the notion of a just social order [8]. Thus, the state of ST is a sum of frustrative states determined by the broader social context experienced by members of a community or society.

\section{THE AIM}

This article aims to determine the prospects of studying social tension as a macro indicator of the psychological well-being of members of society based on empirical research conducted in Ukraine.

\section{MATERIALS AND METHODS}

We interviewed 1,200 respondents, including 548 men and 652 women, from 5 to 20 June 2021, in all regions of Ukraine 
except the Autonomous Republic of Crimea, Sevastopol, and some districts of Donetsk and regions of Luhansk not under the control of Ukrainian authorities. The sample represents the adult population of Ukraine aged 18 and older. The sample error is $3.2 \%$. We used a 16 -item questionnaire developed based on a theoretical model of necessary and sufficient indicators of social tension [8]. More specifically, respondents had to answer the following questions:

1. Please assess the socio-economic and political situation for the area(s) where you, your relatives, and your friends live. (Answer options: completely ok, ok, wrong, completely wrong, difficult to answer.)

2. Do you think that the past socio-economic and political situation in which your life took place was better than now? (Answer options: unequivocally yes, rather yes, difficult to answer, rather no, unequivocally no.)

3. Do you agree that the future socio-economic and political situation in which your life takes place will change for the better? (Answer options: unequivocally yes, rather yes, difficult to answer, rather no, unequivocally no.)

4. Do you agree with the following statements? (Answer options: unequivocally yes, rather yes, difficult to answer, rather no, unequivocally no.)

- The level of my well-being depends primarily on me, not on the socio-economic and political situation in the country.

- Other people and external circumstances have affected (and still affect) my life more than myself.

- Nobody has the power to control his destiny.

- My life has depended (and still depends) more on myself than on other people and circumstances.

- Everyone is the creator of his destiny.

1. Are you satisfied with your ability to influence on the socio-economic and political situation in which your life takes place? (Answer options: completely satisfied, rather satisfied, difficult to answer, rather dissatisfied, not at all satisfied.)

2. In your opinion, do the listed persons, public authorities, and other organizations have a significant impact (positive or negative) on this situation? Directors of enterprises (institutions, organizations), local authorities, the Verkhovna Rada, the Cabinet of Ministers, the President of Ukraine, law enforcement organizations, the Russian Federation Government, the US and EU governments, oligarchs, political and economic clans? (Answer options: unequivocally yes, rather yes, it is difficult to say, rather no, unequivocally no.)

3. Are you satisfied with the results of this influence? (Answer options: unequivocally yes, rather yes, difficult to answer, rather no, unequivocally no.)

The answers to the questions were coded on a five-point scale from -2 to 2 . The formula to calculate the integrated indicator of social tension $(\mathrm{N})$ is

$$
N=O+\frac{O 1+O 2}{2}+i V+j W .
$$

where $\boldsymbol{O}=$ general assessment of the current state of the situation; $\mathbf{O 1}=$ retrospective assessment of the past state of the situation; $\mathbf{O} \mathbf{2}=$ forecast assessment of the future state of the situation; $V=$ satisfaction with the ones ability to influence the situation; $W=$ satisfaction with the results of external influence on the situation; $\boldsymbol{i}=$ level of subjective control (internality) of the subject of evaluation; $\boldsymbol{j}=$ attributed to specific social forces the degree of external influence on the situation.

We compared the results of the 2021 survey with data obtained in 2007-2018 using identical instruments. All respondents voluntarily agreed to participate in the study.

For data processing, we used MakeformWin and OCA for Windows. The analysis of the obtained data was carried out based on descriptive statistics by constructing crosstabs.

\section{RESULTS}

The study indicates that the reduction of social tensions in Ukraine in 2021 is primarily due to a more positive assessment of the current socio-economic and political situation. While in 2018 only a quarter of respondents (26.7\%) considered it to be mostly normal, and more than half (53.7\%) considered it wrong or very bad, now almost a third of respondents are inclined toward positive assessments and less than half (48.8\%) gave negative assessments. Contrary to expectations, the COVID-19 pandemic has not caused a rise in social tension; there is a noticeable decrease. In general, $41.8 \%$ now are satisfied with their lives, $36 \%$ are dissatisfied (in $2018-37.6 \%$ and $40.9 \%$, respectively).

The level of nostalgia for the "beautiful past" has slightly decreased. The recent survey shows that $62.7 \%$ of respondents thought that the situation was better before $(66.7 \%$ in 2018). Ukrainians began to see the future in a slightly more optimistic way. In 2018, only $23.9 \%$ of respondents expected better changes in the future, and $43.5 \%$ did not expect anything good; there are $26.5 \%$ optimists and $38.8 \%$ pessimists among Ukrainians in 2021.

Significant changes have taken place in citizens\&apos; perceptions of the extent to which they can influence the course of their lives in assigned socio-economic and political conditions. About half (46.8\%) of respondents now agree that their level of well-being depends primarily on themselves. One-third of respondents (33.9\%) do not agree with this. In 2018, this statement divided respondents almost in half: $41.3 \%$ and $38.5 \%$, respectively. Only $15.4 \%$ of respondents in 2021 are satisfied with their ability to influence the socio-economic and political situation in the country (13.9\% in 2018). However, the number of dissatisfied Ukrainians has decreased more markedly: from 61, $4 \%$ in 2018 to $55.9 \%$ in 2021.

The social tensions dynamics in Ukraine over the last 15 years (Fig. 1) show that national elections usually lead to a significant reduction in social tensions, as they increase optimistic expectations about the future. One of the most potent stressors for the Ukrainian society was the global financial crisis of 2008, which impacted the level of social tension until 2011. The peak level of social tension recorded in 2017 may result from a specific cumulative effect. During 


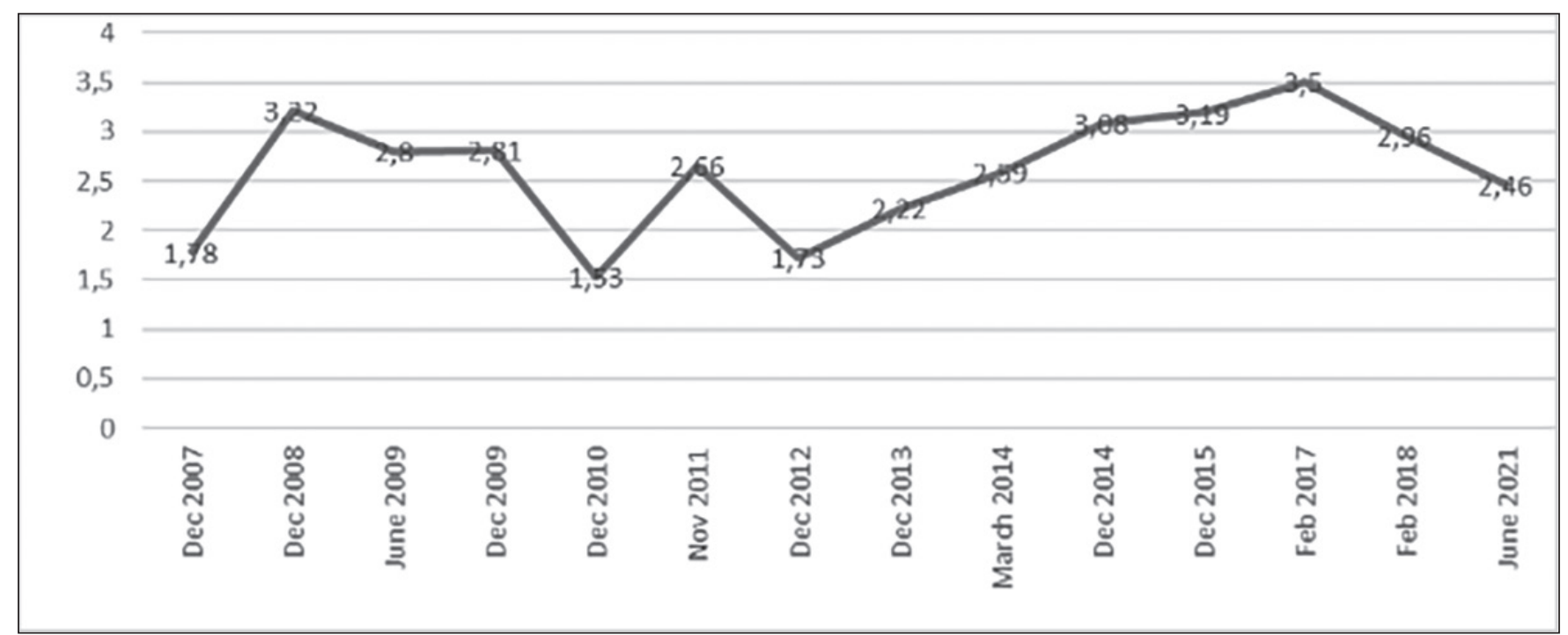

Fig. 1. The social tension dynamic in Ukraine (2007-2021)

ST Model

PW Model

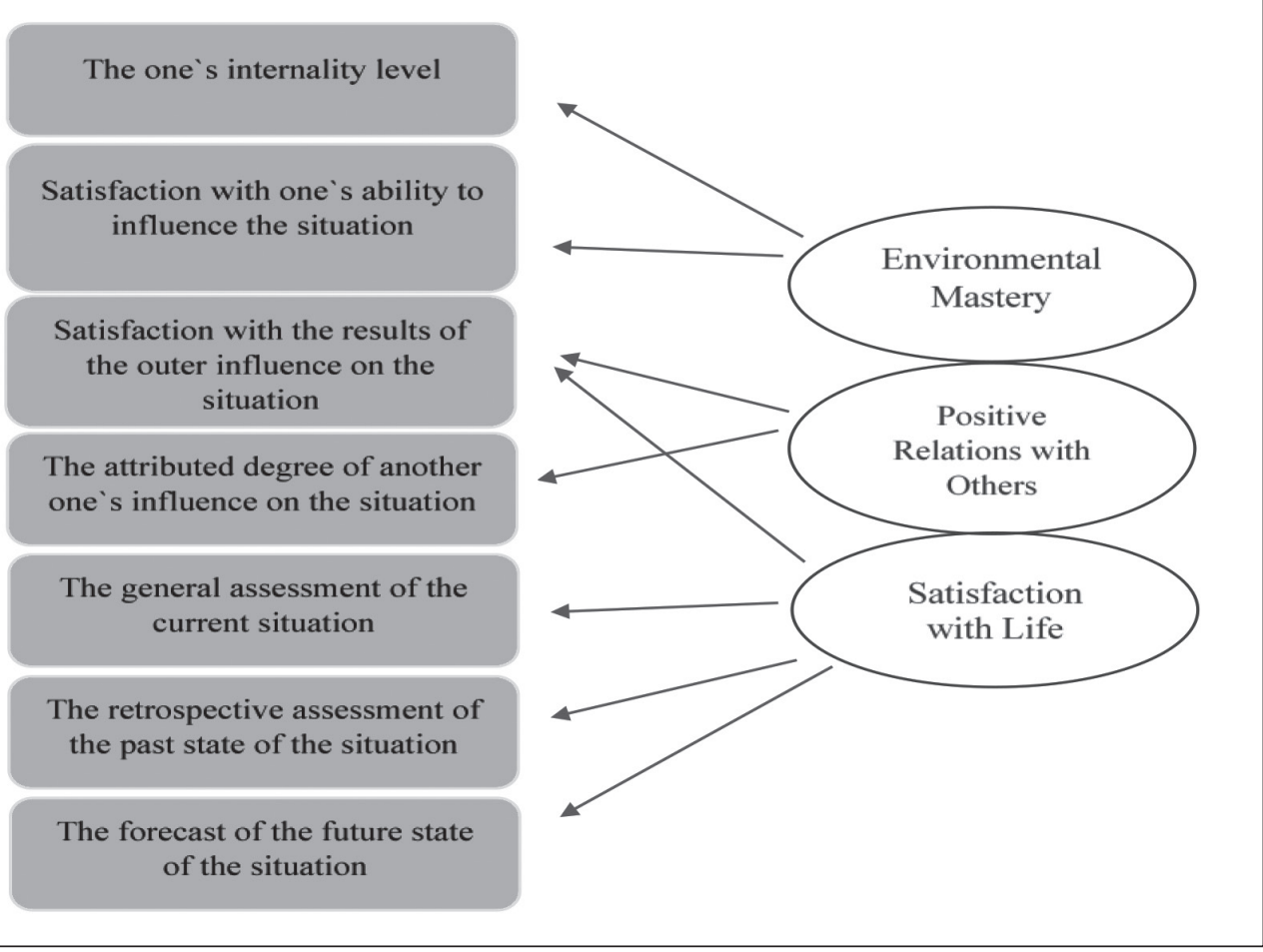

Fig. 2. Comparative analysis of PW and ST models.

the Revolution of Dignity, public inquiries and debates did not find adequate answers, particularly in ideas about the prospects of overcoming a challenging situation.

\section{DISCUSSION}

The presented model of necessary and sufficient indicators of social tension can be extended by projecting on a more comprehensive social context three-factor model of psychological well-being developed in studies of communities' psychological responses to distress [10].
A certain phenomenological similarity between the factors of both models, presented in Fig. 2, is indicated by results of studies conducted separately from each other. Presently, they can be discussed only in terms of a hypothesis. Of course, we ought to empirically test these theoretical assumptions in the future. However, even now, our results provide the directions to describe psychological well-being in the context of subject-environment interaction. Also, it helps us to demonstrate some nuances of psychological well-being as a specific socio-psychological reality when scaling its components to a broader social context. 
Table I. Attitude to the actual social, economic, and political situation

\begin{tabular}{|c|c|c|c|}
\hline & \multicolumn{3}{|c|}{ Value (\%) } \\
\hline & $\begin{array}{c}\text { The situation is } \\
\text { quite normal/ } \\
\text { normal }\end{array}$ & $\begin{array}{c}\text { The situation is definitely } \\
\text { not normal/ } \\
\text { not normal }\end{array}$ & No answer \\
\hline Our family does not have enough money at all & 6,5 & 79,0 & 14,5 \\
\hline Our family has enough money for necessities & 32,8 & 41,4 & 25,9 \\
\hline Our family has enough money & 67,1 & 16,5 & 16,5 \\
\hline Our family has almost enough money & 81,8 & 15,9 & 2,3 \\
\hline The situation will surely / rather change for the better * & 58,4 & 20,3 & 21,3 \\
\hline The situation will surely not change for the better * & 14,4 & 74,0 & 11,6 \\
\hline $\begin{array}{l}\text { I am entirely / rather satisfied with the possibilities of my influence on } \\
\text { the situation * }\end{array}$ & 72,3 & 16,8 & 10,9 \\
\hline $\begin{array}{l}\text { Definitely / rather dissatisfied with the possibilities of their influence } \\
\text { on the situation * }\end{array}$ & 19,3 & 65,4 & 15,4 \\
\hline $\begin{array}{l}\text { Opportunities for external influence on the situation are entirely / } \\
\text { rather satisfied * }\end{array}$ & 68,8 & 17,7 & 13,5 \\
\hline $\begin{array}{l}\text { Opportunities for external influence on the situation are definitely / } \\
\text { rather dissatisfied * }\end{array}$ & 25,9 & 57,8 & 16,2 \\
\hline The level of my own well-being depends entirely on me & 43,6 & 39,3 & 17,1 \\
\hline The level of my own well-being is definitely / rather not up to me & 20,7 & 61,0 & 18,3 \\
\hline
\end{tabular}

* Indicators included in the estimated level of social tension

Table Il. Satisfaction with one`s own life

\begin{tabular}{|c|c|c|c|}
\hline & \multicolumn{3}{|c|}{ Value (\%) } \\
\hline & $\begin{array}{c}\text { Quite } \\
\text { satisfied/ } \\
\text { satisfied }\end{array}$ & $\begin{array}{c}\text { Definitely not } \\
\text { satisfied / not } \\
\text { satisfied }\end{array}$ & No answer \\
\hline Our family does not have enough money at all & 12,5 & 66,5 & 21,0 \\
\hline Our family has enough money for necessities & 48,2 & 26,4 & 25,3 \\
\hline Our family has enough money & 75,4 & 10,9 & 14,0 \\
\hline Our family has almost enough money & 90,9 & 4,5 & 4,5 \\
\hline The situation will surely / rather change for the better * & 69,5 & 12,0 & 18,5 \\
\hline The situation will surely not change for the better * & 23,2 & 59,7 & 17,1 \\
\hline $\begin{array}{l}\text { I am entirely / rather satisfied with the possibilities of my influence } \\
\text { on the situation * }\end{array}$ & 83,8 & 6,1 & 10,1 \\
\hline $\begin{array}{l}\text { Definitely / rather dissatisfied with the possibilities of their } \\
\text { influence on the situation * }\end{array}$ & 28,8 & 52,0 & 19,2 \\
\hline $\begin{array}{l}\text { Opportunities for external influence on the situation are entirely / } \\
\text { rather satisfied * }\end{array}$ & 45,3 & 31,0 & 23,6 \\
\hline $\begin{array}{l}\text { Opportunities for external influence on the situation are definitely } \\
\qquad / \text { rather dissatisfied * }\end{array}$ & 42,9 & 39,4 & 17,7 \\
\hline The level of my own well-being depends entirely on me & 56,7 & 25,6 & 17,7 \\
\hline The level of my own well-being is definitely / rather not up to me & 28,1 & 52,0 & 19,8 \\
\hline
\end{tabular}

* Indicators included in the estimated level of social tension

As we can see from tables I and II, citizens; assessment of the current socio-economic and political situation is not necessarily equal to their level of satisfaction with their own lives. Essentially, the number of respondents who were satisfied with their own lives and whose income is only enough to cover basic needs is almost twice the number of dissatisfied respondents. However, we see a different picture if we differentiate the respondents according to their assessments of their current socio-economic and political situations. Those who consider the situation in the country to be entirely acceptable or rather acceptable, among respondents who have enough money only for the 
most necessary goods, total to $10 \%$ less in number than those who assess the situation negatively.

Even more noticeable is the difference in the distribution of answers to questions about satisfaction with external influences on situation outcomes. Suppose we group respondents according to the general situation in the country. In that case, it turns out that among social optimists, more than two thirds of people are generally optimistic about the results of other countries influencing the situation (authorities, representatives of outgroups), and a quarter of respondents disapprove. If we consider the level of satisfaction with one\&apos;s own life, the distribution of attitudes to the possibilities of such external influences is different. Among respondents generally satisfied with their lives, the number of people satisfied with the outcomes of external influences is almost equal to the number of those who are dissatisfied with it.

The subjective control (internality) of respondents also manifests itself differently depending on whether we consider assessing the situation in the country as a whole or assessing their life circumstances in particular. Among those who consider the situation in the country to be most acceptable, the number of respondents with internality and externality is almost equal. At the same time, among those satisfied with their own lives, there are more than twice as many internally minded respondents as externally minded ones.

So, which of the criteria-assessment of the situation in the country or satisfaction with one\&apos;s own life-is more relevant for measuring psychological well-being? We suppose both are quite informative, as they measure different aspects of socio-psychological reality. By inviting respondents to assess the situation in the country, researchers create some psychological space for the projection of complex, contradictory, or repressed attitudes, feelings, intentions in a more safe, abstract context. When a person needs to assess his life situation, there is not such a projective space, so certain representations of reality, which can be a source of actual psychological discomfort, are either suppressed or not clearly articulated.

The tendency to downplay the impact of a crisis on one\&apos;s own life may be protective. Furthermore, in this case, providing a convenient object for citizens to express their own anxieties, stresses, frustrations, and injuries in a public way can be a source of important information about the extent of tension in a society and the level of psychological well-being of a society's individuals.

\section{LIMITATIONS OF THE STUDY}

This study is our first attempt to use the model of necessary and sufficient indicators of social tension as a macro indicator of psychological well-being. First, further research is needed for a deeper understanding of the causes of changes in social tensions in Ukraine. These cannot be comprehensively explained in a situational or environmental approach. Second, there is a need to create more valid and reliable indicators of psychological well-being in a given socio-cultural, socio-economic, political context.

\section{CONCLUSIONS}

We can now include psychological well-being and social tension in a common phenomenological space. At different levels of the system of subject-environment interactions-personal, group, and societal-we should consider these phenomena as manifestations of joint socio-psychological reality. Applying the model of necessary and sufficient indicators of social tension as a macro indicator of psychological well-being will make it possible to provide greater responsiveness to research on psychological well-being. For example, this model can help identify some repressed or implicit attitudes, feelings, or intentions of individuals regarding their own life situation. The capacity to project the suppressed material of individual consciousness outside or attribute it to other actors-members of the in-group, out-group, community, or society-provided by the model of social tension causes greater responsiveness to psychological well-being studying at the society level.

\section{REFERENCES}

1. Bradburn N.M. The structure of psychological well-being. Chicago: Aldine. 1969, 602p.

2. Folkman S. Positive psychological states and coping with severe stress. Social Science and Medicine. 1997; 45: 1207-1221.

3. McDowell I., Praught E. On the measurement of happiness: An examination of the Bradburn Scale in the Canada Health Survey. American Journal of Epidemiology. 1982; 116: 949-958.

4. RyffC. D. Happiness is everything, or is it? Explorations on the meaning of psychological well-being. Journal of Personality and Social Psychology. 1989; 57: 1069- 1081.

5. Artemov G., Aleinikov A., Daur A. et al. Social Tension: the Possibility of Conflict Diagnosis (on the Example of St. Petersburg). Economics \& Sociology. 2017; 10: 192-208.

6. Karamushka L.M. Social tension in the organization: the essence, approaches to the study, the main types. Actual problems of psychology: coll. Science. 2016; I (45): 3-11.

7. Klebanova T., Rudachenko 0., Gvozdytskyi V. L.et al. Classification of Regions of Ukraine by The Level of Social Tension. Wseas transactions on systems and control. 2020; 15: 576-584.

8. Slyusarevskyy M.M. Sotsialna napruzhenist: teoretychna model neobkhidnykh i dostatnikh pokaznykiv. Naukovi studiyi iz sotsialnoyi ta politychnoyi psykholohiyi. 2002; 5 (8): 24-34. (in Ukrainian).

9. Slyusarevskyy M.M. Neskhodymi tereny Psykheyi: marshruty naukovoho piznannya: vybrani pratsi. Kyiv : Talkom, 2019; 664p. (in Ukrainian).

10. Winefield H.R., Gill T.K., Taylor A.W., Pilkington R.M. Psychological well-being and psychological distress: is it necessary to measure both? Psychology of Well-being. 2012; 2(1); 3. doi:10.1186/22111522-2-3.

\section{ORCID and contributionship:}

Mykola M. Slyusarevskyy: ${ }^{A-D}$

Svitlana Chunikhina: ${ }^{B-D}$

Maureen Flaherty: 0000-0003-0234-0095 E, F

\section{Conflict of interest:}

The Authors declare no conflict of interest. 


\section{CORRESPONDING AUTHOR}

Mykola M. Slyusarevskyy

Institute of Social and Political Psychology National Academy

of Educational Sciences of Ukraine

15 Andriivska St., 04070 Kyiv, Ukraine

e-mail: viktorvus@ukr.net

Received: 19.05 .2021

Accepted: 15.10 .2021

A - Work concept and design, B - Data collection and analysis, C - Responsibility for statistical analysis,

$\mathbf{D}$-Writing the article, $\mathbf{E}$-Critical review, $\mathbf{F}$ - Final approval of the article 


\title{
THE INFLUENCE OF OCCUPATIONAL STRESS ON EMPLOYEES' MENTAL HEALTH
}

D0I: 10.36740/WLek202111124

\author{
Sergii Maksymenko', Oleg Kokun' ${ }^{1}$, legor Topolov' ${ }^{1}$, Olena Nemesh ${ }^{2}$, Maureen Flaherty ${ }^{3}$ \\ 'G.S. KOSTIUK INSTITUTE OF PSYCHOLOGY OF NATIONAL ACADEMY OF EDUCATIONAL SCIENCES OF UKRAINE, KYIV, UKRAINE \\ 2RIVNE STATE UNIVERSITY OF THE HUMANITIES, RIVNE, UKRAINE \\ 3UNIVERSITY OF MANNITOBA, WINNIPEG, CANADA
}

\begin{abstract}
The aim: To identify the features of the influence of occupational stress on occupation-specific indicators of employees' mental health.

Materials and methods: In total, 771 skilled Russian-speaking respondents ( 226 men, 545 women; aged 18-67 years, $M=32.32 \pm 12.28$ years) from different countries and representing various professions participated in a remote online survey. Occupational stress intensity was assessed using the Russian adaptations of the Organizational Constraints Scale, Quantitative Workload Inventory and Aggressive Experiences Scale. Occupation-specific indicators of employees' mental health were assessed using the Russian adaptations of the Maslach Burnout Inventory, Withdrawal Scale and Negative Affect at Work Scale.

Results: The results showed a significant negative influence of occupational stress on occupation-specific indicators of employees'mental health. All three indicators of occupational stress showed strong significant correlations $(p<.001 ; r=.16-.60)$ with all five occupation-specific indicators of negative mental health. Constraints on performance at work had the greatest negative influence on employees' mental health, followed by aggressive experiences and workload. Constraints on performance at work caused withdrawal behaviors and workload caused emotional exhaustion, personal accomplishment and withdrawal behaviors in men significantly more often than in women. Aggressive experiences caused depersonalization and negative affect at work in women significantly more often than in men.

Conclusions: 0 ccupational stress had a significant negative influence on all occupation-specific indicators of employees' mental health. This influence had pronounced gendered characteristics. These results convincingly demonstrate the need for effective measures to prevent occupational stress.
\end{abstract}

KEY WORDS: mental health, burnout, aggressive experiences, workload, withdrawal behaviours, hardiness

Wiad Lek. 2021;74(11 p.l):2818-2822

\section{INTRODUCTION}

Occupational stress is one of the most significant problems for employees of various professions around the world $[1,2]$. It is a global phenomenon with significant negative consequences for employees' health and organizations' economic success $[3,4]$. In the most general sense, occupational stress refers to a sense of psychological pressure arising from different stressors experienced at work [5]. It is also generally defined as the gradual process by which individual cognitive assessments of occupational stressors generate adverse effects on health with severe behavioral consequences [4]. Employees are affected by stress regardless of profession, gender, age and financial or social status [2].

The main factors causing occupational stress can, in our opinion, be divided into three groups: 1) social (role ambiguity [6], low social support, poor psychosocial or unsafe climate, bullying [7]); 2) organizational (promotion; downsizing; wages [6]; lack of information; extreme pressure; low decision-making latitude [4]; effort-reward imbalance; low job control; job insecurity; organizational change; low organizational, procedural or relational justice [7]); and 3) occupational (temperature, noise, work overload [6], high job demands, atypical working hours [7]). These workplace factors can cause employees multiple stress-related mental health problems, including burnout [7-10], anxiety and depression $[4,11]$, lower self-esteem, somatization, negative impacts on social relationships [11], high work-family conflicts [3], job dissatisfaction, aggression, fatigue, substance abuse, poor performance [12] and lowered psychological well-being [4]. Because emotionally and physically demanding work with little control over one's work situation is especially stressful [12], occupational stress can have particularly pronounced negative effects on employees' mental health during work in extreme environments [11,13-15].

In light of the above, protecting employees' mental health is an extremely important task [16-18]. However, as Akerstrom M. [7] has rightly noted, although numerous studies have described the prevalence and determinants of various mental health problems attributable to poor working conditions, there remains only limited knowledge of effective methods for improving these adverse conditions (and consequently employees' mental health). Moreover, although there is significant research interest in explaining the link between stress and mental health [4], occupation-specific 
changes in employees' mental health and gendered patterns in the characteristics of such changes remain insufficiently studied in previous work.

\section{THE AIM}

The aim of our study was to identify the features of the influence of occupational stress on occupation-specific indicators of employees' mental health.

\section{MATERIAL AND METHODS}

Measures: The intensity of participants' occupational stress was assessed using the Russian adaptations of three measures: the Organizational Constraints Scale (OCS), Quantitative Workload Inventory (QWI) and Aggressive Experiences Scale (AES).

The OCS (Spector P. E., Jex S. M. [19]) is intended to measure constraints on performance at work (e.g. faulty equipment, incomplete information). One item assesses each of 11 constraint areas, all of which are summed into a total score. Respondents are asked to indicate how often it is difficult or impossible to do their jobs because of each item. Response choices range from less than once per month or never (coded as 1) to several times per day (coded as 5). High scores represent high levels of constraints, with the possible span of scores ranging from 11 to 55 .

The QWI (Spector P. E., Jex S. M. [19]) is intended to assess amount of work and work pace (as opposed to qualitative workload, which indicates the difficulty of work). The QWI has five items. Respondents are asked to select how often each statement occurs from five response choices, ranging from less than once per month or never (coded as 1) to several times per day (coded as 5). High scores represent a high workload, with a possible range from 5 to 25 .

The AES (Glomb T. M., Liao H. [20]) assesses the frequency with which respondents engage in and are the targets of aggressive behaviors at work. The scale consists of two separate 20 -item subscales. For each subscale, respondents indicate whether they engaged in the aggressive behavior described (AES - engaged in) and whether they were the target of the aggressive behavior (AES - target). Respondents are asked to report the frequency of each of the 20 behaviors (e.g. yelling or raising one's voice, swearing at another person, spreading rumors) using a five-point scale $(1=$ never, $5=$ once a week or more $)$. Possible AES scores range from 20 to 100 .

Occupation-specific indicators of employees' mental health (namely, 'negative mental health', which corresponds to the specific purpose of our study) were also assessed using the Russian adaptations of three measures: the Maslach Burnout Inventory - General Survey (MBI-GS), Withdrawal Scale (WS) and Negative Affect at Work Scale.

The MBI-GS (Maslach C. et al. [21]) is a psychological assessment instrument comprising 22 symptom items revealing occupational burnout. The measure contains three subscales: emotional exhaustion (EE; nine items), depersonalization (DP; five items), and personal accomplish- ment (PA; eight items). All MBI-GS items are scored on a seven-point Likert scale measuring frequency $(0=$ never, $1=$ several times $a$ year or less often, $2=$ once a month or less often, 3 = several times a month, $4=$ once a week, $5=$ several times a week, $6=$ every day). Higher scores on each subscale indicate higher results for each construct.

The WS (Mitchell M.S. [22]) is an eight-item measure that asks respondents to indicate the frequency with which they engaged in withdrawal behaviors involving the tasks they perform for their job over the course of the previous year $(1=$ never, 2 once a year, $3=$ twice a year, $4=$ several times a year, $5=$ monthly, $6=$ weekly, $7=$ daily). Example items include 'I began to do less work' and 'I put less effort into my assigned job duties'.

The Negative Affect at Work Scale (Watson D. et al. [23]) is one of two subscales of the Positive and Negative Affect Schedule - Trait (PANAS). The subscale contains 10 items that assess a person's negative mood or emotion using a five-point scale $(1=$ very slightly or not at all, $5=$ extremely $)$. Example items include 'How often do you feel scared at work?', 'How often do you feel upset at work?' and 'How often do you feel nervous at work?'

Data collection: We conducted a remote online survey using the website http://hr-test.org.

Participants: A total of 2,122 skilled Russian-speaking respondents from different countries and representing various ages and professions participated in the remote online survey. Only 771 respondents ( $226 \mathrm{men}, 545$ women; aged $18-67$ years, $M=32.32 \pm 12.28$ years) filled out all proposed questionnaires and were thus ultimately selected for data processing.

Ethics: The author asserts that all procedures contributing to this work comply with the ethical standards of the relevant national and institutional committees on human experimentation and with the Helsinki Declaration of 1975, as revised in 2008. All participants were informed that their participation in the study was voluntary and that they could refuse to participate in or withdraw from the study at any time. Participants were informed that there were no right or wrong answers and were encouraged to respond candidly. Complete confidentiality was assured. Only de-identified data were used in the statistical analysis. We recorded only general data about respondents, such as gender, age and profession. Participants were motivated to participate in the study by the automatic presentation of their results, which was accompanied by a psychological and professional interpretation.

Statistical analysis: The SPSS software (version 22.0.0) was used to conduct the statistical analysis. Descriptive statistics (means and standard deviations), independent sample $t$-tests and Pearson's correlation coefficient were used to analyses the data. The data were normally distributed according to the one-sample Kolmogorov-Smirnov test.

\section{RESULTS}

Both the general and gendered characteristics of the influence of occupational stress on occupation-specific 
Table I. Correlations between indicators of participants' occupational stress intensity and mental health $(\mathrm{N}=771)$

\begin{tabular}{cccccc}
\hline \multirow{2}{*}{$\begin{array}{c}\text { Indicators } \\
\text { of occupational stress }\end{array}$} & $\begin{array}{c}\text { Emotional } \\
\text { exhaustion }\end{array}$ & Depersonalisation & $\begin{array}{c}\text { Indicators of mental health } \\
\text { accomplishment }\end{array}$ & $\begin{array}{c}\text { Withdrawal } \\
\text { behaviours }\end{array}$ & $\begin{array}{c}\text { Negative affect } \\
\text { at work }\end{array}$ \\
\cline { 2 - 6 } & .46 & .45 & .54 & .38 & .60 \\
\hline $\begin{array}{c}\text { Constraints on performance } \\
\text { at work }\end{array}$ & .17 & .20 & .25 & .38 & .36 \\
\hline Workload & .34 & .28 & .35 \\
\hline Aggressive experiences & & & .38 & .35 \\
\hline
\end{tabular}

Note: $p<.001$ for all correlations.

Table Il. Comparison of the indicators of men's and women's occupational stress intensity and mental health

\begin{tabular}{|c|c|c|c|c|c|c|}
\hline \multirow{3}{*}{$\begin{array}{l}\text { Indicators of participants' occupational stress } \\
\text { intensity and mental health }\end{array}$} & \multicolumn{4}{|c|}{ Results } & \multirow{3}{*}{$\mathbf{t}$} & \multirow{3}{*}{$\mathbf{p}<$} \\
\hline & \multicolumn{2}{|c|}{ Men } & \multicolumn{2}{|c|}{ Women } & & \\
\hline & M & SD & M & SD & & \\
\hline Constraints on performance at work & 23.35 & 9.50 & 23.30 & 9.68 & .03 & - \\
\hline Workload & 12.80 & 4.77 & 14.59 & 5.54 & -2.17 & .05 \\
\hline Aggressive experiences & 70.45 & 29.56 & 70.66 & 26.40 & -.05 & - \\
\hline Emotional exhaustion & 43.95 & 25.57 & 48.89 & 26.73 & -1.45 & - \\
\hline Depersonalisation & 56.67 & 21.62 & 57.90 & 22.06 & -.43 & - \\
\hline Personal accomplishment & 41.28 & 26.39 & 46.76 & 27.21 & -1.54 & - \\
\hline Withdrawal behaviours & 26.46 & 10.89 & 26.49 & 11.60 & -.01 & - \\
\hline Negative affect at work & 21.32 & 8.68 & 22.33 & 8.68 & -.63 & - \\
\hline
\end{tabular}

Table III. Correlations between indicators of men's occupational stress intensity and mental health

\begin{tabular}{|c|c|c|c|c|c|}
\hline \multirow{2}{*}{$\begin{array}{c}\text { Indicators } \\
\text { of occupational stress }\end{array}$} & \multicolumn{5}{|c|}{ Indicators of mental health } \\
\hline & $\begin{array}{l}\text { Emotional } \\
\text { exhaustion }\end{array}$ & Depersonalisation & $\begin{array}{c}\text { Personal } \\
\text { accomplishment }\end{array}$ & $\begin{array}{l}\text { Withdrawal } \\
\text { behaviours }\end{array}$ & $\begin{array}{c}\text { Negative } \\
\text { affect at work }\end{array}$ \\
\hline $\begin{array}{c}\text { Constraints on performance at } \\
\text { work }\end{array}$ & $.48^{* * *}$ & $.38^{* * *}$ & $.61^{* * *}$ & $.66^{* * *}$ & $.53^{* * *}$ \\
\hline Workload & $.30^{* * *}$ & $.18^{* *}$ & $.40^{* * *}$ & $.29^{* * *}$ & $.32^{* * *}$ \\
\hline Aggressive experiences & $.33^{* * *}$ & $.16^{*}$ & $.46^{* * *}$ & $.48^{* * *}$ & $.38^{* * *}$ \\
\hline
\end{tabular}

${ }^{*} p<.05 .{ }^{* *} p<.01 .{ }^{* * *} p<.001$.

Table IV. Correlations between indicators of women's occupational stress intensity and mental health $(\mathrm{N}=545)$

\begin{tabular}{|c|c|c|c|c|c|}
\hline \multirow{2}{*}{$\begin{array}{c}\text { Indicators } \\
\text { of occupational stress }\end{array}$} & \multicolumn{5}{|c|}{ Indicators of mental health } \\
\hline & $\begin{array}{l}\text { Emotional } \\
\text { exhaustion }\end{array}$ & Depersonalisation & $\begin{array}{c}\text { Personal } \\
\text { accomplishment }\end{array}$ & $\begin{array}{l}\text { Withdrawal } \\
\text { behaviours }\end{array}$ & $\begin{array}{c}\text { Negative } \\
\text { affect at work }\end{array}$ \\
\hline Constraints on performance at work & $.46^{* * *}$ & $.47^{* * *}$ & $.52^{* * *}$ & $.30^{* * *}$ & $.62^{* * *}$ \\
\hline Workload & $.14^{* *}$ & $.21^{* * *}$ & $.20^{* * *}$ & $.12^{* *}$ & $.40^{* * *}$ \\
\hline Aggressive experiences & $.33^{* * *}$ & $.31^{* * *}$ & $.35^{* * *}$ & $.32^{* * *}$ & $.58^{* * *}$ \\
\hline
\end{tabular}

${ }^{* *} p<.01 .{ }^{* * *} p<.001$.

indicators of employees' mental health were determined by analyzing the correlations between indicators of participants' occupational stress intensity and their mental health. The correlations obtained for the sample are presented in Table I.

The data show significant correlations $(p<.001$; $r=.16-.60)$ between all occupational stress indicators and all mental health indicators. The indicators of negative mental health were most strongly correlated with the occupational stress indicator constraints on performance at work $(r=.38-.60)$. Aggressive experiences $(r=.28-.55)$ had weaker correlations, and workload $(r=.16-.25)$ had the comparatively weakest correlations.

Before comparing correlations between indicators of occupational stress and mental health in men and women, we compared all indicators for these two subsamples (Table II). This comparison showed that indicators of occupational stress and mental health did not differ significantly between 
men and women except for workload, which was slightly higher in women $(p<0.05)$.

Correlations between the indicators of men's and women's occupational stress and mental health are presented in Tables III and IV.

The results show that constraints on performance at work were much more strongly correlated with withdrawal behaviors in men $(r=.66)$ than in women $(r=.30)$. In addition, workload's correlations with emotional exhaustion ( $r=.30$ vs $r=.14$ ), personal accomplishment ( $r=.40$ vs $r=.20)$ and withdrawal behaviors $(r=.29$ vs $r=.12$ ) were twice as strong in men than in women. In turn, the correlations of aggressive experiences with depersonalization $(r=.31$ vs $r=.16)$ and negative affect at work $(r=.29$ vs $r=.12$ ) were significantly stronger in women than in men.

\section{DISCUSSION}

The results show that occupational stress had a significant negative influence on occupation-specific indicators of employees' mental health, as evidenced by the strong significant correlations $(p<.001 ; r=.16-.60)$ among all three occupational stress indicators used in the study and all five occupation-specific indicators of negative mental health. The occupational stress indicator with the greatest negative influence on employees' mental health was constraints on performance at work. Aggressive experiences had somewhat less influence, and workload had comparatively the least.

In general, these results are quite expected. A study by Malik N. A. and Björkqvist K. [12] revealed that the occupational stress indicator of workplace bullying had a significant effect on stress symptoms. Wilke D. J. et al. [24] reported occupational stress effects for child welfare workers including deteriorated physical and emotional well-being. Monteiro S. et al. [6] found, as in our study, that occupational stress had a sorely negative impact on journalists. Ukil M. I. and Ullah M. S. concluded [2] that occupational stress had a significant negative impact on bank employees' life satisfaction and work-life balance, as well as job performance and job satisfaction. The only somewhat unexpected result in our study was that all three examined occupational stress indicators had significant negative influences on all five mental health indicators.

In addition, our findings revealed that, although there were no differences between men and women in the indicators assessed in our study, the influence of occupational stress on employees' mental health had quite pronounced gendered characteristics. Among men, constraints on performance at work caused withdrawal behaviors and higher workload caused emotional exhaustion, personal accomplishment and withdrawal behaviors to a much greater extent (twice as much or higher) than in women. Among women, aggressive experiences were significantly more likely to cause depersonalization and negative affect at work than in men. Regarding gender differences in occupational stress, we can refer only to a study by Carvalho V. S. et al. [17], which revealed that work-family conflict was more likely to cause deterioration in mental health for women than for men.

The results obtained in our study convincingly demonstrate the need for effective measures to prevent causes of occupational stress (for example, constraints on performance at work, aggressive experiences and workload) that consequently damage employees' mental health. Studies by Monteiro S. et al. [6], Chitra T. and Karunanidhi S. [25] and Brough P. and Boase A. [26] have yielded similar recommendations.

In this context, Demou E et al. [11] have noted that workplace interventions to protect employees' mental health should be implemented not only at the organizational level, targeting working conditions and policies, but also at the individual level, through programmes on stress management and skills training that can provide employees with the tools and resources to cope with work-related problems. In particular, a promising area for such workplace interventions is measures aimed at strengthening employees' hardiness [27]. However, only a few studies have been conducted in this area (related to strengthening the hardiness of service members $[28,29]$ and police officers [25]), so this question remains quite open.

\section{CONCLUSIONS}

Our study showed that occupational stress had a significant negative influence on all occupation-specific indicators of employees' mental health. This influence had pronounced gendered characteristics. Constraints on performance at work had the greatest influence, aggressive experiences a somewhat weaker influence and workload comparatively the least influence. The obtained results convincingly demonstrate the need for effective measures to prevent occupational stress. A promising area for workplace interventions is measures to strengthen employees' hardiness.

\section{REFERENCES}

1. Nakao M. Work-related stress and psychosomatic medicine. BioPsychoSocial Medicine. 2010;4:4-11. doi: 10.1186/1751-0759-4-4.

2. Ukil M.I., Ullah M.S. Effect of occupational stress on personal and professional life of bank employees in Bangladesh: Do coping strategies matter. Journal of Psychological and Educational Research. 2016;24(2):75-100.

3. Yousaf S., Rasheed M.I., Hameed Z. et al. Occupational stress and its outcomes: the role of work-social support in the hospitality industry. Personnel Review. 2020;49(3):755-773. doi: 10.1108/ PR-11-2018-0478.

4. Moreno Fortes A., Tian L., Huebner E.S. Occupational stress and employees complete mental health: a cross-cultural empirical study. International journal of environmental research and public health. 2020;17(10):3629. doi: 10.3390/ijerph17103629.

5. Karasek R., Theorell T. Healthy work: Stress, Productivity, and the Reconstruction of Working Life. New York: Basic Books. 1990, 102p.

6. Monteiro S., Marques P.A., Roberto M.S. Job demands, coping, and impacts of occupational stress among journalists: A systematic review. European Journal of Work and Organizational Psychology. 2016;25(5):751-772. doi: 10.1080/1359432X.2015.1114470. 
7. Akerstrom M., Corin L., Severin J. et al. Can working conditions and employees\&apos; mental health be improved via job stress interventions designed and implemented by line managers and human resources on an operational level? International Journal of Environmental Research and Public Health. 2021;18(4):1916. doi: 10.3390/ijerph18041916.

8. Simoni P.S., Paterson J.J. Hardiness, coping, and burnout in the nursing workplace. Journal of Professional Nursing. 1997;13(3):178-185. doi: 10.1016/S8755-7223(97)80069-5.

9. Chan D.W. Hardiness and its role in the stress-burnout relationship among prospective Chinese teachers in Hong Kong. Teaching and Teacher Education. 2003;19(4):381-395. doi: 10.1016/50742051X(03)00023-4.

10. Azeem S.M. Personality hardiness, job involvement and job burnout among teachers. International Journal of Vocational and Technical Education. 2010;2:36-40.

11. Demou E., Hale H., Hunt K. Understanding the mental health and wellbeing needs of police officers and staff in Scotland. Police practice \& research: an international journal. 2020;21(6):702-716. doi: 10.1080/15614263.

12. Malik N.A., Björkqvist K. Workplace bullying and occupational stress among university teachers: mediating and moderating factors. Europe\&apos;s Journal of Psychology. 2019;15(2):240-259. doi: 10.5964/ejop.v15i2.1611.

13. Flaherty M.P., Sikorski E., Klos L. et al. Peacework and mental health: From individual pathology to community responsibility. Intervention. 2020;18(1):28-36. doi: 10.4103/INTV.INTV_59_18.

14. Kokun 0., Bakhmutova L. Dynamics of indicators of expeditioners' psvcholooical states during long Antarctic stay. International Journal of Psychology \& Psychological Therapy. 2020;20(1):5-12.

15. Kokun 0., Agayev N., Pischko I. et al. Characteristic impacts of combat stressors on posttraumatic stress disorder in Ukrainian military personnel who participated in the armed conflict in eastern Ukraine. International Journal of Psychology \& Psychological Therapy. 2020;20(3):315-326.

16. Martin A., Karanika-Murray M., Biron C. et al. The psychosocial work environment, employee mental health and organizational interventions: improving research and practice by taking a multilevel approach. Stress and Health. 2016;32(3):201-215. doi: 10.1002/smi.2593.

17. Carvalho V.S., Chambel M.J., Neto M. et al. Does work-family conflict mediate the associations of job characteristics with employees mental health among men and women?. Frontiers in Psychology. 2018;9:966. doi: 10.3389/fpsyg.2018.00966.

18. Vus V., Omelchenko L. Interdependent: mental health, social development, youth' socially oriented activity (on the example of a country in transition). Mental Health: Global Challenges Journal. 2018;1(1):86. doi: 10.32437/mhgcj.v1i1.37.

19. Spector P.E., Jex S.M. Development of four self-report measures of job stressors and strain: Interpersonal Conflict at Work Scale, Organizational Constraints Scale, Quantitative Workload Inventory, and Physical Symptoms Inventory. Journal of Occupational Health Psychology. 1998;3(4):356-367. doi: 10.1037/1076-8998.3.4.356.

20. Glomb T.M., Liao H. Interpersonal aggression in work groups: Social influence, reciprocal, and individual effects. Academy of Management Journal. 2003;46(4):486-496. doi: 10.2307/30040640.

21. Maslach C., Jackson S.E., Leiter M.P. Maslach Burnout Inventory manual (4th ed.). Menlo Park: Mind Garden, Inc.. 2017, 245p.
22. Mitchell M.S. Understanding Employees Behavioral Reactions to Aggression in Organizations (Doctoral dissertation). Orlando: University of Central Florida. 2006, 413p.

23. Watson D., Clark L.A., Tellegen A. Development and validation of brief measures of positive and negative affect: the PANAS scales. Journal of Personality and Social Psychology. 1988;54(6):1063-1070. doi: 10.1037//0022-3514.54.6.1063.

24. Wilke D.J., Randolph K., Olson C. Examining occupational stress in early-career child welfare workers. Journal of Workplace Behavioral Health.. 2020;35(3):158-174. doi: 10.1080/15555240.2020.1807354

25. Chitra T., KarunanidhiS. The impact of resilience training on occupational stress, resilience, job satisfaction, and psychological well-being of female police officers. Journal of Police and Criminal Psychology. 2018;36:8-23. doi: 10.1007/s11896-018-9294-9.

26. Brough P., Boase A. Occupational stress management in the legal profession: Development, validation, and assessment of a stress-management instrument. Australian Journal of Psychology. 2019;71(3):273-284. doi: 10.1111/ajpy.12244.

27. Kobasa S., Hilker R.R.J., Maddi S. Who stays healthy under stress? Journal of Occupational Medicine. 1979;21(9):595-598.

28. Escolas S.M., Pitts B.L., Safer M.A. et al. The protective value of hardiness on military posttraumatic stress symptoms. Military Psychologyю 2013;25(2):116-123. doi: 10.1037/h0094953.

29. Hystad S.W., Olsen 0.K., Espevik R. etal. On the stability of psychological hardiness: a three-year longitudinal study. Military Psychology. 2015;27(3):155-168. doi: 10.1037/mil0000069.

\section{ORCID and contributionship:}

Sergii Maksymenko: 0000-0002-3592-4196

Oleg Kokun: 0000-0003-1793-8540

Iegor Topolov: 0000-0002-1312-249 B,D,E,F

Olena Nemesh: 0000-0001-8620-3279 C,D,F

Maureen Flaherty: 0000-0003-0234-0095 E,F

\section{Conflict of interest:}

The Authors declare no conflict of interest.

\section{CORRESPONDING AUTHOR Oleg Kokun \\ G.S. Kostiuk Institute of Psychology \\ 2 Pankivska st., 01033 Kyiv, Ukraine \\ tel: +380677993520 \\ e-mail: kokun@ukr.net}

Received: 01.06 .2021

Accepted: 14.10 .2021

A - Work concept and design, B - Data collection and analysis, C - Responsibility for statistical analysis,

D-Writing the article, E-Critical review, $\mathbf{F}$ - Final approval of the article 


\title{
SOCIAL WORKERS'ACTIVITIES IN THE FIELD OF POPULATION' MENTAL HEALTH PRESERVATION IN THE XXI CENTURY
}

DOI: 10.36740/WLek202111125

\author{
Liliia Y. Klos ${ }^{1}$, Mariana V. Shkoliar', Sofiya G. Stavkova', Olena P. Kokhanova² \\ 'LVIV POLYTECHNIC NATIONAL UNVERSITY, LVIV, UKRAINE \\ 2BORYS GRINCHENKO KYIV UNIVERSITY, KYIV, UKRAINE
}

\begin{abstract}
The aim: Social work is focused on overcoming inequality and social isolation of individuals and communities due to health conditions. Therefore, substantiating the activities of social workers to preserve mental health of citizens is an important component of the new strategy for the development of the profession in the XXI century.

Materials and methods: The methodological basis of the study is a holistic approach to the interpretation of individual health in the unity of physical, mental, social, and spiritual components; ecosystemic approach assumes the impact of the environment on the social functioning of the individual; interdisciplinary approach identifies ways of dealing withmental health challengein the global context; social inclusion approach provides a basis for the practice of experts of the social spherein the XXI century.

Conclusions: The article substantiates the need for social workers to maintain the mental health of the population under the negative impact of global factors within their own countries and internationally. The evolution analysis of the international experience of transformations of social work practice in the area of mental health preservation is carried out. Preserving the mental health of citizens under the negative effects of globalization processes depends on the concerted actions of states, international organizations, civil society, communities, and individuals themselves. This encourages social workers to work at regional and international levels with institutions interested in fair policies and practices in social and health services.
\end{abstract}

KEY WORDS: mental health, social work, globalization, inequality, social inclusion

Wiad Lek. 2021;74(11 p.l):2823-2828

\section{INTRODUCTION}

One of the most typical areas of employment for social work professionals is the area of mental health, including in psychiatric care, along with being involved in the field of healthcare in general. This situation is typical for the United States, Canada, Great Britain, Australia, Israel and a number of European countries, where social work is a well-developed professional activity. The relevant statistics on the situation in the United States can be considered an example of the growing role of social workers in mental healthcare particularly in the context of globalization. A 1982 survey of members of the National Association of Social Workers (NASP) showed that mental health practices were among the largest, with nearly 90,000 employees (26.6\%). The second-largest involvement of social workers is in the field of somatic or physical health where $18.1 \%$ were found, totally almost $45 \%$ of NASP members involved in health care overall[1].

1995 NASP data show that the number of social workers in the mental health area increased to $39 \% ; 12.9 \%$ association members indicated medical institutions as the place of their main practice. This gave reason to consider the health sphere the third largest after the sphere of services to families and children, among $24.9 \%$ of the surveyed members of NASP. At the beginning of 2000, the number of social workers - members of NASP, who recognized the field of health as a place of their main practice, was already $47 \%$ of the total[2]. According to the American Hospital Association (2002), in 2000, 76\% of psychiatric hospitals and $86 \%$ of general emergency hospitals reported the existence of social services in their structures. In January 2005 , almost $40 \%$ of the NASP members self-identified as mental health social workers; $8 \%$ as healthcare workers [3].

Today, in the United States, the healthcare sphere is important both at the clinical/individual level and at the macro level. According to the Bureau of Statistics of the US Department of Labor, for the period from 2014 to 2024, the employment of social workers is expected to increase by $12 \%$, exceeding the average growth rate for all professions (7\%). An increase of $19 \%$ is expected in employment for social and mental healthcare workers, in particular, especially for those who provide services to people with addictions [4].

The first social worker in the psychiatric ward of Massachusetts General Hospital appeared in 1903, so the United States can be considered the "home" of social work in the area of mental health. From the second half of the XXth century, the US was the first in the world at the legislative level to recognize the activities of mental health social workers as professionals of a separate professional field. The US public movement "For Civil Rights" in the 1960s made it possible to reorient hospital social work to the needs of 
the community, ensure the "socialization of psychiatry", and provide social rehabilitation services to people with mental health disorders $[5,6]$.

Since then, different countries have built and developed their own system of training and interaction of mental health professionals. Current trends in world development, including the transparency of European borders and the acquisition of English as a universal tool for professional communication, have led to mutual influences and transformations, active borrowing from, and permanent review of the effectiveness of mental healthcare systems.

\section{THE AIM}

Social work is focused on overcoming inequality and social isolation of individuals and communities due to health conditions. Therefore, substantiating the activities of social workers to preserve mental health of citizens is an important component of the new strategy for the development of the profession in the XXI century. This social work focusis necessary to combat the challenges that deepen health inequalities and social exclusion at the level of individuals, communities, and countries.

\section{MATERIALS AND METHODS}

The methodological basis of the study is a holistic (biopsychosocial-spiritual) approach to the interpretation of individual health as the unity of physical, mental, social, and spiritual components, where the mental component depends largely on social conditions; an exosystemic approach considering the impact of the environment (in a broad sense) on the social functioning of the individual; an interdisciplinary approach in identifying ways and means of solving the problem of mental health disorders in the context of increasing globalization impacts and their negative consequences for mental health; a social inclusion approach, opposing social exclusion, is seen as the basis of practice for social sphere professionals in the XXI century. This approach considers the need to change environmental conditions to adapt them to the needs of people with mental health disorders.

The method of critical review of the literature is used. Sources reflecting the participation and contribution of social workers in maintaining mental health of citizens (publications in scientific periodicals, including those indexed by scientometric databases Scopus, WoS, etc., monographs, collections of scientific papers, conference proceedings, etc.) were considered. Literature was searched and selected on the basis of keywords (social workers, mental health, globalization, social work development, health inequalities). Mostly English sources, as well as materials from the Ukrainian context published in the last 20 years of the XX and XXI centuries were taken into account. Various documents governing the assistance of persons with mental health disorders were used as important resources, in particular reports of international social workers organizations, official documents and regulations of national professional organizations of social workers, and the World Health Organization documents.

\section{REVIEW AND DISCUSSION}

Today WHO defines mental health as a state of well-being in which all people can realize their potential, cope with life stresses, work productively and fruitfully, and contribute to the life of their community. Globally, mental health disorders account for a significant proportion of morbidity and are a major public concern. This is due to the close connection between mental health and macro-social problems, such as poverty, unemployment, lack of social protection, etc. Reflexively, mental health problems have a complex relationship with the economic, social, educational systems, social exclusion trends, and stigmatization of people with mental health disorders. With this in mind, the world community is now actively focused on developing modern approaches to maintaining and improving the population mental health [7].

Numerous epidemiological studies in most countries show major mental health disorders such as depression, schizophrenia, bi-polar disorder, dementia in 5-7\% of the world population; another $15-23 \%$ have borderline mental and behavioral disorders, among which the most common are alcoholism, drug abuse etc. The WHO predicts a further increase in the number of mental illnesses; in the third decade of the XXI century, they will be in the top five diseases, accounting for almost half of all diseases [8].

In modern conditions, when people lives are under constant stress and the impact of unforeseen circumstances, such as military conflicts, man-made disasters, climate change, environmental violations, "mental health of individuals...requires constant attention and needs the most recognition [7]. At the same time, social workers see mental health as part of a holistic health strategy, which is an integral part of building community resilience in overcoming difficulties and challenges towards sustainable development and well-being.

2004 can be considered the beginning of the process of forming a new strategy of social work in the XXI century, when the leadership of the International Federation of Social Workers (IFSW), the International Association of Schools of Social Work (IASSW) and the International Council on Social Welfare (ICSW) concluded the need for changes in everyday social work practice in the XXI century as a response to globalization challenges. Joint research in this area, presented in professional publications [9] and on the websites of international professional organizations of social workers during 2008 - 2012, made it possible during the great financial and social crisis to develop a common platform for action by the world social work community together with the UN, WHO and other interested bodies. This was also facilitated by several international events that identified the key provisions of the Global Strategy for Social Work in the New Environment: the IFSW General Meeting (Brazil, 2008) approved the final "Health and Disease" document; the IASSW, IAASW, and ICSW World 
Conference in Hong Kong (2010) in support of global change initiatives sustained the first report "Promoting Socio-Economic Equality" [10], the tripartite meeting in Ghana (2011) set out a "New Agenda for Social Work".

This decision was preceded by a report by the World Commission on the Social Consequences of Globalization, established in 2002 at the initiative of the International Labor Organization. The main conclusion of the report "Fair globalization: creating opportunities for all" (2004) was to recognize the enormous potential of globalization, which requires immediate direction in a fair direction. This means that deep and persistent inequalities in achieving prosperity are growing between and within countries as well as between groups of people. According to the members of the Commission, "fair" globalization means creating real opportunities for most people and countries. To do this, globalization processes need to be more balanced and based on democratic regulations, strong social dimensions, rest on the principles and values recognized by the international community.

In the report of the UN Department of Economic and Social Affairs "Global Social Crisis" (2011), all the problems identified in 2004 were re-identified. This confirmed the growing negative impacts of globalization on the social sphere and public health, especially mental health. It strengthened the resolve to develop a new social work strategy, where the key place is given to the global responsibility for individual health, including mental health, as described by the social determinants of health[7].

The statement «Health and Disease» identified an important step in this direction for healthcare in social work [11]. This statement reaffirmed IFSW emphasis on the equal right of all people to enjoy basic social conditions for health, including a minimum standard of living to maintain good health and a sustainable, health-promoting environment for living. As all people have an equal right to access healthcare resources and social services aimed at preventing illness, injury, and disorder, IFSSW commits to work towards realizing these universal rights, upholding social justice in health matters in social policy.

Social workers consider health as a vital resource. Therefore, working with people to maximize their opportunities, is recognized as a requirement of social workers daily practice. IFSW experts substantiate three main reasons for recognizing all social work as a healthy activity as follows. First, almost all people have already experienced health problems in different countries or are at risk due to social conditions. Second, every day social workers provide services to meet basic health needs - social determinants (ensuring adequate income, well-being, adequate quality of housing, safe working conditions, safe and sustainable living environment, supportive personal and social relations). Third, social workers fulfil their duties to make it easier for people to reap the full benefits of effective health (care) through performing appropriate roles in health care facilities, work under the guidance of healthcare professionals in interdisciplinary and transdisciplinary health teams.
Based on this, IFSW recognizes the issue of health as a matter of respect for fundamental human rights and social justice, which obliges social workers to apply these principles in policy, education, research, and practice. Social workers acknowledge the two basic values of social work for equal rights of all people to: 1) access social conditions to ensure human health, is the social determinants of health; 2) access services and other resources for health promotion, prevention, treatment or disease management.

The Commissionon Social Determinants of Health(CS$\mathrm{DH}$ ) at the WHO Regional Office for Europe (WHO/Europe), prompted by the Concepts and principles of equity and health and the European strategies for tackling social inequities in health [12], considers achieving equity in matters of public health as the most important and fundamental in the healthcare activities of both social workers and professionals in other specialties. The issue of maintaining the mental health of the population is officially recognized by the UN and WHO as a problem that requires, for solution, an interdisciplinary and cross-sectoral approach. The main recommendations of the CSDH relate to improving the conditions of everyday life; solving the problem of unfair distribution of power, money, and resources.

Health inequalities are the result of the influence of social determinants of health: the social conditions in which people are born, grow, live, work and age; experience of health at an early age; education; economic situation; professional employment, relevant work; housing; environment; effective systems for the prevention and treatment of ill health. These determinants are crucial for the formation of inclusive, equitable, economically productive and healthy communities. Positioning human health and well-being as key features of a successful, inclusive, just society in the XXI century meets high human rights standards at both national and international levels $[13,14]$.

The conceptual principles of social work in the issues of preserving public health in the context of transformations of the social sphere in the XXI century were highlighted. They include: overcoming striking health inequalities between developed and developing countries; promoting economic and social development to achieve a higher level of health for all; encouraging individuals to protect their health as a means of promoting sustainable economic and social development, improving the quality of life and achieving peace and prosperity in the world; acknowledging the preservation of public health as a duty of governments and not an exclusive area of market relations or individual responsibility; participation in individual and collective health decisions as a right and responsibility of everyone [11].

The latter principle means not only the possibility for a person to decide the "fate" of own health but also the responsibility to improve access to services or living conditions. Significant changes in addressing health inequalities can be achieved through participation and empowerment as a way to realize human rights at the global, national, and local levels [15].

IFSW representatives believe that to overcome health inequalities, social work must increase its effectiveness at the political level in working with international, govern- 
mental, and non-governmental organizations committed to work for health development. Therefore, it is necessary to interact with social movements that advocate for reform and improvement of health care and individual health. Examples are the Public Health Movement, the Global Forum for Health Research (GFHR), and the World Social Forum. Cooperation requires a change of approach in the activities of IFSW in the context of globalization. A common problem is the lack of social services that promote the health of individuals, families, and communities in clinics and hospitals. People are not able to access social services "at the point of need". Limited social work and social service resources lead to rationing and, thus, to the unfair distribution of scarce resources. Consequently, the IFSW needs to increase access to social work services in the field of health and, above all, mental health, in all places of practice.

The IFSW has identified the most important steps in the implementation of the social work strategy to preserve and strengthen the health of the population, and above all, mental health in the XXI century: 1)to identify and challenge, at all levels any harmful effects of social policy on health, advocating a policy of strengthening, protecting and preserving health; in this regard, to involve social workers in the main place of work in medical institutions; 2) to rely on a holistic understanding of health and a healthy personality in decision-making in both practice and policies; 3 ) to realize that health is a key aspect of life the preservation of which requires great effort on the part of the individual and the supportive efforts of social workers 4) to acknowledge health is a fundamental human right, with the role of social workers to assist individuals to achieve it ensure universal access to basic health resources and poverty eradication; 5) to acknowledge health depends on social, economic, environmental, and political conditions with associated inequalities and injustices which social workers are ethically bound to work to eradicate; 6) to acknowledge that health depends on local, national and global social policies and practices, necessitating the universalization of primary health care services. In short, maintaining good health depends on concerted actions of states, international organizations, civil society, and the people themselves and motivates social workers to cooperate with international, governmental, non-governmental, and public structures interested in fair policies and practices of social and medical services and involvement people to participate in planning and evaluation of health services.

Negative consequences of globalization lead to other social problems, the solution of which requires the professional intervention of social workers at the macro, mezzo, and micro levels of practice. The final document of the Joint World Conference on Social Work and Social Development (Hong Kong, 2010) - "The Global Agenda for Social Work and Social Development" - presented prospects for the development of the sphere through dialogue between global, regional, and local organizations, which helped identify priorities and action plans for the new conditions. The document identifies the need for new methods of activity, which does not mean abandoning the traditional principles of social work: on the contrary, it requires their active use at all levels [15]. The interrelationship and interdependence of issues of training in the field of social work, practical activities, and sustainable social development were recognized as unchanged.

In the wake of global transformations, social workers at the international level are working to ensure fair and decent standards of well-being for the world population. They recognize that for many people, opportunities for social mobility and full realization of their potential are beyond their own control, and are related to such as factors heredity, place of birth, and access to resources. Social workers realistically assess social constraints and are optimistic about human potential [10]. Respect for human dignity and rights remains the core of the social workers activities, despite the reality that often demonstrates social injustice. Practical experience and research as an integral part of social work practice show that people systems and lifestyles can be changed for the better, and "together we can create a better world". This conviction has been the driving force behind their efforts to shape the Global Agenda for Social Action and Social Development. This will help to address the challenges posed by the global change that perpetuates poverty, oppression, inequality of opportunity, and access to resources [16].

The final consultations on global transformations of social action and social development took place in the form of a tripartite meeting of IFSW, IASSW, and ICSW representatives in Ghana in 2011. This meeting adopted a new Social Work Platform, defining common commitments and determination to promote social justice in the XXI century. Representatives of the three international social workers organizations came to a common conclusion on the state of affairs in the social sphere and noted the following:1) the full range of human rights is available only to a minority of the world population; 2) unjust and poorly regulated economic systems driven by unaccountable market forces, non-compliance with international labor standards and a lack of corporate social responsibility have damaged the health and well-being of peoples and communities, increasing poverty and inequality;3)realization of the rights to cultural diversity and self-expression that contribute to the full intellectual, emotional, moral, and spiritual life of people are threatened by globalization; 4 ) this leads to the "standardization" and marginalization of entire peoples, influences that have especially devastating consequences for indigenous people and representatives of "first nations"; 5 ) the prosperity of people is possible in communities by maintaining relations that in the context of globalization are broken under the influence of dominant economic, political and social forces; 6 ) human health and well-being are affected by inequalities and fragile environments related to climate change, pollutants, hostilities, natural disasters, and violence. Finally, the reaction of the international community is inadequate [15].

Recognizing these realities, representatives of international social work organizations have formulated the 
main tasks for the agenda. Among their top priorities are the issue of healthy social development, the solution of which relates to strong and resilient communities. Achieving this will be facilitated by the stable well-being and strengthening of the role of social work practitioners in improving and strengthening communities. Activities aimed at eliminating the root causes of poverty and oppression and changing social conditions to those that truly ensure respect for human rights and dignity have not been overlooked. The international community of $t$ social workers advise that the path to such changes is through strengthening the role of education and training of social workers, creating an appropriate working environment for effective and ethical practice, coordination of research and activities to improve them [15].

The official presentation of the "Global Agenda for Social Work and Social Development: Commitment to Action" took place during the regular session of the UN General Assembly (03.2012). With this document, IASSW, IFSW, and ICSW set out a strategy for implementing the new Agenda, including a commitment to establish a global network of regional Agenda Support Centers and conducting research on conditions beneficial to positive outcomes in social work and social development. The Stockholm World Conference on Social Work focused on the implementation of the Agenda and the choice of specific action strategies [17]. The document emphasizes the importance of understanding the concept and notion of social work and confirms its characteristic functions, namely social integration and combating failures in other areas of social policy, such as crime, healthcare, education $[18,19]$.

It is worth remembering that the ethical and moral duty of every social worker is to realize the importance of personal practical experience, inform policy development, set priorities by interacting with global and regional political institutions; emphasize the contribution of social work to social development, especially during discussions on the Millennium Development Goals, health inequalities [20], social protection, or the preservation of the physical environment [9] as global issues.

A limitation of this study is that it took into account mainly the experience of social workers activities in the United States, Canada, and the United Kingdom of Great Britain, as countries with a high level of social work in general, and social work in the field of mental health in particular. The peculiarities of the introduction of social work in the field of mental health in the post-Soviet countries have not been studied. These issues in comparison with the Ukrainian experience will be the subject of our further study

\section{CONCLUSIONS}

The globalization processes of the XXI century increase differences and inequalities between people and countries in their ability to achieve health, especially mental health as well-being. This is due to unfair allocation of resources or the inability to use one own health potential. Thus, social work in the area mental health is one of the current areas of development of the sphere, and many challenges for mental health are associated with the impact of unpredictable rapidly changing circumstances. International experience confirms that solving these problems is within the realm of social workers, who can play a spectrum of important roles.

Social workers play roles not only as health managers, coordinators of interaction between different professionals, "health instructors", and liaisons between a person with mental health disorders and the environment. They can also be agents of change and lobbyists of policies aimed at the development of mental health in the community. In particular, social workers can be more active and increase their effectiveness at the political level in cooperation with international, governmental, and non-governmental organizations in the healthcare sector, which will help to address the global challenges of poverty, oppression, inequality, and access to resources.

The need for the practical involvement of social workers in maintaining mental health has increased especially during the COVID-19 pandemic. The vast majority of the population has experienced the negative impact of both illness and quarantine on mental health of themselves or loved ones. This applies not only to people who have already had problems with, for example, substance abuse or previously diagnosed mental illness, but also to anyone who has experienced an infection or is at risk of becoming ill, or is experiencing the effects of a previous illness, or worse, witnessed the fatal outcome of the disease caused by COVID-19. Social workers should be the ones to help return to a "habitual", "normal" life without quarantine, fear of getting sick or dying, anxiety about relatives, pain of loss and limitations. They should help to restore the social inclusion of all citizens as a guarantee of preventing health inequalities and any social dysfunctions. Therefore, social workers should become an integral part of the health team - an interprofessional group of experts who provide care to patients with COVID-19 and also carry out preventive measures. In modern Ukrainian conditions such teams should work in family medicine clinics, educational institutions, and in production.

\section{REFERENCES}

1. National Task Force on the Preparation and Practice of Health Educators. A Framework for the Development of Competency-Based Curricula. New York: National Task Force. 1985, 123p.

2. Cowles L. A. Social Work in the Health Field. A Care Perspective (2nd ed.). New York - London: Oxford. 2003, 306p.

3. NASW Fact Sheet. The National association of social workers. 2006, $35 \mathrm{p}$.

4. United States. Bureau of Labor Statistics. Occupational Outlook Handbook. Social Workers. 2016. URL: https://www.bls.gov/ooh/ community-and-social-service/social-workers.htm. [date access 12.09.2020]

5. Grinker R., MacGregor H., Selan K. et al. Early years of psychiatric social work. Social Service Review. 1961;35: 111-126;

6. Klos L. On Solving the Problem of Mental Health Care with the Social Work Input. Mental Health: Global Challenges Journal. 2018; 1: 32-37. doi: 10.32437/mhgcj.v1i1.16. 
7. Flaherty M. P., Sikorski E., Klos L. et al. Peace work and mental health: From individual pathology to community responsibility. Intervention, Journal of Mental Health and Psychosocial Support in Conflict Affected Areas. 2019; 18 (1): 28-36. doi: 10.4103/INTV.INTV_59_18.

8. World Health Organization. Policy and practice on mental health in Europe struggle with difficulties, WHO Regional Office for Europe, Copenhagen, Denmark. 2019. https://www.euro.who.int/__data/ assets/pdf_file/0006/96450/E91732.pdf [date access 12.09.2020]

9. Jones D., Yuen A., Rollet C. Rising to the Global Challenge: IASSW, ICSW and IFSW Join Hands to Build an Agenda for the Next Decade, International Social Work. 2008; 51(6): 847-849.

10. DePanfilis D., Zlotnik J. L. Retention of Front-line Staff in Child welfare. A Systematic Review of Research, Children and Youth Services Review. 2008; 30: 995-1008.

11. The Social Work and Health Inequalities Network. 2010. http://cdn.ifsw. org/ assets/ifsw_84833-10.pdf. [date access 12.09.2020]

12. Whitehead M., Dahlgren G. European strategies for tackling social inequities in health: Levelling (P. 2; 3).Copenhagen:WHO Collaborating Centre for Policy Research on Social Determinants of Health; University of Liverpool: Studies on social and economic determinants of population health. 2007, 405p.

13. laremenko 0. Formuvannia zdorovoho sposobu zhyttia molodi: problemy i perspektyvy. [Formation of a healthy lifestyle of young people: problems and prospects]. Kyiv: Ukrainskyi in-t sotsialnykh doslidzhen. 2000, 68p. (In Ukrainian)

14. Ministry of Health and Social Policy. Moving forward equity in health: monitoring social determinants of health and the reduction of health inequalities: An independent expert report commissioned through the Spanish Presidency of the EU. 2010. http://www.msssi. gob.es/profesionales/salud Publica/ prev Promocion/ promocion/ desigualdadSalud/PresidenciaUE_2010/ conferencia Expertos/docs/ haciaLa EquidadEnSalud_en.pdf [date access 12.09.2020]

15. International Federation of Social Workers. Hong Kong Agenda Consultation Papers to Build The Global Action Agenda. 2010. http:// www.ifsw.org/ p38001915. html. [date access 12.09.2020]

16. Jones D., Truell R. The Global Agenda for Social Work and Social Development: A place to link together and be effective in a globalized world. International Social Work. 2012; 55(4): 454-472.

17. Stockholm World Conference. Social Work and Social Development 2012: Action and Impact. 2012. http://www.swsd-stockholm-2012.org [date access 12.09.2020]
18. Asquith S., ClarkC., Waterhouse L. The Role of the Social Worker in the 21st Century - A Literature Review. Edinburgh: Scottish Executive. 2005, 74p.

19. Payne M. Which Hats Fit? Approaches to Definitions of Social Work. Community Care. 2006: 26,:34-35.

20. Bywaters P., McLeod E., Napier L. Social Work and Global Health Inequalities: Practice and Policy Developments. Bristol: The Policy Press. $2009,62 p$.

The work is a fragment of the research project "Research Initiatives and Practical Implementation of Social and Political Projects to Resolve Social Problems of Modern Ukraine», state registration No. $0118 \mathrm{U} 000886$.

\section{ORCID and contributionship:}

Liliia Y. Klos: 0000-0001-9972-7450 A, B, D, E

Mariana V. Shkoliar: 0000-0002-8407-4394 ${ }^{\text {A, F }}$

Sofiya G. Stavkova: 0000-0002-0467-6433 B,D,F

Olena P. Kokhanova: 0000-0003-4019-3663 E, F

\section{Conflict of interest:}

The Authors declare no conflict of interest.

\section{CORRESPONDING AUTHOR \\ Liliia Y. Klos}

Lviv Polytechnic National University

12 Bandera St., 79013 Lviv Ukraine

tel:+380506847731

e-mail: liliia.y.klos@lpnu.ua

Received: 20.05.2021

Accepted: 11.10 .2021

A - Work concept and design, B - Data collection and analysis, C - Responsibility for statistical analysis, D-Writing the article, $\mathbf{E}$ - Critical review, $\mathbf{F}$ - Final approval of the article 


\title{
THE BONE-BRAIN AXIS? BIOPSYCHOSOCIAL ASPECTS OF ORTHOPEDICS AND A MENTAL WELLBEING ACTION PLAN IN MUSCULOSKELETAL CARE
}

DOI: 10.36740/WLek202111126

\author{
Christos Tsagkaris ${ }^{1}$, Andreas S. Papazoglou' ${ }^{2}$ Iryna B. Romash ${ }^{3}$, Dimitrios V. Moysidis ${ }^{4}$, Ivan R. Romash ${ }^{3}$, \\ Luiza Gabunia ${ }^{5}$, Taras Gorbatiuk ${ }^{6}$ \\ 'UNIVERSITY OF CRETE, HERAKLION, GREECE \\ ${ }^{2}$ ATHENS NAVAL HOSPITAL, ATHENS, GREECE \\ ${ }^{3}$ IVANO-FRANKIVSK NATIONAL MEDICAL UNIVERSITY, IVANO-FRANKIVSK, UKRAINE \\ ${ }^{4}$ ARISTOTLE UNIVERSITY OF THESSALONIKI, THESSALONIKI, GREECE \\ ${ }^{5}$ TBILISI STATE MEDICAL UNIVERSITY, TBILISI, GEORGIA \\ ${ }^{6}$ NATIONAL UNIVERSITY OF LIFE AND ENVIRONMENTAL SCIENCE OF UKRAINE, KYIV, UKRAINE
}

\begin{abstract}
The aim: To review the biopsychosocial aspects of psychiatric comorbidity in patients with musculoskeletal conditions and recommend a relevant mental health action plan. Materials and methods: Keywords (orthopedics, psychiatry, mental health) were used to list down and analyze the literature in PubMed and Google Scholar. All types of articles, including original research, systematic reviews, and meta-analyses, along with gray literature dating back to 2000 . We excluded studies reporting a significant conflict of interest and findings dispersed through popular media instead of peer-reviewed journals.

Conclusions: The biopsychosocial aspects of the "bone - brain axis" need to be better addressed by means of a pragmatic approach involving all concerned parties and acknowledging the challenges and limitations along the way.
\end{abstract}

KEY WORDS: orthopedics, psychiatry, biopsychosocial model, mental health, bone - brain axis

Wiad Lek. 2021;74(11 p.l):2829-2835

\section{INTRODUCTION}

The connection between musculoskeletal and mental health has been hypothesized since the antiquity, being summarized in the mens sana in corpore sano (a healthy mind resides within a healthy body) grecoroman concept and the humoral theory of diseases[1]. The definition of health as a state of physical, mental and social wellbeing rather than the absence of a disease in 1948 has helped to shed light to the mental manifestations of corporeal diseases[2].

Musculoskeletal conditions include acute and chronic locomotor disorders, with a detrimental impact on individuals' functionality and quality of life. Pain and disability are the most common manifestations, resulting in mental health decline, elevated risk of developing other chronic diseases and increased all-cause morbidity and mortality[3]. According to the WHO, the Disability-adjusted life years (DALYs) associated with musculoskeletal conditions have increased to up to $6.6 \%$ of the global disease burden[4]. Musculoskeletal conditions affect 1.7 billion people worldwide and constitute a major contributor to disability, with low back pain being the single leading cause of disability in 160 countries[5].
Evidence suggests that up to $40 \%$ of patients in orthopedic wards suffer from mental health conditions [5]. The interplay between musculoskeletal and psychiatric conditions, described as the bone - brain axis, has been recognized by studies investigating the increased prevalence of fractures in elderly with dementia, osteoporosis and hypertension associated with calcium metabolism[6]. Simultaneously, practitioners of specialties different from psychiatry desire further training in mental health due to a potential lack of skills related to the prevention, early detection and management of mental health conditions. Particularly, orthopedics are less likely to refer their patients to psychiatrists, despite being able to notice signs of psychological disorders[6]. This stated, it is crucial to investigate the biopsychosocial aspects of the bone - brain axis, raise awareness among healthcare workers and create more space for mental health screening and interventions in orthopedic wards.

\section{THE AIM}

To summarize the existing knowledge about the etiological connection between mental and musculoskeletal conditions, to assess the relevant disease burden and propose a mental wellbeing action plan in musculoskeletal care. 


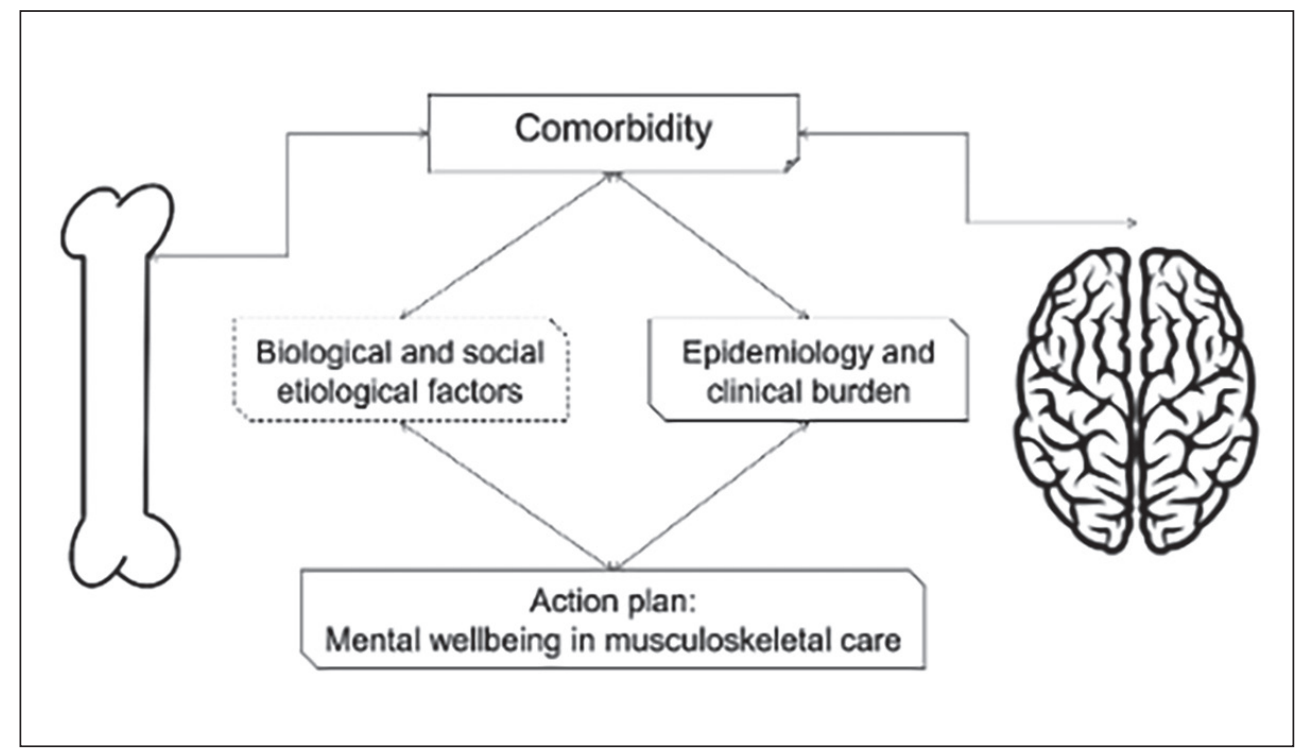

Fig 1. The biopsychosocial concept of the bone-brain axis on the basis of etiological and epidemiological evidence

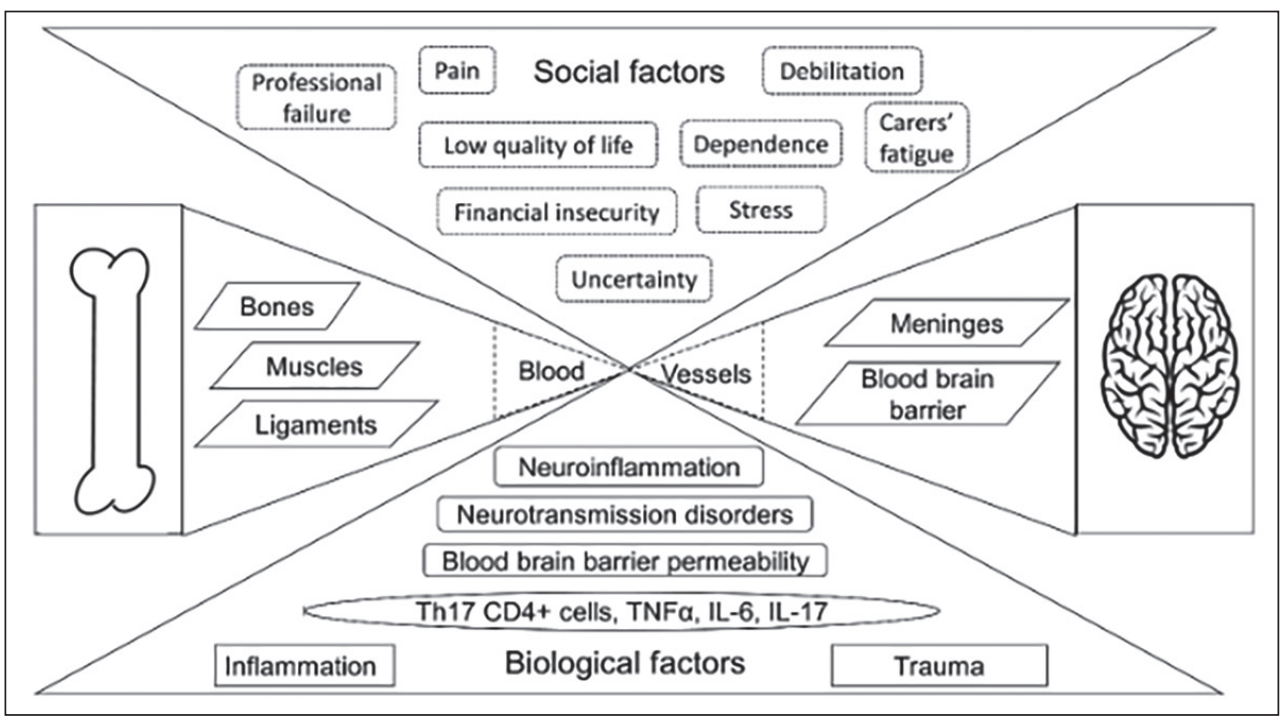

Fig. 2. The socio-biological background of the bone - brain axis

\section{MATERIALS AND METHODS}

Keywords (orthopedics, psychiatry, mental health) were used to list down and analyze the literature in PubMed and Google Scholar. All types of articles, including original research, systematic reviews, and meta-analyses, along with gray literature dating back to 2000 . We excluded studies reporting a significant conflict of interest and findings dispersed through popular media instead of peer-reviewed journals.

\section{REVIEW AND DISCUSSION}

\section{ETIOLOGICAL CONNECTION BETWEEN MENTAL} AND MUSCULOSKELETAL CONDITIONS

Biological and social factors contribute to the interplay of musculoskeletal and mental conditions. In arthritis, pro-inflammatory factors, such as Th17 CD4+ cells, TNFa,
IL-6, IL-17 decrease the expression of tight junctions (TJ) of the blood-brain barrier (BBB) increasing its permeability. Oxidative molecules penetrate the central nervous system (CNS) promoting neuroinflammation and synaptic dysfunction[6]. Negative modulation of serotonergic neurotransmission due to degradation of tryptophan and hyperactivity of the hypothalamus-pituitary-adrenal (HPA) axis may lead to the manifestation of depressive symptoms $[7,8]$.

Patients with autoimmune musculoskeletal conditions experience cognitive impairment due to chronic inflammation (brain fog). Mechanisms involved in this condition include: cytokines interfering with neurotransmitter release, proinflammatory cytokine- mediated increase in the uptake and breakdown of monoaminic neurotransmitters (serotonin, noradrenaline and dopamine), oxidative stress induced by the oxidation of tetrahydrobiopterin, indoleamine-2-, and 3-dioxygenase-mediated removal of 
tryptophan from the serotonin pathway and astrocyte-mediated inhibition of dopamine release [9].

Polytrauma patients may develop psychiatric symptoms related to traumatic brain injury. Concussions, penetrating injuries, closed head injuries, skull fractures, hematomas, lacerations and contusions lead to brain hypoxia and diffuse axonal injuries. Such lesions have been associated with a decrease in dopamine, serotonin and acetylcholine levels, an event implicated in the pathophysiology of various neuropsychiatric disorders from dementia to depression[10]. Peripheral nerve damage also affects neuronal plasticity and somatosensory cortical representation at the CNS resulting in chronic pain and depression as described in the context of phantom limb pain [11].

Beyond biology, several social factors seem to contribute to the development of psychiatric symptoms among these patients. Pain, fatigue, disability, low quality of life, increased costs, dispute with insurance agencies and withdrawal from professional activity constitute potential risk factors for the mental wellbeing of patients with traumatic injuries, congenital deformities, mechanical and autoimmune musculoskeletal conditions, as well as of their carers. Prolonged symptoms and suffering in combination with uncertainty for the prognosis of the disease and the financial security of their dependents also lead to stress, depression and sleep disorders [12].

The coexistence of biological and social factors (Figure 2 ) is in line with the social determinants of health and the socio-biological translation theory [13].

\section{PSYCHIATRIC COMORBIDITY IN ORTHOPEDIC WARDS}

Research focusing on orthopedic inpatients has reported psychiatric comorbidities with prevalence ranging from $19 \%$ to $86 \%$, due to the lack of homogeneous diagnostic criteria [14].

Several studies have assessed psychiatric comorbidities among inpatients in orthopedic and musculoskeletal wards. Vijay et al. (1988) screened 302 orthopedic outpatients with the General Health Questionnaire (GHQ-5) and reported potential psychiatric comorbidity in $41 \%$ of them, particularly in those with chronic inflammatory and degenerative musculoskeletal conditions [15]. Lange et al. (2001) referred 39 in-patients of an orthopedic department for mental health assessment. Following a consultation with mental health professionals, psychiatric comorbidity (ICD-10 Chapter F (V)) was diagnosed in $95 \%$ of the patients. $30 \%$ of these patients were incapable of managing their musculoskeletal condition as outpatients because of their mental health status. In $40 \%$ of them, psychiatric comorbidity was associated with (i) inadequate psychosocial adaptation to chronic symptoms and disability, and (ii) long term orthopedic complications [16]. It is noteworthy that although orthopedic wards' personnel was able to notice psychiatric comorbidity, they would request psychiatric consultation mostly for "difficult" patients [14]. Schwartz et al (2010) investigated patient records from the mus- culoskeletal departments of 507 hospitals in California, USA between 2001 and 2009. Their findings suggest that psychiatric conditions were the commonest comorbidity (24.7\%) in admitted patients with musculoskeletal injury. Among them, the most common diagnoses were dementia (14.3\%) and depression (6.9\%). In comparison to patients with no psychiatric history, patients with psychiatric comorbidities had a higher likelihood of prolonged hospitalisation (7 or more days), surgical complications, and even in-hospital death [17]. Buller et al. (2016) assessed a cohort representative of 526,185 inpatients with humeral fractures from the USA National Hospital Discharge Survey between 1990 and 2007. The study reported an independent association between depression, anxiety, and dementia with increased likelihood of in-hospital adverse events. Depression was linked to higher rates of inpatient blood transfusion, while depression, schizophrenia, and dementia increased the possibility of non-routine discharge or transfer to a different inpatient facility. Moreover, a diagnosis of schizophrenia was associated with a mean of 12 more days of inpatient care [18].

Degen et al. (2016) studied the presence of upper extremity musculoskeletal complaints among workers with symptoms of depression, anxiety and post-traumatic stress disorder (PTSD) by means of the Patient Health Questionnaire (PHQ). The analysis of the responses of 418 individuals suggested that workers suffering from neck pain had significantly higher screening rates of depressive symptoms (62.5\% versus a mean of $20.1 \%)$ and anxiety/panic disorder (37.5\% versus a mean of $12.9 \%$ ) in comparison to other complaints (shoulder, hand pain etc). Similarly, patients with chronic pain had higher rates of depression (54.5\% versus a mean of $20.1 \%$ ) and anxiety - panic disorder (63.6\% versus a mean of $12 \%)$ [19].

McCrabb et al. (2019) conducted a cross - sectional study about the prevalence of smoking, alcohol consumption and addiction among orthopedic inpatients in two major hospitals in Australia. They reported higher prevalence of smoking among inpatients (21.8\%) in comparison to the general population of Australia (13.8\%). More than half of the patients (51.8\%) reported alcohol consumption at hazardous levels during the last year, and about $9.7 \%$ reported use of cannabis during the last month[20]. Furthermore, Yang et al. (2020) investigated retrospectively the prevalence of emotional distress among 1994 orthopedic inpatients in China by means of the "Huaxi Emotional-Distress Index" (HEI). Emotional disorders were traced in $8.1 \%$ of the sample, while $1 \%$ had severe emotional distress according to the HEI index. The latter was positively associated with injury severity, high visual analogue score (VAS) and lengthy and/or arduous surgery [21]. Ohliger et al. (2020) evaluated 553 orthopaedic patients divided in two cohorts, before and during the COVID-19 pandemic. Patients in the during-the-pandemic cohort had a higher prevalence of psychiatric diagnoses and a more frequent history of interpersonal violence $(43 \%$ vs 26\%) compared with the before-the-pandemic cohort [22].

A number of studies have also investigated the association of psychiatric comorbidities with orthopedic proce- 


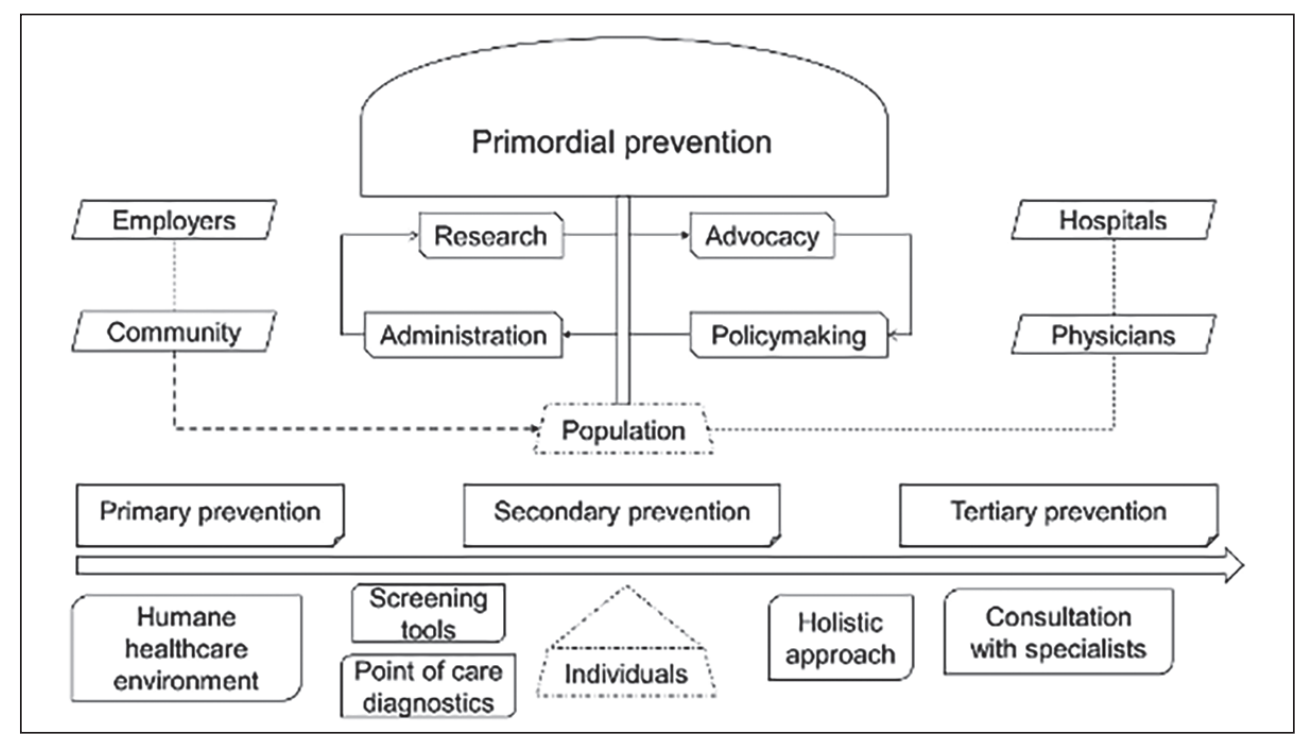

Fig. 3. A mental wellbeing action plan in musculoskeletal care

dures and their outcomes. Buller et al. (2014) assessed the association between a history of dementia, depression or schizophrenia and the outcomes and morbidity following total hip or total knee replacement, two of the most common orthopedic procedures. In a cohort representative of $8,379,490$ patients, depression, dementia and schizophrenia were associated with higher likelihood of adverse events, with schizophrenia and depression linked to higher odds of perioperative blood transfusion. All these comorbidities appeared to increase the odds of non-routine discharge, while dementia was associated with higher in-patient mortality [23]. Bot et al. (2014) retrieved data from the National Hospital Discharge Survey (NHDS) database, to assess psychiatric comorbidity among 348,824 patients having undergone partial or total shoulder arthroplasty between 1990 and 2007. The most prevalent conditions in this sample were depression $(4.4 \%)$, anxiety disorder (1.6\%), dementia (1.5\%) and schizophrenia (0.6\%). All the disorders were associated with a higher likelihood of non - routine discharge. Psychiatric history, with the exception of schizophrenia, was linked to higher rates of adverse events, while depression and schizophrenia were associated with increased odds of perioperative blood transfusion [24]. Frank et al. (2020) investigated a cohort of 378 patients from a Veterans Healthcare Center in the USA and reported that patients with major depression or depressive disorder had 1.78 times higher rates of opioid use prior to spine surgery in comparison with patients with other or no comorbidities [25].

Baron et al. (2021) screened patient records (57.7\% male) in the Humana claims database in the USA. This study assessed 226,402 patients between 2007 and the first quarter of 2017. Psychiatric comorbidities were twice as common in patients undergoing common sports medicine/orthopedic procedures $(21.21 \%)$ in comparison with the entire database. These patients most frequently underwent repair of the rotator cuff (28\%), hip labral repair (26.3\%) and meniscectomy (25\%). On top of this, psychiatric comorbidity was associated with a $50 \%$ increase in healthcare costs for orthopedic procedures[26]. Broggi et al. (2021) conducted a retrospective analysis of complications among elderly $(>65)$ patients after undergoing open reduction internal fixation (ORIF) and intramedullary nailing (IMN) due to traumatic injury between 2009 and 2019 according to the Truven Marketscan claims database in the USA. In 78,435 patients, preoperative depression was associated with up to 1.3 times higher odds for surgical site infections, wound complications and non-union following ORIF. The same was associated with up to 1.44 higher odds of surgical site infections, wound complications, visit for pain and pneumonia following IMN [27].

The available evidence highlights the increased prevalence of dementia, depression, and anxiety - panic disorder among patients with orthopedic conditions. It also seems that psychiatric comorbidity has a negative effect on elective surgery. Depression, anxiety disorder, dementia and, at a smaller scale, schizophrenia increase perioperative morbidity, hospitalization, short and mid-term postoperative complications and mortality. Mental disorders come with a higher cost of care and burden for carers, leading to biopsychosocial stalemate. Nevertheless, the existing research is heterogeneous. Despite the existence of largescale studies, the criteria and methods used for the diagnosis and classification of mental health conditions differ rendering the comparison between studies difficult. The majority of the studies has been conducted in countries with large databases such as USA, Australia and China in a retrospective manner. Access to healthcare and insurance system databases is necessary for similar studies in other countries. In countries and territories with a shortage of data databases - registries and prospective studies can be organized simultaneously. In the coming years, more evidence will support less invasive procedures and conservative management, and it will be also noteworthy to assess the impact of unnecessary surgical operations on existing psychiatric comorbidities [28]. 


\section{A PROPOSED MENTAL WELLBEING ACTION PLAN IN MUSCULOSKELETAL CARE}

During the last decade, there is interest in mental wellbeing action plans. The $\mathrm{WHO}$ has released an action plan for mental health applicable between 2013 and 2020 [29]. The Department of Health of the United Kingdom has also laid down its mental health strategy in the form of an action plan effective between 2020 and 2030 [30]. The aforementioned action plans can be implemented across a number of fields (healthcare facilities, workplaces, community) and concern the population at country or global level. They are supported by potent health bodies, contain detailed consideration of resources involved. At this point, the authors are not capable of presenting such a comprehensive strategy for mental health care in musculoskeletal wards. This section rather outlines recommendations aiming to preventing, early diagnosing or sufficiently addressing psychiatric comorbidities in patients with orthopedic conditions.

The authors' approach follows the four levels of prevention (primordial, primary, secondary, tertiary). As established, primordial prevention targets underlying conditions leading to harmful exposures and causations of disease and entails interventions for the population or specific high - risk groups. Primary, secondary and tertiary prevention target specific causal factor, early - stage disease and established disease respectively. Related interventions target individuals at risk and patients (Figure 3).

At a primordial prevention level, governments, health bodies, patients and workers associations related to musculoskeletal health need to collaborate with mental health professionals. This collaboration should first investigate conditions with a potential to act as mental health risk factors in orthopedic care. Research identifying the most common comorbidities at regional level should be translated to administrative - and if necessary legislative - action at regional, national and local levels. Cost - effectiveness analyses related to the implementation of the necessary interventions ought to be conducted. Interventions should be designed aiming to mitigate mental health stressors such as negligent pain management, long waiting lists, unpleasant hospital environment, lack of etiquette in in the interaction between patients, healthcare workers or the administrative personnel of the concerned facilities and uncertainty related to controversial insurance policies. The latter has been repeatedly highlighted by the American Psychological Association's annual "Stress in America" reports. Relevant action includes:

- Financial coverage of acute orthopedic trauma for uninsured patients and simplified or accelerated refund processes related to emergencies.

- Paid leaves from work for patients with orthopedic trauma, chronic or recurrent pain and disability. Family members - carers also need paid leaves. The state and insurance companies need to support employers afford the financial burden. Similarly, it is essential to include mental health-related expenses to the remuneration of occupational musculoskeletal injuries.

- Regular and confidential mental health assessments for individuals with musculoskeletal conditions at the workplace, in the community or in specialized healthcare facilities.

- Measures against the stigmatization of individuals whose musculoskeletal conditions affect their mental wellbeing (informative campaigns in workplaces, educational institutions and the community, sanctions for employers discriminating them).

- Digital tools (medical wearables monitoring behavior and behavior associated alterations of vital signs, smartphones with a history of activity and internet search) have major potential in identifying individuals with undiagnosed mental health disorders [31]. This technology can be used to assess the mental wellbeing of orthopedic inpatients and outpatients based on 1) sufficient research and 2) relevant medico-legal framework with respect to privacy.

- Reintroducing psychoorthopedics. This concept has been first introduced in the 1950s' with research assessing the effect of mental health disorders on posture [31]. Currently, integrating the epidemiology of psychiatric comorbidity in orthopedic wards with related clinical, public health, biological and social research can help reform clinical practice, workplaces and the community.

At a primary, secondary and tertiary prevention level, mental health risk factors, conditions and related symptoms need to be identified in both inpatients and outpatients:

- Healthcare facilities need to take action against conditions that may aggravate patients' and carers' mental wellbeing. These include long waiting lists, lack of attention to pain management and patients' comfort, unnecessary bureaucratic procedures and uncertainty.

- Discussing with the patients and their carers. Physicians, nurses and other healthcare professionals involved in everyday care can spot stressors aggravating the mental wellbeing of patients with or without psychiatric comorbidities. Special attention should be paid to noise, light and sleeping routine [32].

- Point of care mental health tools and screening tests for prevalent or life-threatening mental health conditions need to be incorporated in musculoskeletal history taking. In case of long - term hospitalization this can be repeated in due intervals.

- Consultation with mental health professionals needs to be enhanced in orthopedic care. Trainees should be instructed to collaborate with mental health professionals. To sustain such a culture a psychiatrist or a psychologist can regularly attend the rounds of orthopedic departments.

- Patients with psychiatric comorbidities need to receive their regular treatment. Hospitalization can have a negative effect on these patients leading physicians of non - psychiatric specialties including orthopedics to increase their sedatives' or antipsychotics dosage. It seems preferable to modify the treatment scheme in consultation with mental health professionals and reassess the patients during their hospitalization and outpatient monitoring time. 


\section{REAL WORLD LIMITATIONS AND CONSIDERATIONS}

This strategy combines an umbrella leg targeting the population as a whole and a personalized leg focusing on individuals with or without psychiatric comorbidities. It is limited by scarce resources, workforce and decision-making. It is also important to secure the mental wellbeing of physicians and other professionals working there. Hospital administrations and healthcare professionals' associations should liaise musculoskeletal department and practices with psychologists and psychiatrists. Healthcare workers need to be encouraged to seek mental health professionals' attention, while confidentiality needs to be upheld and stigmatization - including the possibility or the fear of professional discrimination and sanctions - needs to be waived. This is a major concern, given that the prevalence of burnout is $50-60 \%$ higher among orthopedics in comparison to other surgical specialties [33,34]. It is also noteworthy, that non-psychiatric comorbidities can decrease functionality in patients treated for musculoskeletal conditions [35].

COVID-19 is an additional factor perplexing the equation, because COVID-19 positive patients hospitalized for traumatic injury or other orthopedic conditions can face psychological burden and stigmatization. The need for a holistic approach to these individuals should not be shadowed by the restrictions of the pandemic [36]. When physical consultation and monitoring of such patients by mental health professionals is not possible, digital tools can be used. The same applies to orthopedic outpatients residing in remote areas or inpatients and outpatients in orthopedic departments without psychiatric coverage.

\section{CONCLUSIONS}

Psychiatric comorbidity constitutes a major concern in musculoskeletal care. The presence of biological and social factors leads to the development or the aggravation of neuropsychiatric disorders in individuals with musculoskeletal conditions. Mounting evidence highlights the prevalence and the detrimental impact of psychiatric comorbidity in patients undergoing conservative or surgical orthopedic treatment. Authorities, health bodies and hospital administrations need to take action to prevent, early detect and treat psychiatric comorbidities at population and individual level. The biopsychosocial aspects of the "bone - brain axis" need to be better mapped and addressed t a pragmatic approach involving all concerned parties and acknowledging the challenges and limitations along the way.

\section{REFERENCES}

1. WHO. Preamble to the Constitution of the WHO (entered into force on 7 April 1948). WHO, Geneva. 1948;2: 100.

2. Briggs A.M., Woolf A.D., Dreinhöfer K. et al. Reducing the global burden of musculoskeletal conditions. Bull World Health Organ. 2018;96(5):366.

3. Sebbag E., Felten R., Sagez F. et al. The world-wide burden of musculoskeletal diseases: a systematic analysis of the World Health Organization Burden of Diseases Database. Ann Rheum Dis. 2019 ;78(6):844- 848.
4. Cieza A., Causey K., Kamenov K. et al. Global estimates of the need for rehabilitation based on the Global Burden of Disease study 2019: a systematic analysis for the Global Burden of Disease Study 2019. Lancet. 2020;396(10267):2006.

5. Gerosa L., Lombardi G. Bone-to-Brain: A Round Trip in the Adaptation to Mechanical Stimuli. Front Physiol. 2021;12:565.

6. Pariante C.M. Depression, stress and the adrenal axis. J Neuroendocrinol. 2003;15(8):811.

7. Ruhé H.G., Mason N.S., Schene A.H. Mood is indirectly related to serotonin, norepinephrine and dopamine levels in humans: a meta-analysis of monoamine depletion studies. Mol Psychiatry. 2007;12(4):331.

8. Korte S.M., Straub R.H. Fatigue in inflammatory rheumatic disorders: pathophysiological mechanisms. Rheumatology (0xford). 2019;1;58(5):v35-50.

9. Ahmed S., Venigalla H., Mekala H.M. et al. Traumatic Brain Injury and Neuropsychiatric Complications. Indian J Psychol Med. 2017;39(2):114.

10. Sahu A., Sagar R., Sarkar S., Sagar S. Psychological effects of amputation: A review of studies from India. Ind Psychiatry J. 2016;25(1):4-10.

11. Solé E., Racine M., Tomé-Pires C. et al. Social Factors, Disability, and Depressive Symptoms in Adults With Chronic Pain. Clin J Pain. 2020;36(5):371.

12. Braveman P., Gottlieb L. The social determinants of health: it's time to consider the causes of the causes. Public Health Rep. 2014;129(2):1931.

13. Kuyler P.L., Dunner D.L. Psychiatric disorders and the need for mental health services among a sample of orthopedic inpatients. Compr Psychiatry. 1976;17(3):395-400.

14. Vijay P.M., ShamsundarC., Shivaprakash M.N. al et. Psychiatric morbidity in orthopaedic outpatients. NIMHANS J. 1988;6(1):23.

15. Lange C., Heuft G., Wetz H.H. [Diagnostic control. Psychiatric comorbidity in patients of technical orthopedic units]. Orthopade. 2001;30(4):236.

16. Schwartz S., Bazargan-Hejazi S., Pan D. et al. Association of Psychiatric Diagnostic Conditions with Hospital Care Outcomes of Patients with Orthopedic Injuries. Perm J. 2018;22:1-6.

17. Buller L.T., Best M.J., Alam M. et al. The Influence of Psychiatric Comorbidity on Inpatient Outcomes following Distal Humerus Fractures. Kolb W, editor. Adv Orthop Surg. 2016;2016:4913808.

18. Degen R.M., MacDermid J.C., Grewal R. et al. Prevalence of symptoms of depression, anxiety, and posttraumatic stress disorder in workers with upper extremity complaints. J Orthop Sports Phys Ther. 2016;46(7):590.

19. McCrabb S., Baker A.L., Attia J. et al. Comorbid tobacco and other substance use and symptoms of anxiety and depression among hospitalised orthopaedic trauma patients. BMC Psychiatry. 2019;19(1):28.

20. Yang Y., Tang T., Chen M. et al. Prevalence and association of anxiety and depression among orthopaedic trauma inpatients: a retrospective analysis of 1994 cases. J Orthop Surg Res. 2020;15(1):587.

21. Ohliger E., Umpierrez E., Buehler L., et al. Mental health of orthopaedic trauma patients during the 2020 COVID-19 pandemic. Int Orthop. 2020;44(10):1921.

22. Buller L.T., Best M.J., Klika A.K., Barsoum W.K. The influence of psychiatric comorbidity on perioperative outcomes following primary total hip and knee arthroplasty; a 17-year analysis of the national hospital discharge survey database. J Arthroplasty. 2015;30(2):165.

23. Bot A.G.J., Menendez M.E., Neuhaus V., Ring D. The influence of psychiatric comorbidity on perioperative outcomes after shoulder arthroplasty. J Shoulder Elb Surg. 2014; 1;23(4):519. 
24. Mezzacappa F.M., Schmidt K.P., Tenny S.0. et al. Review of psychiatric comorbidities and their associations with opioid use in elective lumbar spine surgery. Medicine (Baltimore). 2020;99(47).

25. Baron J.E., Khazi Z.M., Duchman K.R. et al. Increased Prevalence and Associated Costs of Psychiatric Comorbidities in Patients Undergoing Sports Medicine Operative Procedures. Arthroscopy. 2021;37(2):686693.e1.

26. Broggi M.S., Oladeji P.0., Tahmid S. et al. Depressive disorders lead to increased complications after geriatric hip fractures. Geriatr Orthop Surg Rehabil. 2021;12:1-7.

27. Blom A.W., Donovan R.L., Beswick A.D. et al. Common elective orthopaedic procedures and their clinical effectiveness: umbrella review of level 1 evidence. BMJ. 2021;374:n1511.

28. Stansbury J.P., Ried L.D., Velozo C.A. Unidimensionality and bandwidth in the Center for Epidemiologic Studies Depression (CES-D) Scale. J Pers Assess. 2006;86(1):10-22.

29. Department of Health. Department of Health Mental Health Action Plan. 2020, 60p.

30. Roberts L.W., Chan S., Torous J. New tests, new tools: mobile and connected technologies in advancing psychiatric diagnosis. NPJ Digit Med. 2018;1:20176.

31. Helbich M., Browning M.H.E.M., Huss A. Outdoor light at night, air pollution and depressive symptoms: A cross-sectional study in the Netherlands. Sci Total Environ. 2020;744:140914.

32. Arora M., Diwan A.D., Harris I.A. Burnout in orthopaedic surgeons: a review. ANZ J Surg. 2013;83(8):512.

33. Romash I. Disorders of social functioning and quality of life in patients with gastroesophageal reflux disease while combined with undifferentiated connective tissue dysplasia. Mental Health Global Challenges Journal. 2020;3(1):11. doi: 10.32437/mhgcj.v3i1.100.

34. Romash I.B., Mishchuk V.G. The frequency of visceral and phenotypic markers in patients with the combination of undifferentiated connective tissue disease and gastroesophageal reflux disease. Wiadomości Lekarskie.2020;73(7):1492-1498.
35. Snider C.J., Flaherty M.P. Stigma and mental health: The curious case of COVID-19. Mental Health Global Challenges Journal. 2020;3(1):27-32. doi: 10.32437/mhgcj.v3i1.89.

\section{ORCID and contributionship:}

Christos Tsagkaris: 0000-0002-4250-574X $X^{A, B, D, F}$

Andreas S. Papazoglou: 0000-0003-4981-8121 $1^{B, D, F}$

Iryna B. Romash: 0000-0002-9749-778E,F

Dimitrios V. Moysidis: 0000-0001-9083-0267 ${ }^{D, E, F}$

Ivan R. Romash: 0000-0002-6591-6613 ${ }^{E, F}$

Luiza Gabunia: 0000-0003-0856-2684 ${ }^{E, F}$

Taras Gorbatiuk: 0000-0002-4304-376X ${ }^{E, F}$

\section{Conflict of interest:}

The Authors declare no conflict of interest.

\section{CORRESPONDING AUTHOR Christos Tsagkaris Novel Global Community Educational Foundation 2770 NSW, Hebersham, Australia tel: +306980513072 e-mail:chriss20x@gmail.com}

Received: 25.05 .2021

Accepted: 12.10 .2021

A - Work concept and design, B - Data collection and analysis, C - Responsibility for statistical analysis, D-Writing the article, $\mathbf{E}$-Critical review, $\mathbf{F}$ - Final approval of the article 


\title{
COVID-19 IMPACT: NEW TENDENCIES AND TRENDS IN MENTAL HEALTH RESEARCH
}

D0I: 10.36740/WLek202111127

\author{
Viktor Vus ${ }^{1}$, Anastasiia Puzyrina ${ }^{2}$ \\ IINSTITUTE OF SOCIAL AND POLITICAL PSYCHOLOGY NATIONAL ACADEMY OF EDUCATIONAL SCIENCES OF UKRAINE, KYIV, UKRAINE \\ ${ }^{2}$ TURNING POINT PSYCHOLOGICAL SERVICES, VAUGHAN, ONTARIO, CANADA
}

\begin{abstract}
The aim: To provide an analysis of contemporary investigations in the area of Mental Health Care for the individual \ population; to define the main trends, tendencies, key concepts of these investigations during $\backslash$ after Covid -19 pandemic and established restrictions.

Materials and methods: A literary review (163 research publications totally) of relevant articles was performed (a scoping review method) based on the followings criteria: publication year (2020-2021), publication source (only PubMed and Open Access), mental health issues in regards of individual \ population. We used "mental health,"'covid19 mental health", "impact of covid 19 on mental health," and "covid 19 mental health impact" keywords for searching related research papers in the Pubmed database. Additionally, the clinical case of social restrictions' impact on a patient' mental health is described.

Conclusions: The main trends of modern research are determined by: the search for more modern scientific terms and categories ( $\mathrm{E}$ - Mental Health, digital Mental Health, Tele-Mental Health, etc.); study of risks and benefits of widespread use of virtual and information technologies in the field of Mental Health Care; diagnosis and treatment of new mental health disorders; reassessment of traditional values, active search for new meanings in the field of interpersonal and intergroup relationships; development of health-responsive economy and health-responsive society
\end{abstract}

KEY WORDS: mental health; COVID-19 mental health impact; restrictions; Mental Health research; health-responsive economy; health-responsive society

Wiad Lek. 2021;74(11 p.l):2836-2839

\section{INTRODUCTION}

The Covid-19 pandemic affected not only the physical health of the population/individual. Significant changes have occurred in intergroup relations, social and political life (changes in the usual interpersonal/social/political constructions of interaction). The relevant questions are: "How long will the pandemic last and the restrictions imposed?", "What will the world be like after the pandemic?"

The answers to these questions are crucial to forecasting and developing strategies for the further development of global society, large national societies, and individual communities. Also, an important component for these forecasts is undoubtedly the mental health and well-being of the population/individual. After all, the mental health of the population/individual is traditionally seen as an integrated indicator of the population/individual's experience of physical and emotional well-being and perception/reflection of various aspects of social life (WHO) [1]. Analysis of current research on the impact of the Covid-19 pandemic on the mental health of individuals/populations, highlighting the main criteria for this impact and the factors that determine it, identifying the latest challenges, etc., is essential information for policymaking in the field of mental health. After all, the results of scientific research are quickly integrated into the qualitative basis for the development of practical recommendations in various areas of society.

\section{THE AIM}

The purpose and objective of this study are to clarify the specifics of reflection by modern scientists on mental health issues by analyzing current research in the field of mental health of different populations and highlighting the main directions, trends, key research concepts after the Covid-19 pandemic.

\section{MATERIALS AND METHODS}

\section{STUDY SELECTION}

Research papers were found by searching the PubMed database (https://pubmed.ncbi.nlm.nih.gov/) using the keywords "mental health." In addition, we used related "covid19 mental health", "impact of covid 19 on mental health," and "covid 19 mental health impact" keywords to ensure the inclusion of all relevant studies fitting our criteria (publication year (2020-2021), publication source (only PubMed and Open Access), mental health issues).

\section{STUDY "SAMPLE"}

A total of 163 selected publications were analyzed based on our criteria. 


\section{STUDY METHOD}

We used a scoping review research method to provide an overview of the available research evidence. This method allows us to define particular topics and key concepts in current Mental Health research. In the review part of this paper, we cited possible related articles. From the relevant literature, we excluded reports of highly specific studies of mental health issues (e.g., keywords: "covid 19 mental health healthcare", "covid 19 mental health students" "covid 19 mental health children", "covid 19 mental health healthcare workers", "covid 19 and mental health and healthcare workers", "covid 19 mental health medical", "covid 19 mental health college" and "covid 19 mental health nurses" etc.).

\section{CASE STUDY}

Additionally, the clinical case of social restrictions' impact on a patient' mental health is described.

\section{REVIEW AND DISCUSSION}

The analysis of scientific articles on mental health issues, published for the period 2020 - 2021, showed that the subject of the authors' research revolves around four phenomena:

1) the effect of social media on the human psyche $[2 ; 3]$

2) the interdependent: Mental Health of individual/population and social development [4-6]

3 ) the effect of social restrictions on inter- and intra- groups relations (especially for women, LGBT communities, children etc) [7-9]

4) the effect of factors related to the COVID-19 pandemic on the human psyche [10-22].

At the same time, the interest in studying the impact of social media on human mental health is due to observations of a sharp increase in the incidence of depression, suicide among young people during the active spread of social networks [2] and understanding of mental health as associated with the use of information and communication technologies [3]. Furthermore, the COVID-19 pandemic and the restrictions imposed have changed the territorial context of Mental Health research. Instead of the different geographical and socio-cultural dimensions and "territories" in which the mental life of the modern individual unfolds in different parts of the world, the "territory" is just a small group: family, friends, and so forth. Despite the processes of segmentation of society, there is a trend of globalization in cyberspace. In this regard, along with the term "mental health," the authors use the concepts: electronic mental health (E - Mental Health), mobile mental health, tele-mental health, and digital mental health $[3,4]$.

At the same time, the impact of the pandemic on mental health is being studied by researchers both in a generalized form and in relation to specific social groups and cohorts of the population. The authors single out the following changes that occur in the human psyche under the influence of various factors related to the pandemic (isolation, lifestyle changes, etc.): symptoms corresponding to "moderate" or "severe" generalized anxiety disorder, recourse to psychoactive substances $[5 ; 8 ; 10]$, stress, fear $[11 ; 17]$, experiencing violence [11], exacerbation of pre-existing mental disorders [13], increased anxiety combined with the development of obesity [13], depression [14], panic, paranoia, obsessive behavior, PTSD [19], decreased life satisfaction [22], etc. In addition, the level of mental health of an individual during a pandemic may be adversely affected by loss [23] The following vulnerable categories attract the attention of scientists: adolescents [10], students [11], the elderly [13], and nurses [17].

Among the factors that have a positive effect on maintaining the mental health of the individual, the researchers identify the organization of social support, a positive style of coping with stress, time for rest; level of education, psychological flexibility of reactions $[15 ; 16]$.

The article "The impact of COVID-19 pandemic on mental health of Nurses" (authors: Chidiebere Okechukwu E, Tibaldi L, La Torre G.) [16] rightly suggests the emergence of a new category of diagnosis of specific mental disorders caused by the pandemic COVID- 19 and the imposed restrictions.

Many authors put forward the idea of studying the potential of the positive impact of social networks on the individual in order to use it to strengthen mental health. In particular, Nesi J. [2] recommends its use for screening and interventions in mental health. Drissi N, Ouhbi S, Janati Idrissi MA, Fernandez-Luque L, Ghogho M. [3] note that the use of information and communication technologies can help manage, treat and diagnose mental health problems and help overcome existing barriers in providing mental health care.

Dubey S, Biswas P, Ghosh R, Chatterjee S, Dubey MJ, Chatterjee S, Lahiri D, Lavie CJ. [18] draw attention to the fact that information from the media and social networks should be carefully monitored, as it has a significant impact on the mental health of the individual/population.

Some researchers note the need to study the long-term effects of physical distancing [10;22], the need to study special social groups of subjects that may need psychological help: for example, parents who have to combine work, homework, and control of school activities and tasks of children [10].

We consider it appropriate to note the availability of articles of a consultative nature - on resources with information on mental health issues [6].

Despite the large number of articles in which mental health is considered to be dependent on pandemic conditions, there have recently been articles justifying the potential economic benefits of investing in mental health policies and programs [4]. The authors note that the widespread dissemination of the ideas of Mental Health Awareness and support for such initiatives at the state level will help maintain the mental health of individuals/populations and have a positive impact on the development of their socio-economic well-being. 


\section{CASE}

A 30-year-old woman has been experiencing increased agitation, uncertainty, difficulty sleeping, and symptoms of anxiety in recent weeks. "I don't know what to do," "I don't know how to convince my son," she said during the intake session.

Ms. $\mathrm{K}$ is 30 years old, in the process of divorce, and raising a 4-year-old son. Before lockdown, she had an orderly life with a stable job and her child attending school. However, as a result of the Covid-19 lockdown, she is forced to work from home online. Similarly, her son's JK class was transferred to online learning for the same reason.

According to the client, the child has difficulties concentrating and is experiencing increased fatigue since he must be in front of the laptop screen for 6 hours. In addition, the child often refuses to learn because "he is not interested, and I don't know how to motivate him," the client says.

At the same time, the client needs to work, and she does not have the opportunity to be in the lessons with her son. The client notes that concerning her son, she allows him to skip classes. The client's ex-spouse takes an active part in raising their child and, not even though there is still no court decision, participates in the child's life as equal custody. The client is afraid that the child, having skipped school, will fall behind in his studies. At the same time, she is worried that prolonged exposure in front of the computer screen will affect the psycho-emotional development of the child.

Furthermore, the client worries that her social life will be destroyed due to the lockdown and her transition to working from home. She is afraid that her employer will not be interested in bringing employees back to the office after the lockdown ends.

The client noted that she has difficulty falling asleep, she is not satisfied with her sleep, does not get enough sleep, and her sleep quality is poor. She has a T-score of 60.4, which is interpreted as Moderate according to the LEVEL 2 - Sleep Disturbance - Adult (PROMIS - Sleep Disturbance - Short Form). In addition, the client stated that she is unable to relax, is unsteady, nervous, and fears losing control. According to the Beck Anxiety Inventory, she has a score of 22, which is interpreted as moderate.

As a result of the completed cognitive behaviour course, the client has improved sleep and stabilization of their emotional state. According to LEVEL 2 - Sleep Disturbance - Adult (PROMIS - Sleep Disturbance - Short Form), she has a T-score, which is interpreted as none to slight. According to Beck Anxiety Inventory, she has a score of 14 which is interpreted as low anxiety.

\section{CONCLUSIONS}

- Modern scientists have established tendencies to "virtualize» the mental life of both individuals and social groups. The scientific thesaurus introduces such categories as electronic mental health (E-Mental Health), mobile mental health, telemental health, and digital mental health, etc.
- Traditional territorial and socio-cultural contexts are gradually being replaced by virtual space and virtual "scenes" on which the mental life of modern humanity unfolds. In this regard, the possibilities, potential risks, and benefits of widespread use of information and communication technologies in the field of Mental Health Care are studied.

- Modern scholars note the intensification of the process of reassessment of traditional values, the active search for new meanings in the field of interpersonal and intergroup relationships. The number of in-depth studies of the peculiarities of relationships in small groups (family, friends, etc.) is increasing in order to develop effective mechanisms to ensure the long-term experience of mental well-being by individuals/populations.

- The clinical and psychophysiological effects of COVID-19 on the Mental Health of individuals/populations are still poorly understood. The duration, course, and consequences of the COVID-19 viral disease are still unpredictable. Many current studies describe and analyze clinical cases and discuss the prospects for developing a new category of diagnosis and treatment of specific mental disorders caused by the COVID-19 pandemic and the restrictions imposed.

- Modern research on individual mental health is based on the idea of the side and long-term effects of the COVID-19 pandemic and suggests that they can be mitigated by adequate and timely intervention. Emphasis is placed on the urgent need for Mental Health Awareness activities and programs. It is noted that psychosocial measures to mitigate the side effects of the pandemic need to be actively implemented, especially in working with the most vulnerable.

- Emphasis is placed on the need to develop appropriate state and social policies to build a health-responsive economy and a health-responsive society at the national and international levels.

\section{REFERENCES}

1. World Health Organisation. Mental Health:Strengthening our Response. 2018. https://www.who.int/news-room/fact-sheets/detail/mentalhealth-strengthening-our-response [date access 06.08.2020]

2. Nesi J. The impact of social media on youth mental health: challenges and opportunities. N C Med J. 2020;81(2):116-121. doi: 10.18043/ ncm.81.2.116.

3. Drissi N., Ouhbi S., Janati Idrissi M.A. et al. Connected mental health: systematic mapping study. J Med Internet Res. 2020;22(8):e19950. doi: 10.2196/19950.

4. Rayan R.A., Tsagkaris C., Iryna R.B. The internet of things for healthcare: applications, selected cases and challenges.studies in computational intelligence. Springer, Singapore. 2021; 933:1 - 15. doi: 10.1007/978981-15-9897-5_1.

5. Kirby T. Sonia Johnson-helping shape mental health policy. Lancet Psychiatry. 2020;7(8):669. doi: 10.1016/S2215-0366(20)30293-5.

6. Baldwin P. Government resources on mental health. sr care pharm. 2020;35(12):573. doi: 10.4140/TCP.n.2020.573..

7. Fish J.N. Future Directions in Understanding and Addressing Mental Health among LGBTQ Youth. J Clin Child Adolesc Psychol. 2020;49(6):943-956. doi: 10.1080/15374416.2020.1815207. 
8. Ricciardelli R., McKendy L. Women parolees'mental health in the context of reintegration. Crim Behav Ment Health. 2020;30(6):303-311. doi: 10.1002/cbm.2181.

9. Crook S. Historicising the "crisis" in undergraduate mental health: British universities and student mental illness, 1944-1968. J Hist Med Allied Sci. 2020;75(2):193-220. doi: 10.1093/jhmas/jrz060.

10. de Figueiredo C.S., Sandre P.C., Portugal L.C.L. et al. COVID-19 pandemic impact on children and adolescents' mental health: Biological, environmental, and social factors. Prog neuropsychopharmacol biol psychiatry. 2021;106:110171. doi: 10.1016/j.pnpbp.2020.110171.

11. CopelandW.E., McGinnis E., Bai. Et al. Impact of COVID-19 pandemic on college student mental health and wellness. J Am Acad Child Adolesc Psychiatry. 2021;60(1):134-141.e2. doi: 10.1016/j.jaac.2020.08.466.

12. Grolli R.E., Mingoti M.E.D., Bertollo A.G. et al. Impact of COVID-19 in the mental health in elderly: psychological and biological updates. Mol Neurobiol. 2021;58(5):1905-1916. doi: 10.1007/s12035-020-02249-x.

13. Flanagan E.W., Beyl R.A., Fearnbach S.N. et al. The impact of COVID-19 stay-at-home orders on health behaviors in adults. Obesity (Silver Spring). 2021;29(2):438-445. doi: 10.1002/oby.23066.

14. Xiong J., Lipsitz 0., Nasri F. et al. Impact of COVID-19 pandemic on mental health in the general population: A systematic review. J Affect Disord. 2020;277:55-64. doi: 10.1016/j.jad.2020.08.001.

15. Heitzman J. Impact of COVID-19 pandemic on mental health. Psychiatr Pol. 2020;54(2):187-198.. doi: 10.12740/PP/120373.

16. Chidiebere Okechukwu E., Tibaldi L., La Torre G. The impact of COVID-19 pandemic on mental health of Nurses. Clin Ter. 2020;171(5):e399-e400. doi: $10.7417 /$ CT.2020.2247.

17. Torales J., O'Higgins M., Castaldelli-Maia J.M., Ventriglio A. The outbreak of COVID-19 coronavirus and its impact on global mental health. Int J Soc Psychiatry. 2020;66(4):317-320. doi: 10.1177/0020764020915212.

18. Dubey S., Biswas P., Ghosh R. et al. Psychosocial impact of COVID-19. Diabetes Metab Syndr. 2020;14(5):779-788. doi: 10.1016/j. dsx.2020.05.035.

19. Talevi D., SocciV., Carai M. et al. Mental health outcomes of the CoViD-19 pandemic. Riv Psichiatr. 2020;55(3):137-144. doi: 10.1708/3382.33569.
20. Gloster A.T., Lamnisos D., Lubenko J. et al. Impact of COVID-19 pandemic on mental health: An international study. PLoS One. 2020;15(12):e0244809. doi: 10.1371/journal.pone.0244809.

21. Magson N.R., Freeman J.Y.A., Rapee R.M. et al. Risk and protective factors for prospective changes in adolescent mental health during the COVID-19 pandemic. J Youth Adolesc. 2021;50(1):44-57. doi: 10.1007/ s10964-020-01332-9.

22. Roy D., Ghosh R., Dubey S. et al. Neurological and neuropsychiatric impacts of COVID-19 pandemic. Can J Neurol Sci. 2021;48(1):9-24. doi: 10.1017/cjn.2020.173.

\section{ORCID and contributionship:}

Viktor Vus: 0000-0002-1042-5323 ${ }^{\text {A,B,D-F }}$

Anastasiia Puzyrina: 0000-0002-4482-8622 B,D-F

\section{Conflict of interest:}

The Authors declare no conflict of interest

\author{
CORRESPONDING AUTHOR \\ Viktor Vus \\ Institute of Social and Political Psychology National Academy \\ of Educational Sciences of Ukraine \\ 15 Andriivska st., 04053 Kyiv, Ukraine \\ tel: +380677408429 \\ e-mail:viktor.vus@mhgc21.org
}

Received: 27.05.2021

Accepted: 11.10 .2021

A - Work concept and design, B - Data collection and analysis, C - Responsibility for statistical analysis, D - Writing the article, $\mathbf{E}$-Critical review, $\mathbf{F}$ - Final approval of the article 


\title{
USE OF THE HEROIC JOURNEY NARRATIVE IN THE DIAGNOSTIC INTERVIEW AND TREATMENT WITH FAMILIES OF CHILDREN WITH SPECIAL NEEDS
}

DOI: $10.36740 /$ WLek202111128

\author{
Galina Itskovich', Elena Shopsha², Liudmyla Fedosova² \\ IINTERDISCIPLINARY COUNCIL ON DEVELOPMENT AND LEARNING; PRIVATE PRACTICE, NEW YORK, USA \\ ${ }^{2}$ INDEPENDENT RESEARCHER
}

\begin{abstract}
The aim: To explore and corroborate personal and family narratives within the framework of "heroic journey", delineate function of the narrative in the diagnosis and treatment of families of children with special needs, and to describe the process of improving psychological well-being of these families.

Materials and methods: The study material consisted of articles on the subject found in American and international databases (Springer, Thompson ISI's Web of Science, Scopus and PsycINF0, Google Scholar), using keywords "family and child psychotherapy"," "heroic journey", "differentially able", "attachment","narrative", "therapeutic storytelling". Two case vignettes, parents of a) a special-needs adult and b) a pre-teen psychotherapeutic patient, illustrate application of the heroic journey narrative in psychotherapeutic treatment. Conclusions: Formation of the narrative identity is simultaneously the ends and the means: while a parent is encouraged to tell the story repeatedly over time, a new narrative identity emerges. Purpose, roles, patterns, and the structure of the storytelling process are outlined. Increased coherence of the family stories leads to strengthening attachment patterns.

Using personal and family narratives for the purpose of diagnosis and treatment; incorporating and interpreting stories told in treatment can become a useful tool in the clinicians' toolbox.
\end{abstract}

KEY WORDS: family and child psychotherapy, heroic journey, differentially able, attachment, narrative, therapeutic storytelling

Wiad Lek. 2021;74(11 p.l):2840-2845

\section{INTRODUCTION}

This paper explores the use of narrative techniques in psychotherapeutic assessment and treatment of families and children, specifically, those with special needs. Frequently, such families present with the heightened levels of stress, which are even higher among families of children on autistic spectrum [1]. Subjective feelings of stress complicate family relationships [2]. Comorbid clinical issues may include marital discord, trauma, grief and loss, domestic violence, poverty, abuse and neglect. The abovementioned factors negatively influence the quality of parental attachment; in turn, deviations in early attachment impact consequent adult functioning [3]. Lowered self-esteem can also originate from the unspoken implicit beliefs that their children are perceived as weird and "uncanny" [4]. Such internalized negative self-image may create obstacles to participation in therapy, ultimately undermining the treatment success.

Parent involvement is crucial for the success of relationship-based treatment interventions. Likewise, parent's input is necessary for forming the bond with the child. S. Greenspan [2] holds that the affective "glue" becomes the nutritional component assuring healthy maturation of the child. At times, mental health clinicians walk the tight rope when the identified patient is a child and not a family, or when parents are resistant to the clinician's probing into the seemingly unrelated family history. When it comes to traumatic experiences, including child's disability, "the first step should be assessing parental trauma and attachment history" [3]. Clinicians need to engage parents sufficiently as to collect essential information on their own functional emotional functioning [2]. However, parents' responses may range from skepticism and distrust to denial and anger.

Collecting family history is not over after the initial interview. The backstory told to an active listener can be re-narrated multiple times, and subsequently used for many purposes, from establishing therapeutic alliance to planning interventions. We offer the concept of the heroic journey borrowed from comparative mythology as an information gathering and therapy tool. Narrative model proposed herein can also be successfully applied as a free-standing treatment approach that is aimed at strengthening self-image, identifying coping skills and promoting regulatory and reflecting capacities.

Non-mental health specialists across medical and health-related disciplines that champion the whole-person treatment philosophy can find it daunting to delve into a family history. The proposed model offers non-intrusive, 
respectful yet comprehensive tool for collecting family information in the non-judgmental fashion and can be used by psychotherapists, pediatricians and allied health professionals practicing in the relationship-based paradigm.

\section{THE AIM}

The purpose of this study is to explore and corroborate personal and family narratives within the framework of "heroic journey", delineate function of the narrative in the diagnosis and treatment of families of children with special needs, and to describe the process of improving psychological well-being of these families.

\section{MATERIALS AND METHODS}

The study material consisted of articles on the subject found in American and international databases (Springer, Thompson ISI's Web of Science, Scopus and PsycINFO, Google Scholar), using keywords "family and child psychotherapy", "heroic journey", "differentially able", "attachment", "narrative", "therapeutic storytelling". Two case vignettes, parents of a) a special-needs adult and b) a preteen psychotherapeutic patient, illustrate application of the heroic journey narrative in psychotherapeutic treatment.

\section{REVIEW AND DISCUSSION}

\section{LITERATURE REVIEW}

Stories are a natural way for our psyche to perceive and organize information about the world. J. Hillman [5] believed that each person lives in his plot, which develops according to the laws of certain genre and has certain predisposed resolution. The significance of stories is substantiated by representatives of various branches of knowledge. In particular, "the psychologist George Kelly has described how our personalities grow out of the stories we have chosen to construct from our perceptions of what has happened to us, and how these stories influence our future expectations. Similarly, sociologist Peter Berger has emphasized the importance of stories in shaping social realities, showing how people\&apos;s characteristic stories change as they progress from one life theme to another" [6]. Representatives of the neuropsychological point of view, D. Siegel and T. Bryson, note that the experience of storytelling helps to create new neural pathways and increase brain connectivity [7].

The experience of the authors' practical work shows that it is important that the client can tell his/her own story, rethink life events, transform and tell them in a new way, reprocessing, justifying or accepting the past. The task of psychotherapy is to facilitate storytelling and assist in finding new interpretations and solutions. Using the heroic journey model allows therapists to identify main (archetypal) "characters", reframe the events in terms of the classical monomyth, and move beyond merely factual, in the attempt to strengthen the client's sense of self and the quest for meaning making.
Retelling one's story is at the core of talk therapy. The study by J. Adler [8] demonstrates that clients told stories about their experiences with the emerging sense of agency that also increased over the course of treatment. Furthermore, coherence of narrative is shown to be associated with secure attachments [7]. Therapeutic value of storytelling is preconditioned linguistically and psychologically, as well as by the neural wiring, and doesn't need to be vouched for; bringing the narrative threads together in the coherent fashion makes for a sound therapeutic goal.

The narrative discourse in the therapeutic setting can take different shapes and forms, from the repetitive circle to the upward bound arrow. Narratology, initially a literary theory, lends a model of a labyrinth which encompasses the story itself, with all its (archetypal and repeating) elements, and the way a story is told, and compares the narrative journey to travels through such labyrinth [9]. First labyrinths imitated intricate patterns built by the intestines of slaughtered animals. Minotaur's labyrinth is one of the most famous. As per Greek mythology, Minotaur, a monstrous creature with the bull's head on a man's body, dwelt at the center of the elaborate labyrinth constructed for him on the island of Crete. In the myth about the Labyrinth, the Cretan princess Ariadne fell in love with the hero, Theseus, who had ventured to kill the monster, and helped him navigate his way back by giving him a ball of thread that allowed to retrace his steps.

Similar mythical plots can be traced in the narratives of many clients; it is fully explained by C. Jung's theory of the collective unconscious. He argued that "deposits of the constantly repeated experiences of humanity" are characteristic of people; there's "a kind of readiness to reproduce over and over again the same or similar mythical ideas...." [10]. This shared memory of universally meaningful emotional experiences resonated in the concepts of hero and/or heroine that transcend time, place and culture. Jung called these recurring personalities archetypes, from the Greek word archetypes, meaning "first of its kind." Theory of archetypes, in turn, preceded the creation of Campbell's monomyth.

The heroic journey is essentially a resilience model that can be utilized across ages, settings, and with most clinical issues. Originally coined by J. Campbell [11], this universal storytelling framework encompasses cultural and spiritual tradition from around the globe and across time. Way beyond the content of people\&apos;s life stories, the storytelling process is also essential to understanding the historically significant role of the narrator (genograms [12] can effectively delineate his/her place in the family constellation) and his/her reflective capacity. The purpose of a story, the role of the listener, and storytelling patterns influence the way stories are told, shape the narrative identity of the storyteller and, ultimately, present-day decisions and behaviors.

Research on narrative identities focuses on thematic elements of personal narratives. McAdams delineates seven constructs: redemption, contamination, agency, communion, exploratory narrative processing, coherent positive resolution, and meaning making [13]. The purpose of the 
(symbolic) heroic journey is to reach all of them, one by one, and finally achieve the stage of meaning making. A psychoanalytically minded therapist may call this meaning making "an insight". During the reconstruction of our own stories, we rely on the key, "nuclear" episodes, which served as turning points in the development of personality. Response to the nuclear episodes, too, may differ: the narrator with a strong motivation to power will seek to seize the reward, while those looking for intimacy will focus on achieving unity. From the DIR perspective [2], the higher functional emotional levels get activated while the storyteller tries to make sense of the described event from the family past and to express his/her attitude or take a moral stand.

Byng-Hall [14] remarks that the term 'myth' implies a false belief in certain contexts. Cultural myths, on the other hand, often take the form of stories. He further describes family mythology as a combination of the family's beliefs about itself (myths) and stories and legends that illustrate those beliefs. As we try to look at the family as people who jointly recreate shared history, it is hard not to notice that in many families there are shared anecdotes and legends easily acknowledged by all members; judgments and conclusions can vary greatly but the story itself is a fixed presence in members' lives, even though open for interpretation. We all recall and subsequently reconstruct, or even fully redesign family stories. It occurs spontaneously and continuously, from almost automatic retelling of events of the day at dinner, to reminiscing about the traumatic or funny anecdote at a family function. In this, barely conscious, process we usually welcome the input of others who might have been a witness or heard the same story many times from different narrators within the family. While members create their very own (sometimes, multiple) versions of the same facts from the shared history, they arrive to the better understanding of who they are. That's how myths develop and grow.

There are character types who typically appear in story after story. Review of literary tradition reveals that the protagonist types who recur in these stories fall into seven (some scholars suggest, sixteen) distinctive categories. Terminology borrowed from the field of hermeneutics may be helpful in classifying them. In V. Propp 's system, there are seven archetypal characters that reappear in folk tales and literary works: the villain, the donor, the helper, the princess and her father, the dispatcher, the hero (victim) and the false hero [15]. In the context of the family narrative, the above roles are not set in stone. While narrating family stories, parents may take on roles of these characters one by one or assign them to various family members at different times. Intonation and content of these tales from the past are linked directly to the subjective sense of safety, security and well-being of children in the family.

Types of narrators also differ. Notably, "the narrator factor" influences and shapes not only the form, but also the context of a story told. It is a known fact that the same event can be interpreted and subsequently described in many ways, "Rashōmon" by Akutagawa a textbook example of such phenomenon. The resourceful narrator (the hero or the helper) is radically different from the victim or the false hero. Change of personal stanza during the retelling helps to shape the new myth: "In reacting to narratives, children grow in their ability to compare their constructs of the world with others', and they learn to question whether their system of expectations is adequate for the future. "Storying," in other words, is central to personal and ethical development "[6]. The narrator plays a role that may be misconstrued. Therapist's interpretation is crucial to moving the narrator closer to insight. While some myths from the past get debunked, family members may give up the passive role of "the victim of the circumstance" or modify the behaviors of learned helplessness to the position of the active resourcefulness.

The narrative in the therapeutic discourse can follow chronology or be non-chronological, "daisy-chain", when the narrator offers episodes drawing from and referring to a present-moment, parallel event. It requires a good observer to weave the episode into one whole piece, together with the previous material. It may so happen that the narrator may have difficulty accepting more coherent version of a story or, conversely, may be compelled to retell the episodes in the chronological order as she sees it. A proliferation of empirical research studies focused on narrative identity sufficiently and convincingly explored its relationship with psychological well-being. It was found to spur short-term personality change via an emphasis on narrative identity as it relates to mental health $[8,13,14]$.

Therapeutically meaningful experience of storytelling is more than just the return from the ordeal, or from the center of the labyrinth: it requires a so-called "spiral return" (Abrams) [16], allowing the storyteller to grow in the process and leaving room for the emergence of higher functional emotional developmental levels: as the mature mind returns to the memories of the childhood, the experience is applied to the child's unconditional acceptance of the world.

Since the story of a heroic journey often resembles journey through a maze, the role of the guiding active listener - a psychotherapist - is very important. If we are to use Campbell's constructs, a therapist can be a mentor, giving direct suggestions, an ally or a helper at the challenging juncture, but most importantly, the therapist becomes witness to the heroic handling of the challenge. Such interviewing/genogram techniques as reframing, clarification, interpretation and generalization [12] can propel the story and build emotionally meaningful connections. One can say that killing Minotaur necessitates getting equipped with better coping devices. Clinician's gentle prodding and attention to the storyteller becomes the guiding principle. Therapist as an affectionate, clue-offering (scaffolding, in Greenspan's [2] term) facilitator and protector (Ariadne of the myth) who provides guidelines; thus, facing the central part, the inner conflict of the story-labyrinth becomes less threatening to the storyteller and assure his/her safe "return" to the present. 


\section{CASE VIGNETTES}

\section{"A PRINCESS AND HER FATHER", POSITIVE SELF-TRANSFORMATION THROUGH THE NARRATIVE.}

A 60-y. o. male self-referred to treatment due to lifelong difficulties with social skills, obsessive compulsive traits and navigating family relationships, specifically, conflicts with the 20-y. o. daughter. "I think I am struggling with Asperger's," he stated at intake. He further discussed his "compulsiveness", need for maintaining things in the same order and adhering to a schedule, and feeling totally devastated at the smallest change of routine. He has been in individual therapy because of the above issues for many years, with moderate success.

$\mathrm{Mr}$. C is married for 33 years and has two daughters. His older daughter, 27, is married with children, and lives independently. His younger daughter Lisa is single, unemployed, and lives with patient and his wife. She is diagnosed with seizure disorder and borderline personality traits. Her lifestyle is vastly different from her father's; she functions in ways that create tremendous stress for Mr. C: sleeps late, never completes anything, and is chronically late. This led in the past to her being fired and dropping out of academic programs. Mr. C gets very angry at her, belittles and threatens her; his behavior totally ruined father-daughter relationship. Mr. C regrets this estrangement from his daughter and is constantly worried about inability to help her "to shape up." He further described close yet tense relationship with Lisa, with concurrent desires to hold her "captive" (protected) and to encourage her independence.

As Mr. C's answered questions about his daughter's functional emotional development and individual differences (see [2] for the details on DIR assessment), we tried to examine the differences between the parent and the adult child. It became apparent to $\mathrm{Mr}$. C that Lisa and he functioned at the different pace; their sensory preferences were vastly different, and their circadian rhythms mismatched. Proceeding to Mr. C's family genogram, we found out that he did not know about his predecessors beyond his parents' generation, as he comes from the family of Holocaust survivors. He recalled that his mother was extremely compulsive and structured in her behavior, which caused perpetual anguish to him and his siblings. She was never in treatment nor ever was she diagnosed, but Mr. C believed, looking back, that she had Obsessive Compulsive Disorder. His sisters, Deena and Mindy, both functioned with difficulty. While his older sister, Deena, insisted on being called Doctor, she never finished medical school. Over the years, she tried and failed multiple programs, and finally received a certificate of a life coach, but never ever practiced. Mr. C remarked that she was "the handy one" and could perform tasks like fixing household appliances. Mr. C, on the other hand, had difficulty with fine motor tasks his entire life. At the same time, he was the only one who could take care of the financial affairs of his mother and sister Mindy (diagnosed with Bipolar Disorder), organize and plan family gatherings and trips, and maintain in order complex paperwork.
In the course of his narrative, familial patterns became apparent. Reflecting on the session, Mr. C observed how much he resembled his mother in his insistence on sameness, the very behavior that he found so disruptive in his youth. He also observed similarity between Lisa's behavior patterns and issues that had affected his sister Deena's life. He commented that, had his mother recognized the need to support Deena at her "breaking points", Deena would have had a fulfilled professional life. In subsequent sessions, we further expanded and built on this insight. We could identify his emotions, among them, anger at Lisa for getting him in touch with parts of self that reminded him of his mother. Together, we could fantasize about her future "escape", what it would look like and how it repeated his own quest for independence and validation. In a few months, Mr. C reported that Lisa ventured out on a date. "I would never choose that boy if I was her," he remarked in session. Yet, he became more tolerant of Lisa choices overall.

\section{"A DONOR", THE STORY OF REDEMPTION AND CROSSING A PERSONAL THRESHOLD.}

Ms. P brought her 9-y. o. son into treatment because of multiple, previously undiagnosed yet pervasive problems in relating to others and in daily functioning: "homework wars", breaking rules both at home and in school, frequent conflicts with siblings and peers.

Ms. $\mathrm{P}$ is a single parent. Brian is the middle of her three children, and "the unhappiest one." Mom has been a highly functional yet rigid super achiever (she was running a start-up and, on occasion, related difficulty staffing and supervising her employees) and the sole provider. She finds Brian's behavior annoying and sees it as challenging her authority. She admits that at times she resents him.

Family history was explored, including Mom's failed marriage. She was initially vague about the backstory of her marriage and divorcing Brian's father, offering snippets of information in short encounters at the end of Brian's sessions, and avoiding one-on-one sessions by cancelling and rescheduling. She eventually was able to narrate a story of a man who started off as a steady provider but then suffered a mental breakdown, which Ms. P interpreted as a sign of her personal shortcomings in understanding people.

Within the context of the story, Ms. P was encouraged to identify her own role and roles of other family members. She was able to reflect on pressure and expectations imposed by the extended family, and her own need to redeem herself through becoming a strong parent and a provider. Mom's regulatory profile was explored along with Brian's so that coregulation between the two could be achieved. Her ability to assure family's survival was interpreted as "taking all the roles in the family upon herself and becoming both mother and father!" The donor is a person who gives the hero something special, such as a magical weapon or some particular wisdom. Once Ms. P accepted that Brian's behavior was not rebellious or a direct criticism of her, she finally reached out to multiple sources and actively sought comprehensive diagnosis. After a battery of evaluations 
(OT, auditory processing, PT, SLP), it became clear that Brian was experiencing difficulties with motor planning and sequencing, auditory hyper/hyposensitivity, and difficulty converting emotions into words, associated with poor motor planning (speech dyspraxia).

The formation of the narrative identity is simultaneously the ends and the means: in the process of the clinically significant information gathering, while a parent is encouraged to retell the story over and over again, a new narrative identity emerges. Specifically, Mr. C's self-image was negatively influenced by betrayal by the mother. Breaking her spell and, through perceived self-mastery, building independence helped him empathize with his daughter's struggles and eventually accept her quest for independence. The story of transcending from contamination (his own struggles and, later, the struggle to shield Lisa) was reframed as the journey towards the sense of agency. Mr. C's ability to reflect on own actions, seeing the consequences and guessing its impact on others increased during treatment. Identifying patterns (repetition of the family history) helped him to progress to the increasingly enjoyable and positive relationship with his daughter. V. Propp [15] notes that Princess is impossible without her father. Once Mr. C reflected on and adjusted his behavior, Lisa showed improvement.

Ms. P's story, initially a story of contamination, was told from the position of a victim. However, over time, as she better understood her son's behavior and learned how to communicate without haste, anger and frustration, a new narrative identity, that of a donor, emerged: she was able to enlist resources that she found, and strategies learned to reevaluate own function. As a result of work in therapy, Ms. $\mathrm{P}$ was able to make sense of the past events and behaviors, empathize with Brian and provide better support for his self-regulation issues, thus becoming instrumental in his success. In both cases, increased coherence of the family stories led to strengthening attachment.

The story of heroic journey, more complex than a genogram or a family tree, appears to include all narrative threads and episodes, conflicting views, memories, whole or partial - anecdotes about friends, summaries of family tales, histories, intellectual musings. The "heroic journey" that started in the therapist's office can go on indefinitely, reshaping the narrative and making it more coherent. During the "journey" through adversity or challenge, the hero him/herself evolves, getting equipped with better coping devices. Metacognitive clues, constructing together family genogram, using such techniques as reframing and clarification, and giving clients an opportunity to repeat the story again the next time assures that the narrating family member won't get lost in the gruesome or tragic content but will see him/herself as a hero winning the battle or overcoming the unfavorable circumstance, and safely reemerge from the labyrinth. Identity that emerges in such process is the internalized, ever evolving story of the self that each person crafts to provide his or her life with a sense of purpose and unity.

The role of a therapist, the listener to the heroic journey narrative, becomes essential to the success of the therapeutically meaningful, co-constructed storytelling experience.
S/he becomes the vehicle of therapeutic change, reframing the story in "heroic journey" terms and allowing safe space for uncovering the repressed, oftentimes traumatic material from the past. Psychotherapist's remarks and observations help clients to correct errors of judgment, clarify questions, think aloud (non-judgmental reflection on the "morale of the story") and, essentially, activate memory circuits in the brain. Shared implicit therapist-parent relationship allows gentle support and guidance in the process of storytelling. If not the friendly and open-minded clinician offering a leading central idea or some other safety device, the narrator won't dare enter "the labyrinth" of past relationships and events; won't get to the center with its core issues, frightening discoveries or shameful secrets; won't reflect on what's uncovered without losing his/her identity or self-respect, and safely reemerge. In the narrative terminology, the hero needs to get to the core issue, win the battle, and return unscathed.

The process of reconstructing family history in multiple repetitions and iterations in front of the genuinely concerned, sympathetic yet impartial outsider allows full integration of past experiences where subsequent healing occurs. The experienced listener will dot on the important facts and emotional truths, on replay of the main scenes and events and analysis of the power balance within the family. In this process, listening becomes a boon (reward) of its own. A psychotherapist can also supply questions that propel the story, or provide pointers to guide the client to find ways out of the situation: "What could a helper (e.g., Fairy Godmother or Prince Charming) help you with in this situation?" Also, using the heroic journey model as the treatment template allows for the overall positive reframing of the family history ("Yours was such an adventurous move!", "I recall your miraculous story of...").

Metacognitive regulation and tips from the listener-clinician help to transform the position, passing through the stages of incompleteness, positioning, implementation and completion, and are reflected in the everyday functioning of the communication and not only the child but the whole family. As therapists we are looking for patterns and repetitions, as well as getting back to the entrance which is usually an exit. It may prove useful to think about the therapeutic storytelling as the upward spiral where rethinking and rewriting the story previously told may help change the meaning of the actual event and promote healing from the past trauma.

\section{LIMITATIONS AND DIRECTIONS FOR FURTHER RESEARCH}

The objectives of this paper are to become comfortable with the use of the heroic journey vocabulary, learn its use for establishing therapeutic alliance with families and caretakers, elicit stories from family legends to narrated play scenarios, and positively reframe the narrated content with the goal to promote self-reflection, healing and/ or coping while move patients and their family members up the developmental ladder. Increasing coherence of the 
family stories leads to strengthening attachment patterns (Siegel) [7]. This is definitely worth further examining. Another direction for future research is using heroic narratives with children who witnessed violence or experienced psychological trauma, as well as in play-based therapy dealing with attachment disruptions. In such treatment, the "heroic journey" storytelling creates opportunities for reprocessing and reframing memories. Weaving narration and the running commentary into the actual traumatic reenactment can facilitate healing.

\section{CONCLUSIONS}

The heroic journey narrative model has significant psychotherapeutic value. Using it for the purposes of diagnostic interview and, later, incorporating elicited material in treatment can become a useful tool in the clinicians' toolbox and ultimately benefit, among other groups of clinical population, many families of children with special needs. Learning occurs in tight corridors of the family narrative labyrinth. Family's success is child's success. Following family "heroic" stories and reframing them along the way strengthens parents' self-esteem and positively affects their relationship with the children, setting the ground for mutually respectful and robust growth and learning.

\section{REFERENCES}

1. Estes Munson J., Dawson G., Koehler E. et al. Parenting stress and psychological functioning among mothers of preschool children with autism and developmental delay. Autism, 2009;13(4):375-87. doi: 10.1177/1362361309105658.

2. Greenspan S. Engaging Autism. DaCapo Press. 2006, 502p.

3. Itskovich G. Infant and parent mental health: developmental trajectory as a communal concern: Developmental trajectory as a communal concern. Mental Health: Global Challenges Journal. 2019; 1: 29-31. doi: 10.32437/mhgcj.v1i1.14.

4. Harvey C. The Uncanny Effect of Disability: Uncomfortable Maternal Love for a Disabled Child. Contemporary Psychoanalysis. 2020;56:1-28.

5. Hillman J. Healing fiction. Tompson: Spring Publications. 1998, 280p.

6. Pradl G. Narratology: the study of story structure. ERIC Clearinghouse on Reading and Communication Skills, Urbana IL. 1984, 702p.

7. Siegel D.J., Bryson T. P. The Whole Brain Child. Delacorte Press. 2011, 52p.

8. Adler J.M. Living into the story: Agency and coherence in a longitudinal study of narrative identity development and mental health over the course of psychotherapy. Journal of Personality and Social Psychology, 2011;102(2):367-89. doi: 10.1037/a0025289.
9. Solnit R. The Faraway Nearby, Penguin Books. 2013, 259 p.

10. Jung C.G. Psychology of the Unconscious. New York: Dover Publications. 2003, 306p.

11. Campbell J. The Hero with a Thousand Faces. Princeton University Press. 2004,76p.

12. McGoldrick M. Genograms in Family Assessment. 3rd Ed., Norton. 1986, $456 \mathrm{p}$.

13. McAdams D. "Narrative Identity". Current Directions in Psychological Science. 2013;22 (3): 233-238. doi:10.1177/0963721413475622.

14. Byng-Hall J. Evolving ideas about narrative: the re-editing of family mythology. Journal of Family Therapy. 1998; 20; 133-141.

15. Propp V. Morphology of the Folktale, trans. Austin: University of Texas Press. 1968, 364p.

16. Abrams M. H. Mirror and the lamp: romantic theory and the critical tradition. London: Oxford University Press. 1953, 503p.

ORCID and contributionship:

Galina Itskovich: 0000-0002-1722-2203 ${ }^{A, B, D, F}$

Elena Shopsha: 0000-0002-2192-8911 ${ }^{\text {E,F }}$

Liudmyla Fedosova: 0000-0002-2582-9865 ${ }^{E, F}$

Conflict of interest:

The Authors declare no conflict of interest

\section{CORRESPONDING AUTHOR Galina Itskovich \\ LCSW P.C. (Private Practice) \\ 1525 Marine Parkway, 11234 Brooklyn, New York, USA \\ tel: 17187818513 \\ e-mail: galaitsk@gmail.com}

Received: 02.06 .2021

Accepted: 14.10 .2021

A - Work concept and design, B - Data collection and analysis, C - Responsibility for statistical analysis,
D - Writing the article, E - Critical review, F - Final approval of the article 


\title{
LESSONS FROM THE HEART: REVISITING THE PSYCHOCARDIOLOGICAL THEORIES OF ARISTOTLE IN THE $21^{\text {ST }}$ CENTURY
}

DOI: 10.36740/WLek202111129

\author{
Christos Tsagkaris' ${ }^{1}$, Dimitrios V. Moysidis ${ }^{2}$, Svetlana Storozhuk ${ }^{3}$, Natalija G. Mozgova ${ }^{4}$, Andreas S. Papazoglou², \\ Anna Loudovikou' ${ }^{2}$, Galyna Poperechna ${ }^{5}$ \\ 'NOVEL GLOBAL COMMUNITY EDUCATIONAL FOUNDATION, HEBERSHAM, NSW, AUSTRALIA \\ ${ }^{2}$ ARISTOTLE UNIVERSITY OF THESSALONIKL, THESSALONIKI, GREECE \\ ${ }^{3}$ TARAS SHEVCHENKO NATIONAL UNIVERSITY OF KYIV, KYIV, UKRAINE \\ ${ }^{4}$ DRAGOMANOV PEDAGOGICAL NATIONAL UNIVERSITY, KYIV, UKRAINE \\ 5TERNOPIL VOLODYMYR HNATIUK NATIONAL PEDAGOGICAL UNIVERSITY, KYIV, UKRAINE
}

\begin{abstract}
The aim: To provide an overview of the psychocardiological theories of Aristotle and discuss their implications in contemporary research and clinical practice Materials and methods: Specific keywords (brain, heart, cardiology, psychiatry, psychocardiology, Aristotle, cardiocentric) were subjected to list down and analyze the literature in PubMed and Google Scholar. All types of articles, including original research, systematic reviews, and meta-analyses, along with gray literature dating back to 1950 . We excluded studies reporting a significant conflict of interest and findings dispersed through popular media instead of peer-reviewed journals. Out of all articles, as per inclusion criteria and readings, we selected 26 for further analysis and narrative to build.

Conclusions: Although this knowledge is currently outdated, revisiting his findings and methods is a source of lessons and inspirations for modern researchers and practitioners.
\end{abstract}

KEY WORDS: cardiology, psychiatry, Aristotle, psychocardiology, psyche

Wiad Lek. 2021;74(11 p.l):2846-2849

\section{INTRODUCTION}

Psychocardiology is a complex term generated by the need to understand, conduct research and improve clinical practice based on the heart - brain interaction. Humanity has known these interactions since the era of Hippocrates. A wealth of medical, erudite and non - erudite sources have emphasized the connection of cardiovascular and mental health and the devastating impact of mental health conditions on the heart. Harvey, the first anatomist to accurately describe the circulatory system has stated that "Every affection of the mind that is attended with either pain or pleasure, hope or fear, is the cause of an agitation whose influence extends to the heart"[1].

The $21^{\text {st }}$ century has marked a new era of investigating the heart - brain interaction from the ground up, including its epidemiological and pathophysiological characteristics. Evidence indicates that cardiovascular and psychiatric conditions have a bidirectional association. Genetic, epigenetic, social and environmental factors contribute to a "coalition" of mental stress with unhealthy nutrition and lack of physical exercise paving the way to the co-occurrence of dyslipidemia, hypertension and coronary heart disease with depression, sleep disorders and anxiety disorders. Frequently, a feedback loop is detected between these co- morbidities with sleep disorders aggravating hypertension [2] and, conversely and emotional instability precipitating arrhythmias [3]. Psychiatric comorbidities can increase the length of hospitalization of patients with heart failure to up to 9 days [4]. While the prevalence of simultaneous mental and cardiovascular morbidity is highly variable, both of them account for increased global rates of morbidity, mortality, social burden of disease and healthcare associated costs [5]. Both fields would benefit from relevant - and if possible joint - health promotion, prevention and early diagnosis strategies. In recognition of the aforementioned, terms and concepts such as "psychocardiology" and "heart - brain connection" or "axis" have emerged.

Nevertheless, global funding for cardiology exceeds funding for psychiatry, which equals to a mere $0.3 \%$ of the total development assistance for health [6]. Although stigmatization can contribute to the development of cardiovascular diseases, individuals with hypertension or atrial fibrillation are less likely to face discrimination than individuals with bipolar disorder and schizophrenia [7]. In response to these disparities between the two fields, it is pivotal to raise more awareness about the heart - brain connection and encourage relevant research and evidence based interventions at clinical and community level. 
History of Medicine and medical humanities have a record of contributing to spreading awareness about important public health and clinical issues. Historical and philosophical perspectives can shed light to unseen aspects of the brain - health axis, inform practitioners about relevant popular perceptions and their roots, and set ethical boundaries and even fuel novel concepts [8]. In particular, revisiting the work of Aristotle, an influential philosopher leading the cardiocentric school of thought highlights the long-term perception of the health - brain connection and helps conceptualize psychocardiology in the $21^{\text {st }}$ century.

\section{THE AIM}

To present the philosophical theories of Aristotle about the heart - brain connection and discuss their practical implications in contemporary psychocardiology research and practice.

\section{MATERIALS AND METHODS}

Specific keywords (brain, heart, cardiology, psychiatry, psychocardiology, Aristotle, cardiocentric) were subjected to list down and analyze the literature in PubMed and Google Scholar. All types of articles, including original research, systematic reviews, and meta-analyses, along with gray literature dating back to 1950 . We excluded studies reporting a significant conflict of interest and findings dispersed through popular media instead of peer-reviewed journals. Out of all articles, as per inclusion criteria and readings, we selected 26 for further analysis and narrative to build.

\section{REWIEV AND DISCUSSION}

\section{ARISTOTLE IN HISTORY}

Aristotle was born in 384 BC in Stagira, Chalkidiki, Greece. The son of a physician, who grew up among his father's medical writings, was introduced to philosophy by the prominent Plato (c. $428-348 \mathrm{BC}$ ). After the demise of his teacher he founded the peripatetic school of philosophy in Athens and served as the tutor of Alexander the Great
(356-323 BC). He spent his last days in Chalcis, Euboea Greece and died in the waters of the Euboea gulf while studying the peculiarities of the local stream. Aristotle's work is astonishingly diverse covering several major areas of human inquiry, from art, ethics, rhetoric, and politics to physics, biology, and even metaphysics. Being familiar with human health and disease since his early years, he paid special attention to biology, physiology and medicine. His relationship with Alexander helped him obtain and study animals and specimens found all the way from Egypt to India. Aristotle authored nine anatomy books and two treatises on medicine, which have not been preserved. His philosophical theories and observations related to biology, anatomy, physiology and reproduction can be traced in History of Animals (Historia animalium), Movement of Animals (De motu Animalium) and Generation of Animals (De generatione animalium) [9].

\section{CARDIOCENTRIC PHILOSOPHY - THE HEART AS THE HABITAT OF THE PSYCHE}

Aristotle considered the heart as the most prominent organ of the body. According to him, cognition, motion, and sensation were anatomically and physiologically based on the heart, while the brain served as a pump and a cooler supporting the circulation of blood [10]. The whereabouts of this model dated back to ancient Egypt and Mesopotamia. This perception has been "sang" in Homeric sagas and was endorsed by philosophers such as Empedocles, physicians such as Philistion of Lokri or even medical communities of the era such as the School of Knidos in Asia Minor. Ibn Sina, the father of Arab Medicine incorporated the psychocardiological theories of Aristotle to his work and practice. Variants of the theory survived until Renaissance in erudite medicine and even until the $19^{\text {th }}$ century in folk medicine textbooks $[11,12]$.

Aristotle has epitomized the cardiocentric (heart - centered) model and attempted to provide biological evidence for this by means of embryology, comparative anatomy and physiology. He elaborated on the embryology of the heart in the second book of Generation of Animals (De Generatione Animalium) indicating the heart as the first

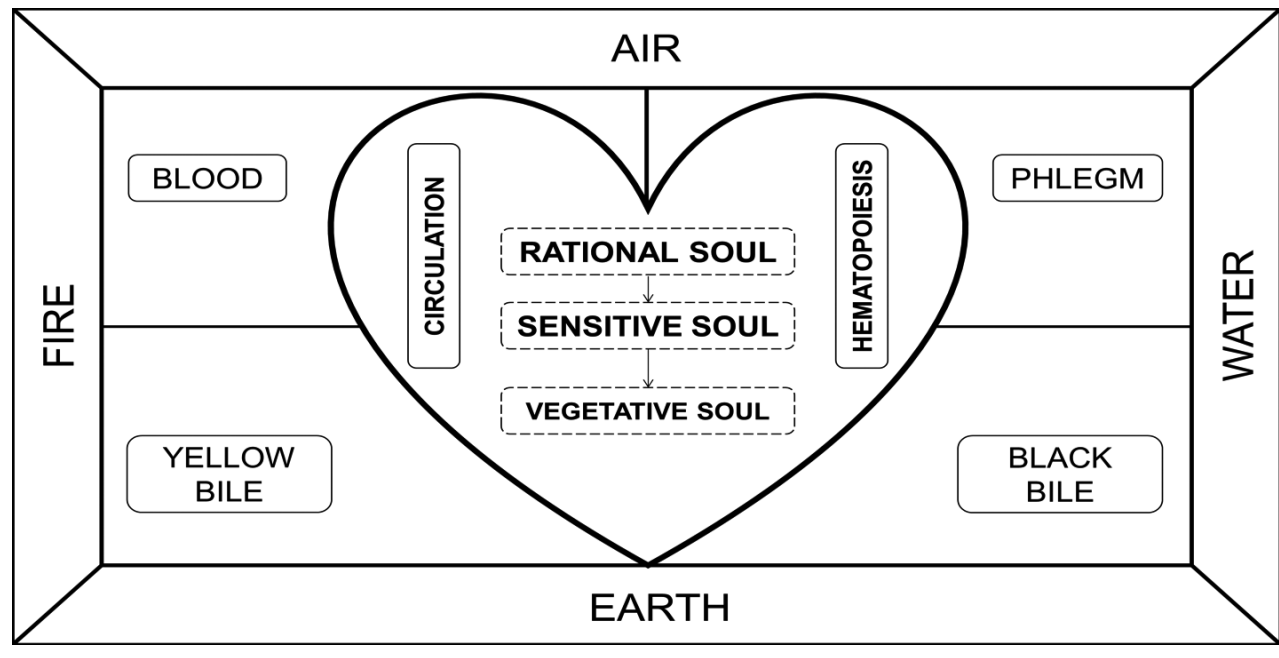

Fig. 1. The tripartite soul (psyche) located in the heart and combined with the four humors and the cosmic elements according to Aristotle and the ancient Greek medical, philosophical and cosmological paradigm. 
organ to form in the body of the fetus. Aristotle used to dissect fetuses of several species - but not humans as it was prohibited by religious norms of the era - and justified the primacy of the heart because of the need of heartbeat for the development of the fetus. He also assumed that the heart served as the source of sensation [13].

In the third book of the History of Animals (Historia animalium)[14], Aristotle introduced the concept of cardiac cavities and described the heart as a triventricular structure. He was unable to detect the fourth cavity due to the way he strangulated animals before dissection. Being unaware of the connection between arterial and venous circulation, he dedicated one ventricle to each leg of (his understanding of) the circulation and associated the remaining third ventricle with metaphysical purposes. This was in accordance to hylomorphism, a central doctrine of Aristotle's natural philosophy suggesting that every natural bodies host two intrinsic principles, one potential and one actual[15]. In this frame it was possible for the heart to regulate the circulation while hosting the rational soul, the highest intellectual component of the human being[16]. An overview of the soul (psyche) in the philosophy of Aristotle is presented in Figure $1[17,18]$.

The cardiac neurophysiology of Aristotle is presented in On Youth, Old Age, Life and Death, and Respiration (De Juventute et Senectute, De Vita et Morte, De Respiratione) and in Parts of Animals (Partibus animalium). According to Aristotle, pulsation derives from the inmost warmth, a metaphysical vital force of the psyche residing in the heart. Blood, one of the four vital humors, was supposed to be generated in the heart, transport the vital force of sensation, movement and cognition throughout the body and then evaporate. Despite its metaphysical connotations, the blood evaporation theory was based on Aristotle's observations of the arterioles, whose connection to trichoids, venules and veins could not be visualized in the dissections performed by the philosopher $[19,20]$. It becomes evident that Aristotle considered cognitive, affective functions and mental wellbeing tightly joined with physiological cardiovascular function. Aristotle's cardiovascular physiology could be rephrased as "I have a heartbeat and therefore I am".

\section{ARISTOTLE'S PSYCHOCARDIOLOGY IN THE 21ST CENTURY}

The perception of human physiology has changed a lot since the era of Aristotle. In spite of his metaphysical bias and the moral restrictions of the era, Aristotle worked hard to discover the biological evidence of the heart brain connection. Nowadays, revisiting his work can provide researchers, clinicians and intellectuals with a number of lessons.

Biological evidence is important and its sources should be as diverse as possible. However, its results can be misinterpreted and should be reconsidered in the light of new evidence. Aristotle dissected a great variety of animals at different stages of their development, seeking anatomical and physiological evidence for his theories about the soul and the heart. Due to the lack of equipment and techniques, he misinterpreted some of his research, failed to describe the circulation and was led to faulty conclusions. Nevertheless, Aristotle made a paradigm shift in an era, when most intellectuals would only develop theoretical concepts and argue over them. His approach to biology and medicine inclined towards observation and experiment, as suggested by Hippocrates and his disciples [21]. Contemporary intellectuals can benefit from a deeper understanding and even involvement in life and natural sciences [22].

Vaguely interpreted, the hylomorphic perception of Aristotle affirms that each organ has hidden cultural and social representations. Nowadays, the heart is regarded as a vital organ with a prominent role in circulation and homeostasis, an innate system of electrophysiology and a diverse spectrum of pathologies. Nevertheless, the heart is still considered as a residence or a host of sentiment and affection in popular beliefs. In religious context, the heart remains connected to the soul and psyche. Modern medicine can take into account these beliefs in its efforts to raise awareness about cardiovascular and psychiatric diseases and comorbidity among lay people. Pastoral care can help, those who freely seek it as a complement to evidence based medicine, understand and even relieve their own cardiovascular and mental risk factors. Evidence has highlighted spiritual and social perceptions as a determinant of coherence and mental wellbeing in rural populations with (usually) limited access to health [23-25] aimed at exploring an association between spirituality, religiousness, and sense of coherence in a population group residing in a rural area of Crete, Greece. STUDY DESIGN AND METHODS: The study was conducted during the period 2007-2009. Subjects aged 65 years and older $(n=$ 118. In this context, psychocardiology is an ideal field for compassionate biopsychosocial human centered interventions and related research [26].

Multidisciplinarity is an equally important lesson from Aristotle's psychocardiology. Modern medicine can be enriched with philosophy, particularly when it comes to ethical boundaries and considerations and communication with patients. Beyond erudite philosophical treatises, art, proverbs, fiction and literature can help physicians and researchers understand risk and stigmatization factors and decode the hesitancy of the public to seek medical attention. Acquiring this knowledge - without neglecting continuous medical education - has also been shown to help physician and healthcare practitioners become more resilient and mindful [27].

\section{CONCLUSIONS}

Health promotion, prevention and early diagnosis constitute a shared goal by healthcare professionals in cardiovascular and psychiatric wards, which can be enhanced by cooperation between them. Revisiting the work of Aristotle provides methods and principles to advance psychocardiology research and practice in a biopsychosocial and human - centered context. 


\section{REFERENCES}

1. Halaris A. Psychocardiology: Understanding the Heart-Brain Connection: Part 1, https://www.psychiatrictimes.com/view/ psychocardiology-understanding-heart-brain-connection-part-1. [date access 23.08.2020]

2. Makarem N., Alcántara C., Williams N. et al. Effect of Sleep Disturbances on Blood Pressure. Hypertens. 2021; 77: 1036-1046.

3. Buckley U., Shivkumar K. Stress-induced cardiac arrhythmias: The heartbrain interaction. Trends Cardiovasc Med 2016; 26: 78-80.

4. Carter P., Reynolds J., Carter A. et al. The impact of psychiatric comorbidities on the length of hospital stay in patients with heart failure. Int J Cardiol. 2016; 207: 292-296.

5. Mensah G.A., Collins P.Y.Understanding mental health for the prevention and control of cardiovascular diseases. Glob Heart. 2015; 10: 221-224.

6. Liese B.H., Gribble R.S.F., Wickremsinhe M.N. International funding for mental health: a review of the last decade. Int Health. 2019; 11: $361-369$.

7. Panza G.A., Puhl R.M., Taylor B.A. et al. Links between discrimination and cardiovascular health among socially stigmatized groups: A systematic review. PLoS One. 2019; 14: e0217623-e0217623.

8. Scally G., Womack J. The importance of the past in public health. J Epidemiol Community Health. 2004; 58: 751 - 755.

9. Tsagkaris C., Kalachanis K., lakovis P. et al. Heart in the work of the eminent Greek philosopher and physician Aristotle (384-322 BC). Arch Balk Med Union. 2020;55(4):728-730. doi:10.31688/ ABMU.2020.55.4.24.

10. Dede E., Zalonis I., Gatzonis S. et al. From discovering to better understanding the relationship between brain and behavior. Integrative Neuroscience Research. 2017;1(1):5-16.

11. Bestetti R.B., Restini C.B.A., Couto L.B. Development of anatomophysiologic knowledge regarding the cardiovascular system: from Egyptians to Harvey. Arq Bras Cardiol. 2014; 103: 538-545.

12. Tsagkaris C., Koliarakis I., Tselikas A. et al. The Anatomy in Greek latrosophia during the Ottoman domination era. J BUON. 2021;26:33-38.

13. VanPraagh R.,VanPraaghS. Aristotle's\&quot;triventricular\&quot; heartand the relevant early history of the cardiovascular system. Chest. 1983;84:462.

14. Aristotle. The history of animals. http://classics.mit.edu/Aristotle/ history_anim.1.i.html. [date access 23.08.2020]

15. Sallam H.N. Aristotle, godfather of evidence-based medicine. Facts, views Vis 0bGyn. 2010; 2: 11-19.

16. Pandya S.K. Understanding brain, mind and soul: contributions from neurology and neurosurgery. Mens Sana Monogr. 2011; 9: 129-149.

17. Santoro G., Wood M.D., Merlo L. et al. The anatomic location of the soul from the heart, through the brain. To the whole body, and beyond: a journey through western history. Science. And philosophy.. Neurosurgery. 2009; 65: 633-643.

18. Kalachanis K., Panou E., Kostikas I. et al. From the human elements to the elements of the Universe. Appl Sci Reports, PSCI Publ. 2016. doi: 10.15192/PSCP.ASR.2016.14.2.219222.

19. Nemesius. De Natura Hominis B. Einarson, Nemesius of Emesa, [Corpus medicorum Graecorum. https://www.researchgate.net/ publication/307599542_Judaic_Authority_in_Nemesius_of Emesa's_De_natura_hominis_390_CE [date access 23.08.2020]

20. Kalachanis K., Michailidis J.The Hippocratic View on Humors and Human Temperament. European Journal of Social Behaviour. 2015;2(2): 1-5.

21. Yapijakis C. Hippocrates of Kos, the Father of Clinical Medicine, and Asclepiades of Bithynia, the Father of Molecular Medicine. In Vivo (Brooklyn). 2009; 23:507- 514.
22. Laplane L., Mantovani P., Adolphs R. et al. Opinion: Why science needs philosophy. Proc Natl Acad Sci USA. 2019; 116: 3948-3952.

23. Stefanaki I.N., Shea S., Linardakis M. et al. Exploring the association of sense of coherence, and spiritual and religious beliefs in a rural population group on the island of Crete, Greece. Int J Psychiatry Med. 2014; 47: 207-230.

24. Anyfantakis D., Symvoulakis E.K., Linardakis M. et al. Effect of religiosity/ spirituality and sense of coherence on depression within a rural population in Greece: the Spili III project. BMC Psychiatry. 2015; 15: 173.

25. Romash I.B., Mischuk V.H., Romash I.R. Relation between the level of ghrelin. Prostaglandins E2 and F2a and daily pH monitoring data in patients with a combined course of gastroesophageal reflux disease and undifferentiated connective tissue disease. Lekarsky Obzor. 2020, 69(8): 245-251.

26. Isaac K.S., Hay J.L., Lubetkin E.I. Incorporating Spirituality in Primary Care. J Relig Health. 2016; 55: 1065-1077.

27. Ellis L.D. Using the Arts and Humanities to Build Resilience and WellBeing and Reduce Burnout in Pediatrics Health Leaders. 2019. https:// postgraduateeducation.hms.harvard.edu/trends-medicine/using-artshumanities-build-resilience-well-being-reduce-burnout-pediatricshealth-leaders. [date access 23.08.2020]

\section{ORCID and contributionship:}

Christos Tsagkaris: 0000-0002-4250-574X $X^{A, B, D, F}$

Dimitrios V. Moysidis: 0000-0001-9083-0267 D,E,F

Svetlana Storozhuk; 0000-0002-7947-6268 ${ }^{E, F}$

Andreas S. Papazoglou: 0000-0003-4981-8121 $1^{B, D, F}$

Anna Loudovikou: 0000-0002-5339-1688 B,E,F

Ivan R. Romash: 0000-0002-6591-6613 E,F

Natalija G. Mozgova; 0000-0001-9464-9852 E,F

Galyna Poperechna: 0000-0003-2191-9908E,F

\section{Conflict of interest:}

The Authors declare no conflict of interest.

\section{CORRESPONDING AUTHOR}

Christos Tsagkaris

Novel Global Community Educational Foundation

2770 NSW, Hebersham, Australia

tel: +306980513072

e-mail:chriss20x@gmail.com

Received: 04.06 .2021

Accepted: 12.10 .2021

A - Work concept and design, B - Data collection and analysis, C - Responsibility for statistical analysis, D-Writing the article, $\mathbf{E}$-Critical review, $\mathbf{F}-$ Final approval of the article 


\title{
EFFECTS OF THE EASTERN MIND-BODY PRACTICES ON MENTAL HEALTH DURING THE COVID-19 PANDEMIC: WHEN EAST MEETS WEST
}

DOI: 10.36740/WLek202111130

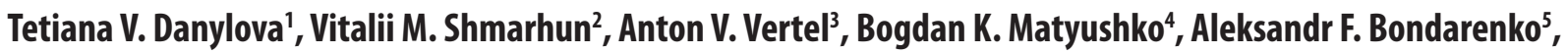 \\ Tetiana Kychkyruk2 ${ }^{2}$ Jørli Petersen ${ }^{6}$ \\ IINSTITUTE OF SOCIAL AND POLITICAL PSYCHOLOGY NATIONAL ACADEMY OF EDUCATIONAL SCIENCES OF UKRAINE, KYIV, UKRAINE \\ ${ }^{2}$ NATIONAL UNIVERSITY OF LIFE AND ENVIRONMENTAL SCIENCES OF UKRAINE, KYIV, UKRAINE \\ ${ }^{3}$ SUMY STATE PEDAGOGICAL UNIVERSITY NAMED AFTER A.S. MAKARENKO, SUMY, UKRAINE \\ ${ }^{4}$ DRAGOMANOV NATIONAL PEDAGOGICAL UNIVERSITY, KYIV, UKRAINE \\ 5KYIV NATIONAL LINGUISTIC UNIVERSITY, KYIV, UKRAINE \\ ${ }^{6}$ INDEPENDENT RESEARCHER, COPENHAGEN, DENMARK
}

\begin{abstract}
The aim: The paper aims at reviewing the recent studies on the impact of the Eastern mind-body practices on mental health during the COVID-19 pandemic.

Materials and methods: The recent studies (2020 - 2021) on the Eastern mind-body practices in combating the psychological impacts of the COVID-19 pandemic were identified in PubMed, Scopus, Google Scholar. Research papers were found by using the keywords "mental health", "psychological impacts of the CoVID-19 pandemic", "Eastern mind-body practices", "meditation", "mindfulness", "yoga", "tai chi", "qigong". A total of 27 selected publications were analyzed based on our criteria. Given the relatively small number of relevant articles in recent years, we also examined papers published before 2020. Along with the aforementioned, the authors used integrative anthropological approach and interpretive research paradigm.

Conclusions: The Eastern mind-body practices are becoming increasingly popular, especially now when the outbreak of COVID-19 has created mental health concerns among the general population worldwide. They may prove an effective preventive or therapeutical intervention for mental health issues during and after the pandemic. However, the underlying mechanisms of these techniques are still insufficiently studied. Therefore, it is necessary to conduct a well-planned study and interpret it from multiply perspectives involving an interdisciplinary team of specialists.
\end{abstract}

KEY WORDS: mind-body medicine, mental health, COVID-19, meditation, mindfulness, yoga, tai chi, qigong, psycho spiritual approach

Wiad Lek. 2021;74(11 p.l):2850-2855

\section{INTRODUCTION}

Although it is too early to talk about a "new post-covid world", more and more researchers warn us about the negative consequences of the COVID-19 pandemic and discuss the measures taken by the world community to cope with it. The new disease has caused physical health concerns and specific traumatic experiences. It affects mental health causing anxiety, depression, stress, fear, xenophobia, stigma, guilt, anger/frustration, sadness, loneliness [1-6]. Social isolation, uncertainty, social distrust, alienation, domestic violence, job insecurity, economic hardship, substance abuse are risk factors for impacting mental health across the world [7-9]. The extensive media coverage of the COVID-19 pandemic turned into "infodemic" that can lead to downstream effects on mental health [10-12]. Health professionals who treat patients with COVID-19 often face mental health problems, and therefore adequate responses to these problems should become an essential part of treatment and prevention measures [13].
Social distancing and a culture of "no touching" have become serious problems. Before quarantine and self-isolation, communication took place in a real environment, where, according to R.A. Wilson, humans play with their bodies, another's bodies and the world around them; there was that playfulness which is a characteristic feature of all obviously healthy persons [14]. But the COVID-19 pandemic has completely changed our reality isolating people and depriving them of their usual contacts. This "forcible alienation" can cause higher levels of cortisol, weaker immune responses to pathogens, depression, anxiety, suicidal thoughts and other conditions [15]. As Jansson-Boyd emphasizes, "once the outbreak is over, one vital challenge will be to reset our thinking about touch, keeping in mind its importance. After all, a hug may be just what we need to move on from the traumatic experience of the coronavirus" [16].

The COVID-19 pandemic has had a dramatic impact on the world and our daily lives, "with seemingly low 
capacity to respond, it is unclear how the world will deal with this looming mental health crisis" [17]. However, unprecedented upheavals like this pandemic could lead to the development of a new system of values that our world has long needed $[18 ; 19]$. Realizing the fragility of human life, instability of social structures under conditions of dramatic challenges and constant changes, humanity needs to return to the vertical principle that shapes deep meanings and enables to maintain physical, mental, and spiritual wellbeing.

\section{THE AIM}

The paper aims at reviewing the recent studies on the impact of the Eastern mind-body practices on mental health during the COVID-19 pandemic.

\section{MATERIALS AND METHODS}

\section{STUDY SELECTION}

The recent studies (2015 - 2021) on the Eastern mind-body practices in combating the psychological impacts of the COVID-19 pandemic were identified in PubMed, Scopus, Google Scholar. Research papers were found by using the keywords "mental health", "psychological impacts of the COVID-19 pandemic", "eastern mind-body practices", "meditation", "mindfulness", "yoga", "tai chi", "qigong".

\section{STUDY SAMPLE AND METHOD}

A total of 270 selected publications were analyzed based on our criteria. We used integrative anthropological approach and interpretive research paradigm.

\section{REVIEW AND DISCUSSION}

Cartesian "mind - body" dualism had led to the collapse of the holistic phenomenon of a human being and eventually "the biological aspects of human illness assumed a predominant role in medical science and practice" [20]. However, within the context of the debate over the relationship between the mind and the brain, the "body - mind" opposition gradually disappears in the process of understanding that psychic phenomena have physical correlates [21]. The mind and the brain are not separate independent entities, but, conversely, represent different aspects of one reality. The aim of a new interpretation of a human is to reintegrate opposite poles and transcend them. The contemporary world demonstrates the urgent need for an integral, holistic paradigm of a human: "this holistic approach, according to which a human is an undivided, alive and organic, ideal and material being, may be seen as a launching pad for a new transdisciplinary paradigm" [22], when East meets West. A better understanding of integral human nature attracts the researchers' attention and expands the functional field of treatment methods for mental disorders and related psychosomatic diseases.
Through the lens of "mind - body" integrity, mind-body practices strengthen the connections between our metal, emotional and physical aspects, build new neurological pathways, and induce the relaxation response. More and more people around the world are engaged in the practices that encompass a diverse group of psychological and/ or physical approaches administered/taught by a trained practitioner/teacher [23]. Mind-body practices, or mindbody interventions, are the fruitful strategies of mind-body medicine, which "focuses on the interactions among the brain, mind, and behavior, and the powerful ways in which emotional, mental, social, spiritual, and behavioral factors can directly affect health" [24]. The Eastern physical, spiritual and intellectual practices such as Yoga, Tai Chi, Qigong, Meditation and Mindfulness are among them.

Mindfulness is a certain mental state and a therapeutic technique which is deeply rooted in the ancient times. It is an essential component of Buddhist and other Eastern spiritual teachings. Our conscious attention is focused on the present moment and perceives the world without any judgement. This calm awareness of our body, feelings and mind is the path to self-realization. Sometimes words "mindfulness" and "meditation" are used interchangeably, but it is a slight difference between the two. Meditation might be interpreted as a practice, while mindfulness (being an aspect of meditation) as a quality. Meditation might be interpreted as a method through which we learn to live mindfully, while mindfulness can be used in treatment that does not include meditation [25]. Mindfulness can be practiced both informally and formally and can be applied to any situation, while meditation is usually practiced for a specific amount of time and is commonly referred to as formal practice [26]. Meditation is about finding peace within. The practitioners get rid of the anxious mind experiencing a total cessation of the process of conscious thought - thought that Zen calls "wrong thought". "In zazen, you first learn how active your mind is. Then, after the shock wears off, by simply returning to the breath, you gradually strengthen your ability to put your mind where you want it, when you want it there, for as long as you want it there. This process of quieting and centering yourself continues for a while. You eventually reach a point where you slip into samadhi or single-pointedness of mind. The thoughts disappear for a short period of time and you enter into a state of mind where you're not processing anything. You're not letting go of anything. The watcher disappears. And then, in an instant, you're back again, aware of something" [27]. Both mindfulness and meditation rely on the ability to be focused on the present moment [28], "here and now". Z. Segal and M. Williams combined cognitive behavioral therapy with mindfulness-based stress reduction program elaborated by J. Kabat-Zinn that led to the development of mindfulness-based cognitive therapy [29].

The term yoga in a broad sense means a set of different spiritual, mental and physical practices aimed at managing the mental and physiological functions of the body in order to achieve an elevated state of mind. The purpose of yoga is personal self-improvement. Yoga includes psychophysical 
training that helps to change the psyche through intense concentration. The practice of yoga uses various techniques such as breathing, asanas, meditation and contributes to positive mental health and wellbeing.

Tai Chi (Tai Chi Chuan) is a form of exercise that is based in martial arts and involves deep breathing and flowing movements to achieve mental and bodily relaxation [30]. Qigong is a spirit-mind-body practice for healing and preventing diseases and improving the quality of life [31]. The core of it is activation and application of "qi" (vital life energy) by integrating posture, movements, breathing, special sounds, focus intent.

Contemporary research on the Eastern mind-body practices for different conditions shows that they help to control pain, may reduce blood pressure [32], reduce stress and depression [33-38], lead to increases in regional brain gray matter density [39], may reduce age-related memory loss [40], enhance self-awareness [41], promote recovery from and treatment of addiction [33;34], reduce feelings of loneliness and increase social contacts [42], improve sleep patterns [33-35], cultivate more creative problem-solving skills [43], have immediate and long-lasting effect on anxiety reduction $[33 ; 34 ; 38 ; 44]$, enhance muscular strength and body flexibility, promote and improve respiratory and cardiovascular function [33], improve quality of life $[34 ; 38]$.

During the COVID-19 pandemic, the Eastern mindbody practices can serve as helpful tools people can use to manage negative after-effects and strengthen their innate coping skills [45]. As C. Behan emphasizes, "crises such as the COVID-19 pandemic have shown that change is the only constant. Meditation and mindfulness can offer a helpful way to live with this constant change" [46].

In "Meditation and Yoga Practices as Potential Adjunctive Treatment of SARS-CoV-2 Infection and COVID-19: A Brief Overview of Key Subjects", Bushell et al. conclude that "there is evidence of stress and inflammation modulation, and also preliminary evidence for possible forms of immune system enhancement, accompanying the practice of certain forms of meditation, yoga, and pranayama, along with potential implications for counteracting some forms of infectious challenges" [47].

The COVID-19 pandemic brought uncertainty, anxiety, fear into our lives. According to a Yale internist A.H. Fortin VI, "mindfulness is really important in time like this" [48], when we try to cope with our stresses and maintain mental wellbeing. Mindfulness-based approaches are useful tools to deal with contemporary challenges that help us to accept our painful experiences without judgement until we are ready to let them go and to open ourselves to new experiential and behavioral possibilities [49]. During this extremely uncertain time when we have no idea what will happen, when we feel we are falling apart, it is very important to learn how to tolerate this frightening uncertainty, and "practicing mindfulness helps bring us back to the present, and away from the brink" [50].

A promising study, especially during quarantine and self-isolation, is presented by Farris at al. [51]. Being in- spired by a program "Mindfulness for Milan", this clinical trial examined usefulness and potency of a single virtual mindfulness session aimed at reducing stress, anxiety and concerns about pandemic in patients with migraine, healthcare personnel and the general public, as well as identified modalities of service to others and evaluated different facets of online mindfulness resources. Most participants evaluated the session as helpful (89\%, 95\% CI: [82 to 93\%]) and considered the electronic platform to be an effective tool for mindfulness practice (89\% [82 to 93\%]) [51]. After the session, $76 \%$ demonstrated decreased anxiety; $80 \%$ decreased stress; 55\% decreased COVID-19 concern; 92\% were satisfied with the experience; $65 \%$ demonstrated their interest in learning more about mindfulness; $69 \%$ would participate again; $74 \%$ would recommend to friends/family [51]. Participants reported about a sense of unity and desire to help others, especially most vulnerable groups; demonstrated engagement with the other humans and altruistic behavior; described the importance of a positive attitude and self-compassion [51]. Insofar as this study covered one mindfulness session, the researchers emphasize that for more reliable conclusions a further longitudinal study is required.

The research conducted by Matiz et al. [52] was aimed at studying the phenomenon of resilience in emergencies like COVID-19 among Italian teachers. The researchers delivered 8-week Mindfulness-Oriented Meditation course ( 2 face-to face meetings and 6 video-lessons). Though primarily this course was not intended at reducing the level of distress caused by the pandemic, it was demonstrated that mindfulness meditation increased resilience and improved the well-being during critical events such as the lockdown due to the COVID-19 pandemic [52]. Mindfulness-based interventions improve emotional self-regulation that is at the core of resilience against stress, anxiety and depression during the pandemic $[53 ; 54]$.

Contemporary research supports the fact that yoga is an effective way to manage stress-related problems and maintain psychological wellbeing during the COVID-19 lockdown [55]. Kulkarni et al. [56] have come to the conclusion that practicing yoga is beneficial for health during the COVID-19 pandemic. However, due to the complex nature of mental health problems caused by the pandemic, it is quite difficult to propose the only one type of yoga practice that fits for all and "it needs to be customized depending on the age, gender, physical constitution, and psychological symptoms" [56]. Yoga practices release stress, anxiety and depression and prevent immune suppression during the pandemic $[57 ; 58]$; maintain respiratory health and improve immunity; serve as a supplementary or alternative intervention for COVID-19 related mental health issues [59] and effective method for post-covid rehabilitation [60]. As a component of integrative therapy, yoga may offer an effective treatment option for COVID-19 patients [61]. Tillu et al. considered yoga as an add-on therapy and a useful home-based practice for the prevention and post-recovery management of COVID-19 [62]. Examining the role of yoga in working from home during the lock- 
down, Kanuprija et al. stated that yoga could "provide the necessary tool for risk reduction, amelioration of stress and anxiety and strengthening of the immune function" [63].

The outbreak of the COVID-19 pandemic has caused serious psychological and physical problems to the senior citizens. One of the effective tools to prevent and tackle these problems is Tai Chi Chuan - a gem of traditional Chinese culture that promotes all systems of the human body, develops combat and self-defense skills, improves well-being. Tai Chi has a potential impact on the prevention, treatment and rehabilitation of COVID-19 patients reducing stress, anxiety, depression, enhancing immunity, pulmonary and cardiovascular function, and improving quality of life [38]. Tai Chi practice is safe and effective on elderly COVID-19 patients during the recovery period [64]. The practice of Tai Chi helps to better the health status and reduce health problems that heighten COVID-19 risk [65] and can be delivered under pandemic conditions to improve physical and mental function in the seniors [66].

Qigong may be potentially useful in the prevention, treatment and rehabilitation of COVID-19 patients too. It helps to reduce stress and inflammation, regulate emotions, strengthen respiratory muscles, boost immune system [67], restore the physiology of the lungs [68]. In Wuhan's hospitals, patients with COVID-19 were encouraged to practice Qigong. As an integrative and complementary practice for health, Qigong may be effective during the COVID-19 pandemic being learned through classes (including online) and being used as a home rehabilitation program [69].

\section{CONCLUSIONS}

The Eastern mind-body practices are becoming increasingly popular, especially now when the outbreak of COVID-19 has created mental health concerns among the general population worldwide. They may prove an effective preventive or therapeutical intervention for mental health issues during and after the pandemic. However, the underlying mechanisms of these techniques are still insufficiently studied. Therefore, it is necessary to conduct a well-planned study and interpret it from multiply perspectives involving an interdisciplinary team of specialists.

\section{REFERENCES}

1. Moukaddam N. Psychiatrists Beware! The Impact of Covid-19 and Pandemics on Mental Health. Psychiatric Times. 2020; 37(3).

2. Javed B., Sarwer A., Soto E.B., Mashwani Z.R. The Coronavirus (COVID-19) Pandemic's Impact on Mental Health. The International Journal of Health Planning and Management. 2020. doi: 10.1002/hpm.3008.

3. Debiec J. Fear can spread from person to person faster than the Coronavirus - but there are ways to slow it down. The Conversation. 2020. https://theconversation.com/fear-can-spread-from-person-toperson-faster-than-the-coronavirus-but-there-are-ways-to-slow-itdown-133129. [date access 16.09.2020]

4. Kanter J., Kuczynski A. Social distancing comes with social side effects - here's how to stay connected. The Conversation. 2020. https:// theconversation.com/social-distancing-comes-with-social-side-effectsheres-how-to-stay-connected-133677. [date access 16.09.2020]
5. Mazza M.G., De Lorenzo R., Conte C. et al. Anxiety and depression in COVID-19 survivors: Role of inflammatory and clinic predictors. Brain, Behavior, and Immunity. 2020; 89:594-600. doi: 10.1016/j. bbi.2020.07.037.

6. Salari N., Hosseinian-Far A., Jalali R. et al. Prevalence of stress, anxiety, depression among the general population during the COVID-19 pandemic: a systematic review and meta-analysis. Global Health. 2020; 16(57). doi: 10.1186/s12992-020-00589-w.

7. Usher K., Bhullar N., Durkin J. et al. Family violence and COVID-19: increased vulnerability and reduced options for support. International Journal of Mental Health Nursing. 2020; 29:549-552. doi: 10.111/ inm.12735.

8. Mazza M.,Marano G., Lai C. etal. Danger in danger: Interpersonal violence during COVID-19 quarantine. Psychiatry Research. 2020;289:113046. doi: 10.1016/j.psychres.2020.113046.

9. Snider C. J., Flaherty M. P. Stigma and mental health: The curious case of COVID-19. Mental Health: Global Challenges Journal. 2020;3(1):27-32. doi: $10.32437 /$ mhgcj.v3i1.89.

10. Gao J., Zheng P., Jia Y. et al. Mental health problems and social media exposure during COVID-19 outbreak. PLOS ONE. 2020; 15:e0231924. doi: 10.1371/journal.pone.0231924.

11. Garfin D.R., Silver R.C., Holman E.A. The novel coronavirus (COVID-2019) outbreak: amplification of public health consequences by media exposure. Health Psychology, 2020; 39:355-357.

12. Zakout Y.M.-A., Alreshidi F.S., Elsaid R.M., Ahmed H.G. The magnitude of COVID-19 related stress, anxiety and depression associated with intense mass media coverage in Saudi Arabia. AIMS Public Health. 2020; 7(3):664-678. doi: 10.3934/publichealth.2020052.

13. Minter A. Quarantine for Coronavirus Has Serious Side Effects. Politics \& Policy. Bloomberg Opinion. 2020. https://www.bloomberg.com/ opinion/articles/2020-02-27/coronavirus-quarantine-raises-mentalhealth-concerns-for-china. [date access 16.09.2020]

14. Wilson R.A. Prometheus Rising. Hilarites Press, LLC. 2016, 405p.

15. Kanter J., Kuczynski A. Social distancing comes with social side effects - here's how to stay connected. The Conversation. 2020. https://theconversation.com/social-distancing-comes-with-socialside-effects-heres-how-to-stay-connected-133677. [date access 16.09.2020]

16. Jansson-Boyd C. Coronavirus is accelerating a culture of no touching - here's why that's a problem. The Conversation. 2020. https:// theconversation.com/coronavirus-is-accelerating-a-culture-of-notouching-heres-why-thats-a-problem-133488. [date access 16.09.2020]

17. The intersection of COVID-19 and mental health. The Lancet. Infectious Diseases. 2020; 20(11):1217. doi: 10.1016/S1473-3099(20)30797-0.

18. Danylova T.V., Komisarenko S.V. Double Nobel Prize Winner: Frederick Sanger - The Father of Genomics. Ukrainian Biochemical Journal. 2021;93(2):116-122. doi: 10.15407/ubj93.02.116.

19. Danylova T.V., Komisarenko S.V. A Legend in His Own Lifetime: Double Nobel Prize Winner Linus Pauling. Ukrainian Biochemical Journal. 2021; 93(3):123-132.

20. Bornstein S. The Challenges of Behavioral Health Integration: The Persistence of the Mind-Body Problem. Annals of Internal Medicine. 2020; 173(2):151-152. doi: 10.7326/M20-2887.

21. Francis D., Kaufer D. Beyond Nature vs. Nurture. The Scientist. 2011; 25(10):94.

22. Danylova T.V. Eastern Mysticism and Timothy Leary: Human Beyond the Conventional Reality. Anthropological Measurements of Philosophical Research. 2017; 11:135-142. doi: 10.15802/ampr.v0i11.105498. 
23. Complementary, Alternative, or Integrative Health: What's In a Name? National Center for Complementary or Integrative Health. National Institutes of Health. US Department of Health and Human Services. https://www.nccih.nih.gov/health/complementary-alternative-orintegrative-health-whats-in-a-name. [date access 16.09.2020]

24. Mind-Body Medicine:An Overview. MentalHelp.net. An American Addiction Centers Resource. 2005.https://www.mentalhelp.net/alternative-medicine/ mind-body-medicine-an-overview. [date access 16.09.2020]

25. Schultz J. 5 Differences Between Mindfulness and Meditation. Positive Psychology. 2020. https://positivepsychology.com/differencesbetween-mindfulness-meditation/. [date access 16.09.2020]

26. Eisler M. explaining the difference between mindfulness \& meditation. Chopra. 2019. https://chopra.com/articles/explaining-the-differencebetween-mindfulness-meditation. [date access 16.09.2020]

27. Mondo: Samadhi and Zazen with John Daido Loori, Roshi. Mountain Record. The Zen Practitioner's Journal. 2005;23(3). http://www.mro. org/mr/archive/23-3/articles/mondo.html. [date access 16.09.2020]

28. Remati K. Are Mindfulness and Meditation the Same?Yoga International. 2021. https://yogainternational.com/article/view/are-mindfulnessand-meditation-the-same. [date access 16.09.2020]

29. Jacobson S. CBT vs MBCT - What is the Difference? Harley Therapy. Counselling Blog. 2014. https://www.harleytherapy.co.uk/counselling/ cbt-mbct-difference.htm. [date access 16.09.2020]

30. Sauer M. 11 Ways Tai Chi Can Benefit Your Health. Healthline. 2018. https://www.healthline.com/health/tai-chi-benefits. [date access 16.09.2020]

31. What is Qigong? National Qigong Association. 2021. https://www.nqa. org/what-is-qigong-. [date access 16.09.2020]

32. Meditation: In Depth. National Center for Complementary and Integrative Health. 2016. https://www.nccih.nih.gov/health/ meditation-in-depth. [date access 16.09.2020]

33. Woodyard K. Exploring the therapeutic effects of yoga and its ability to increase quality of life. International Journal of Yoga. 2011;4(2):49-54. doi: 10.4103/0973-6131.85485.

34. Abbott R., Lavretsky H. Tai Chi and Qigong for the Treatment and Prevention of Mental Disorders. Psychiatric Clinics of North America. 2013; 36(1):109-119. doi: 10.1016/j.psc.2013.01.011.

35. Elstad T., Ulleberg P., Klonteig S. et al. The effects of yoga on student mental health: a randomized controlled trial. Health Psychology and Behavioral Medicine. 2020; 8(1):573-586. doi: 10.1080/21642850.2020.184366.

36. Hagen I., Nayar U.S. Yoga for children and young people's mental health and well-being: research review and reflections on the mental health potentials of yoga. Frontiers in Psychiatry. 2014; 5:35. doi: 10.3389/ fpsyt.2014.00035.

37. Kong J., Wilson G., Park J. et al. Treating depression with Tai Chi: State of the Art and Future Perspectives. Frontiers in Psychiatry. 2019; 10:237. doi: 10.3389/fpsyt.2019.00237.

38. Xianjian C., Datao X. Effects of Tai Chi Chuan on the Physical and Mental Health of the Elderly: A Systematic Review. Physical Activity and Health. 2021; 5(1):21-27. doi: http://doi.org/10.5334/paah.70.

39. Hölzel B.K., Carmody J., Vangel M. et al. Mindfulness practice leads to increases in regional brain grey matter density. Psychiatry Research: Neuroimaging. 2011; 191(1):36-43. doi: 10.1016/j. pscychresns.2010.08.006.

40. Khalsa D.S. Stress, meditation, and Alzheimer's disease prevention: where the evidence stands. Journal of Alzheimer's Disease. 2015; 48(1):1-12. doi: 10.3233/JAD-142766.
41. Dahl C.J., Lutz A., Davidson R.J. Reconstructing and deconstructing the self: cognitive mechanisms in meditation practice. Trends in cognitive sciences. 2015. 19(9):515-523. doi: 10.1016/j.tics.2015.07.001.

42. Lindsay E.K., Young S., Brown K.W. et al. Mindfulness training reduces loneliness and increases social contact in a randomized controlled trial. Psychological and Cognitive Sciences. 2019; 116(9):3488-3493. doi: $10.1073 /$ pnas. 1813588116.

43. Capurso V., Fabbro F., Crescentini C. Mindful creativity: the influence of mindfulness meditation on creative thinking. Frontiers in Psychology. 2013; 4:1020. doi: 10.3389/fpsyg.2013.01020.

44. Gururaja D., HaranoK., Toyotakel., KobayashiH. Effect ofyoga on mental health: Comparativestudy between young and senior subjects in Japan. International Journal of Yoga. 2011; 4(7):7-12. doi: 10.4103/0973-6131.78173.

45. Meditation and Yoga for Heightened Anxiety Related to COVID-19. Columbia University. Department of Psychiatry. 2020. https://www. columbiapsychiatry.org/meditation-and-yoga-heightened-anxietyrelated-covid-19. [date access 16.09.2020]

46. Behan C. The benefits of meditation and mindfulness practices during times of crisis such as COVID-19. Irish Journal of Psychological Medicine. 2020; 14:1-3. doi: 10.1017/ipm.2020.38.

47. Bushell W., Castle R., Williams M.A. et al. Meditation and Yoga Practices as Potential Adjunctive Treatment of SARS-CoV-2Infection and COVID-19:ABrief Overview of Key Subjects. The Journal of Alternative and Complementary Medicine. 2020; 26(7):547-556. doi: 10.1089/acm.2020.0177.

48. Katella K. Mindfulness: How It Can Help Amid the Covid-19 Pandemic. Yale Medicine. 2020. https://www.yalemedicine.org/news/ mindfulness-covid. [date access 16.09.2020]

49. Antonova E., Schlosser K., Pandey R., Kumari V. Coping with COVID-19: mindfulness-based approaches for mitigating mental health crisis. Frontiers in Psychiatry. 2021; 12:563417. doi: 10.3389/ fpsyt.2021.563417.

50. Jacobson R. How mindfulness can help during COVID-19. Child Mind. https://childmind.org/article/how-mindfulness-can-help-duringcovid-19/. [date access 16.09.2020]

51. Farris S.R., Grazzi L., Holley M. et al. Online mindfulness may target psychological distress and mental health during COVID-19. Global Advances in Health and Medicine. 2021; 9:1-15. doi: 10.1177/21649561211002461.

52. Matiz A., Fabbro F., Raschetto A. et al. Positive Impact of Mindfulness Meditation on Mental Health of Female Teachers during the COVID-19 Outbreak in Italy. International Journal of Environmental research and Public Health. 2020; 17(18):6450. doi: 10.3390/ijerph17186450.

53. Zhu J.L., Schülke R., Vatansever D. et al. Mindfulness practice for protecting mental health during the COVID-19 pandemic. Translational Psychiatry. 2021; 11:329. doi: https://doi.org/10.1038/s41398-02101459-8.

54. Fradelos E.C., Alikari V., Vus V et al. Assessment of the relation between religiosity, anxiety, depression and psychological resilience in nursing staff. Health Psychology Research. 2020; 8(1):30-34. doi: 10.4081/ hpr.2020.8234

55. Sahni P.S., Singh K., Sharma N., Garg R. Yoga an effective strategy for self-management of stress-related problems and wellbeing during COVID-19 lockdown: A cross-sectional study. PLOS ONE. 2021. doi: 10.1371/journal.pone.0245214.

56. Kulkarni M.S., Kakodkar P., Nesari T.M., Dubewar A.P. Combating the psychological impact of COVID-19 pandemic through yoga: Recommendation from an overview. Journal of Ayurveda and Integrative Medicine. 2021. doi: 10.1016/j.jaim.2021.04.003. 
57. Nagendra H.R. Yoga for COVID-19. International Journal of Yoga. 2020; 13(2):87-88. doi: 10.4103/ijoy.IJOY_27_20.

58. Jerrin J., Theebika S., Panneerselvam P. et al. Yoga and Naturopathy intervention for reducing anxiety and depression of Covid-19 patients A pilot study. Clinical Epidemiology and Global Health. 2021; 11:100800. doi. 10.1016/j.cegh.2021.100800.

59. Ransing R., Costa M.P., Adiukwu F. et al. Yoga for COVID-19 and natural disaster related mental health issues: Challenges and perspectives. Asian Journal of Psychiatry. 2020; 53:102386. doi:10.1016/j.ajp.2020.102386.

60. BhawnaV., Kundu Z.S. Exercise and yoga as modalities for post COVID-19 rehabilitation. International Journal of Science and Research. 2021; 10(2):75-85. doi: 10.21275/SR201202155829.

61. Mishra A., Bentur S.A., Thakral S. et al. The use of integrative therapy based on Yoga and Ayurveda in the treatment of a high-risk case of COVID-19/SARS-CoV-2 with multiple comorbidities: a case report. Journal of Medical Case Reports. 2021; 15:95. doi: 10.1186/s13256020-02624-1.

62. Tillu G., Chaturvedi S., Chopra A., Patwardhan B. Public Health Approach of Ayurveda and Yoga for COVID-19 Prophylaxis. The Journal of Alternative and Complementary Medicine. 2020. doi:10.1089/ acm.2020.0129.

63. Kanuprija S., Akshay A., Raj K. The role of Yoga in working from home during the COVID-19 global lockdown. Work. 2020; 66(4):731-737. doi:10.3233/WOR-203219.

64. Zhu X., Luo Z., Chen Y. et al. Tai Chi for the elderly patients with COVID-19 in recovery period. Medicine. 2021; 100(3):e24111. doi:10.1097/ MD.0000000000024111.

65. Marks R. A review of Tai-Chi and its Potential Benefits for Older Dwelling Adults with Osteoarthritis in the Context of Covid-19. Open Journal of Geriatrics. 2020.3(1):14-29.

66. Solianik R., Mickevičienė D., Žlibinaitė L., Čekanauskaitė A. Tai chi improves psychoemotional state, cognition, and motor learning in older adults during the COVID-19 pandemic. Experimental Gerontology. 2021; 150. doi: 10.1016/j.exger.2021.111363.

67. Feng F., Tuchman S., Denninger J.W. et al. Qigong for the Prevention, Treatment, and Rehabilitation of COVID-19 Infection in Older Adults. The American Journal of Geriatric Psychiatry. 2020; 28(8):812-819. doi:10.1016/j.jagp.2020.05.012.
68. Zhang S., Zhu Q., Zhan C. et al. Acupressure therapy and Liu Zi Jue Qigong for pulmonary function and quality of life in patients with severe novel coronavirus pneumonia (COVID-19): a study protocol for a randomized controlled trial. Trials. 2020;21:751. doi: 10.1186/s13063-020-04693-5.

69. Alschuler L., Chiasson A.M., Horwitz R. et al. Integrative medicine considerations for convalescence from mild-to-moderate COVID-19 disease. Explore. 2020. doi: 10.1016/j.explore.2020.12.005.

\section{ORCID and contributionship:}

Tetiana V. Danylova: 0000-0002-0297-9473 $3^{A, B, D, E, F}$

Vitalii M. Shmarhun: 0000-0001-9727-5083 ${ }^{B, E, F}$

Anton V. Vertel: 0000-0003-2247-7443 ${ }^{E, F}$

Bogdan Matyushko: 0000-0001-9178-1938 E,F

Aleksandr F. Bondarenko: 0000-0002-9458-1787 E,F

Tetiana V. Kychkyruk: 0000-0003-4719-7923

Jørli Petersen: 0000-0003-4944-6110 B, E,F

\section{Conflict of interest:}

The Authors declare no conflict of interest

\section{CORRESPONDING AUTHOR Tetiana V. Danylova}

Institute of Social and Political Psychology National Academy

of Educational Sciences of Ukraine

15 Andriivska st., 04053 Kyiv, Ukraine

e-mail:danilova_tv@ukr.net

Received: 17.05 .2021

Accepted: 08.10 .2021

\footnotetext{
A - Work concept and design, B - Data collection and analysis, C - Responsibility for statistical analysis,
} D-Writing the article, $\mathbf{E}$-Critical review, $\mathbf{F}$ - Final approval of the article 